\title{
WestVirginiaUniversity
}

THE RESEARCH REPOSITORY @ WVU

Graduate Theses, Dissertations, and Problem Reports

2007

\section{The regulation and role of hypoxia inducible factor-1 (HIF-1) in human cancer}

Heath Devin Skinner

West Virginia University

Follow this and additional works at: https://researchrepository.wvu.edu/etd

\section{Recommended Citation}

Skinner, Heath Devin, "The regulation and role of hypoxia inducible factor-1 (HIF-1) in human cancer" (2007). Graduate Theses, Dissertations, and Problem Reports. 4335.

https://researchrepository.wvu.edu/etd/4335

This Dissertation is protected by copyright and/or related rights. It has been brought to you by the The Research Repository @ WVU with permission from the rights-holder(s). You are free to use this Dissertation in any way that is permitted by the copyright and related rights legislation that applies to your use. For other uses you must obtain permission from the rights-holder(s) directly, unless additional rights are indicated by a Creative Commons license in the record and/ or on the work itself. This Dissertation has been accepted for inclusion in WVU Graduate Theses, Dissertations, and Problem Reports collection by an authorized administrator of The Research Repository @ WVU.

For more information, please contact researchrepository@mail.wvu.edu. 


\title{
The Regulation and Role of Hypoxia Inducible Factor-1 (HIF-1) in Human Cancer
}

\author{
Heath Devin Skinner
}

Dissertation submitted to the School of Medicine at West Virginia University in partial fulfillment of the requirements for the degree of

\author{
Doctor of Philosophy \\ In \\ Biological Science \\ Bing-Hua Jiang, Ph.D., Chair \\ Daniel C. Flynn, Ph.D. \\ Fred Minnear, Ph.D. \\ Pingian He, Ph.D. \\ Xianglin Shi, Ph.D. \\ Department of Microbiology, Immunology and Cell Biology \\ Morgantown, WV \\ 2007
}

Key words: HIF-1 $\alpha$, PI3K, VEGF, ovarian cancer, angiogenesis

Copyright 2007 Heath D. Skinner 


\title{
The Regulation and Role of Hypoxia Inducible Factor-1 (HIF-1) in
}

\section{Human Cancer}

\author{
Heath Devin Skinner
}

\begin{abstract}
Hypoxia inducible factor-1 is a heterodimeric basic-loop-helix transcription factor composed of two subunits, HIF-1 $\alpha$ and HIF-1 $\beta$. HIF-1 $\beta$ is constitutively expressed in cells, while HIF-1 $\alpha$ is upregulated by hypoxia as well as growth factors and oncogenes. In this study we focus on the regulation of HIF-1 $\alpha$ expression by phosphatidylinositol-3 kinase (PI3K), and novel functions of HIF-1 $\alpha$. Chapter 1 of this dissertation, consists of background and a brief review of the literature regarding PI3K signaling and HIF-1 $\alpha$. Chapter 2 focuses on the observation that basal HIF-1 $\alpha$ expression is upregulated in ovarian cancer and the mechanism by which PI3K regulates this effect. Chapter 3 show the results of inhibition of HIF-1 $\alpha$ using small interfering RNA (siRNA) in several in vivo models of ovarian cancer. Chapter 4 presents data showing that manipulation of HIF-1 $\alpha$ expression affects cancer cell sensitivity to common chemotherapeutic agents. Chapter 5 discusses a novel target of HIF-1, cyclooxygenase-2. In chapter 6 , we present the overall summary and conclusions of this dissertation.
\end{abstract}




\section{ACKNOWLEDGEMENTS}

The author would first and foremost like to thank all of the members of his committee for their ideas and support: Fred Minnear, Ph.D., Xianglin Shi, Ph.D., Pingian He, Ph.D., and Danial C. Flynn, Ph.D. and the committee chairperson and the author's mentor Bing-Hua Jiang, Ph.D. The author would also like to thank all past and present members of Dr. Jiang's laboratory for their assistance throughout his graduate training. Also, the author would like to thank Tim Wiltshire, Valerie Walker, DVM and Amanda Gatesman, Ph.D. for their scientific and insight and encouragement. On a personal note, the author wishes to thank his parents, Douglas and Cheral Ann Skinner, and his brother, Braden Lynn Marshall Skinner for their love and support over the years. Finally, the author wants to extend his heartfelt thanks to his colleague and fiancée, Lesly Ann Lopez. Without her love, support and encouragement, none of this would have been possible. 


\section{TABLE OF CONTENTS}

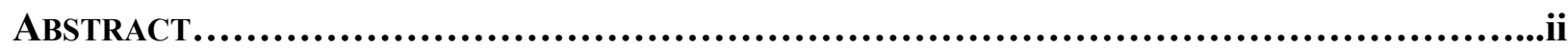

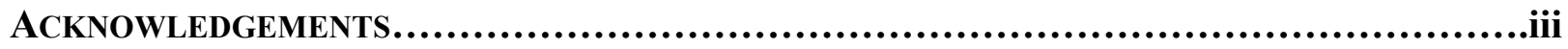

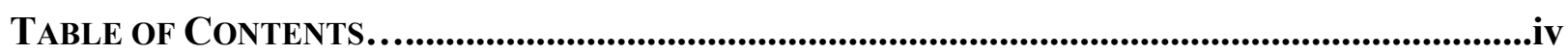

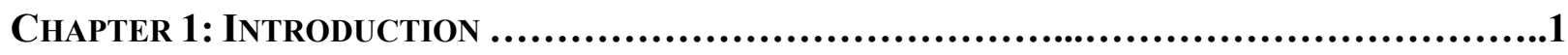

PHOSPHATIDYLINOSITIOL 3-KINASE (PI3K) SIGNALING....................................

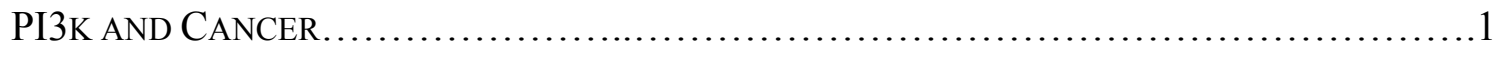

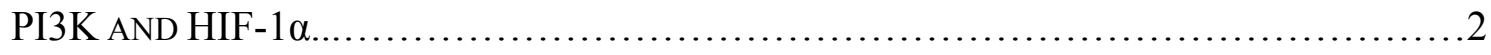

PI3K/AKT/HIF-1 $\alpha$ AND P53/MdM2 SIGNALING PATHWAYS ............................

CYCLOOXYGENASE-2 (COX-2) AND HIF-1 $1 \alpha \ldots \ldots \ldots \ldots \ldots \ldots \ldots \ldots \ldots \ldots \ldots \ldots \ldots \ldots$

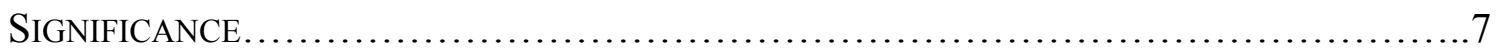

CHAPTER 2: VEGF TRANSCRIPTIONAL ACTIVATION IS MEDIATED BY HIF-1 $\alpha$, HDM2, AND

P70S6K1 IN RESPONSE TO PI3K/AKT SIGNALING.........................................8

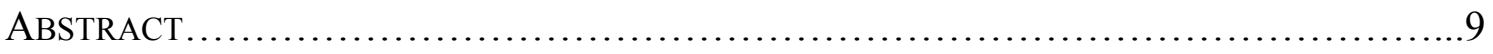

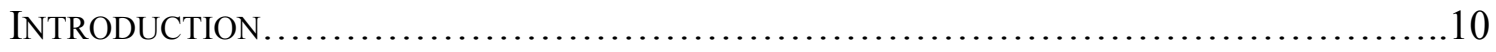

MATERIALS AND METHODS........................................................

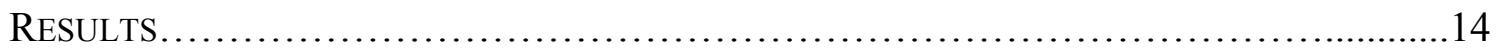

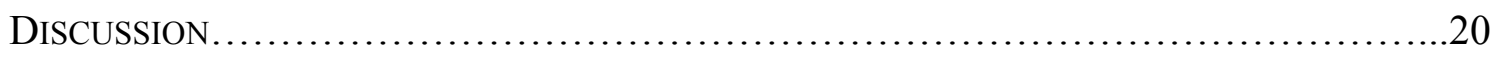

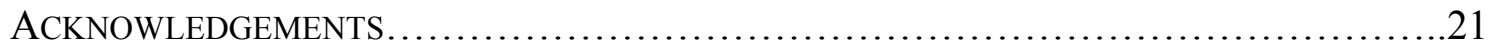

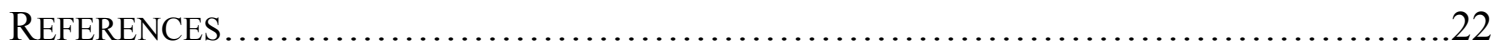

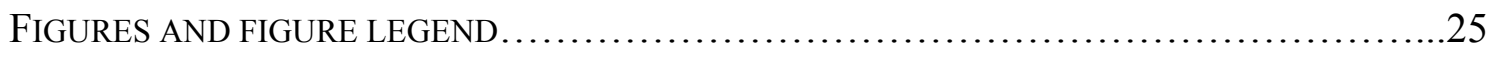




\section{CHAPTER 3: INHIBITION OF HIF-1 $\alpha$ BY SIRNA HAS OPPOSITE EFFECTS ON OVARIAN TUMOR}

GROWTH AND ANGIOGENESIS IN DIFFERENT MICROENVIRONMENTS..........................40

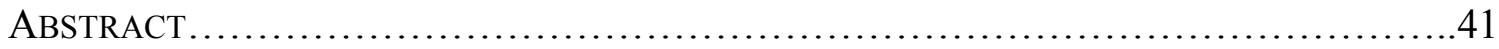

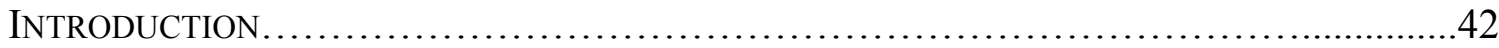

MATERIALS AND METHODS..................................................43

RESULTS................................................................ 47

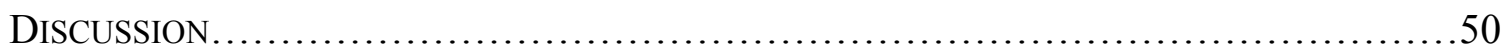

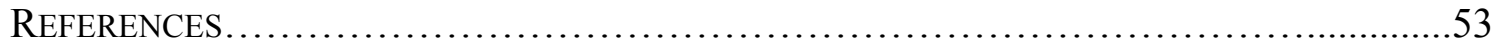

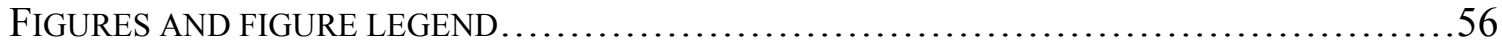

\section{CHAPTER 4: HIF-1 $\alpha$ AFFECTS THE SENSITIVITY TO CHEMOTHERAPY IN OVARIAN AND}

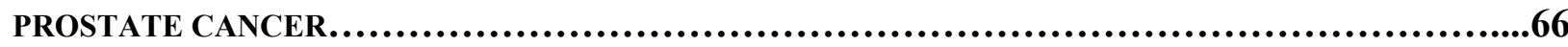

ABSTRACT .............................................................67

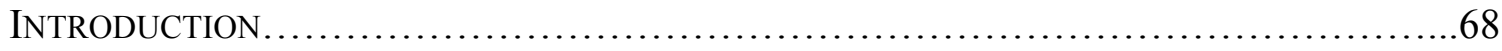

MATERIALS AND METHODS...................................................69

RESULTS..............................................................72

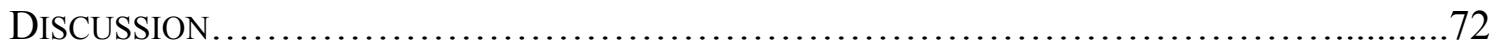

REFERENCES........................................................... 75

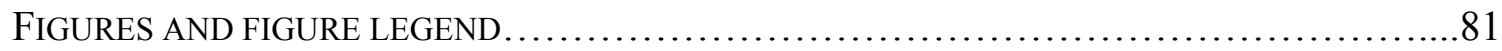

CHAPTER 5: HIF-1 $\alpha$ REGULATES THE BASAL AND HYPOXIA -INDUCED TRANSCRIPTION OF

CYCLOOXYGENASE-2 IN OVARIAN AND PROSTATE CANCER................................98

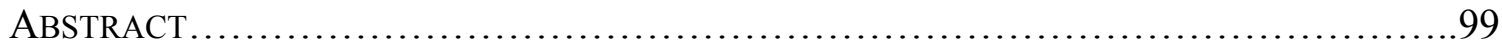

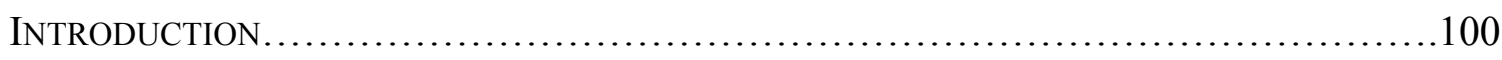

MATERIALS AND METHODS................................................... 102 
RESULTS............................................................... 107

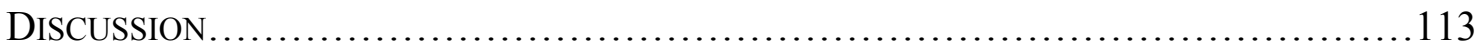

REFERENCES.......................................................... 115

FIGURES AND FIGURE LEGEND............................................. 121

CHAPTER 6: SUMMARY AND CONCLUSIONS............................................,142 


\section{Phosphatidylinositol 3-kinase (PI3K) signaling}

Phosphatidylinositol-3 kinases (PI3Ks) phosphorylate the D3 position of the inositol ring in phosphoinositides (118). Several members of this family are known, however the only member directly linked to carcinogenesis are Class IA PI3K which are usually activated by receptor tyrosine kinases (3). PI3K is a heterodimer consisting of two subunits, a regulatory subunit, p85, and a catalytic subunit, p1 $10(28,40,45,55)$. Activation of PI3K normally occurs via interaction with the regulatory subunit; however it has been shown that Ras can directly bind and activate the p110 catalytic subunit(87). Once activated, PI3K leads to the generation of phosphatidylinositol $(3,4,5)$ trisphosphate $\left(\mathrm{PIP}_{3}\right)$ which recruits Akt, a serine/threonine kinase, to the plasma membrane. The activity of PI3K is opposed by the lipid phosphatase PTEN which preferentially removes a phosphate group from the D3 position $(68,120)$. $\mathrm{PIP}_{3}$ also recruits phosphatidylinositol dependent kinase-1 (PDK1) to the plasma membrane (2,31). PDK1 then phosphorylates Akt at Thr 308 leading to its activation $(1,104)$. After being phosphorylated, Akt activates a series of down stream targets including: NF- $\mathrm{B}(52,79,88)$, BAD $(26)$, FHTF $(73,86)$, glycogen synthase kinase-3 $\boldsymbol{\beta}$ (24) and the mammmalin target of rapamycin (mTOR) $(14,93)$.

\section{PI3K and cancer}

Recently it has been shown that PI3K plays an important role in cancer. The first evidence of the importance of PI3K in cancer was the finding that an avian virus known to cause hemangiosarcoma in chickens, AV-16, encoded an active form of the catalytic domain of PI3K (18). Later, it was shown that other forms of PI3K are oncogenic due to the activation of Akt $(4,51,56)$. Other studies have shown that PTEN, an antagonist of PI3K, is inactivated in a large number of human cancers including: glioblastoma, melanoma, endometrial carcinoma, prostate cancer, breast carcinoma and ovarian carcinoma $(7,29,33,61,64,71,84,101)$. This is the most 
common cause of PI3K activation in cancer, however in ovarian carcinoma, $P I 3 C A$, the gene that encodes the catalytic subunit of PI3K, is increased in copy number in about $40 \%$ of cases (98). Also, the p85 $\alpha$ regulatory subunit of PI3K is often mutated in primary ovarian cancer cells (83). Furthermore, two isoforms of Akt, Akt 1 and Akt2, are activated in a large number of ovarian carcinomas $(106,122)$.

One of the mechanisms by which PI3K stimulates tumorigenesis is via the regulation of new blood vessel formation or angiogenesis. Direct inhibition of PI3K as well as expression of functional PTEN leads to decreased synthesis of vascular endothelial growth factor (VEGF) and decreased angiogenesis $(50,77)$. Constitutively activation of either PI3K or Akt has the opposite effect (50). Furthermore, PI3CA null mouse embryos exhibit defective angiogenesis (8).

Finally, forced expression of wild type PTEN in cancer has been shown to decrease both tumor growth and angiogenesis $(57,117)$.

\section{PI3K/Akt and HIF-1 $\alpha$}

Recently it has been shown by our group and others that the PI3K/Akt signaling cascade can regulate HIF-1 $\alpha$ expression $(48,72)$. Hypoxia inducible factor-1 (HIF-1) is a heterodimeric basic helix-loop-helix transcription factor composed of two subunits, $\operatorname{HIF-1} \alpha$ and $\operatorname{HIF}-1 \beta(49,114)$. Because HIF-1 $\beta$ is constitutively expressed in human cells, the transcriptional activity of HIF-1 is regulated by the level of HIF-1 $\alpha$. Inhibition of PI3K signaling has been shown to inhibit HIF$1 \alpha$ expression in response to a variety of different stimuli, including hypoxia, growth factors and oncogenes $(48,80,90,102)$. This inhibitory effect can be reversed by forced expression of Akt (111) PTEN has also been shown to regulate HIF-1 $\alpha$ expression $(48,128)$. Under normoxic

conditions within the cell, HIF-1 $\alpha$ is hydroxylated by a family of prolyl hydroxylases on Pro ${ }^{402}$ and Pro ${ }^{564}$ within a region of HIF-1 $\alpha$ known as the oxygen dependent degredation domain 
(ODDD) $(17,46,47)$. This allows the binding of the E3 ubquitin ligase, von Hippel Lindau protein (pVHL) to HIF-1 $\alpha(46,47)$. After ubquitinylation, HIF-1 $\alpha$ is rapidly degraded by the proteosome, such that the half-life of HIF-1 $\alpha$ in normoxia is less than 5 minutes. However, in hypoxia, prolyl hydroxylase does not function, therefore, pVHL cannot bind and ubquitinylate HIF-1 $\alpha(46,47)$. This stabilizes HIF-1 $\alpha$, allowing it to translocate to the nucleus and bind HIF$1 \beta$, forming the active transcription factor, HIF-1. After translocation into the nucleus, HIF-1 specifically binds a 5'-RCGTG-3' hypoxic response element (HRE) present in the promoters of a number of genes leading to their transcription $(96,97)$. p300/CBP is a required co-factor for HIF-1 DNA binding. This represents another level of HIF-1 regulation, as a asparaginyl hydroxylase that hydroxylates HIF-1 at Asn ${ }^{851}$, dubbed factor inhibiting HIF-1 (FIH), can abrogate the binding of HIF-1 and p300/CBP, leading to decreased levels of HIF-1 transcriptional activation (100). Genes upregulated by HIF-1 include: iNOS, heme oxygenase1, erythropoietin, aldolase, several glycolytic enzymes, and vascular endothelial growth factor (VEGF) $(25,34,35,62,63,95,97)$.

HIF-1 $\alpha$ plays a major role in tumor angiogenesis. HIF- $1 \alpha$ is over-expressed in both primary and metastatic human cancer, and is correlated to tumor angiogenesis and aggressiveness as well as patient mortality $(9-11,13,123,126)$. HIF-1 $\alpha$ has also been found to be overexpressed in tumor biopsies from several different types of cancer along the invading margin $(123,126)$. Manipulation of HIF-1 $\alpha$ expression in tumor xenograft studies has led to conflicting results. Some studies have shown that inhibition of HIF-1 $\alpha$ decreases tumor growth and angiogenesis, however others have shown that inhibition of HIF-1 $\alpha$ has no effect on tumor angiogenesis $(20,89,103)$. One study even showed that inhibition of HIF-1 $\alpha$ led to the generation of larger tumors (16). Thus, the role of HIF-1 $\alpha$ in tumorigenesis has yet to be explained. 


\section{PI3K/HIF-1 $\alpha$ and p53/Mdm2 signaling pathways}

Discovered in the early 1980 's, p53 is one of the most widely studied tumor suppressor genes. This protein functions to induce apoptotic cell death in response to a number of oncogenic stresses and mutations in p53 occur in greater than half of all human cancers (113). Levels of p53 in the cell are controlled primarily at the post-translational level by the E3 ubquitin ligase, Mdm2, in a mode of regulation similar to that observed with HIF-1 $\alpha$ and pVHL $(43,44,59)$. Interestingly, Mdm2 transcription is upregulated by p53, forming an auto-regulatory loop to control the levels of p53 in the cell (119). Recently it has been shown that p53 and Mdm2 interact with the PI3K signaling cascade. Specifically, it has been shown that activated Akt phosphorylates Mdm2, leading to decreased p53 levels in the cell and decreased p53 transcriptional activity $(69,75)$. HIF-1 $\alpha$ has also been shown to interact with p53/Mdm2 signaling. The DNA binding region of p53 has been shown to bind HIF-1 $\alpha$ in an in vitro assay (42). HIF-1 $\alpha$ has also been shown to bind Mdm2 leading to increased transcriptional activity (Agani 2005). Another recent study showed that loss of p53 leads to increased expression of HIF-1 $\alpha$ in the cell (85). However, the exact physiological significance of the interaction between PI3K, HIF-1 $\alpha$ and Mdm2 remains to be elucidated.

\section{COX-2 and HIF-1a}

Recently it has been shown that cyclooxygenase 2 (COX-2), a dual function peroxidase, plays a significant role in angiogenesis. Cyclooxygenases are a group of enzymes that convert arachadonic acid to prostaglandins (PG) such as $\mathrm{PGD}_{2}$ and $\mathrm{PGE}_{2}$ and thromboxane (THX) (39). COX-2 and HIF-1 $\alpha$ have been linked to similar processes in the cell. Both COX-2 and HIF-1 $\alpha$ stimulate cancer cell invasion via MMP activity $(23,58,100,107)$ and promote tumor 
angiogenesis $(38,94)$. Both have been associated with VEGF secretion $(38,94)$ and both are stimulated by hypoxia, as well as chemical mimetics of hypoxia such as $\mathrm{CoCl}_{2}(66,116)$ and iron chelators like desferroxamine $(109,115)$. NSAIDs have been shown to inhibit HIF-1 $\alpha$ expression, however this effect was shown to be at least partly COX-2 independent $(82,127)$. Interestingly, a recent study has shown that PI3K/Akt is an important COX-2-independent target of celecoxib, a "selective" COX-2 inhibitor, in prostate cancer (60). Specifically, celecoxib dramatically inhibits PI3K/Akt signaling in the absence of COX-2. This phenomenon could account for the COX-2 independent inhibitory effect of COX-2 inhibitors on HIF-1 $\alpha$ expression. Previously, some have shown that COX-2 may upregulate HIF-1 $\alpha$ expression via $\mathrm{PGE}_{2}(65)$. However, the exact nature of the interaction between HIF-1 $\alpha$ and COX-2 has yet to be elucidated.

Cyclooxygenases perform two enzymatic functions in the formation of prostaglandins. Initially, arachadonic acid, found almost exclusively at the 2-position of membrane phospholipids, is cleaved from the cell membrane by phospholipase $\mathrm{A}_{2}\left(\mathrm{PLA}_{2}\right)$ to form free arachadonate (process rev. in (27)). This arachadonate is then oxidized by cyclooxygenase to form $\mathrm{PGG}_{2}$, an unstable intermediate prostaglandin. This is then converted to $\mathrm{PGH}_{2}$ by the peroxidase activity of cyclooxygenase. $\mathrm{PGH}_{2}$ is the progenitor of a variety of different prostaglandins, such as $\mathrm{PGE}_{2}$, as well as thromboxane (TXA). Two cyclooxygenases, dubbed COX-1 and COX-2, have been described thus far. COX-1 is constitutively expressed in most tissues and is responsible for maintainence of the mucosa of the gastric lining as well as the regulation of renal blood flow (27). Conversely, COX-2 is inducible by a variety of different stimuli including cytokines, growth factors, oncogenes and tumor promoters (27). This property allows COX-2 to play a significant role in inflammation and malignancy. 
COX-2 affects a variety of different process in tumors including apoptosis, angiogenesis, invasion and metastasis. Previously it has been shown that COX-2 expression is upregulated in tumors compared to surrounding tissue (124). Furthermore, inhibition of COX-2 via NSAIDs and selective inhibitors leads to decreased size and angiogenesis in a variety of tumor xenograft models (124).

The pro-apoptotic effects of COX-2 inhibition in cancer cells are well established (27). In many different cancer cell lines, treatment with NSAIDs, as well as with selective COX-2 inhibitors leads to apoptosis (27). The mechanism by which this occurs is not completely known. COX-2 inhibition has been shown to upregulate Par-4, a prostate specific pro-apoptotic gene (125), while COX-2 overexpression decreases the expression of caspase-3 (70). Interestingly, COX-2 also negatively regulates $\mathrm{p} 53$ expression to protect against hypoxiainduced apoptosis (67). Conversely, p53 expression can also decrease expression of COX-2 (105).

COX-2 also stimulates cell migration and invasion. COX-2 expression is correlated with tumor invasiveness in several different types of cancer $(76,99,108)$. Furthermore, treatment with COX-2 inhibitors decreases cell migration and invasion $(5,54,78,107,121)$. Furthermore, forced expression of COX-2 increases cell motility and invasiveness in breast cancer cells (100). One downstream product of COX-2 enzymatic activity, $\mathrm{PGE}_{2}$, has also been shown to stimulate cell motility and invasion $(15,81,110)$. The mechanism for this effect is disputed, as some data indicates PGE2 acts via the prostaglandin receptor EP4 and the second messenger cAMP (110), while others have indicated that PGE2 acts to stimulate cell motility via activation of the epidermal growth factor receptor (EGFR) and subsequent activation of PI3K/Akt signaling 
$(15,81)$. The stimulatory effect of COX-2 and PGE2 on cell motility and invasion has been shown to be dependent upon MMP activity $(5,54,107)$ as well as CD $44(30)$.

COX-2 is also a potent inducer of angiogenesis. COX-2 expression is correlated with tumor angiogenesis in clinical samples $(19,21,36,37,53)$. COX-2 inhibitors have been shown to inhibit angiogenesis via the suppression of secreted pro-angiogeneic factors such as basic fibroblastic growth factor (bFGF) and VEGF (27). In co-culture with endothelial cells, colon cancer cells engineered to over-expression COX-2 increased levels of endothelial cell migration and tube formation (112). Inhibition of COX-2 via NSAID or COX-2 specific-inhibitor has been shown to decrease angiogenesis in tumor xenograft models (91). Furthermore, it has been shown that PGE2 stimulates capillary sprouting and angiogenesis (38). Taken together, it seems that COX-2 plays a strong stimulatory role in angiogenesis.

\section{Significance}

All of these signaling proteins play an important role in tumorigenesis and angiogenesis. Many are upregulated in metastasis and are correlated with patient morbidity and mortality in clinical studies. Although many of these proteins, such as PI3K and HIF-1 $\alpha$, have been linked previously, it has yet to be determined how these signaling proteins interact with HIF-1 $\alpha$. Thus, this study will focus on these interactions as well as novel functions of HIF-1 $\alpha$ in cancer cells. 


\title{
CHAPTER 2: VEGF TRANSCRIPTIONAL ACTIVATION IS MEDIATED BY HIF-1 $\alpha$, HDM2, AND P70S6K1 IN RESPONSE TO PI3K/AKT SIGNALING.
}

\author{
Heath D. Skinner ${ }^{1}$, Jenny Z. Zheng ${ }^{1}$, Jing Fang ${ }^{1}$, Faton Agani $^{2}$, and Bing-Hua Jiang ${ }^{1 \#}$ \\ ${ }^{1}$ Mary Babb Randolph Cancer Center, Department of Microbiology, Immunology and Cell Biology, \\ West Virginia University, Morgantown, WV 26506-9300, USA. \\ ${ }^{2}$ Department of Anatomy, School of Medicine, Case Western Reserve University, Cleveland, Ohio \\ 44106, USA.
}

Running title: HDM2, p70S6K1, and HIF-1 $\alpha$ mediate VEGF Expression

\# To whom correspondence should be addressed: Mary Babb Randolph Cancer Center, Department of Microbiology, Immunology and Cell Biology, West Virginia University, Morgantown, West Virginia 26506. Fax: 304-293-4667; E-mail: bhjiang@hsc.wvu.edu.

Key Words: vascular endothelial growth factor (VEGF); hypoxia-inducible factor 1 (HIF-1); PI3K, AKT, HDM2, p70S6K1, tumor angiogenesis

* This work was supported by National Institutes of Health Grant RR16440 (to B.H. Jiang) and NS41309 (to F.H. Agani), and by American Cancer Society Research Scholar Grant 04-076-01TBE (to B.H. Jiang). 


\section{ABSTRACT}

Vascular endothelial growth factor (VEGF) expression is elevated in ovarian and other cancer

cells. However, the mechanism that causes this increase in VEGF expression still remains to be elucidated. In this study, we demonstrated that activation of PI3K signaling mediated VEGF protein expression at the transcriptional level through hypoxia-inducible factor 1 (HIF-1 $\alpha$ ) expression in human ovarian cancer cells. We found that inhibition of PI3K activity by LY294002 decreased VEGF transcriptional activation, and that forced expression of AKT completely reversed the inhibitory effect. HDM2 and p70S6K1 are two downstream targets of AKT that mediate growth factor-induced VEGF transcriptional activation and HIF-1 $\alpha$ expression. We found that inhibition of PI3K by LY294002 inhibited p70S6K1 and HDM2 activity in the cells. Forced expression of p70S6K1 or HDM2 reversed LY294002-inhibited VEGF transcriptional activation and HIF-1 $\alpha$ expression. This study identifies a potential novel mechanism responsible for increased VEGF expression in ovarian cancer cells. It also indicates the important role of VEGF and HIF-1 in ovarian tumorigenesis and angiogenesis, which is mediated by the PI3K/AKT/HDM2 and AKT/p70S6K1 pathways in ovarian cancer cells. 


\section{Introduction}

Vascular endothelial growth factor (VEGF) is essential for both physiological and pathological angiogenesis and has been shown to play a critical role in ovarian cancer. Many studies have shown that increased VEGF expression correlates with poor prognosis in ovarian cancer patients (1-3). VEGF is expressed by ovarian cancer cells (4), and is found at high levels in the malignant ascites of humans as well as in animal tumor models (5-7). Flt-1 and KDR, the two VEGF receptors, are expressed in both ovarian cancer cells and the ovarian tumor vasculature $(8,9)$. VEGF production correlates with ovarian cancer cell proliferation $(10)$, whereas inhibition of VEGF, whether pharmacologically or by an inhibitory antibody, decreases ascites formation and mortality in ovarian cancer models (11-14).

VEGF is a primary transcriptional target of hypoxia-inducible factor 1 (HIF-1). HIF-1 is a heterodimeric basic helix loop helix transcription factor composed of HIF$1 \alpha$ and HIF-1 $\beta$ subunits $(15,16)$. HIF- $1 \beta$ is constitutively expressed in cells, while HIF-1 $\alpha$ expression is upregulated by hypoxia, as well as by a variety of growth factors and oncogenes (16-23). HIF-1 has previously been shown to play a crucial role in both angiogenesis and tumor growth (24-27). HIF-1 activity is primarily regulated by the levels of HIF-1 $\alpha$ in the cells. Inhibition of HIF-1 $\alpha$ expression leads to decreased tumor size in vivo, while increased HIF-1 $\alpha$ expression has the reverse effect (25-27). In some cancers, HIF-1 $\alpha$ expression is associated with tumor aggressiveness and patient mortality (28-31). Under hypoxic conditions, HIF-1 $\alpha$ expression is controlled primarily at the post-transcriptional level, due to an inability to bind the E3 ubquitin ligase, von Hippel Lindau protein (pVHL). However, the mechanism of HIF-1 $\alpha$ expression induced by growth factor stimulation has not been completely elucidated. PI3K signaling was shown to regulate HIF-1 $\alpha$ expression in some cell systems in response to growth 
factors and hypoxia $(20-23,32,33)$, while it was shown not to be involved in HIF-1 $\alpha$ regulation in other cell lines (34).

PI3K signaling is frequently upregulated in ovarian cancer cells. $P I 3 C A$, the gene that encodes the p1 10 catalytic subunit of PI3K, is increased in copy number in $40 \%$ of ovarian cancer occurrences (35). The p85 $\alpha$ regulatory subunit of PI3K is also frequently mutated in ovarian cancer (36). AKT1 and AKT2 are both activated in a large number of ovarian carcinomas, with activation being associated with a higher tumor stage $(37,38)$. Pharmacologic inhibition of PI3K decreased ovarian cancer cell proliferation and tumor growth in vivo, and rendered ovarian cancer cells more sensitive to chemotherapy agents $(35,39,40)$.

In this study, we wanted to determine if PI3K signaling regulates VEGF expression and transcriptional activation, and to determine whether PI3K-mediated VEGF expression is regulated by HIF-1 $\alpha$ expression in ovarian cancer cells. We further investigated the possible mechanism by which PI3K signaling mediates VEGF and HIF-1 $\alpha$ expression as well as identified potential signaling molecules for regulating VEGF and HIF-1 $\alpha$ expression.

\section{Materials and Methods}

Reagents and Cell Culture-The human ovarian cancer cell lines A2780, A2780/CP70, OVCAR-3, and SKOV-3 were maintained in RPMI media supplemented with $10 \%$ fetal bovine serum (Intergen, Purchase, NY), 0.2 units/ml human insulin (Sigma, St. Louis, MO), 2 mM glutamine, 50 units/ml penicillin, and $50 \mu \mathrm{g} / \mathrm{ml}$ streptomycin (Invitrogen, Carlsbad, CA). Human umbilical vein endothelial cells (HUVECs) were maintained in EGM Endothelial Cell medium (Cambrex, East Rutherford, $\mathrm{NJ}$ ). All cells were cultured at $37^{\circ} \mathrm{C}$ in a $5 \% \mathrm{CO}_{2}$ incubator, and trypsin (0.25\%) was used to detach adherent cells for subculture. LY294002 and 
wortmannin were obtained from Calbiochem (La Jolla, CA) and rapamycin was obtained from Cell Signaling Technology (Beverly, MA).

Immunoblotting Analysis — Cells were washed in cold 1x PBS and lysed with RIPA buffer (150 $\mathrm{mM} \mathrm{NaCl}, 100 \mathrm{mM}$ Tris, $\mathrm{pH}$ 8.0, 1\% Triton X-100, 1\% deoxycholic acid, 0.1\% SDS, $5 \mathrm{mM}$ EDTA, and $10 \mathrm{mM} \mathrm{NaF}$ ) supplemented with $1 \mathrm{mM}$ sodium vanadate, $0.5 \mathrm{mM}$ dithiothreitol (DTT), $1 \mathrm{mM}$ phenylmethylsulfonyl fluoride (PMSF), $2 \mathrm{mM}$ leupeptin, $2 \mathrm{mM}$ aprotinin, and 2 $\mathrm{mM}$ pepstatin on ice for $30 \mathrm{~m}$. Cellular debris was removed by centrifugation at 13,000 rpm for 15 min at $4^{\circ} \mathrm{C}$. Total cellular protein concentration was assayed using Bio-Rad ${ }^{\circledR}$ protein assay reagent (Richmond, CA). Aliquots $(40 \mu \mathrm{g})$ of protein were loaded onto a SDS/polyacrylamide gel, and resolved by gel electrophoresis. Proteins were then transferred to a nitrocellulose membrane in $20 \mathrm{mM}$ Tris- $\mathrm{HCl}(\mathrm{pH} 8.0)$ with $150 \mathrm{mM}$ glycine and 20\% (v/v) methanol. Membranes were blocked with either $5 \%$ nonfat dry milk in 1x TBS or $5 \%$ bovine serum albumin in 1x TBS, and incubated with protein specific antibodies. Proteins were detected via horseradish-peroxidase conjugated antibodies (NEN, Boston, MA), and visualized through enhanced chemiluminescence reagent (NEN, Boston, MA).

cDNA Constructs - HIF-1 $\alpha$ wild type and HIF- $1 \alpha$ dominant negative were cloned into the pCEP4 vector (Invitrogen, Carlsbad, CA) described previously (1). The human VEGF reporter was constructed by inserting a $2.65 \mathrm{~kb}$ KpnI-BssHII fragment of human VEGF gene promoter into the pGL2-basic vector (Promega, Madison, WI) (pVEGF-Luc). The pMAP11wt VEGF reporter was constructed by PCR amplification of a fragment of the VEGF promoter from -985 to -939 . This fragment regulates VEGF transcription in response to hypoxia and contains 
the HIF-1 binding site. The pMAP11mut was constructed by substituting three base pairs in the HIF-1 binding sequence of the pMAP11wt VEGF reporter. This three base pair substitution abolishes HIF-1 binding to the region. The $\beta$-galactosidase gene driven by the CMV promoter was used as a control plasmid for transfection efficiency.

Transient Transfection and Luciferase Assays_-OVCAR-3 cells were seeded in a 6-well plate at a density of $0.3 \times 10^{6}$ cells/well the day before the transfection. The cells were washed twice with warm Hank's buffered salt solution (Invitrogen, Carlsbad, CA), and then transfected with lipofectamine (Sigma, St. Louis, MO) per the manufacturer's instructions. Briefly, the DNA to be transfected was incubated with $5 \mu \mathrm{l} /$ well lipofectamine in serum-free Opti-MEM media (Invitrogen, Carlsbad, CA) for $30 \mathrm{~min}$. This solution was then added to the cells and allowed to incubate at $37^{\circ} \mathrm{C}$ for $4.5 \mathrm{~h}$. The lipofectamine was then removed and cells were cultured as described above. For the luciferase assays, cells were transfected with VEGF promoter reporter, and pCMV- $\beta$-gal (control). The cells were cultured for $12 \mathrm{~h}$ after transfection, followed by incubation in the absence or presence of LY294002 or rapamycin. At the end of incubation, the cells were collected in luciferase lysis buffer (Promega, Madison, WI) per the manufacturer's instructions. Briefly, $250 \mu \mathrm{l}$ of luciferase lysis buffer was added to each well and placed at $70^{\circ} \mathrm{C}$ until frozen. Cells and lysis buffer were allowed to thaw and were then collected and stored at $-70^{\circ} \mathrm{C}$ until use. Aliquots of protein samples were used for luciferase assay using luciferase substrate (Promega, Madison, WI), and measured by a monolight luminometer. $\beta$ galactosidase ( $\beta$-gal) activity was determined using $40 \mu \mathrm{g}$ of cellular protein extracts by the hydrolysis of o-nitrophenyl-b-D-galactopyranoside at $37^{\circ} \mathrm{C}$ for $1 \mathrm{~h}$. 
Stable Transfection-A2780/CP70 cells were transfected using pcDNA3 vector alone or pcDNA3-HDM2, which contains a neomycin resistance cassette. The cells were cultured overnight after transfection, followed by the addition of G418. The G418 resistant cells were pooled after two weeks and cultured as described above in media supplemented with G418.

VEGF ELISA-Media were collected from cells and centrifuged at $800 \mathrm{rpm}$ for $4 \mathrm{~min}$ at room temperature to remove any cellular debris and stored at $-70^{\circ} \mathrm{C}$. Wells of a $96-$ well plate were coated with VEGF polyclonal capture antibodies (R\&D Systems, Minneapolis, MN) overnight at $4^{\circ} \mathrm{C}$. Aliquots of media were then added to each well and allowed to incubate at room temperature. VEGF monoclonal detection antibody coupled to horseradish peroxidase (R\&D systems, Minneapolis, MN) was added to the wells and incubated. The wells were washed and levels of VEGF were detected using 2,2'-Azino-bis(3-ethylbenzathione-6-sulfonic acid [ABTS]) as substrate and $1 \% \mathrm{H}_{2} \mathrm{O}_{2}$ were then added. The color change was then measured in a 96-well micro plate reader, and compared to the VEGF standard in the same assay.

\section{Results}

\section{The PI3K Inhibitor LY294002 Inhibited VEGF Transcriptional Activation and Protein} Expression in Ovarian Cancer Cells - Increased VEGF expression is an important factor for inducing ovarian tumorigenesis; however, the mechanism of its elevation still remains to be elucidated. To determine whether PI3K activity plays a role in VEGF transcriptional activation, OVCAR-3 cells were transfected with a VEGF promoter reporter containing a $2.6 \mathrm{~kb}$ human VEGF promoter. Inhibition of PI3K activity by LY294002 inhibited the VEGF reporter activity (Figs. 1A and 1B). This result indicates that PI3K activity is required for VEGF transcriptional 
activation. It is known that VEGF transcription is mainly regulated by HIF-1 in response to hypoxia. To test whether the HIF-1 binding site at the VEGF promoter is important for PI3Kmediated VEGF transcriptional activation, we constructed a VEGF reporter containing a functional promoter fragment with the HIF-1 binding site. Inhibition of PI3K by LY294002 also inhibited the VEGF reporter in a time- and dose-dependent manner (Fig. 1C and 1D). Mutation of the HIF-1 binding site abolished the inhibitory effect of LY294002 on VEGF transcriptional activity (Fig. 1E). Thus, the inhibitory effect of LY294002 on VEGF transcriptional activation requires the HIF-1 binding site at the VEGF promoter. To determine whether LY294002 treatment affects VEGF protein levels, OVCAR-3 and A2780/CP70 cells were treated with LY294002. A2780/CP70 cells contain the lost function of p53 protein, which would test the effect of PI3K inhibition without p53 activity in the cells. The VEGF protein levels in the medium were measured by ELISA. As shown in Figs. 1F and 1G, LY294002 treatment significantly decreased VEGF protein levels in both cell lines.

LY294002-inhibited VEGF transcriptional activation was reversed by HIF-1 $\alpha$-To further study whether the inhibitory effect of LY294002 on VEGF transcriptional activation depends on HIF-1 $\alpha$ expression, the cells were co-transfected with VEGF promoter reporters and HIF-1 $\alpha$ plasmids. Transfection with HIF-1 $\alpha$ alone significantly increased the VEGF reporter activity, completely reversed LY294002-inhibited VEGF transcriptional activation and resulted in even higher levels of activity (Fig. 2A). This result shows that HIF-1 $\alpha$ is sufficient to induce VEGF transcriptional activation in the cells. To test whether HIF-1 activity is required for the VEGF expression, the cells were transfected with HIF-1 $\alpha$ dominant negative construct, which inhibited the VEGF promoter activity in a dose dependent manner (Fig. 2B). The inhibition was not 
affected significantly by combined treatment with LY294002 and the HIF-1 dominant negative construct (Fig. 2B). These results suggest that LY294002-inhibited VEGF transcriptional activation depends on HIF-1 $\alpha$ expression.

HIF-1 $\alpha$ Protein Expression in Ovarian Cancer Cells Required PI3K Activity-To determine whether HIF- $1 \alpha$ expression is mediated by PI3K in ovarian cancer cells, HIF-1 $\alpha$ protein levels were measured in several ovarian cancer cells in the absence or presence of LY294002. HIF-1 $\alpha$ protein levels in human endothelial cells (HUVEC) were used as a negative control. HIF-1 $\alpha$ expression levels in all ovarian cancer cell lines were much higher than those in HUVEC cells (Fig. 3A). LY294002 treatment specifically inhibited HIF-1 $\alpha$, but not HIF-1 $\beta$ expression, indicating that HIF-1 $\alpha$ expression in these cells required PI3K activation. To determine whether PI3K is required for growth factor-induced HIF-1 $\alpha$ expression, the cells were cultured in serumfree medium for $24 \mathrm{~h}$, followed by the addition of $10 \%$ serum, insulin, or IGF-1. Treatment with serum, insulin, or IGF-1 greatly increased HIF-1 $\alpha$ expression in OVCAR-3, A2780/CP70, and A2780 cell lines, and the induced HIF-1 $\alpha$ expression was inhibited by LY294002 (Figs. 3B and 3C). Due to the high basal level in SKOV-3 cells, HIF-1 $\alpha$ expression was not induced by IGF-1, but induced by insulin (Fig. 3C). Both the basal level and induced HIF-1 $\alpha$ expression were inhibited by LY294002 treatment. These data further confirm that PI3K mediates VEGF transcriptional activation through HIF-1 $\alpha$, but not HIF-1 $\beta$ levels in the ovarian cancer cells with different properties.

AKT is Essential for PI3K-mediated VEGF Transcriptional Activation-AKT is a known target of PI3K. To confirm that AKT was activated by serum and inhibited by LY294002 in the 
ovarian cancer cells, the cells were cultured in serum-free medium for $24 \mathrm{~h}$, pretreated with LY294002 for $30 \mathrm{~min}$, and then stimulated by serum for $1.5 \mathrm{~h}$. AKT activation, indicated by its protein phosphorylation, was increased by serum stimulation and inhibited by LY294002 (Fig. 4A). To determine whether expression of active form of AKT is sufficient to restore LY294002inhibited VEGF transcriptional activation, OVCAR-3 cells were transfected with VEGF reporter and myristrylated AKT. Transfection of AKT significantly increased VEGF reporter activity and completely reversed LY294002-inhibited VEGF reporter activity in a dose-dependent manner (Figs. 4B and 4C). Because the full activation of AKT still requires PI3K activity, the reporter activity is much lower in the presence of LY294002 than that in the absence of LY294002 (Fig. 4). This data indicates that AKT is a sufficient target of PI3K for mediating VEGF expression.

\section{Rapamycin Decreased VEGF Transcriptional Activation and VEGF Protein Production}

-Rapamycin is a specific inhibitor for mTOR and p70S6K1. To investigate whether rapamycin inhibited VEGF transcriptional activation, OVCAR-3 cells were transfected with the VEGF reporter, followed by the treatment with solvent alone or rapamycin. VEGF reporter activity was decreased by rapamycin treatment in a dose-dependent manner (Figs. 5A and 5B), suggesting that activation of mTOR and p70S6K1 is involved in VEGF transcriptional activation. To determine whether rapamycin treatment also inhibited VEGF protein levels in ovarian cancer cells, the cells were treated with rapamycin and VEGF levels were analyzed by ELISA. Rapamycin treatment decreased VEGF protein levels in both cell lines in a dose-dependent manner (Figs. 5C and 5D). 
P70S6K1 Was Sufficient to Reverse LY294002-inhibited VEGF Transcriptional Activation-To test whether expression of an active form of p70S6K1 is sufficient to reverse LY294002inhibited VEGF transcriptional activation, OVCAR-3 cells were transfected with a VEGF reporter and a constitutively active form of p70S6K1. As shown in Fig. 6, forced expression of p70S6K1 greatly increased VEGF reporter activity and reversed LY294002-inhibited VEGF transcriptional activation in a dose-dependent manner. These data indicate that p70S6K1 is an important downstream target of PI3K and AKT for inducing VEGF transcriptional activation in ovarian cancer cells.

Rapamycin Inhibited HIF-1 $\alpha$, but not HIF-1 $\beta$ expression in OVCAR-3 and A2780/CP70 cells-To determine whether rapamycin inhibits HIF- $1 \alpha$ and HIF-1 $1 \beta$ expression in response to growth factor stimulation, OVCAR-3 and A2780/CP70 cells were cultured in serum-free medium for $24 \mathrm{~h}$, followed by the addition of serum, IGF-1, or insulin. Rapamycin specifically inhibited HIF-1 $\alpha$ but not HIF-1 $\beta$ expression in response to serum, IGF-1, and insulin (Fig. 7). This result indicates that rapamycin may inhibit VEGF transcriptional activation through a decrease of HIF-1 $\alpha$ expression in the cells.

Inhibition of PI3K Decreased HDM2 Phosphorylation and Expression in Ovarian Cancer Cells - Previous studies have indicated that Akt may upregulate the function of HDM2 via phosphorylation $(42,43)$. To determine whether inhibition of PI3K/Akt by LY294002 affects HDM2 phosphorylation and protein levels, OVCAR-3 cells were treated with LY294002 and analyzed by immunoblotting for HDM2 expression. Both HDM2 phosphorylation and protein expression were inhibited by LY294002 (Fig. 8). 
Forced Expression of HDM2 Reversed LY294002-inhibited VEGF Transcriptional Activation, VEGF Expression, and HIF-1 $\alpha$ Expression-To determine whether HDM2 acts downstream of PI3K to affect VEGF transcriptional activation, OVCAR-3 cells were transfected with VEGF reporter and HDM2 plasmids. After the transfection, the cells were incubated in the absence or presence of LY294002. Forced expression of HDM2 reversed LY294002-inhibited VEGF reporter activity in a dose-dependent manner (9A), indicating that HDM2 was sufficient to restore LY294002-inhibited VEGF transcriptional activation. To test whether the HIF-1 binding site is required for HDM2-mediated VEGF reporter activity, we used the mutant VEGF reporter at the HIF-1 DNA binding site. Neither LY294002 nor HDM2 affected the mutant VEGF reporter activity (Fig. 9B), indicating that LY294002 and HDM2 regulate the reporter activity through HIF-1 binding site.

HDM2 restored LY294002-inhibited VEGF protein production — To study whether HDM2 reversed LY294002-inhibited VEGF protein expression, the cells were transiently tranfected with vector alone or HDM2, followed by treatment with LY294002. HDM2 partially reversed the inhibitory effect of LY294002 on VEGF protein levels (Fig. 10). These data indicate that HDM2 plays an important role in PI3K-mediated VEGF transcriptional activation and VEGF protein expression.

To determine whether HDM2 restores LY294002-inhibited HIF-1 $\alpha$ expression, A2780/CP70 cells stably expressing HDM2 or vector alone were cultured in serum-free medium, then treated with $10 \%$ serum in the presence or absence of LY294002. Expression of HDM2 in the cells reversed LY294002-inhibited HIF-1 $\alpha$ expression $\quad$ (Fig. 11). Taken together, these 
results suggest that PI3K and AKT mediate VEGF transcriptional activation through HIF-1 $\alpha$ expression, and that HDM2 and p70S6K1 signaling pathways are two parallel pathways that mediate this process.

\section{Discussion}

It is known that VEGF plays an important role in ovarian tumorigenesis and angiogenesis. However, the mechanism by which VEGF expression is elevated is not completely understood. Genes encoding PI3K are frequently amplified in copy number in ovarian cancer cells, leading to activation of PI3K signaling $(35,36)$. In this study, we showed that VEGF protein expression and transcriptional activation were induced by PI3K activation in ovarian cancer. To understand the mechanism of the observed increased VEGF expression, we found that PI3K signaling upregulated VEGF expression through HIF-1 $\alpha$. VEGF and HIF-1 are known to increase tumor growth and angiogenesis. Thus, PI3K may increase ovarian tumor growth and angiogenesis through VEGF and HIF-1 expression.

To identify the downstream mediators of PI3K necessary for regulating HIF- $1 \alpha$ and VEGF expression in ovarian cancer cells, we investigated potential downstream targets of PI3K in response to growth factor stimulation. We found that AKT was essential for VEGF transcriptional activation in the cells. In this study, we were particularly interested in the downstream targets of AKT that mediate VEGF transcriptional activation in ovarian cancer cells. We found that p70S6K1 and HDM2 are two parallel pathways that mediate growth factorinduced VEGF transcriptional activation and HIF-1 $\alpha$ expression. These results are consistent

with recent studies demonstrating that AKT activation increased HDM2 phosphorylation and its 
activity $(41,42)$. These results may provide useful information regarding VEGF and HIF-1 regulation in other human cancer cells.

Overall, these results identify a novel mechanism by which the observed PI3K activation and other oncogenic signals in ovarian cancer cells may increase VEGF expression, which in turn induces angiogenesis and tumor growth. We have identified several members of this signaling cascade including AKT, HDM2, and p70S6K1 that are necessary for VEGF transcriptional activation and HIF-1 $\alpha$ expression. This study may also provide useful information and potential targets for anti-ovarian cancer therapy in the future.

\section{Acknowledgements}

We thank Dr. John Blenis and Dr. Zhi-Min Yuan (Harvard Medical School, MA) for kindly providing p70S6K1 and HDM2 constructs, respectively. 


\section{Reference List}

1. Paley, P. J., Staskus, K. A., Gebhard, K., Mohanraj, D., Twiggs, L. B., Carson, L. F., and Ramakrishnan, S. (1997) Cancer 80, 98-106

2. Hazelton, D. A. and Hamilton, T. C. (1999) Curr.Oncol.Rep. 1, 59-63

3. Tempfer, C., Obermair, A., Hefler, L., Haeusler, G., Gitsch, G., and Kainz, C. (1998) Obstet.Gynecol. 92, 360-363

4. Olson, T. A., Mohanraj, D., Carson, L. F., and Ramakrishnan, S. (1994) Cancer Res. 54, $276-280$

5. Kraft, A., Weindel, K., Ochs, A., Marth, C., Zmija, J., Schumacher, P., Unger, C., Marme, D., and Gastl, G. (1999) Cancer 85, 178-187

6. Yoneda, J., Kuniyasu, H., Crispens, M. A., Price, J. E., Bucana, C. D., and Fidler, I. J. (1998) J.Natl.Cancer Inst. 90, 447-454

7. Nagy, J. A., Masse, E. M., Herzberg, K. T., Meyers, M. S., Yeo, K. T., Yeo, T. K., Sioussat, T. M., and Dvorak, H. F. (1995) Cancer Res. 55, 360-368

8. Boocock, C. A., Charnock-Jones, D. S., Sharkey, A. M., McLaren, J., Barker, P. J., Wright, K. A., Twentyman, P. R., and Smith, S. K. (1995) J.Natl.Cancer Inst. 87, 506-516

9. Abu-Jawdeh, G. M., Faix, J. D., Niloff, J., Tognazzi, K., Manseau, E., Dvorak, H. F., and Brown, L. F. (1996) Lab Invest 74, 1105-1115

10. Mattern, J., Stammler, G., Koomagi, R., Wallwiener, D., Kaufmann, M., and Volm, M. (1997) Anticancer Res. 17, 621-624

11. Mu, J., Abe, Y., Tsutsui, T., Yamamoto, N., Tai, X. G., Niwa, O., Tsujimura, T., Sato, B., Terano, H., Fujiwara, H., and Hamaoka, T. (1996) Jpn.J.Cancer Res. 87, 963-971

12. Yukita, A., Asano, M., Okamoto, T., Mizutani, S., and Suzuki, H. (2000) Anticancer Res. 20, 155-160

13. Xu, L., Yoneda, J., Herrera, C., Wood, J., Killion, J. J., and Fidler, I. J. (2000) Int.J.Oncol. 16, $445-454$

14. Mesiano, S., Ferrara, N., and Jaffe, R. B. (1998) Am.J.Pathol. 153, 1249-1256

15. Jiang, B. H., Rue, E., Wang, G. L., Roe, R., and Semenza, G. L. (1996) J.Biol.Chem. 271, 17771-17778

16. Wang, G. L., Jiang, B. H., Rue, E. A., and Semenza, G. L. (1995) Proc.Natl.Acad.Sci.U.S.A 92, 5510-5514 
17. Jiang, B. H., Semenza, G. L., Bauer, C., and Marti, H. H. (1996) Am.J.Physiol 271, C1172$\mathrm{C} 1180$

18. Huang, L. E., Arany, Z., Livingston, D. M., and Bunn, H. F. (1996) J.Biol.Chem. 271, 32253-32259

19. Fukuda, R., Hirota, K., Fan, F., Jung, Y. D., Ellis, L. M., and Semenza, G. L. (2002) J.Biol.Chem. 277, 38205-38211

20. Jiang, B. H., Jiang, G., Zheng, J. Z., Lu, Z., Hunter, T., and Vogt, P. K. (2001) Cell Growth Differ. 12, 363-369

21. Stiehl, D. P., Jelkmann, W., Wenger, R. H., and Hellwig-Burgel, T. (2002) FEBS Lett. 512, $157-162$

22. Page, E. L., Robitaille, G. A., Pouyssegur, J., and Richard, D. E. (2002) J.Biol.Chem. 277, 48403-48409

23. Sandau, K. B., Faus, H. G., and Brune, B. (2000) Biochem.Biophys.Res.Commun. 278, 263267

24. Ryan, H. E., Lo, J., and Johnson, R. S. (1998) EMBO J. 17, 3005-3015

25. Maxwell, P. H., Dachs, G. U., Gleadle, J. M., Nicholls, L. G., Harris, A. L., Stratford, I. J., Hankinson, O., Pugh, C. W., and Ratcliffe, P. J. (1997) Proc.Natl.Acad.Sci.U.S.A 94, 81048109

26. Ryan, H. E., Poloni, M., McNulty, W., Elson, D., Gassmann, M., Arbeit, J. M., and Johnson, R. S. (2000) Cancer Res. 60, 4010-4015

27. Kung, A. L., Wang, S., Klco, J. M., Kaelin, W. G., and Livingston, D. M. (2000) Nat.Med. 6, $1335-1340$

28. Birner, P., Gatterbauer, B., Oberhuber, G., Schindl, M., Rossler, K., Prodinger, A., Budka, H., and Hainfellner, J. A. (2001) Cancer 92, 165-171

29. Birner, P., Schindl, M., Obermair, A., Plank, C., Breitenecker, G., and Oberhuber, G. (2000) Cancer Res. 60, 4693-4696

30. Bos, R., Zhong, H., Hanrahan, C. F., Mommers, E. C., Semenza, G. L., Pinedo, H. M., Abeloff, M. D., Simons, J. W., van Diest, P. J., and Van Der, W. E. (2001) J.Natl.Cancer Inst. 93, 309-314

31. Zagzag, D., Zhong, H., Scalzitti, J. M., Laughner, E., Simons, J. W., and Semenza, G. L. (2000) Cancer 88, 2606-2618

32. Treins, C., Giorgetti-Peraldi, S., Murdaca, J., Semenza, G. L., and Van Obberghen, E. (2002) J.Biol.Chem. 277, 27975-27981 
33. Hudson, C. C., Liu, M., Chiang, G. G., Otterness, D. M., Loomis, D. C., Kaper, F., Giaccia, A. J., and Abraham, R. T. (2002) Mol.Cell Biol. 22, 7004-7014

34. Alvarez-Tejado, M., Alfranca, A., Aragones, J., Vara, A., Landazuri, M. O., and del Peso, L. (2002) J.Biol.Chem. 277, 13508-13517

35. Shayesteh, L., Lu, Y., Kuo, W. L., Baldocchi, R., Godfrey, T., Collins, C., Pinkel, D., Powell, B., Mills, G. B., and Gray, J. W. (1999) Nat.Genet. 21, 99-102

36. Philp, A. J., Campbell, I. G., Leet, C., Vincan, E., Rockman, S. P., Whitehead, R. H., Thomas, R. J., and Phillips, W. A. (2001) Cancer Res. 61, 7426-7429

37. Sun, M., Wang, G., Paciga, J. E., Feldman, R. I., Yuan, Z. Q., Ma, X. L., Shelley, S. A., Jove, R., Tsichlis, P. N., Nicosia, S. V., and Cheng, J. Q. (2001) Am.J.Pathol. 159, 431-437

38. Yuan, Z. Q., Sun, M., Feldman, R. I., Wang, G., Ma, X., Jiang, C., Coppola, D., Nicosia, S. V., and Cheng, J. Q. (2000) Oncogene 19, 2324-2330

39. Hu, L., Zaloudek, C., Mills, G. B., Gray, J., and Jaffe, R. B. (2000) Clin.Cancer Res. 6, 880-886

40. Hu, L., Hofmann, J., Lu, Y., Mills, G. B., and Jaffe, R. B. (2002) Cancer Res. 62, 10871092

41. Mayo, L. D. and Donner, D. B. (2001) Proc.Natl.Acad.Sci.U.S.A 98, 11598-11603

42. Ogawara, Y., Kishishita, S., Obata, T., Isazawa, Y., Suzuki, T., Tanaka, K., Masuyama, N., and Gotoh, Y. (2002) J.Biol.Chem. 277, 21843-21850 
A
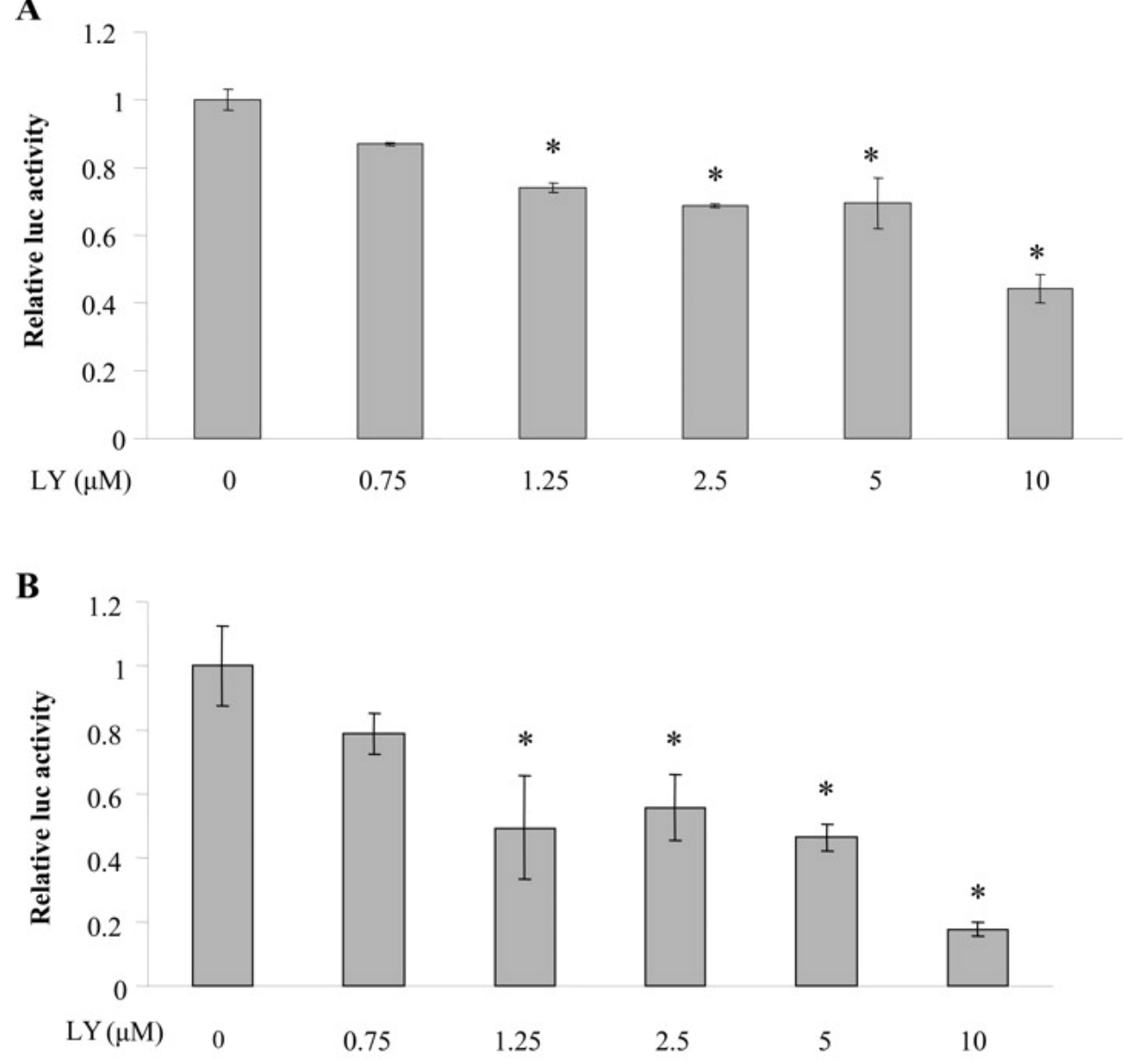

C

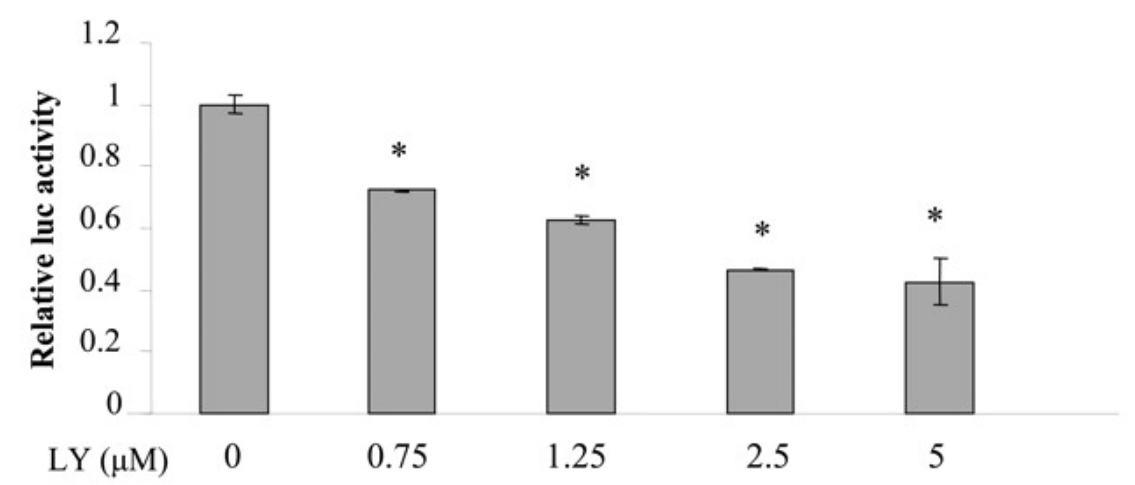


D

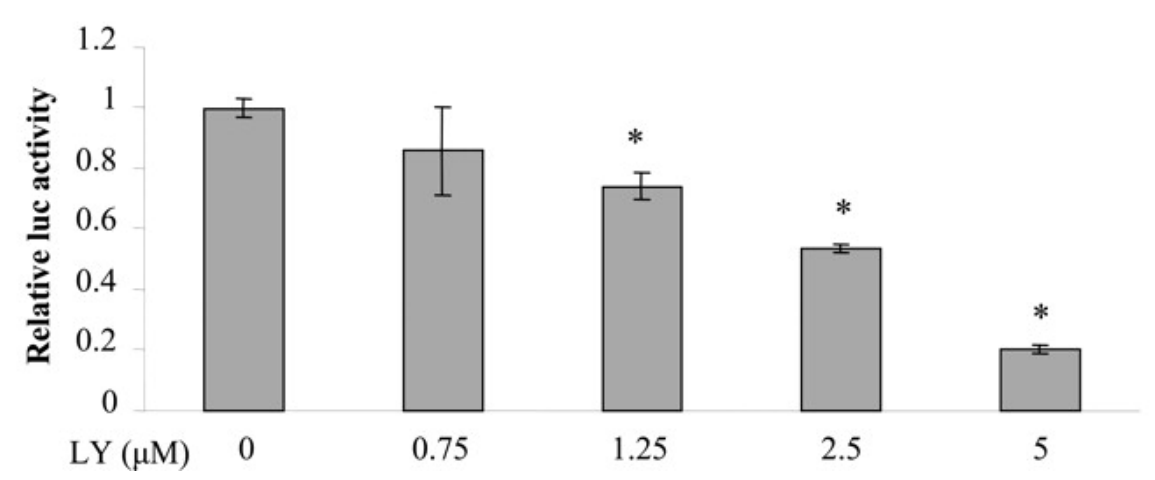

E

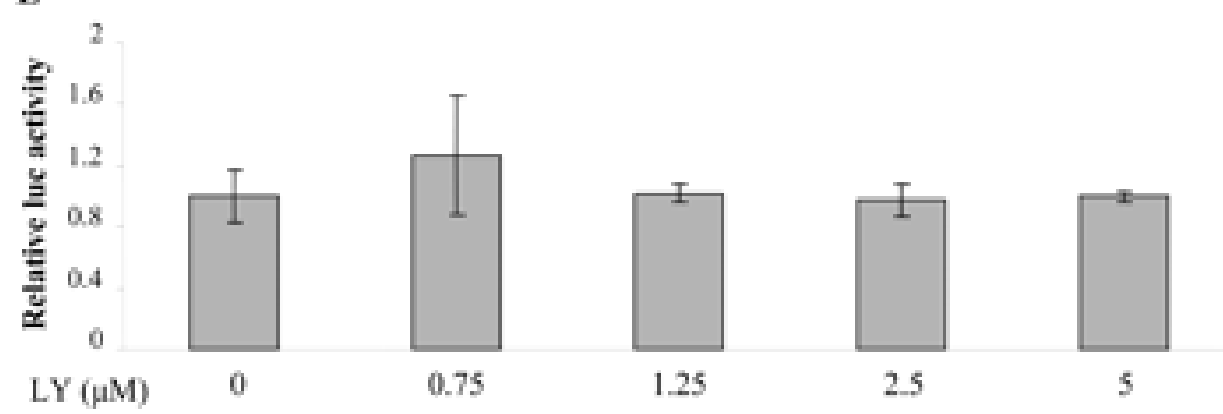

F

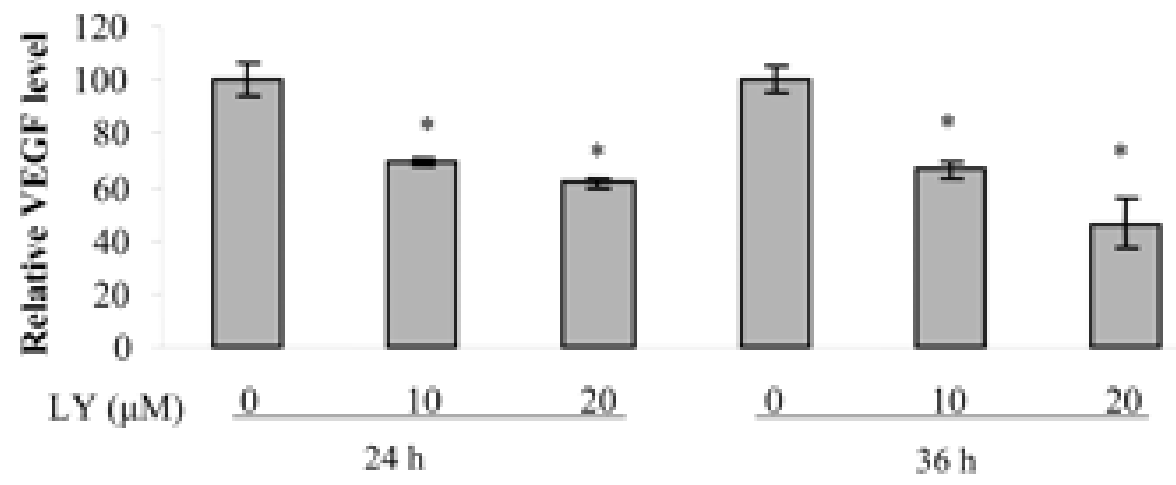

G

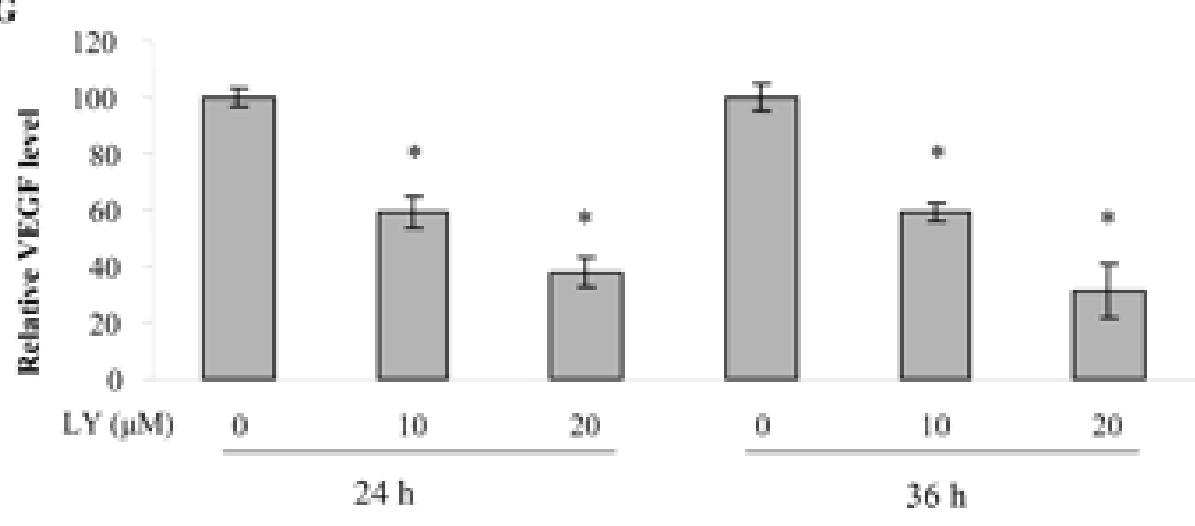


Figure 1. The effects of PI3K inhibitor LY294002 on VEGF transcriptional activation and VEGF protein level. $A$ and $B$, OVCAR-3 cells were seeded at $0.5 \times 10^{6}$ cells/well on a 6 -well plate the day before the transfection. To test VEGF transcriptional activation, the cells were cotransfected with pCMV- $\beta$-gal plasmid and a VEGF reporter containing a $2.6 \mathrm{~kb}$ human VEGF promoter fragment in the pGL2 vector, pVEGF-Luc. After the transfection, the cells were cultured for $12 \mathrm{~h}$, followed by incubation in the absence or presence of LY294002 at the indicated concentrations for $24 \mathrm{~h}(A)$ and $36 \mathrm{~h}(B)$. The relative luciferase activity was determined by the ratio of luciferase: $\beta$-gal activity and normalized to the control in the cells. $C$ and $D$, Cells were co-transfected with pCMV- $\beta$-gal plasmid and a VEGF reporter containing a 46 bp functional human VEGF promoter with HIF-1 binding site, pMAP11wt. The cells were cultured and treated with LY294002 for $24 \mathrm{~h}(C)$ and $36 \mathrm{~h}(D)$ as described above. E, The cells were co-transfected with pCMV- $\beta$-gal plasmid and the pMAP11mut, which contained three base pair substitutions at the HIF-1 binding site of pMAP11wt. The cells were treated with LY294002 as described above for $36 \mathrm{~h} . F$ and $G$, OVCAR-3 $(F)$ and A2780/CP70 $(G)$ cells were treated with DMSO or LY294002 for $24 \mathrm{~h}$ and $36 \mathrm{~h}$. VEGF protein levels were analyzed by ELISA using $100 \mu \mathrm{l}$ of media as described in Materials and Methods, and the values were normalized to the control. $*$ indicates a significant difference from the control $(\mathrm{p}<0.05)$. 

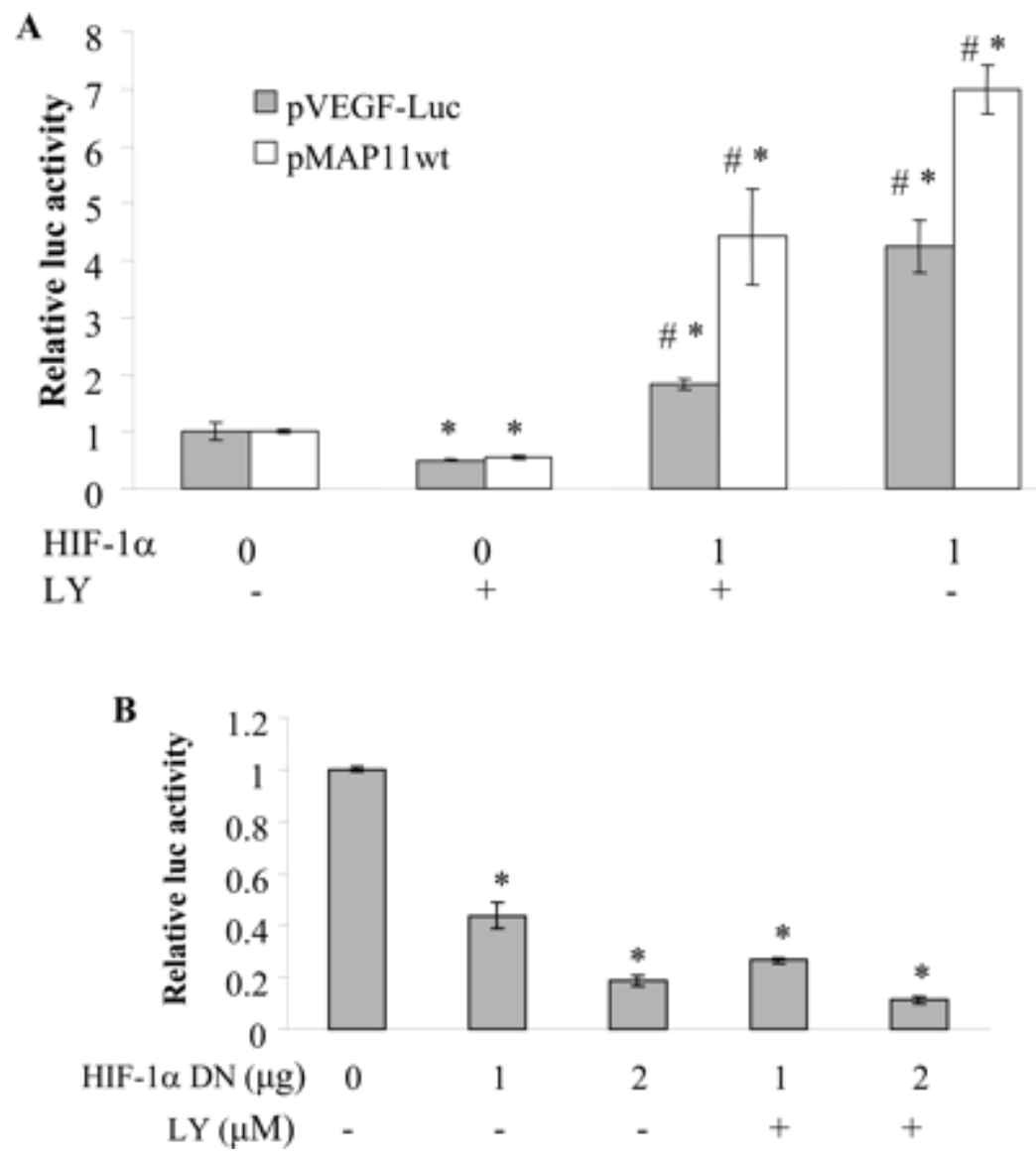

Figure 2. HIF-1 $\alpha$ reversed LY294002-inhibited VEGF transcriptional activation. A, OVCAR-3 cells were seeded at $0.5 \times 10^{6}$ cells/well on a 6 -well plate the day before the transfection. The cells were co-transfected with pCMV- $\beta$-gal, pCEP4-HIF- $1 \alpha$, and pVEGF-Luc or pMAP11wt plasmids. The parental pCEP4 vector was used to adjust the equal amount of plasmid used for each transfection. The cells were incubated for $12 \mathrm{~h}$ after transfection, and then treated with DMSO alone or $10 \mu \mathrm{M}$ LY294002 for $24 \mathrm{~h}$. The relative luciferase activity was determined by the ratio of luciferase: $\beta$-gal activity and normalized to the control. $B$, The cells were cotransfected with pCMV- $\beta$-gal, pVEGF-Luc, and pCEP4 vector or HIF- $1 \alpha$ dominant negative construct. The cells were incubated for $12 \mathrm{~h}$ after transfection and then treated with DMSO alone or $10 \mu \mathrm{M}$ LY294002 for $24 \mathrm{~h}$. The relative luciferase activity was determined as described 
above. * indicates a significant difference from the control $(\mathrm{p}<0.05)$. \# indicates a significant difference from the LY294002-treated group $(\mathrm{p}<0.05)$.

A

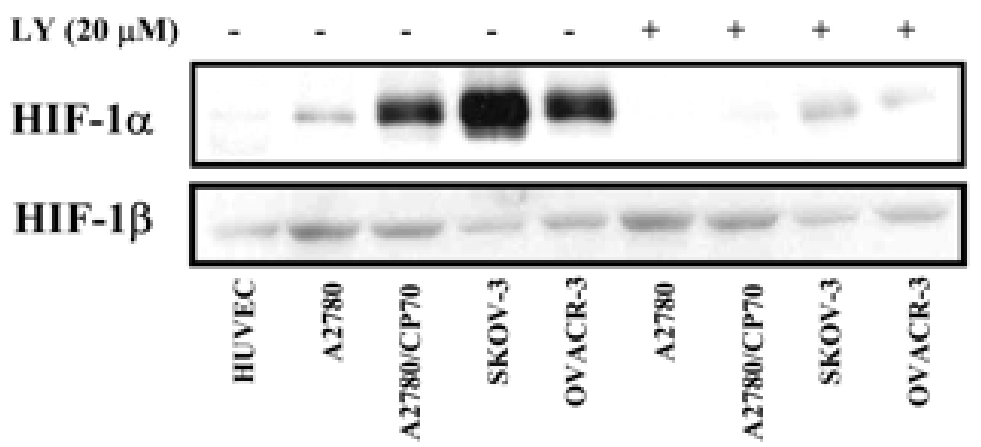

B

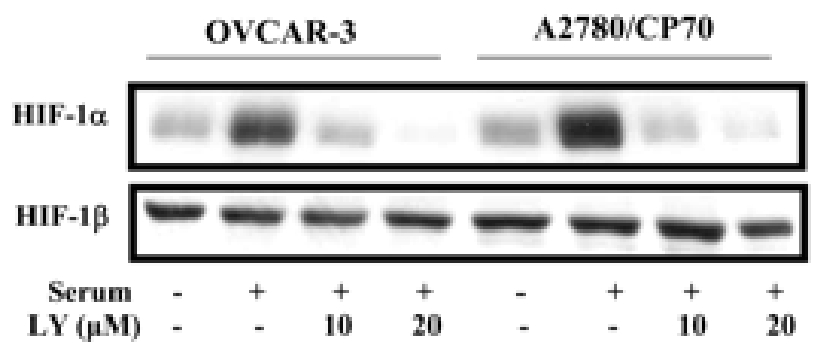

C

A2780

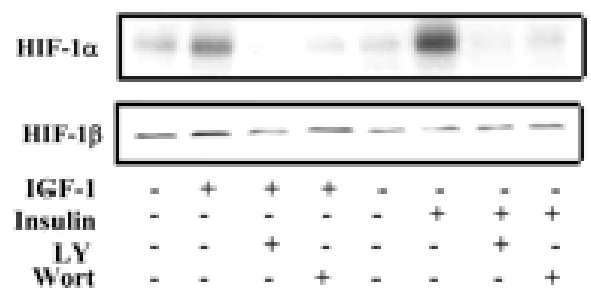

SKOV-3

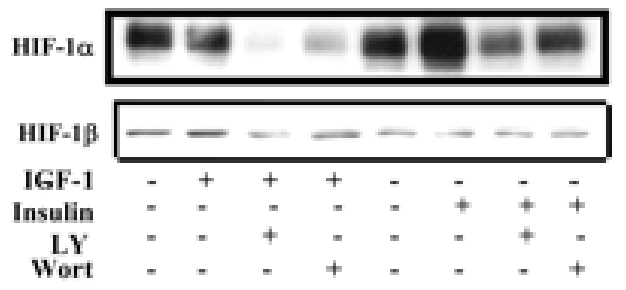

Figure 3. HIF-1 $\alpha$ expression is inhibited by PI3K inhibitor LY294002 in ovarian cancer cells. A, Four human ovarian cancer cell lines (A2780, A2780/CP70, SKOV-3, and OVCAR-3) were cultured to confluence in $60 \mathrm{~mm}$ dishes in RPMI supplemented with 10\% FBS, 5\% L-glutamine, $5 \%$ penicillin-streptomycin and $0.2 \%$ insulin at $37^{\circ} \mathrm{C}$ in $5 \% \mathrm{CO}_{2}$. The cells were treated with DMSO or $20 \mu \mathrm{M}$ LY294002 for $6 \mathrm{~h}$. The HIF-1 $\alpha$ and HIF-1 $\beta$ protein levels were analyzed by 
immunoblotting using antibodies specific for HIF-1 $\alpha$ and HIF-1 $\beta$. $B$, The cells were cultured to $90 \%$ confluence, then switched to serum-free medium for $24 \mathrm{~h}$. The cells were incubated in the absence or presence of $10 \%$ serum and LY294002 $(10$ or $20 \mu \mathrm{M})$ for $6 \mathrm{~h}$. Aliquots $(40 \mu \mathrm{g})$ of total cellular proteins were analyzed by immunoblotting using antibodies specific for HIF-1 $\alpha$ and HIF-1 $\beta$. $C$, The serum-starved cells were pretreated with DMSO, $20 \mu \mathrm{M}$ LY294002, or 100 $\mathrm{nM}$ wortmannin for $30 \mathrm{~min}$, followed by the addition of $200 \mathrm{nM}$ insulin or $4 \mathrm{nM} \mathrm{IGF-1} \mathrm{as}$ indicated for $6 \mathrm{~h}$. HIF-1 $\alpha$ and HIF-1 $\beta$ proteins were analyzed as described above.

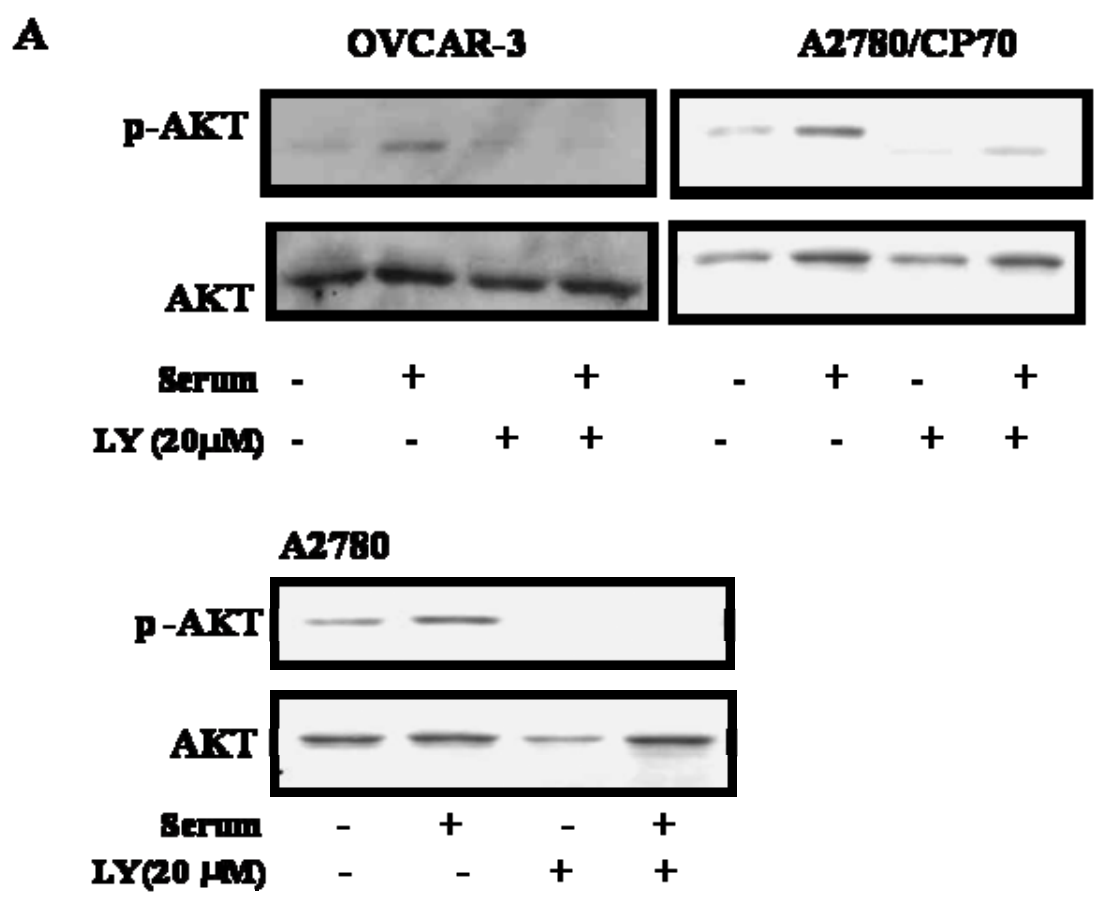




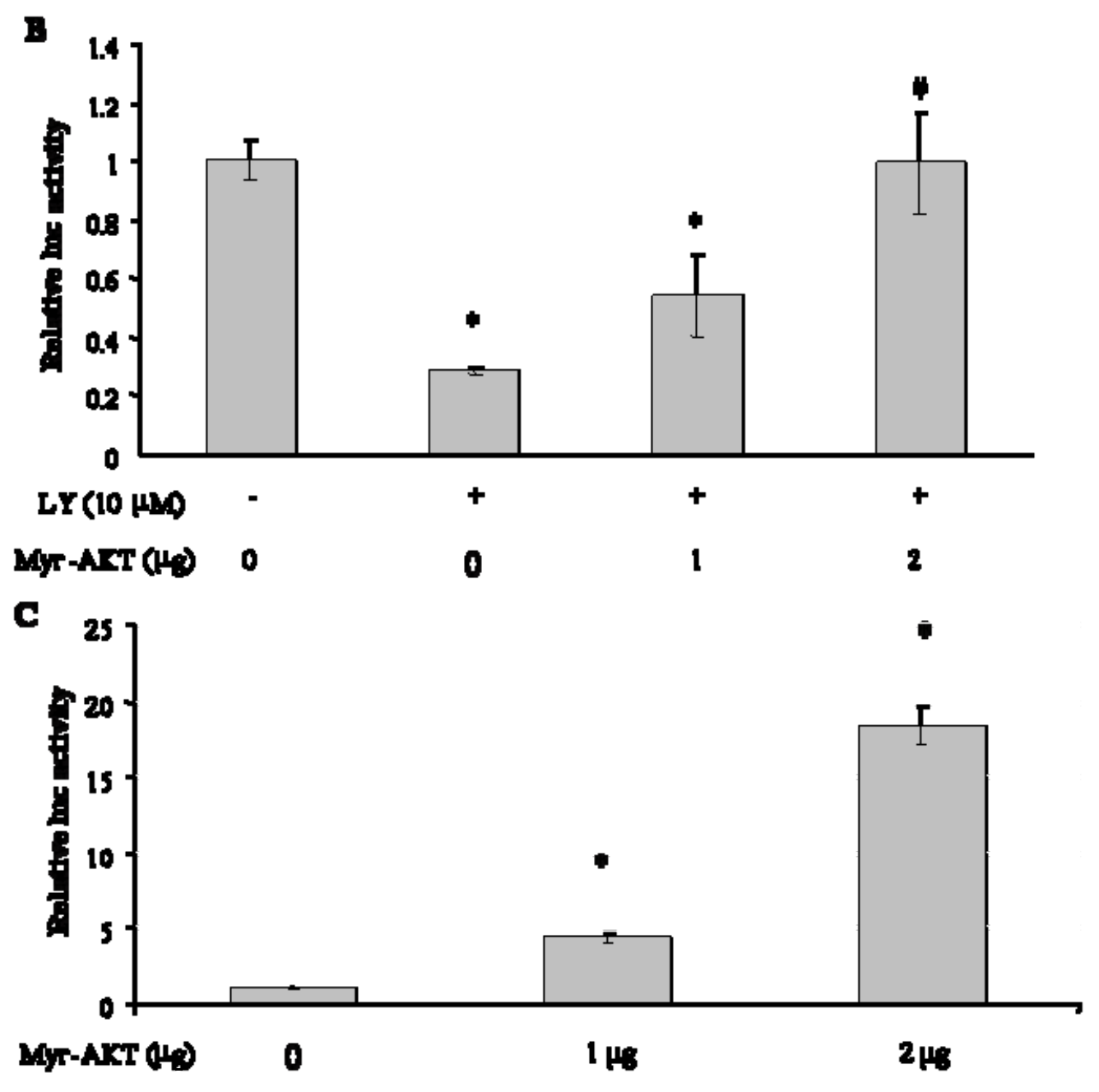

Figure 4. AKT is essential for VEGF transcriptional activation. $A$, AKT activation was inhibited by LY294002 in ovarian cancer cells. A2780, A2780/CP70 and OVCAR-3 cells were cultured to $90 \%$ confluence and switched to serum-free medium for $24 \mathrm{~h}$. The cells were pretreated with LY294002 for $30 \mathrm{~min}$, followed by treatment with 10\% FBS for $1.5 \mathrm{~h}$. The phospho-AKT and total AKT protein levels were analyzed by immunoblotting. $B$ and $C$, AKT reversed LY294002inhibited VEGF transcriptional activation. OVCAR-3 cells were seeded at $0.5 \times 10^{6}$ cells/well on a 6-well plate the day before the transfection. The cells were co-transfected with pCMV- $\beta$-gal control, the pVEGF-Luc reporter, and a constitutively active AKT (Myr-AKT) plasmid or the 
vector. The cells were cultured for $12 \mathrm{~h}$ after transfection, and then treated with DMSO and 10 $\mu \mathrm{M}$ LY294002 (B) or with DMSO alone (C), for $24 \mathrm{~h}$. The relative luciferase activity was determined by the ratio of luciferase: $\beta$-gal activity and normalized to the control. $*$ indicates a significant difference from the control $(\mathrm{p}<0.05)$. \# indicates a significant difference from the LY294002 treatment $(\mathrm{p}<0.05)$.

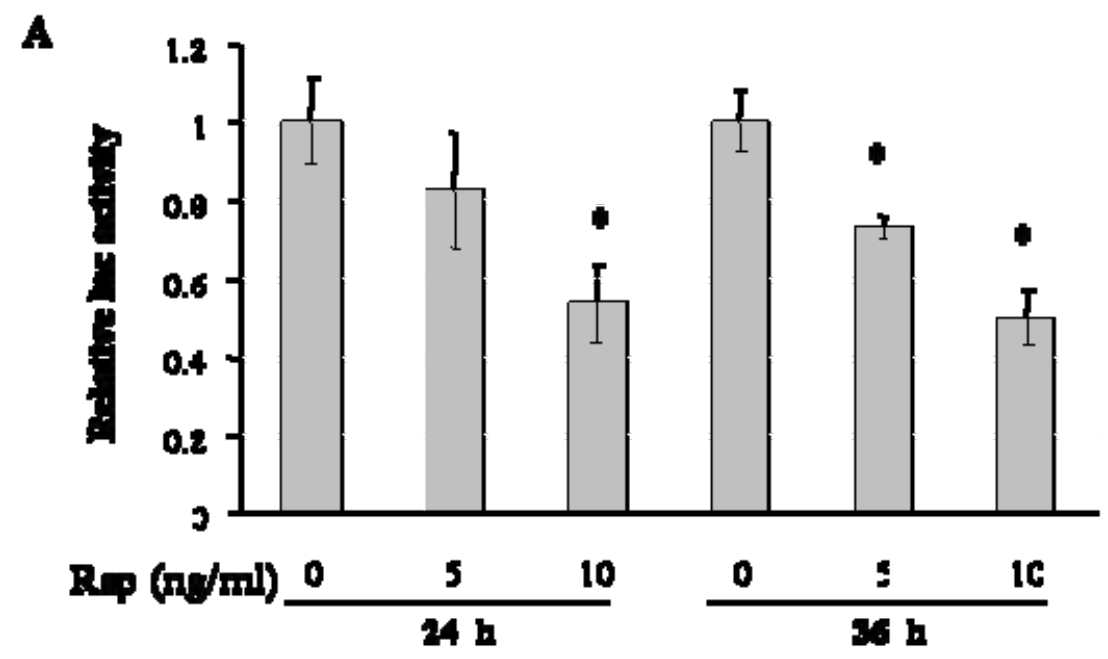

$\mathbf{B}$

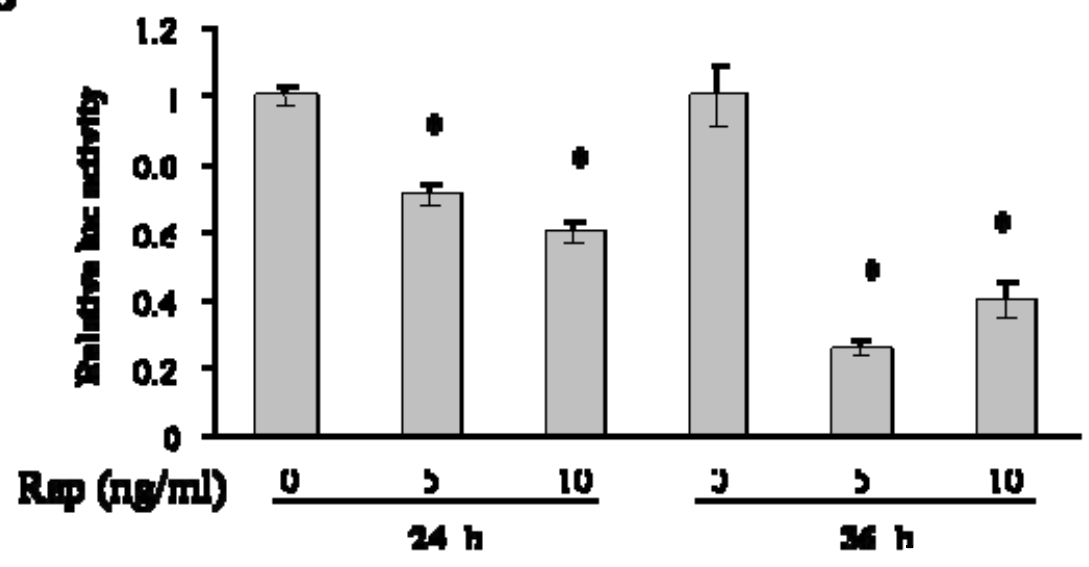


C

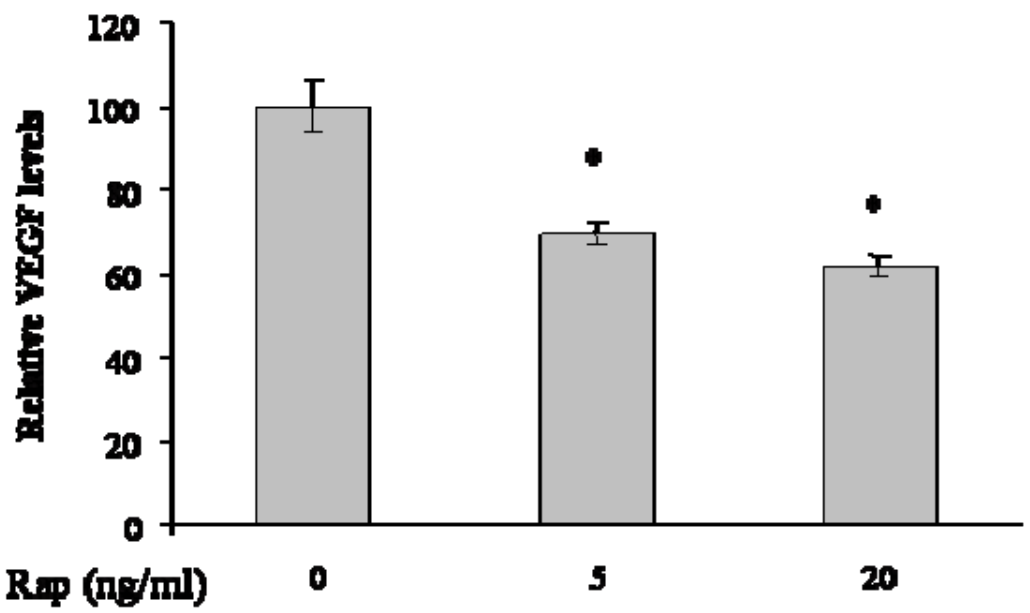

D

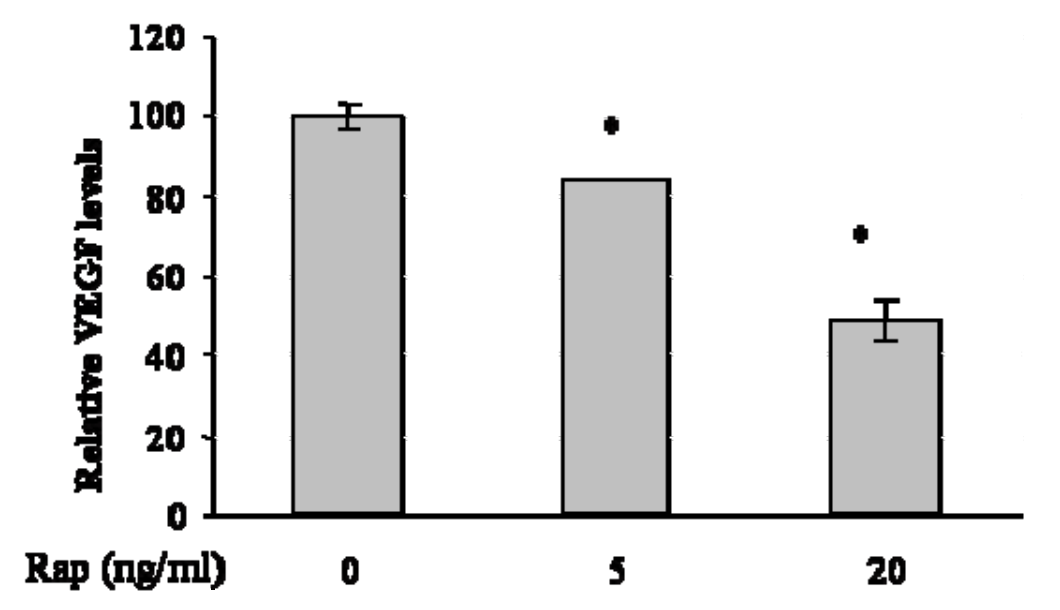

Figure 5. Rapamycin inhibited VEGF transcriptional activation and VEGF protein levels in ovarian cancer cells. $A$ and $B$, To test the effect of rapamycin on VEGF transcriptional activation, OVCAR-3 cells were co-transfected with pCMV- $\beta$-gal plasmid and pVEGF-Luc $(A)$ or pMAP11wt plasmid $(B)$. The cells were incubated for $12 \mathrm{~h}$ after transfection, followed by the treatment with DMSO, or rapamycin $(5$ or $10 \mathrm{ng} / \mathrm{ml})$ for $24 \mathrm{~h}$ and $36 \mathrm{~h}$. The relative luciferase activity was determined by the ratio of luciferase: $\beta$-gal activity and normalized to the control. $C$ and $D$, To study the VEGF protein levels in the cells, OVCAR-3 (C) and A2780/CP70 (D) cells were treated for $24 \mathrm{~h}$ with rapamycin. The VEGF protein levels in the cultured medium were analyzed by sandwich ELISA as described in Materials and Methods, and the VEGF protein 
levels were normalized to the control as the relative VEGF protein levels. * indicates a significant difference from the control $(\mathrm{p}<0.05)$.

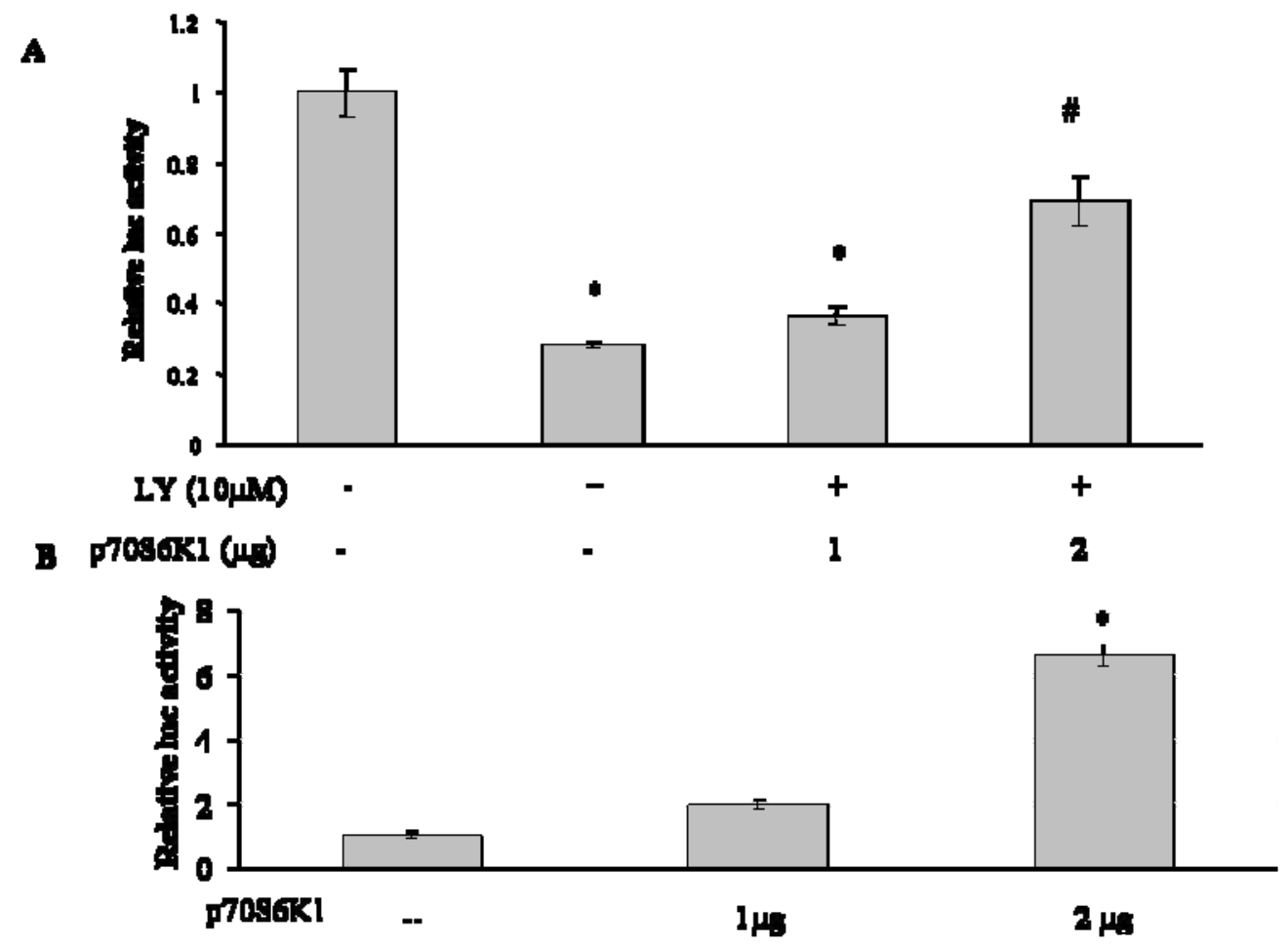

Figure 6. Expression of p70S6K1 reversed LY294002-inhibited VEGF transcriptional activation. OVCAR-3 cells were seeded at $0.5 \times 10^{6}$ cells/well on a 6 -well plate the day before the transfection. The cells were transfected with pCMV- $\beta$-gal, pVEGF-Luc, and p70S6K1 or vector plasmid. The cells were cultured and treated with DMSO and LY294002 (A) or DMSO alone $(B)$ for $24 \mathrm{~h}$ as described above. The relative luciferase activity was determined in the cells as described above. *indicates a significant difference from the control $(\mathrm{p}<0.05)$. \# indicates a significant difference from the LY294002-treated group $(\mathrm{p}<0.05)$. 

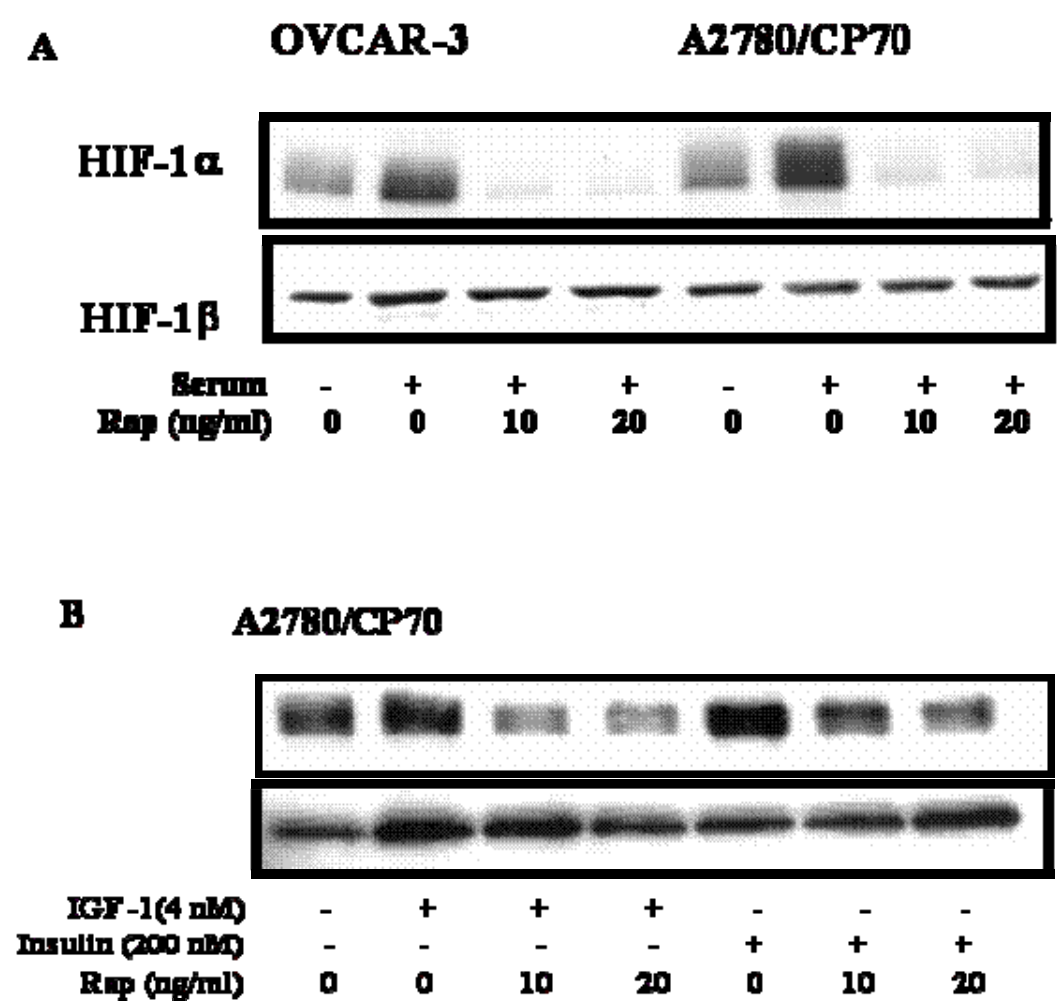

Figure 7. Rapamycin inhibited HIF-1 $\alpha$ expression in ovarian cancer cells. A, OVCAR-3 and A2780/CP70 cells were cultured to $90 \%$ confluence, and switched to serum-free medium for 24 h. The cells were pretreated with rapamycin at the indicated concentrations for $30 \mathrm{~min}$, and then incubated with or without $10 \%$ FBS for 6 h. HIF- $1 \alpha$ and HIF- $1 \beta$ protein levels were analyzed by immunoblotting as described above. $B, \mathrm{~A} 2780 / \mathrm{CP} 70$ cells were cultured as described above and then pretreated with rapamycin as indicated for $30 \mathrm{~min}$, followed by the incubation with or without $4 \mathrm{nM}$ IGF-1 or $200 \mathrm{nM}$ insulin for 6 h. HIF-1 $\alpha$ and HIF-1 $\beta$ were analyzed as described above. 


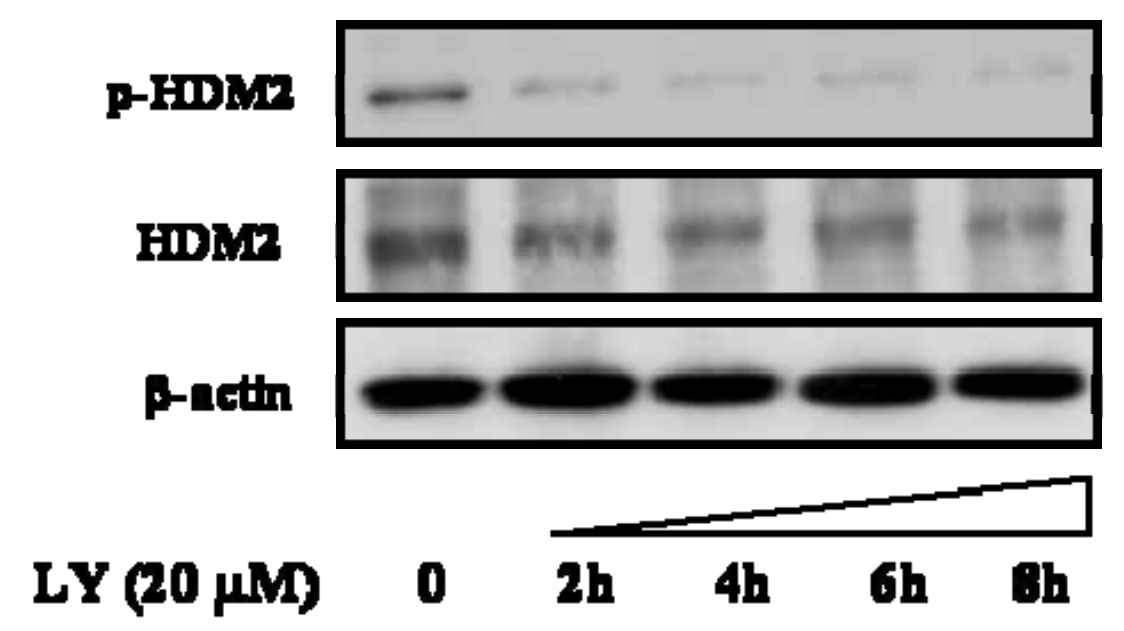

Figure 8. LY294002 treatment inhibited HDM2 phosphorylation and protein levels. OVCAR-3 cells were cultured in RPMI media supplemented with $10 \%$ fetal bovine serum to $80 \%$ confluence, and then treated with $20 \mu \mathrm{M}$ LY294002 for different times as indicated. Aliquots $(40 \mu \mathrm{g})$ of cellular protein extracts were analyzed using antibodies specific for phospho-HDM2, total HDM2, and $\beta$-actin by immunoblotting. 


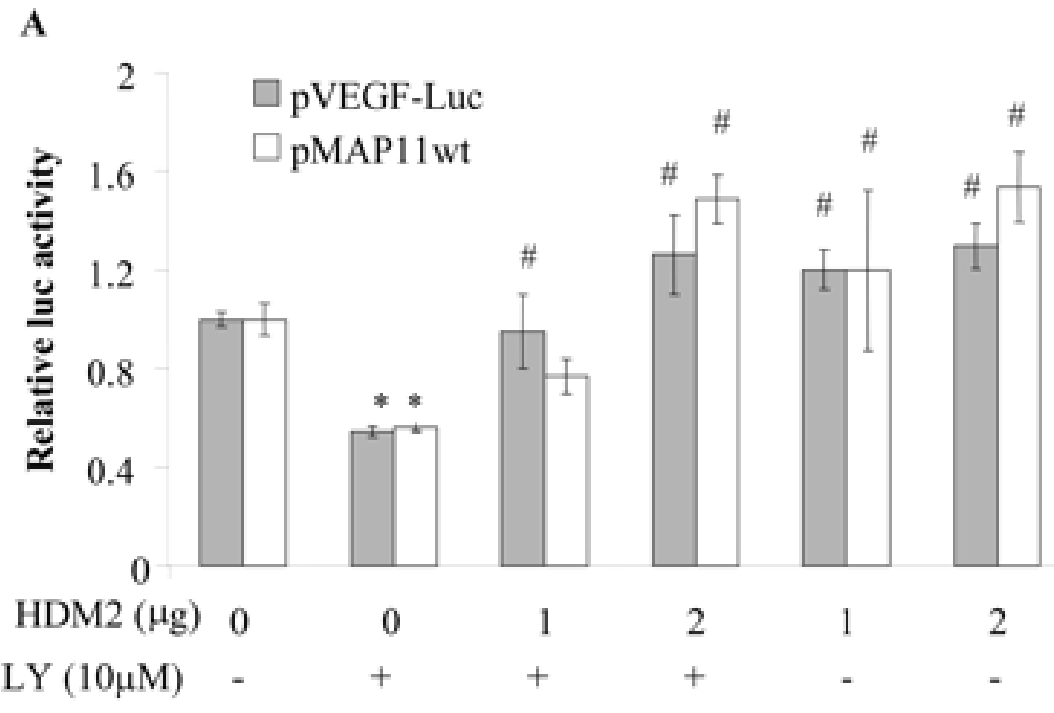

B

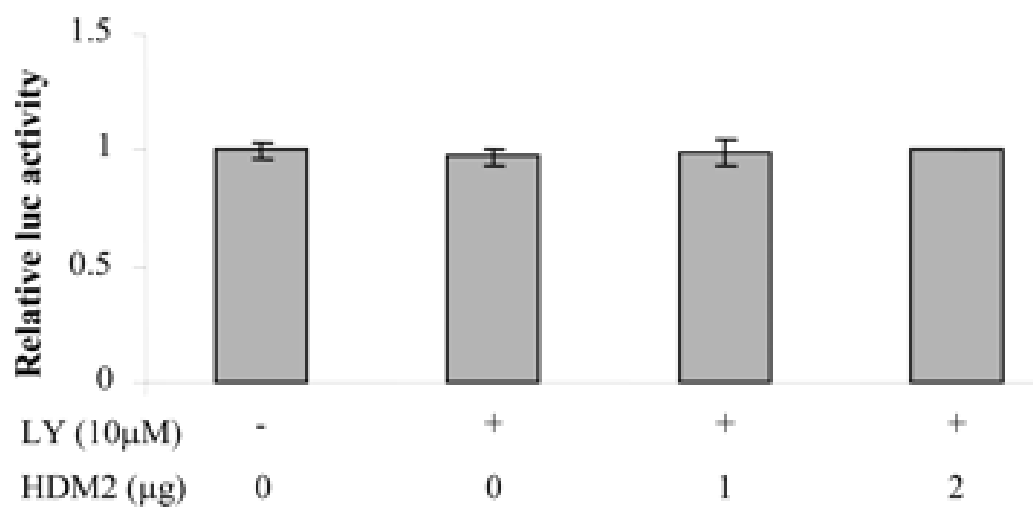

Figure 9. HDM2 reversed LY294002-inhibited VEGF transcriptional activation. OVCAR-3 cells were seeded at $0.5 \times 10^{6}$ cells/well. $A$, To test the effect of HDM2 on VEGF transcriptional activation, the cells were co-transfected with pCMV- $\beta$-gal, HDM2, and pVEGF-Luc or pMAP11wt plasmids as indicated. The cells were cultured overnight, and then treated with DMSO alone or $10 \mu \mathrm{M}$ LY294002 for $24 \mathrm{~h}$. The relative luciferase activity was determined as described above. $B$, To test whether the HIF-1 binding in the VEGF promoter is essential for mediating VEGF transcriptional activation, cells were co-transfected with pCMV- $\beta$-gal and pMAP11mut plasmid with the empty vector or pCMV-HDM2. The cells were treated as 
described above, and the relative luciferase activity was determined in the cells. * indicates a significant difference from the control $(\mathrm{p}<0.05)$. \# indicates a significant difference from the LY294002-treated group $(\mathrm{p}<0.05)$.

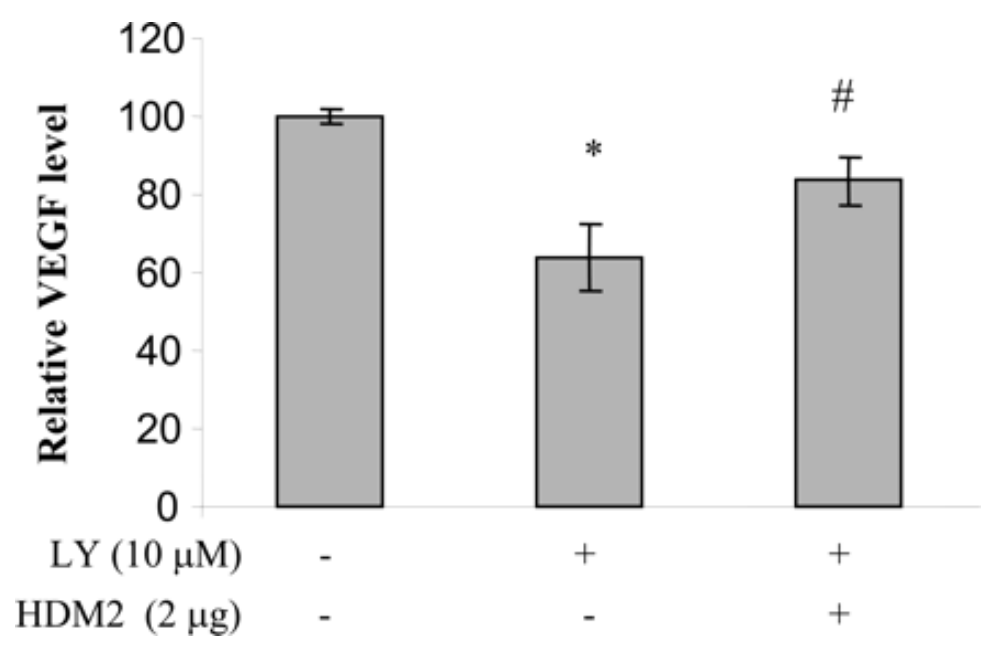

Figure 10. HDM2 transfection increased VEGF protein production in the presence of LY294002. OVCAR-3 cells were seeded at $0.5 \times 10^{6}$ cells/well on a 6 -well plate the day before the transfection. The cells were transfected with $2 \mu \mathrm{g}$ of empty vector or pCMV-HDM2 plasmid. The cells were cultured for $12 \mathrm{~h}$ after transfection, and then treated with DMSO or 10 $\mu \mathrm{M}$ LY294002 for $24 \mathrm{~h}$. The VEGF protein levels in the medium were analyzed by ELISA and normalized to the control. * indicates a significant difference in VEGF levels from the control. \# indicates a significant difference in VEGF levels from the LY294002-treated group $(\mathrm{p}<0.05)$. 


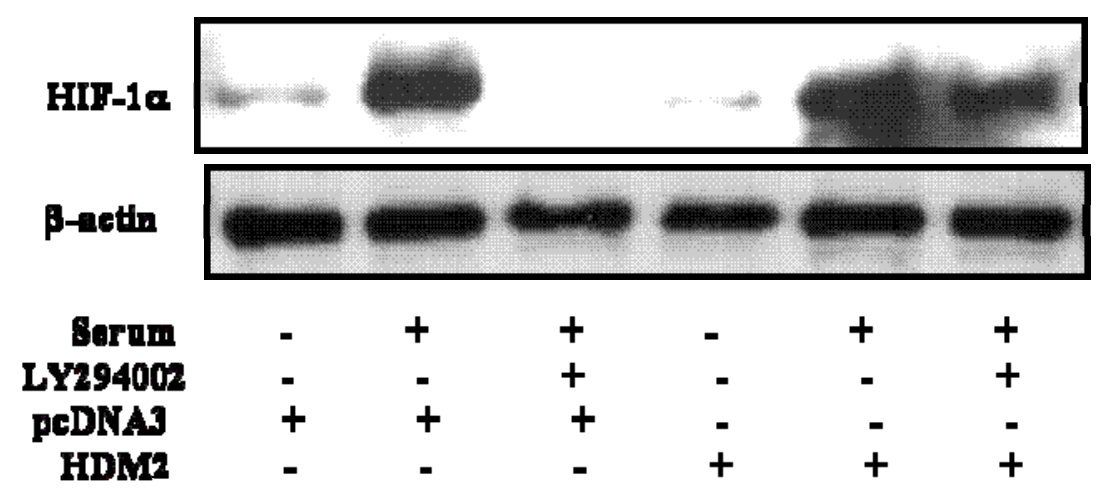

Figure 11. HDM2 reverses LY294002-inhibited HIF-1 $\alpha$ expression. A2780/CP70 cells were transfected with either pcDNA3 vector or pcDNA3-HDM2 as described previously. After the transfection, the cells were selected with G418 for two weeks. Resistant colonies were pooled and cultured in the presence of low levels of G418 to maintain selection pressure. The cells were cultured in serum-free medium for $24 \mathrm{~h}$, followed by incubation in the absence or presence of $10 \%$ serum and $20 \mu \mathrm{M} \mathrm{LY} 294002$ for $6 \mathrm{~h}$. Aliquots of protein extracts were analyzed using antibodies specific for HIF-1 $\alpha$ and HIF-1 $\beta$ by immunoblotting. 


\title{
CHAPTER 3: HIF-1 $\alpha$ INHIBITION EXERTS OPPOSITE EFFECTS ON TUMORIGENESIS BASED ON THE MICROENVIRONMENT*
}

\author{
Heath D. Skinner ${ }^{1}$, Chang Xia ${ }^{1}$, Lesly Anne Lopez ${ }^{1}$, Min Ding ${ }^{2}$, Faton Agani ${ }^{3}$ and Bing- \\ Hua Jiang ${ }^{1 \#}$
}

${ }^{1}$ Mary Babb Randolph Cancer Center, Department of Microbiology, Immunology and Cell Biology, West Virginia University, Morgantown, WV 26506-9300, USA.

${ }^{2}$ Health Effects Laboratory Division, National Institute for Occupational Safety and Health, Morgantown, WV 26505, USA.

${ }^{3}$ Department of Anatomy, School of Medicine, Case Western Reserve University, Cleveland, Ohio 44106, USA.

Running title: The effects of HIF-1 $\alpha$ siRNA vary with microenvironment.

\# To whom correspondence should be addressed: Mary Babb Randolph Cancer Center, Department of Microbiology, Immunology and Cell Biology, West Virginia University, Morgantown, West Virginia 26506. E-mail: bhjiang@hsc.wvu.edu.

*This work was supported by American Cancer Society Research Scholar Grant 04-076-01-TBE, and by National Cancer Institute Grant CA109460 to B.H. Jiang 


\begin{abstract}
Hypoxia inducible factor-1 (HIF-1) is a basic-helix-loop helix transcription factor composed of two subunits, HIF-1 $\alpha$ and HIF-1 $\beta$. HIF- $1 \alpha$ is a regulatory subunit, which is stabilized in response to several stimuli including hypoxia, growth factors, and oncogenes. HIF-1 $\alpha$ is overexpressed in the majority of human cancers including ovarian cancer. In this study we showed that inhibition of HIF-1 $\alpha$ by stable expression of small interfering RNA (siRNA) against HIF-1 $\alpha$ (siHIF-1 $\alpha)$ decreased ovarian cancer cell motility and invasion. The siHIF-1 $\alpha$ expression dramatically decreased HIF-1 $\alpha$ and VEGF expression. When ovarian cancer cells expressing either scramble siRNA or siHIF-1 $\alpha$ were mixed with Matrigel, and injected into the chicken embryos or nude mice subcutaneously, expression of siHIF-1 $\alpha$ greatly decreased tumor growth and angiogenesis. However, the same ovarian cancer cells without Matrigel were implanted into nude mouse, which allows the direct contact of cancer cells with the pre-existing blood vessels, the expression of siHIF-1 $\alpha$ increased tumor growth without affecting tumor angiogenesis. These studies suggest that HIF-1 $\alpha$ is required for tumor growth in vivo in a microenvironment, which requires angiogenesis, but HIF-1 $\alpha$ is not required for tumor growth if the host microenvironment contains sufficient existing vasculatures to support tumor growth. This study suggests that HIF-1 $\alpha$ expression has different effects on tumor growth and angiogenesis based on the microenvironments.
\end{abstract}




\section{Introduction}

High expression levels of hypoxia inducible factor-1 (HIF-1) are associated with several predictors of negative outcomes in human cancer, such as angiogenesis and metastasis. HIF-1 is a basic helix-loop-helix transcription factor composed of HIF-1 $\alpha$ and HIF-1 $\beta$ subunits $(13,24)$. HIF-1 $\beta$ is constitutively expressed in cells (13), while HIF-1 $\alpha$ is upregulated by hypoxia, growth factors and oncogenes such as Ras and v-Src $(2,11,12)$. HIF-1 $\alpha$ is predominantly regulated at the

post-translational level via the prolyl hydroxylation of two proline residues: Pro $^{402}$ and Pro ${ }^{564}$ $(9,10,15)$. Under normoxic conditions, prolyl hydroxylases (PHDs) hydroxylate proline residues in HIF-1 $\alpha$, which allows for the binding of an E3 ubiquitinylation complex given specificity by the von Hippel Lindau protein (pVHL) $(4,10,15)$. However, under hypoxic conditions HIF-1 $\alpha$ is not hydroxylated, which prevents both the binding of pVHL to HIF-1 $\alpha$ and its subsequent ubiquitinylation.

Previously, we and others have shown that HIF-1 $\alpha$ expression is upregulated in a PI3Kdependent manner in several types of cancer $(12,22,27)$. HIF-1 $\alpha$ stabilization is associated with mutations in the tumor suppressor genes VHL and PTEN $(4,12,14,29)$. Also, activation of PI3K and its downstream target mTOR has been shown to increase HIF-1 $\alpha$ expression under normoxic conditions $(8,19)$. This regulation is especially relevant to ovarian cancer in which PI3K is frequently mutated, leading to increased activation of PI3K and mTOR signaling pathways and, consequently, high basal expression of HIF-1 $\alpha(16,21,22,26)$.

HIF-1 can upregulate several hypoxia-responsive genes, including VEGF, heme oxygenase 1 and inducible nitric oxide synthase (20). Expression of HIF-1 $\alpha$ is elevated in a large number of human solid tumors, including prostate, ovarian, lung, breast, and colon cancers (28). Studies addressing the inhibition of HIF-1 $\alpha$ expression in in vivo models of human cancer have produced 
contradictory results. Forced expression of HIF-1 $\alpha$ leads to increased tumor growth and angiogenesis in nude mice (17). But a recent study has shown that HIF-1 $\alpha-/-$ MEFs generated tumors that were larger than those derived from normal MEFs (1). Others have shown that genetic inhibition of HIF-1 $\alpha$ via dominant-negative constructs decreased pancreatic and gastric tumor growth and angiogenesis $(3,23)$. But, it has not yet been determined that the primary effect of inhibiting HIF-1 $\alpha$ in tumors is due to decrease of angiogenesis In at least one study it was shown that inhibiting HIF-1 $\alpha$ decreases tumor growth but not as a result of inhibiting angiogenesis (18). These inconsistent results may derive partly from differences in the experimental conditions, such as the use of a different cell types or the use of a different assay system. Particularly, because the tumor microenvironment is critical to angiogenesis, the different tumor microenvironment between these studies could account for many of the variable findings. To address the function of HIF-1 $\alpha$ in ovarian tumor growth and angiogenesis, we used small interfering RNA (siRNA) to knock down HIF-1 $\alpha$ expression in ovarian cancer cells, and used these cells to generate tumors in either blood vessel poor or blood vessel rich microenvironments using the same ovarian cancer cells to determine whether the tumor microenvironments affected the role of HIF- $1 \alpha$ in ovarian tumor growth and angiogenesis.

\section{Materials and Methods}

Reagents and Cell Culture - The human ovarian cancer cells A2780/CP70, OVCAR-3 and SKOV-3 were cultured in RPMI 1640 media supplemented with 10\% FBS (Intergen, Purchase, NY), 0.2 units $/ \mathrm{ml}$ penicillin, and $50 \mu \mathrm{g} / \mathrm{ml}$ streptomycin (Invitrogen, Carlsbad, CA). Cells were

cultured at $37^{\circ} \mathrm{C}$ in a $5 \% \mathrm{CO}^{2}$ incubator and trypsin $(0.25 \%)$ was used to detach adherent cells for subculture. 
Immunoblot Analysis - Cells were washed 3 times in cold PBS, harvested, and lysed in RIPA buffer containing $1 \mathrm{mM}$ sodium vanadate, $0.5 \mathrm{mM}$ dithiothreitol (DTT), $1 \mathrm{mM}$ phenylmethylsulfonyl fluoride (PMSF), $2 \mathrm{mM}$ leupeptin, $2 \mathrm{mM}$ aprotinin, and $2 \mathrm{mM}$ pepstatin on ice for $20 \mathrm{~min}$. Whole cell lysates were obtained by centrifugation at $13,000 \mathrm{rpm}$ for $15 \mathrm{~min}$ at $4^{\circ} \mathrm{C}$. Total cellular protein concentration was assayed using the Bio-Rad ${ }^{\circledR}$ protein assay reagent (Richmond, CA). Aliquots $(40 \mu \mathrm{g})$ of protein were loaded onto an SDS/polyacrylamide gel and resolved via electrophoresis. Proteins were then transferred to a nitrocellulose membrane and blocked in 5\% nonfat dry milk in 1xTBS-T. Proteins were detected via horseradish-peroxidase conjugated antibodies (NEN, Boston, MA) and visualized through enhanced chemiluminescence reagent (NEN, Boston, $\mathrm{MA})$.

Luciferase Assay_-The human VEGF reporter used was constructed via the insertion of a 2.65 kb KpnI-BssHII fragment of the human VEGF gene promoter into the pGL2-basic vector (Promega, Madison, WI) (pVEGF-Luc). The $\beta$-galactosidase/CMV promoter was used as a control plasmid for transfection efficiency. To perform the luciferase assay, cells were seeded in a 12 -well plate at a density of $0.3 \times 10^{6}$ cells per well. After $12 \mathrm{~h}$ of culture the cells were washed twice with warm 1xPBS and transfected with lipofectamine (Sigma) per the manufacturer's instructions. Briefly, $0.5 \mu \mathrm{g}$ were mixed with $2 \mu \mathrm{l} /$ well Lipofectamine in serum-free Opti-MEM media (Invitrogen, Carlsbad, CA) and allowed to incubate for $30 \mathrm{~min}$. This solution was then added to the cells and allowed to incubate at $37^{\circ} \mathrm{C}$ for $4.5 \mathrm{~h}$. The Lipofectamine was then removed and cells were cultured as described previously for $24 \mathrm{~h}$, after which the cells were collected in luciferase lysis buffer (Promega, Madison, WI) per the manufacturer's instructions. 
Briefly, $250 \mu \mathrm{l}$ of luciferase lysis buffer was added to each well and placed at $-70^{\circ} \mathrm{C}$ until frozen. Cells and lysis buffer were allowed to thaw and were spun at $13,000 \mathrm{rpm}$ for $1 \mathrm{~min}$ at $4^{\circ} \mathrm{C}$. The supernantant was incubated with luciferase substrate (Promega, Madison, WI), and the results were measured by a monolight luminometer. $\beta$-galactosidase ( $\beta$-gal) activity was determined as a control by the hydrolysis of onitrophenyl-b-D-galactopyranoside (ONPG) at $37^{\circ} \mathrm{C}$ for $1 \mathrm{~h}$.

Generation of Cancer Cell Lines Stably Expressing siHIF-1 $\alpha$ —siRNA specific for HIF-1 $\alpha$ was designed using a siRNA target finder program available at the website of Ambion, Inc. (Austin, TX). Oligonucleotide DNA sequences encoding HIF-1 $\alpha$ siRNA were then inserted into the pSilencer Neo vector (Ambion, Austin, TX). A commercially available pSilencer Neo vector containing a siRNA sequence of no known mammalian homology was used as a control (Ambion, Austin, TX). Control or siHIF-1 $\alpha$ constructs were transfected into cancer cells via Lipofectamine per the manufacturer's instructions. After $24 \mathrm{~h}$ of culture, $500 \mu \mathrm{g} / \mathrm{ml} \mathrm{G} 418$ was added to the media. Over the course of two weeks cells were selected for control or siHIF-1 $\alpha$ expression and the resultant colonies were pooled. No differences in cell morphology or basal levels of apoptosis were observed following selection of stably-expressing siHIF-1 $\alpha$ cells.

Wound Healing and Invasion assays - To determine cell motility the cells were cultured in 6well plates to $80 \%$ confluence. Wounds were made in the center of each well using a p200 pipet tip and wells were washed twice in warm PBS after wounding. Cells were cultured as described previously for the indicated times then fixed using 3.5\% formalin and stained with hematoxylin. Cell distance was measured and normalized to the control. To determine invasion, $0.5 \times 10^{6}$ cells were placed in the upper chamber of an invasion chamber (BD Biosciences, San Jose, CA), 
which is separated from the lower chamber by a membrane covered with Matrigel and containing $8.0 \mu \mathrm{M}$ pores. Cells in the upper chamber were cultured for the indicated times in RPMI 1640 media containing $1 \%$ FBS, while the lower chamber was filled with media containing $10 \%$ FBS. Cells were removed from the upper surface of the membrane insert, and then the insert was fixed in $3.5 \%$ formalin and stained using hematoxylin. Invasion was measured by counting the number of cells on the lower surface of the membrane.

CAM Tumor Assay — Chicken embryos (CBT Farms) were incubated at $37^{\circ} \mathrm{C}$ with gentle rotation. On E8, the embryonic air sac was punctured and moved via vacuum pressure to the superior surface of the embryo. This area was then exposed, revealing the CAM. To generate tumors on the CAM 1 $\times 10^{7}$ OVCAR-3 cells were resuspended in RPMI 1640 media and mixed with an equal volume of Matrigel (BD Biosciences, San Jose, CA) and implanted onto the exposed CAM. The eggshell was then sealed with transparent tape. Each group contained 8 embryos. On days 6 and 10 of post-implantation, the resultant tumors were photographed, weighed and either fixed in $10 \%$ formalin or frozen for protein analysis.

Nude Mouse Tumor Assay — Nude mice were housed in accordance with WVU's Animal Care and Use Committee guidelines. For tumor generation, $1 \times 10^{7}$ OVCAR-3 cells were resuspended in RPMI 1640 media and were either injected subcutaneously into the flank of each mouse directly or mixed with an equal volume of Matrigel. The resultant tumors were measured periodically and tumor volume was calculated using the formula $0.4 \times\left(\mathrm{L} \mathrm{x} \mathrm{W}^{2}\right)$ where $\mathrm{W}$ is the shortest dimension. Tumors were photographed, weighed and either fixed in $10 \%$ formalin, frozen for protein analysis or placed in cold PBS overnight for hemoglobin assay. 


\section{Results}

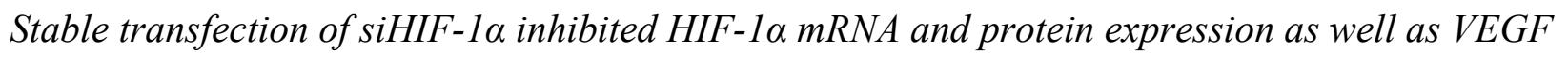
transcriptional activation. Previously, we demonstrated that HIF-1 $\alpha$ basal levels are elevated in some ovarian cancer cell lines (22). To determine the significance of this phenomenon, siRNA specific to HIF-1 $\alpha$ was designed, and inserted into a vector containing neomycin resistant gene (siHIF-1 $\alpha$ ). We then generated several different ovarian cancer cell lines stably expressing siHIF-1 $\alpha$ or a control siRNA with no known homology to any mammalian target. HIF-1 $\alpha$ mRNA and protein expression levels were inhibited by stable expression of siHIF-1 $\alpha$ in OVCAR-3 cells (Figs. 1A and 1B). To test whether siHIF-1 $\alpha$ inhibited VEGF transcriptional activation, we measured VEGF reporter activity via luciferase assay. The results showed a dramatic decrease in OVCAR-3 cells stably expressing siHIF-1 $\alpha$ (Figs. 1C and 1D). Similar results were obtained in A2780/CP70 and SKOV-3 cells stably expressing siHIF-1 $\alpha$, which showed a dramatic reduction in HIF-1 $\alpha$ expression and VEGF reporter activity in both cell lines stably expressing siHIF-1 $\alpha$ (Figs. 1E-1H). These results demonstrate that siRNA against HIF-1 $\alpha$ can reduce the expression of HIF-1 $\alpha$ and its downstream target, VEGF, in ovarian cancer cells.

siRNA-mediated inhibition of HIF-1 $\alpha$ decreased cell migration and invasion. Previously, it has been shown that HIF-1 $\alpha$ may play a role in cell invasion and metastasis. To determine whether stable expression of siHIF-1 $\alpha$ decreased cell migration in ovarian cancer cells, the motility of OVCAR-3 and SKOV-3 ovarian cancer cells stably expressing siHIF-1 $\alpha$ was measured using the wound healing assay. A wound was made and observed at the time periods indicated. As shown in Figs. 2, expression of siHIF-1 $\alpha$ led to dramatic reductions in the wound healing in both 
OVCAR-3 and SKOV-3 cells at various time periods (Figs. 2A and 2B). Cell proliferation was not decreased in either cell line by siHIF-1 $\alpha$ in the same experiment (data not shown).

Furthermore, stable expression of siHIF-1 $\alpha$ dramatically decreased cell invasion in both SKOV-3 and A2780/CP70 cells with 5-fold and 8-fold reduction, respectively (Figs. 2C and 2D). These data demonstrate that HIF-1 $\alpha$ expression plays an important role in both cell migration and invasion in ovarian cancer cells.

Inhibition of HIF-1 $1 \alpha$ expression by siRNA decreased angiogenesis and tumor growth in the CAM. To determine the significance of inhibiting HIF-1 $\alpha$ via siRNA in an in vivo model of ovarian cancer, we mixed $1 \times 10^{7}$ OVCAR-3 cells stably expressing either scramble siRNA or siHIF-1 $\alpha$ with an equal volume of Matrigel, and implanted onto the CAM. These tumors were then observed and collected in 6 and 10 days post-implantation. Ovarian tumors stably expressing siHIF-1 $\alpha$ exhibited decreased angiogenesis and tumor growth (Figs. 3A-C). HIF-1 $\alpha$ expression was dramatically decreased in siHIF-1 $\alpha$ expressing tumors, indicating that the siRNA inhibited HIF-1 $\alpha$ expression, in vivo (Figs. 3D and 3E). PCNA expression was dramatically decreased in the siHIF- $1 \alpha$ tumors, indicating that siHIF- $1 \alpha$ decreased cell proliferation in tumors, probably due to the inhibition of angiogenesis (Figs. 3E). These data suggest that inhibition of HIF-1 $\alpha$ via siRNA decreased both angiogenesis and tumor growth in the CAM tumor model, in which the nascent tumor does not have direct contact with pre-existing vasculature.

Inhibition of HIF-1 $\alpha$ expression by siRNA decreased tumor growth in a nude mouse Matrigel model. To further study how inhibition of HIF- $1 \alpha$ affects ovarian tumor growth and angiogenesis in another avascular microenvironment, we mixed 1x 10 $0^{7}$ OVCAR-3 cells with an 
equal volume of Matrigel, and injected subcutaneously into the nude mouse flank. We collected the tumors 26 days after the implantation. The tumors stably expressing siHIF-1 $\alpha$ were dramatically smaller and weighed less than the control tumors (Figs. 4A and 4B). HIF-1 $\alpha$ and VEGF expression was decreased in siHIF-1 $\alpha$-expressing tumors, demonstrating that siHIF-1 $\alpha$ also has the same effect in vivo, as described above (Figs. 4C). The tumors expressing siHIF-1 $\alpha$ showed reduction in cell proliferation (Figs. 4D). Tumor angiogenesis was also decreased in siHIF-1 $\alpha$ expressing tumors as evidenced by decreased density of blood vessels positively stained by CD31, and by the reduction of hemoglobin content in the tumors (Figs. 4E and 4F). Thus, in tumors generated from cells isolated from the host microvasculature, inhibition of HIF$1 \alpha$ expression decreased both tumor growth and angiogenesis. This data is consistent with the results of tumor growth and angiogenesis using the CAM model.

\section{Inhibition of HIF-1 $\alpha$ expression increased tumor growth in a nude mouse model in a} subcutaneous microenvironment. There are contradictory results in terms of the roles of HIF-1 $\alpha$ in tumor growth in different model systems. We hypothesized that HIF-1 $\alpha$ may not affect ovarian tumor growth and angiogenesis with a sufficient pre-existing vascular structure. To test his hypothesis, we injected $1 \times 10^{7}$ OVCAR-3 cells in 1x PBS buffer subcutaneously into the nude mouse flank. Matrigel was not used in this experiment; thus, tumor cells were directly exposed to the pre-existing blood vessels in the subcutaneum. We monitored tumor growth by measuring the height and width of tumors when they became visible, and harvested the tumors 26 days after the implantation. In contrary to the results obtained from both the chicken CAM and the nude mouse experiments above, in which the tumor cells were implanted into the animal in a Matrigel matrix, tumors induced by siHIF-1 $\alpha$-expressing cells were significantly larger than 
the control tumors (Figs. 5A and 5B). To confirm that the siHIF-1 $\alpha$ decreased HIF-1 $\alpha$ and VEGF expression in the tumors in this model, we analyzed HIF-1 $\alpha$ and VEGF expression in tumor sections and tissue lysate, and found that both HIF-1 $\alpha$ and VEGF expression was greatly inhibited in the siHIF-1 $\alpha$-expressing tumors (Figs. 5C and 5D). This result suggests that the tumor growth is independent of HIF-1 $\alpha$ and VEGF expression in this tumor model. To further study whether siHIF-1 $\alpha$ affects cell proliferation and angiogenesis in this model, tumor tissues were analyzed with antibodies against PCNA, a cell proliferation marker. We found that the control and siHIF-1 $\alpha$-expressing tumors showed similar PCNA levels, suggesting that they have similar levels of cell proliferation (Figs. 5C). We also found that there is no significant difference in angiogenesis with similar hemoglobin content between the control and siHIF-1 $\alpha$ tumors (Figs. 5E). These results suggest that the pre-existing host microvasculature is sufficient to support tumor growth without the expression of HIF-1 $\alpha$. Taken together, these results showed that HIF- $1 \alpha$ is required for inducing angiogenesis and tumor growth when tumors are generated in an avascular microenvironment, but that HIF-1 $\alpha$ is not required for inducing angiogenesis and tumor growth when tumors are in the presence of a pre-existing vascular network.

\section{Discussion}

HIF-1 $\alpha$ is overexpressed in many types of human cancers. It has been associated with tumor aggressiveness, and high patient mortality rates. In this study we use ovarian cancer cells stably expressing siRNA specific for HIF-1 $\alpha$. These siRNA-expressing cells exhibited decreased cell motility and invasion compared to the control cells, suggesting that HIF-1 $\alpha$ expression is critical to ovarian cancer cell migration and invasion. HIF-1 $\alpha$ expression is correlated with 
metastasis in several types of human cancer (28). Hypoxia also induces cell motility and invasion $(6,25)$. Our data provides a possible explanation for these data.

Studies examining the inhibition of HIF-1 $\alpha$ in vivo have produced contradictory results. The effect of HIF-1 $\alpha$ on tumor angiogenesis also remains to be defined. One recent study showed that inhibition of HIF-1 $\alpha$ has no effect on tumor angiogenesis (18), while others have documented that the inhibition of HIF-1 $\alpha$ greatly decreased angiogenesis $(1,3,23)$. We speculated that these contradictory data were due to the use of different cell types and tumor models. To test this hypothesis, we inhibited HIF-1 $\alpha$ expression using a HIF-1 $\alpha$ siRNA construct stably expressed in the same cell line to study its effect in tumor growth and angiogenesis. HIF-1 siRNA approach has an advantage over HIF-1 $\alpha$ dominant-negative constructs, in that HIF-1 siRNA specifically inhibits HIF-1 $\alpha$ expression, while HIF-1 dominantnegative construct may exert other effects by binding to HIF-1 $\beta$ and other partners such as Mdm2 and p53. Similarly, HIF-1 $\alpha$ siRNA approach has an advantage over the inhibition of HIF$1 \beta$ (ARNT) which also binds to HIF-2 $\alpha$ and HIF-3 $\alpha(5,7)$, thus inhibiting HIF-1 $\beta$ may exert non-specific effects on other targets.

In this study, we show that inhibition of HIF-1 $\alpha$ via siRNA decreased ovarian tumor growth and angiogenesis in the CAM model (Figs. 3) as well as in a mouse subcutaneous xenograft model (Figs. 4). Both of these models involved the implantation of the cancer cells within Matrigel to prevent the direct contact of cancer cells with pre-existing blood vessels. However, inhibition of HIF-1 $\alpha$ via siRNA increased tumor growth in the nude mouse xenograft model in the absence of Matrigel (Figs. 5). Thus, HIF-1 $\alpha$ expression is required in the context of an avascular microenvironment to recruit a de novo microvasculature that will allow tumor growth beyond a small size. However, in a microenvironment possessing a vascular network, 
this process is not necessary. It was known that the expression of HIF-1 $\alpha$ by tumors may be proapoptotic, leading to upregulation of BNIP 3 and other pro-apoptotic proteins. This could account for higher tumor growth induced by HIF-1 $\alpha$ siRNA-expressing cells than by the control cells in blood vessel-rich microenvironment (Figs. 5).

The current study showed that HIF-1 $\alpha$ has conflicting roles in tumor growth in vivo. Our data suggest that the effects of HIF-1 $\alpha$ in mediating tumor growth and angiogenesis vary based on the microenvironments. These results have important implication for the utilization of HIF$1 \alpha$ inhibition therapy as a cancer treatment. Our results suggest that the efficacy of using a HIF$1 \alpha$ inhibitor to treat cancer may be determined by the location and surrounding microenvironment of the tumor in addition to the tumor types. Primary tumors and metastases to some locations may be successfully treated with a HIF-1 $\alpha$ inhibitor if their microenvironment is fairly avascular; however, this mode of treatment may increase tumor growth if a tumor is in a rich pre-existing blood vessel network.

Taken together, this study uses HIF-1 $\alpha$ siRNA to specifically inhibit HIF-1 $\alpha$ expression in ovarian cancer cells. We showed the specific roles of HIF-1 $\alpha$ in inhibiting cancer cell migration and invasion without affecting cell proliferation in vitro. In this study, we specifically inhibited HIF- $1 \alpha$ using siRNA, and use the same cell lines expressing HIF-1 $\alpha$ siRNA or control siRNA to study the effects of HIF-1 $\alpha$ in tumor growth and angiogenesis. This approach overcomes the variation of different cell types and potential non-specific effects from other HIF interaction proteins on the tumor growth and angiogenesis. We demonstrated that the effects of HIF-1 $\alpha$ in tumor growth and angiogenesis vary based on the microenvironments, in which tumors grow. These data provide a reasonable explanation of previous conflicting results of HIF-1 in tumor growth and angiogenesis. 
Reference List

1. Carmeliet, P., Y. Dor, J. M. Herbert, D. Fukumura, K. Brusselmans, M. Dewerchin, M. Neeman, F. Bono, R. Abramovitch, P. Maxwell, C. J. Koch, P. Ratcliffe, L. Moons, R. K. Jain, D. Collen, and E. Keshert. 1998. Role of HIF-1alpha in hypoxia-mediated apoptosis, cell proliferation and tumour angiogenesis

7. Nature 394:485-490.

2. Chen, C., N. Pore, A. Behrooz, F. Ismail-Beigi, and A. Maity. 2001. Regulation of glut1 mRNA by hypoxia-inducible factor-1. Interaction between $\mathrm{H}$-ras and hypoxia 1. J.Biol.Chem. 276:9519-9525.

3. Chen, J., S. Zhao, K. Nakada, Y. Kuge, N. Tamaki, F. Okada, J. Wang, M. Shindo, F. Higashino, K. Takeda, M. Asaka, H. Katoh, T. Sugiyama, M. Hosokawa, and M.

Kobayashi. 2003. Dominant-negative hypoxia-inducible factor-1 alpha reduces tumorigenicity of pancreatic cancer cells through the suppression of glucose metabolism

1. Am.J.Pathol. 162:1283-1291.

4. Cockman, M. E., N. Masson, D. R. Mole, P. Jaakkola, G. W. Chang, S. C. Clifford, E. R. Maher, C. W. Pugh, P. J. Ratcliffe, and P. H. Maxwell. 2000. Hypoxia inducible factoralpha binding and ubiquitylation by the von Hippel-Lindau tumor suppressor protein 7. J.Biol.Chem. 275:25733-25741.

5. Ema, M., S. Taya, N. Yokotani, K. Sogawa, Y. Matsuda, and Y. Fujii-Kuriyama. 1997. A novel bHLH-PAS factor with close sequence similarity to hypoxia-inducible factor 1alpha regulates the VEGF expression and is potentially involved in lung and vascular development. Proc.Natl.Acad.Sci.U.S.A 94:4273-4278.

6. Graham, C. H., J. Forsdike, C. J. Fitzgerald, and S. Macdonald-Goodfellow. 1999. Hypoxia-mediated stimulation of carcinoma cell invasiveness via upregulation of urokinase receptor expression. Int.J.Cancer 80:617-623.

7. Gu, Y. Z., S. M. Moran, J. B. Hogenesch, L. Wartman, and C. A. Bradfield. 1998. Molecular characterization and chromosomal localization of a third alpha-class hypoxia inducible factor subunit, HIF3alpha. Gene Expr. 7:205-213.

8. Hudson, C. C., M. Liu, G. G. Chiang, D. M. Otterness, D. C. Loomis, F. Kaper, A. J. Giaccia, and R. T. Abraham. 2002. Regulation of hypoxia-inducible factor 1alpha expression and function by the mammalian target of rapamycin. Mol.Cell Biol. 22:7004-7014.

9. Ivan, M., K. Kondo, H. Yang, W. Kim, J. Valiando, M. Ohh, A. Salic, J. M. Asara, W. S. Lane, and W. G. Kaelin, Jr. 2001. HIFalpha targeted for VHL-mediated destruction by proline hydroxylation: implications for $\mathrm{O} 2$ sensing

2. Science 292:464-468.

10. Jaakkola, P., D. R. Mole, Y. M. Tian, M. I. Wilson, J. Gielbert, S. J. Gaskell, A. Kriegsheim, H. F. Hebestreit, M. Mukherji, C. J. Schofield, P. H. Maxwell, C. W. Pugh, 
and P. J. Ratcliffe. 2001. Targeting of HIF-alpha to the von Hippel-Lindau ubiquitylation complex by O2-regulated prolyl hydroxylation

3. Science 292:468-472.

11. Jiang, B. H., F. Agani, A. Passaniti, and G. L. Semenza. 1997. V-SRC induces expression of hypoxia-inducible factor 1 (HIF-1) and transcription of genes encoding vascular endothelial growth factor and enolase 1: involvement of HIF-1 in tumor progression 41. Cancer Res. 57:5328-5335.

12. Jiang, B. H., G. Jiang, J. Z. Zheng, Z. Lu, T. Hunter, and P. K. Vogt. 2001. Phosphatidylinositol 3-kinase signaling controls levels of hypoxia-inducible factor 1. Cell Growth Differ. 12:363-369.

13. Jiang, B. H., E. Rue, G. L. Wang, R. Roe, and G. L. Semenza. 1996. Dimerization, DNA binding, and transactivation properties of hypoxia-inducible factor 1. J.Biol.Chem. 271:17771-17778.

14. Kondo, K. and W. G. Kaelin, Jr. 2001. The von Hippel-Lindau tumor suppressor gene 2. Exp.Cell Res. 264:117-125.

15. Ohh, M., C. W. Park, M. Ivan, M. A. Hoffman, T. Y. Kim, L. E. Huang, N. Pavletich, V. Chau, and W. G. Kaelin. 2000. Ubiquitination of hypoxia-inducible factor requires direct binding to the beta-domain of the von Hippel-Lindau protein

8. Nat.Cell Biol. 2:423-427.

16. Philp, A. J., I. G. Campbell, C. Leet, E. Vincan, S. P. Rockman, R. H. Whitehead, R. J. Thomas, and W. A. Phillips. 2001. The phosphatidylinositol 3'-kinase p85alpha gene is an oncogene in human ovarian and colon tumors

1. Cancer Res. 61:7426-7429.

17. Ravi, R., B. Mookerjee, Z. M. Bhujwalla, C. H. Sutter, D. Artemov, Q. Zeng, L. E. Dillehay, A. Madan, G. L. Semenza, and A. Bedi. 2000. Regulation of tumor angiogenesis by p53-induced degradation of hypoxia-inducible factor 1alpha. Genes Dev. 14:34-44.

18. Ryan, H. E., M. Poloni, W. McNulty, D. Elson, M. Gassmann, J. M. Arbeit, and R. S. Johnson. 2000. Hypoxia-inducible factor-1alpha is a positive factor in solid tumor growth 2. Cancer Res. 60:4010-4015.

19. Semenza, G. 2002. Signal transduction to hypoxia-inducible factor 1. Biochem.Pharmacol. 64:993-998.

20. Semenza, G. L. 2000. HIF-1: mediator of physiological and pathophysiological responses to hypoxia

15. J.Appl.Physiol 88:1474-1480.

21. Shayesteh, L., Y. Lu, W. L. Kuo, R. Baldocchi, T. Godfrey, C. Collins, D. Pinkel, B. Powell, G. B. Mills, and J. W. Gray. 1999. PIK3CA is implicated as an oncogene in ovarian cancer 
3. Nat.Genet. 21:99-102.

22. Skinner, H. D., J. Z. Zheng, J. Fang, F. Agani, and B. H. Jiang. 2004. Vascular endothelial growth factor transcriptional activation is mediated by hypoxia-inducible factor 1alpha, HDM2, and p70S6K1 in response to phosphatidylinositol 3-kinase/AKT signaling 10. J.Biol.Chem. 279:45643-45651.

23. Stoeltzing, O., M. F. McCarty, J. S. Wey, F. Fan, W. Liu, A. Belcheva, C. D. Bucana, G. L. Semenza, and L. M. Ellis. 2004. Role of hypoxia-inducible factor 1alpha in gastric cancer cell growth, angiogenesis, and vessel maturation

2. J.Natl.Cancer Inst. 96:946-956.

24. Wang, G. L., B. H. Jiang, E. A. Rue, and G. L. Semenza. 1995. Hypoxia-inducible factor 1 is a basic-helix-loop-helix-PAS heterodimer regulated by cellular $\mathrm{O} 2$ tension 6. Proc.Natl.Acad.Sci.U.S.A 92:5510-5514.

25. Yoon, S. O., S. Shin, and A. M. Mercurio. 2005. Hypoxia stimulates carcinoma invasion by stabilizing microtubules and promoting the Rab11 trafficking of the alpha6beta4 integrin. Cancer Res. 65:2761-2769.

26. Zhang, X. and D. Yee. 2000. Tyrosine kinase signalling in breast cancer: insulin-like growth factors and their receptors in breast cancer

1. Breast Cancer Res. 2:170-175.

27. Zhong, H., K. Chiles, D. Feldser, E. Laughner, C. Hanrahan, M. M. Georgescu, J. W. Simons, and G. L. Semenza. 2000. Modulation of hypoxia-inducible factor 1alpha expression by the epidermal growth factor/phosphatidylinositol 3-kinase/PTEN/AKT/FRAP pathway in human prostate cancer cells: implications for tumor angiogenesis and therapeutics. Cancer Res. 60:1541-1545.

28. Zhong, H., A. M. De Marzo, E. Laughner, M. Lim, D. A. Hilton, D. Zagzag, P. Buechler, W. B. Isaacs, G. L. Semenza, and J. W. Simons. 1999. Overexpression of hypoxiainducible factor 1alpha in common human cancers and their metastases. Cancer Res. 59:58305835 .

29. Zundel, W., C. Schindler, D. Haas-Kogan, A. Koong, F. Kaper, E. Chen, A. R. Gottschalk, H. E. Ryan, R. S. Johnson, A. B. Jefferson, D. Stokoe, and A. J. Giaccia. 2000. Loss of PTEN facilitates HIF-1-mediated gene expression 1. Genes Dev. 14:391-396. 

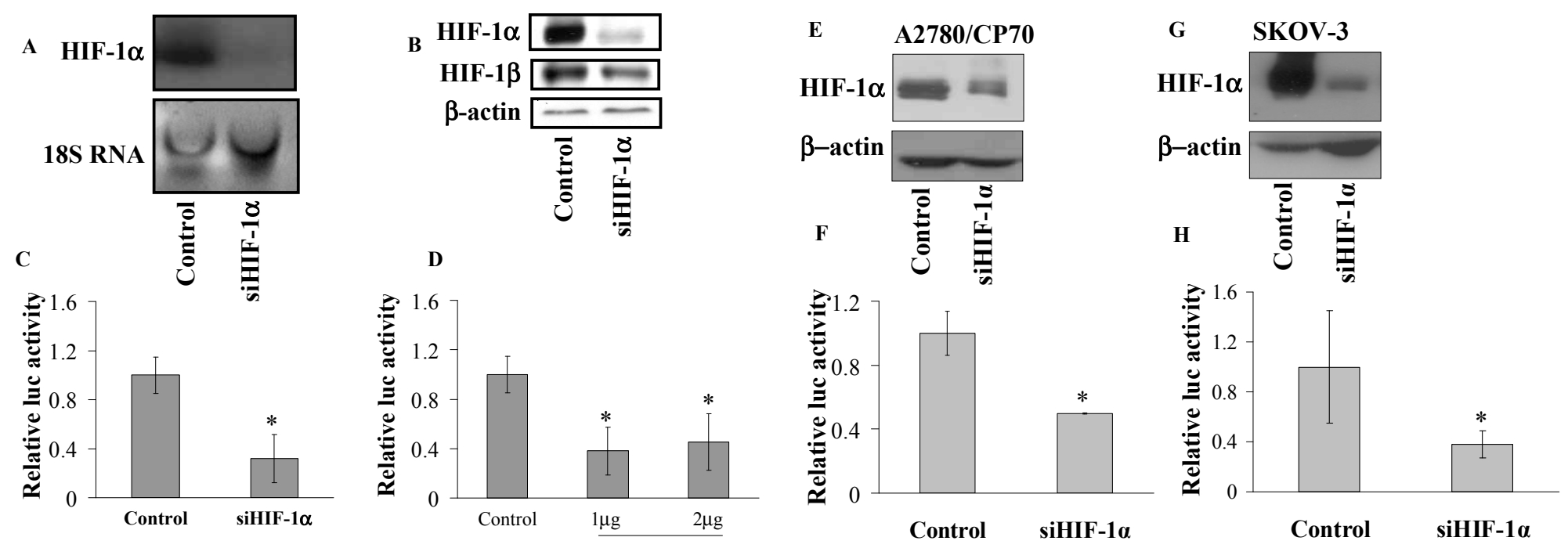

Figure 1. Expression of siRNA against HIF-1 $\alpha$ (siHIF-1 $\alpha$ ) decreased HIF-1 $\alpha$ mRNA and protein expression, and inhibited VEGF transcriptional activation in ovarian cancer cells. A, OVCAR-3 cells were transfected with either pSilencer 2.1-neo vector carrying scramble siRNA (control) or siHIF-1 $\alpha$. After transfection, the cells were cultured overnight, and then cultured in medium containing G418. HIF-1 $\alpha$ mRNA levels from the cells expressing scramble siRNA control or siHIF-1 $\alpha$ were analyzed by Northern blot using human HIF-1 $\alpha$ cDNA probe. The levels of $18 \mathrm{~S}$ RNA served as an internal control. B, HIF- $1 \alpha$ and HIF-1 $\beta$ protein levels in the cells expressing scramble siRNA (control) or siHIF-1 $\alpha$ were treated as described above and analyzed by Immunoblottingting. GAPDH served as an internal control. $\boldsymbol{C}$, OVCAR-3 cells were cotransfected with pCMV- $\beta$-gal plasmids and a VEGF reporter containing the human VEGF promoter reporter. Relative luciferase activity was determined by the ratio of luciferase: $\beta$-gal activity, and normalized to the control. The graph represents mean \pm SD of relative luciferase activities from three replicate experiments. * indicates a significant difference when compared to the control. $D$, OVCAR-3 cells were co-transfected with siHIF-1 $\alpha$ plasmids and the VEGF reporter as described above $(\mathrm{p}<0.05)$. Relative luciferase activity was determined by the ratio of 
luciferase: $\beta$-gal activity, and normalized to the control. The graph represents mean \pm SD from three replicate experiments. * indicates a significant difference when compared to the control (p<0.05). E, A2780/CP70 cells were transfected with either the pSilencer 2.1-neo vector carrying scramble siRNA (control) or siHIF-1 $\alpha$. After transfection, the cells were cultured overnight, and then cultured in medium containing G418 for three weeks to obtain stable cell lines. HIF-1 $\alpha$ protein levels were analyzed by immunoblotting. $\beta$-actin served as an internal control. F, A2780/CP70 cells expressing scramble siRNA or siHIF-1 $\alpha$.were co-transfected with pCMV- $\beta$-gal plasmids and the VEGF promoter reporter. Relative luciferase activity was determined by the ratio of luciferase: $\beta$-gal activity, and normalized to the control. The data represents mean \pm SD from three replicate experiments. * indicates a significant difference when compared to the control $(\mathrm{p}<0.05)$. G, SKOV-3 cells were transfected with either the pSilencer 2.1-neo vector carrying scramble siRNA (control) or siHIF-1 $\alpha$ to obtain stable cell lines as described above. HIF-1 $\alpha$ protein levels were analyzed by immunoblotting. $\beta$-actin served as an internal control. $\mathbf{H}, \mathrm{SKOV}-3$ cells expressing the control siRNA or siHIF-1 $\alpha$ were co-transfected with pCMV- $\beta$-gal plasmids and the VEGF promoter reporter. Relative luciferase activity was determined by the ratio of luciferase: $\beta$-gal activity and normalized to the control. The data represents mean \pm SD from three replicate experiments. $*$ indicates a significant difference when compared to the control $(p<0.05)$. 


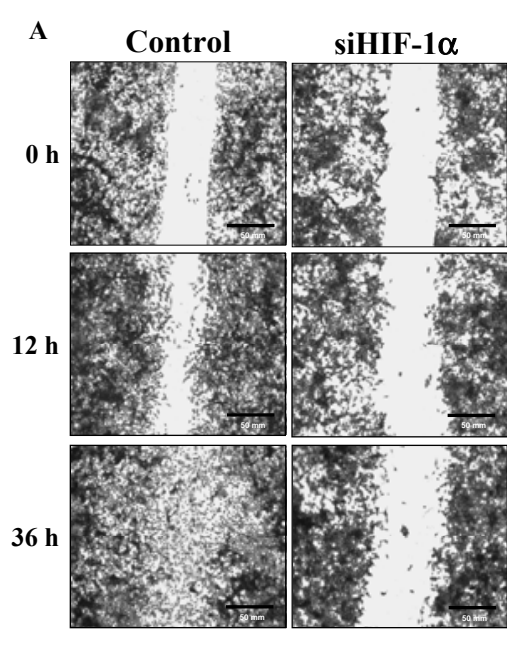

C
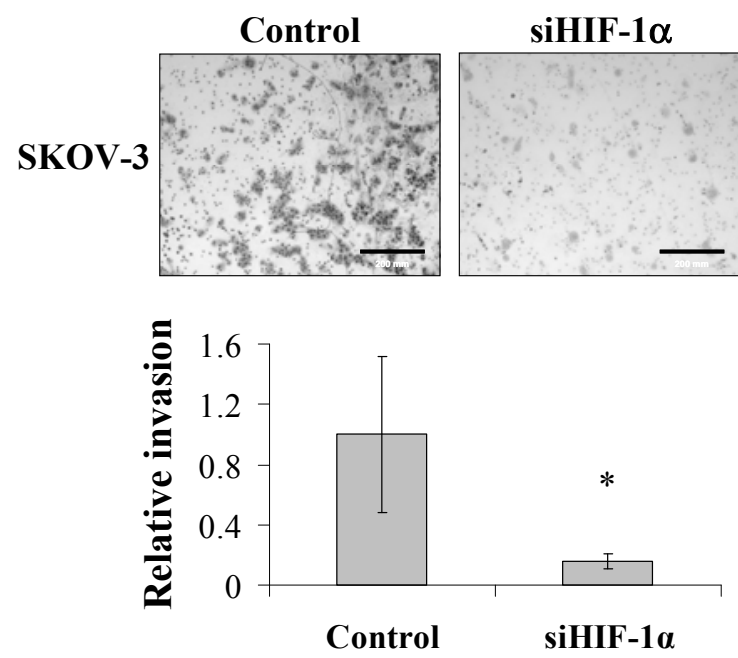

siHIF-1 $\alpha$

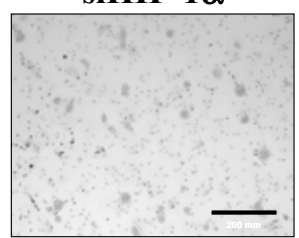

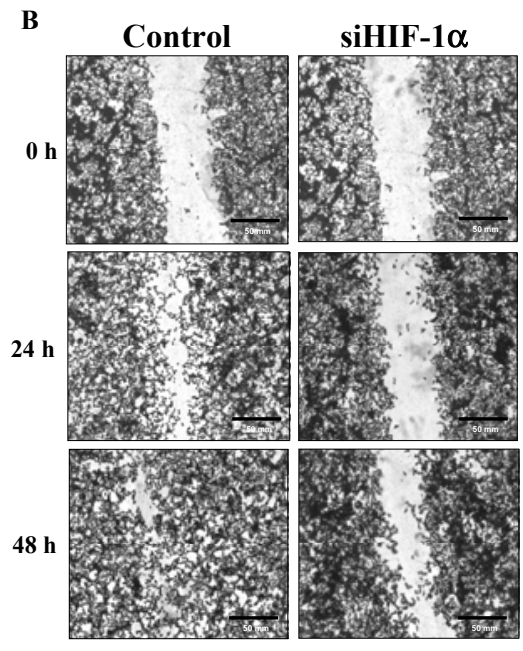

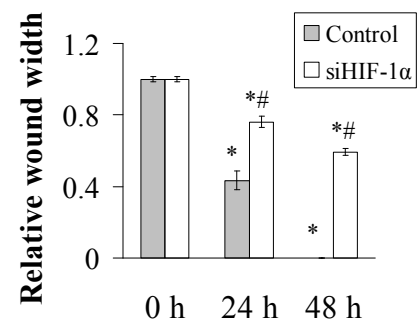

D

A2780/CP70

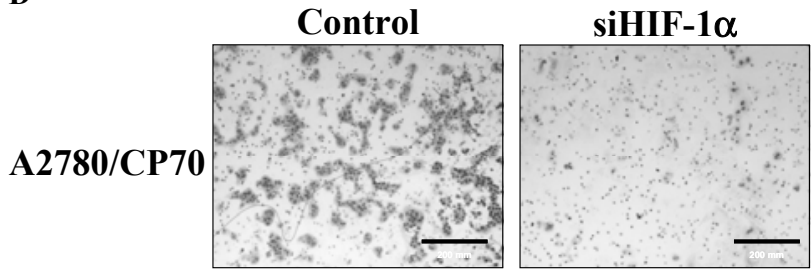

siHIF-1 $\alpha$

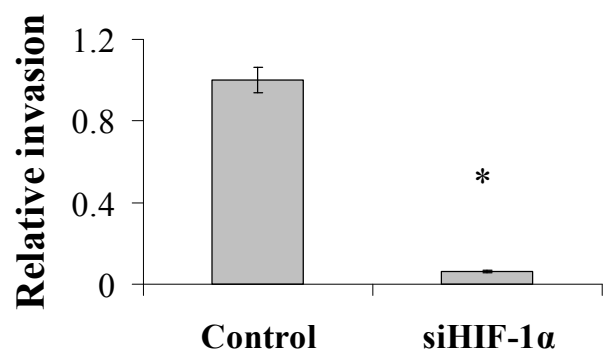

Figure 2. Stable expression of siHIF-1 $\alpha$ dramatically decreased ovarian cancer cell migration and invasion. A, OVCAR-3 cells stably expressing a scramble siRNA (control) or siHIF-1 $\alpha$ were cultured in 6-well plates. When the cells reached $80 \%$ confluence, a wound was made using a p200 pipet tip. Representative photos of the wound were taken at $0 \mathrm{~h}, 12 \mathrm{~h}$, and $36 \mathrm{~h}$. Relative wound width was measured by quantitative analysis to get the average distance of the cell migration from three independent experiments with four representative areas per experiment, and was shown as mean $\pm \mathrm{SD}$. * indicates a significant difference when compared to the $0 \mathrm{~h}$ control $(\mathrm{p}<0.05)$, \# indicates a significant difference between control and siHIF-1 $\alpha$ at the 
indicated time point $(\mathrm{p}<0.05)$. $\boldsymbol{B}, \mathrm{SKOV}-3$ cells stably expressing a scramble siRNA (control) or siHIF-1 $\alpha$ were cultured in 6-well plates. The wound healing assay was performed as described above, and representative photos of the wound were analyzed in $24 \mathrm{~h}$ and $48 \mathrm{~h}$, and the relative wound width was measured by quantitative analysis to get the average distance of the cell migration as above, and was shown as mean \pm SD. $C$, For the invasion assay, SKOV-3 cells expressing the scramble siRNA or siHIF- $1 \alpha$ were cultured in medium containing $2 \%$ serum and placed in the upper chamber. RPMI medium supplemented with $10 \%$ serum was placed in the lower chamber which was coated with collagen. The number of cells on the lower membrane was counted, and shown as mean $\pm \mathrm{SD} . *$ indicates a significant difference when compared to the control $(\mathrm{p}<0.05) . \quad D, A 2780 / \mathrm{CP} 70$ cells expressing the scramble siRNA or siHIF-1 $\alpha$ were cultured as described above. The number of cells on the lower membrane was counted and analyzed. The graph represents mean $\pm \mathrm{SD} . *$ indicates a significant difference when compared to the controll $(\mathrm{p}<0.05)$. 
A

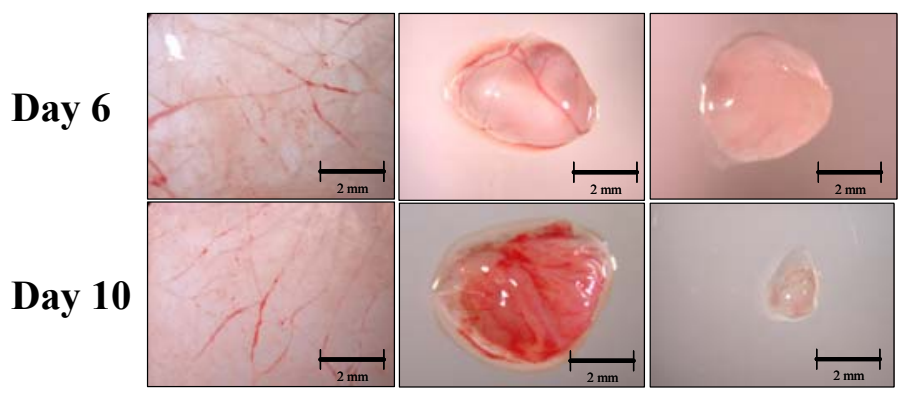

D

HIF-1 $\alpha$

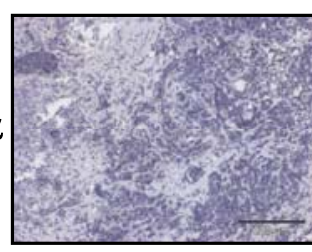

B

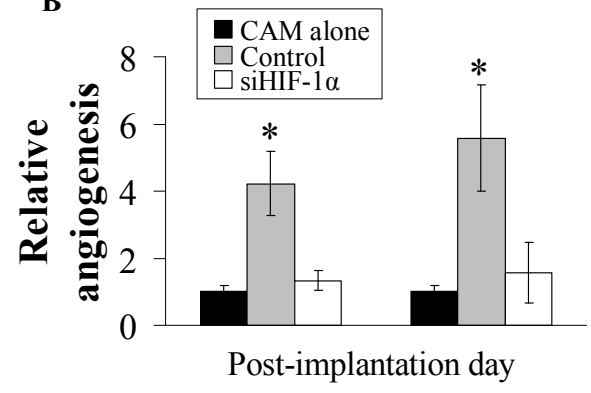

C

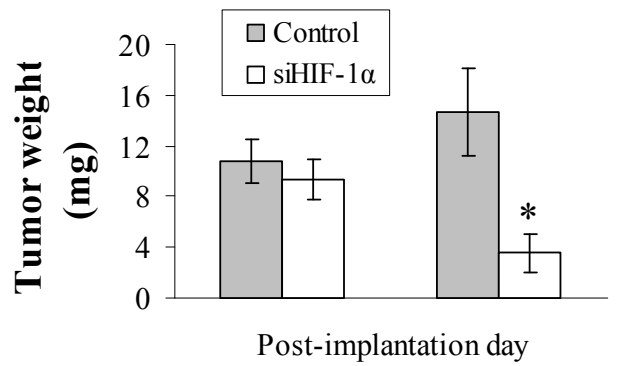

$\mathbf{E}$

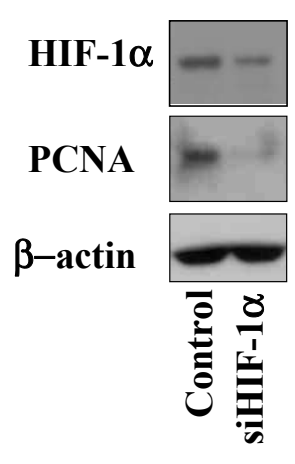

Figure 3. Stable expression of siHIF-1 $\alpha$ decreased tumor growth and angiogenesis. Chicken embryos were prepared as described in Materials and Methods. OVCAR-3 cells expressing the scramble siRNA or siHIF-1 $\alpha$ were implanted onto the CAM. On Days 6 and 10 postimplantation, the tumors were harvested, weighed and stored. A, Representative CAM tissue alone and OVCAR-3-induced tumors at day 6 and 10. B, The number of blood vessel branch points per high power field was counted for three separate quadrants in four samples per group, and mean $\pm \mathrm{SD}$ was showed. * indicates a significant difference when compared to the control $(\mathrm{p}<0.05) . C$, Tumor weight was determined by quantitative analysis (mean $\pm \mathrm{SD})$. * indicates a 
significant difference when compared to the control $(\mathrm{p}<0.05)$. $\boldsymbol{D}$, Representative tumor sections derived from cells expressing the scramble siRNA or siHIF-1 $\alpha$ were stained using specific antibodies against HIF-1 $\alpha . E$, Total proteins were prepared from the tumor tissues, and analyzed by immunoblottingting using antibodies against HIF- $1 \alpha$ and PCNA. $\beta$-actin served as the control.

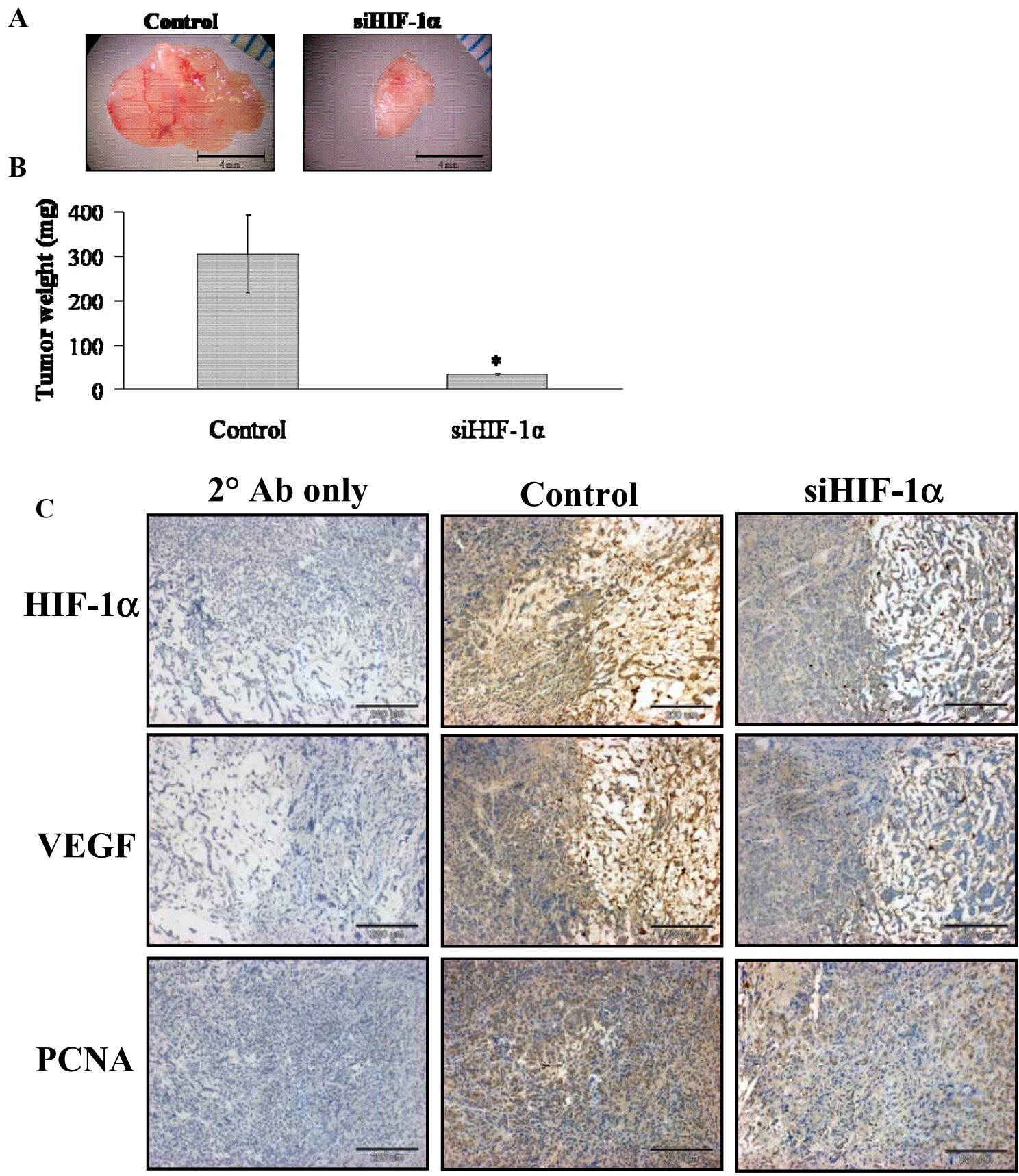


D
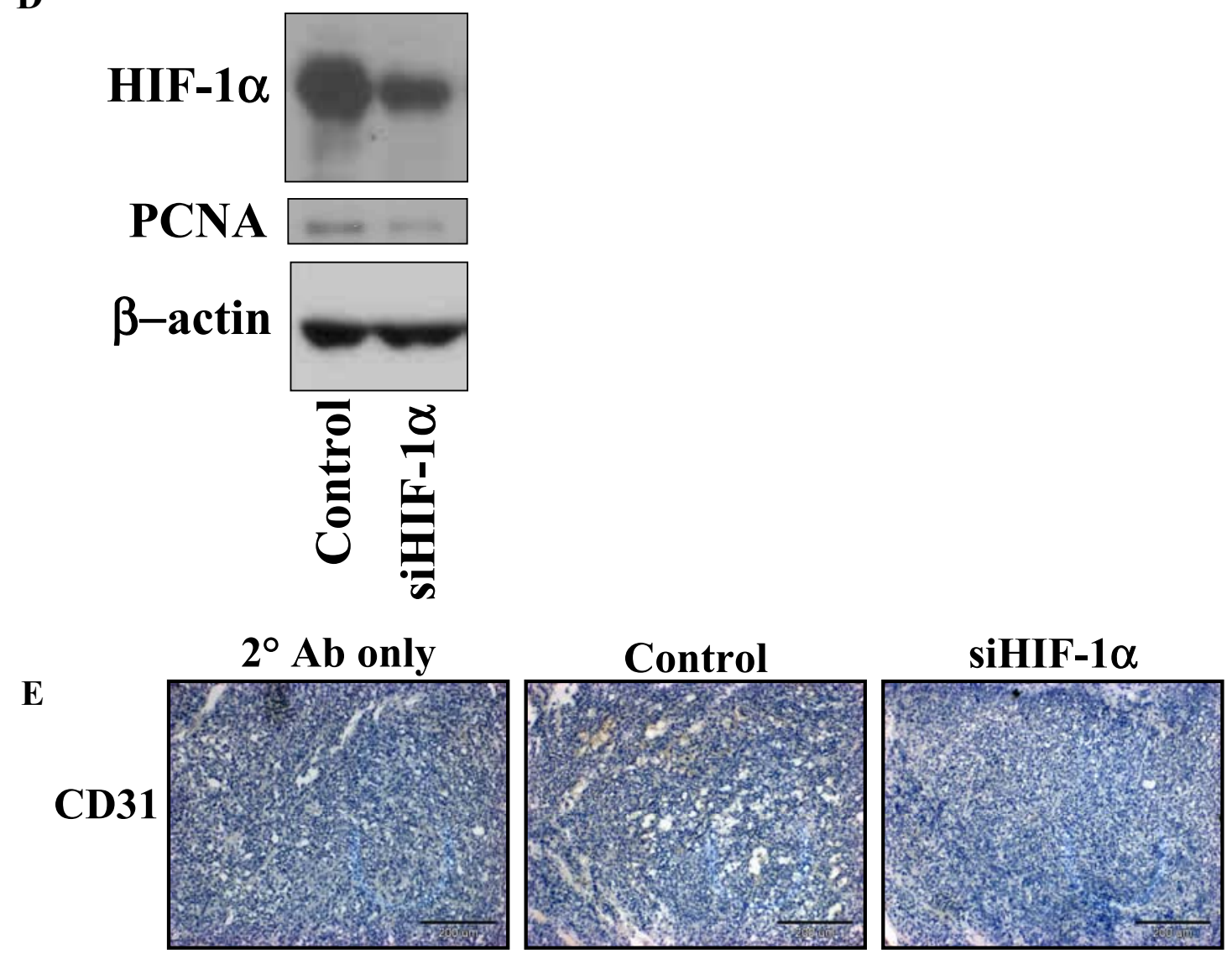

F
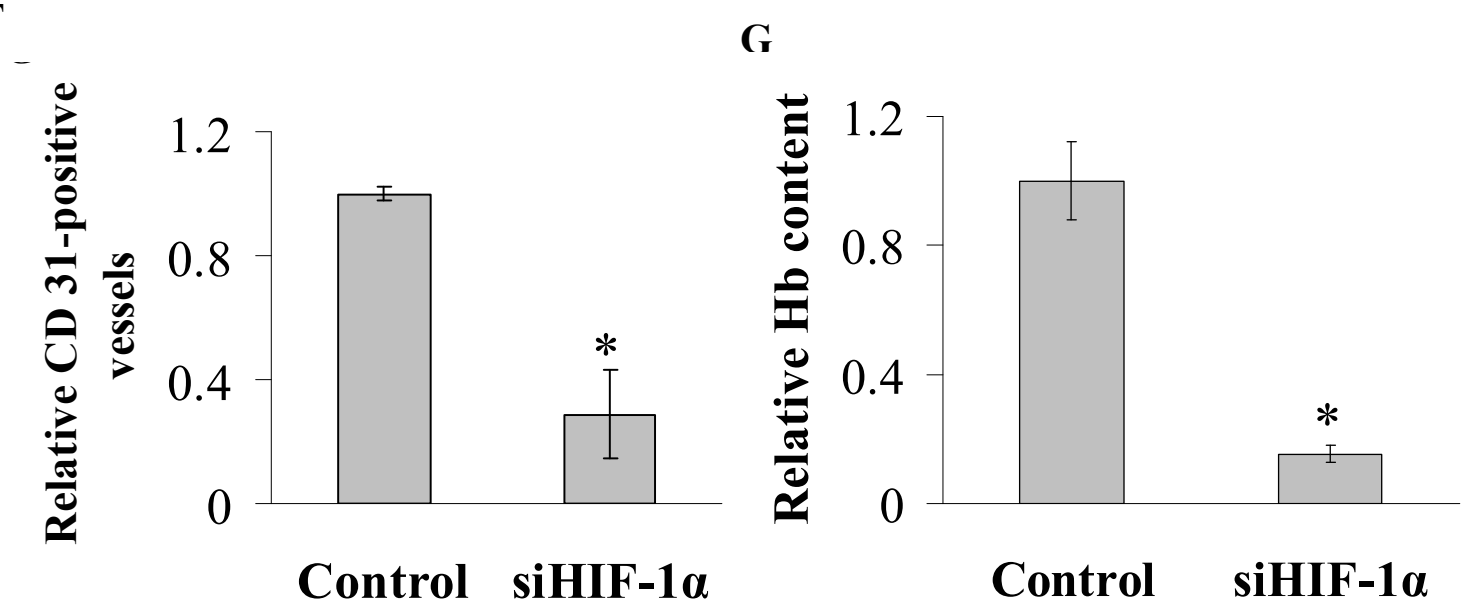

Figure 4. Stable expression of siHIF-1 $\alpha$ decreased angiogenesis and tumor growth in a vascularpoor microenvironment. The tumors were generated from OVCAR-3 cells expressing the scramble siRNA or siHIF-1 $\alpha$ as described in Materials and Methods. Tumors were removed and weighed 10 days after implantation, the tumor tissues were used for hemoglobin content assay, 
or fixed in $10 \%$ formalin solution for immunohistology analysis. A, Photographs of representative tumors expressing the scramble siRNA or siHIF-1 $\alpha$. B, Relative tumor weight was analyzed from 10 individual tumors. The data indicates the mean \pm SD from the replicate experiments. * indicates a significant difference when compared to the control $(\mathrm{p}<0.05) . C$, Cells expressing the scramble siRNA or siHIF-1 $\alpha$ were subjected to immunostaining using antibodies against HIF-1 $\alpha$, VEGF, and PCNA. D, Cells expressing the scramble siRNA or siHIF-1 $\alpha$ were analyzed by immunoblotting with antibodies against HIF- $1 \alpha, \beta$-actin, and PCNA. $\boldsymbol{E}$, Tumor sections were stained with antibodies against CD31, and CD31-positive staining cells were quantified using high power field in three random areas per tumor and from three tumors. Expression of siHIF-1 $\alpha$ decreased CD31 staining in these tumors. F, Relative CD31 staining was measured by quantitative analysis from three replicate experiments, and data was shown as mean \pm SD. * indicates a significant difference when compared to the control $(\mathrm{p}<0.05) . G$, The hemoglobin content from tumors induced by the cells expressing the scramble siRNA or siHIF$1 \alpha$ were measured, and normalized to the control. The relative levels of hemoglobin content are presented as mean \pm SD from replicate experiments. * indicates a significant difference when compared to the control $(\mathrm{p}<0.05)$. 
A

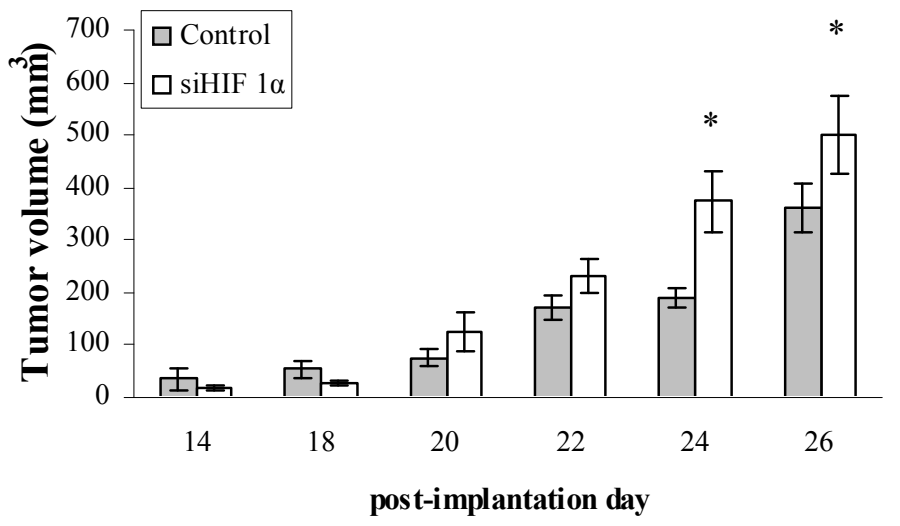

B

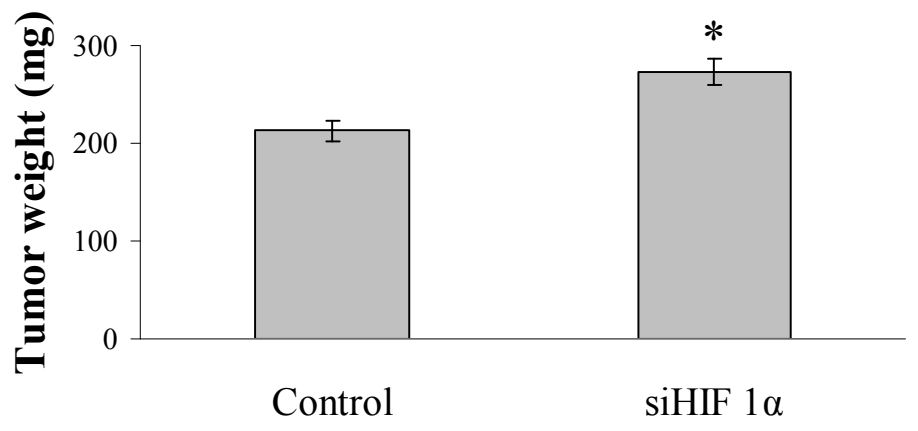

Control
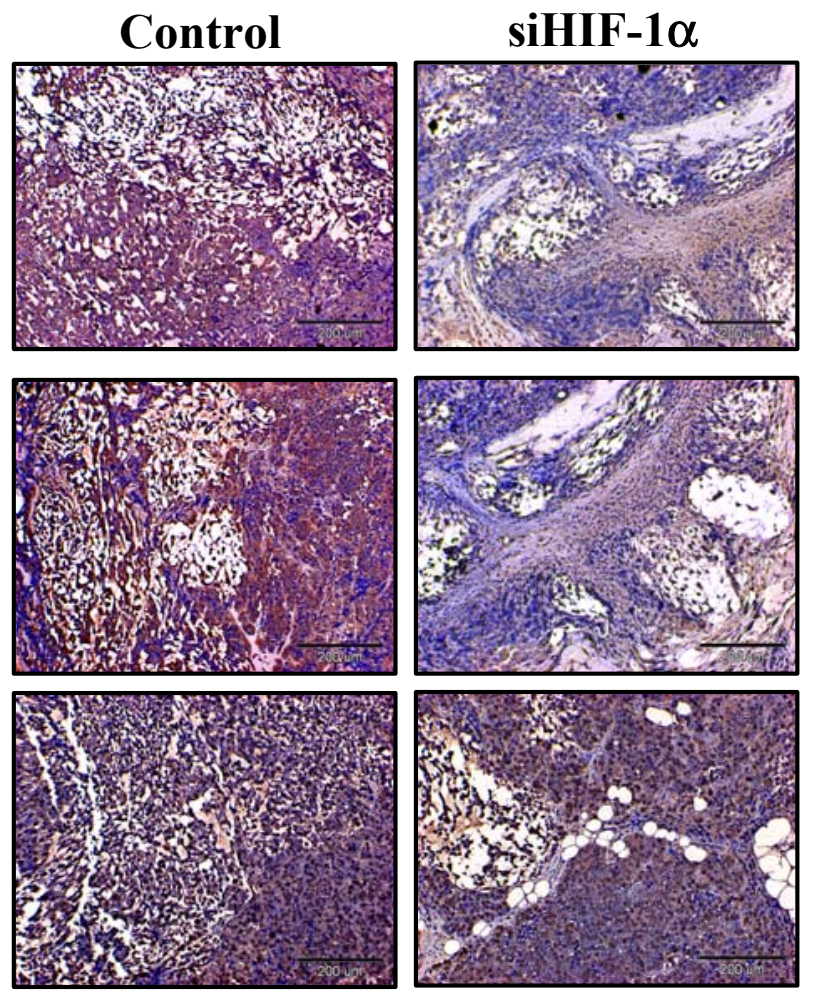

Control siHIF-1a 
Fig. 5. Stable expression of siHIF-1 $\alpha$ increased tumor growth in a vascular-rich microenvironment. The OVCAR-3 cells expressing the scramble siRNA or siHIF-1 $\alpha$ were injected into the subcutaneum of mice as described in Materials and Methods. A, Tumor volumes were measured when tumors were visible, and the volumes were calculated using the equation $=0.4\left(\right.$ length $\mathrm{x}$ width $\left.{ }^{2}\right)$. Tumors were removed at the times indicated and weighed, stored at $-70^{\circ} \mathrm{C}$, or fixed in formalin solution. The data represents the mean $\pm \mathrm{SD}$ from replicate experiments. * indicates a significant difference when compared to the control $(p<0.05) . \quad B$, Relative tumor weight was measured from eight tumors at the end of the experiment. The data represents the mean $\pm \mathrm{SD}$ from replicate experiments. * indicates a significant difference when compared to the control $(\mathrm{p}<0.05)$. $C$, Total proteins were analyzed for assaying HIF-1 $\alpha$, VEGF, and PCNA expression by immunostaining. $\boldsymbol{D}$, Tumor sections from the tumors were analyzed by immunoblotting using antibodies against HIF-1 $\alpha$, PCNA, and $\beta$-actin. E, Hemoglobin levels from the tumors induced by the cells expressing the scramble siRNA or siHIF-1 $\alpha$, were measured, and normalized to the control. The data represents mean \pm SD. 


\title{
CHAPTER 4: HIF-1 $\alpha$ EXPRESSION DETERMINES CHEMOTHERAPY SENSITIVITY IN OVARIAN AND PROSTATE CANCER*.
}

\author{
Heath D. Skinner ${ }^{1}$, Lesly Anne Lopez ${ }^{1}$, Chang Xia ${ }^{1}$, and Bing-Hua Jiang ${ }^{1 \#}$ \\ ${ }^{1}$ Mary Babb Randolph Cancer Center, Department of Microbiology, Immunology \\ and Cell Biology, West Virginia University, Morgantown, WV 26506-9300, USA.
}

Running title: The effects of HIF-1 $\alpha$ expression on chemosensitivity.

\# To whom correspondence should be addressed: Mary Babb Randolph Cancer Center, Department of Microbiology, Immunology and Cell Biology, West Virginia University, Morgantown, West Virginia 26506. Tel: 304-293-5949; Fax: 304-293-4667; E-mail: bhjiang@hsc.wvu.edu. 


\begin{abstract}
HIF-1 is a heterodimeric basic-helix-loop-helix transcription factor composed of two subunits, HIF-1 $\alpha$ and HIF-1 $1 \beta$. The regulatory subunit, HIF-1 $\alpha$, is over-expressed in a large number of tumors and has been correlated with tumor angiogenesis, metastasis and patient mortality. HIF-1 $\alpha$ is upregulated by hypoxia as well as by growth factors and oncogenes and is over-expressed in ovarian and prostate cancer cells. Previously, it has been shown that tumor hypoxia contributes to resistance to chemotherapy. In this study we wanted to determine whether modulation of HIF-1 $\alpha$ expression affected response to chemotherapy in ovarian and prostate cancer cells. Here we show that inhibition of HIF-1 $\alpha$ via siRNA ( resistance to several commonly used chemotheraputic agents, including cisplatin, taxol and doxorubicin, in both ovarian and prostate cancer cells in normoxia and hypoxia. This increased chemosensitivity in cells expressing siHIF-1 $\alpha$ was due to increased levels of drug-induced apoptosis. Furthermore, forced expression of HIF-1 $\alpha$ increased resistance to chemotherapy in these ovarian and prostate cancer cells, due to decreased levels of drug-induced apoptosis. This indicates a role for the inhibition of HIF-1 $\alpha$ in combination with other conventional modes of chemoetherapy.
\end{abstract}




\section{Introduction}

Hypoxia inducible factor-1 (HIF-1) is a heterodimeric basic helix-loop-helix transcription factor composed of two subunits, HIF-1 $\alpha$ and HIF-1 $\beta$. HIF-1 $\beta$ is constitutively expressed in most cells, while HIF-1 $\alpha$ is induced by a variety of different stimuli including hypoxia (31), growth factors (30) and oncogenes such as Src (20) and Ras $(9,26)$. HIF-1 regulates the transcription of a number of different genes controlling multiple processes such as glycolytic metabolism, cell cycle regulation and angiogenesis (30). Over-expression of HIF-1 $\alpha$ is found in most tumors and is correlated with tumor angiogenesis, tumor metastasis and patient mortality $(2-5,37,38)$.

HIF-1 $\alpha$ expression is regulated at the post-transcriptional level via the E3 ubquitin ligase von Hippel Lindau protein (pVHL). In normoxia, HIF-1 $\alpha$ is hydroxylated due to the activity of a family of prolyl hydroxylases, which allows it to be bound by pVHL and ubquitinylated $(12,18,19,27,27)$. However, in hypoxia, these prolyl hydroxylases are inactive, and allowing HIF-1 $\alpha$ and HIF-1 $\beta$ to form the active transcription factor HIF-1. Previously we have shown that HIF-1 $\alpha$ expression is upregulated in normoxia in ovarian and prostate cancer cells via constitutive activation of phosphatidylinositol-3 kinase (PI3K) signaling $(21,32)$.

One of the most difficult problems to overcome in cancer therapy is that of resistance to conventional chemotherapy. A number of different factors in the tumor contribute to its ability to resist drug therapy, one of the most interesting and most recently targeted being tumor hypoxia. Areas of hypoxia are common in most, if not all, solid tumors, due to inadequate and defective vascularization (7). Tumor hypoxia is associated with chemotherapy resistance and poor outcome clinically $(6,35)$. Furthermore, it has been shown that hypoxia increases resistance to many common anti-tumor drugs in cancer cells $(15,22,23,25,29,36)$. Although some 
chemotherapy resistance seen in hypoxic tumors is due to physical factors such as the increased distance of hypoxic cells from the vasculature and subsequent decreased drug dosage, molecular alterations also occur in the cell during hypoxia that have been linked to chemoresistance (16). One of the molecular mechanisms by which hypoxia could induce chemoresistance is via activation of HIF-1. Several studies have shown that HIF-1 activation by hypoxia leads to expression of multi-drug resistance gene 1 (MDR 1) in several cell types $(13,14)$, while another study showed that HIF-1 dependent down- regulation of Bid is necessary for resistance to etoposide in colon cancer (15). It has been shown that MEF HIF-1 -/- cells are more sensitive to certain types of chemotherapy (34). However, the exact mechanism by which HIF-1 activation affects the molecular response to chemotherapy in cancer cells remains unclear.

Because HIF- $1 \alpha$ is over-expressed in prostate and ovarian cancer cells in normoxia, and hypoxia-induced HIF-1 $\alpha$ has been linked to chemotherapy resistance, we wanted to determine whether specific inhibition of HIF-1 $\alpha$ by siRNA would affect ovarian and prostate cancer cell response to chemotherapy. Furthermore, we wanted to determine whether forced expression of HIF-1 $\alpha$ would increase chemotherapy resistance in these cells.

\section{Materials and Methods}

Cell culture and reagents - OVCAR-3, SKOV-3 and A2780/CP-70 ovarian cancer and DU-145 and PC-3 prostate cancer cells were cultured in RPMI 1640 (Mediatech, Verndon, VA) supplemented with $10 \%$ fetal bovine serum supplemented (Intergen, Purchase, NY), 0.2 units $/ \mathrm{ml}$ penicillin, and $50 \mu \mathrm{g} / \mathrm{ml}$ streptomycin (Invitrogen, Carlsbad, CA). Cells were cultured at $37^{\circ} \mathrm{C}$ in a $5 \% \mathrm{CO} 2$ incubator and trypsin $(0.25 \%)$ was used to detach adherent cells for subculture. 
Cisplatin (CDDP) and doxorubicin (Sigma, St. Louis, MO) were dissolved in 1xPBS. Taxol was purchased in solution $(6 \mathrm{ng} / \mathrm{ml})$ (PGC scientifics?) and diluted with 1xPBS.

Generation of cell lines-OVCAR-3, SKOV-3, A2780/CP70, PC-3 and DU-145 cells stably expressing either siRNA specific for HIF-1 $\alpha$ (siHIF-1 $\alpha$ ) or siRNA with no known mammalian homology (siControl) were generated as described previously (Skinner et al 2005). Similar selection methods were used to generate cells stably expressing pcDNA3 or HIF-1 $\alpha$ CA. Briefly, the cells were plated in 6-well plates, the next day the cells were transfected with $0.5 \mu \mathrm{g}$ of either empty pcDNA3 vector or pcDNA3/HIF-1 $\alpha$ CA per well using lipofectamine (Invitrogen, Carlsbad, CA) per the manufacturer's instructions. After an overnight recovery the media was supplemented with $600 \mu \mathrm{g} / \mathrm{ml} \mathrm{G} 418$. The cells were selected for two weeks, and the resultant colonies were pooled. No gross differences in morphology or cell proliferation or basal rate apoptosis were observed.

MTT assay-Cells were plated at 50,000 cells/well of a 96-well plate. The following day, the cells were washed once in 1xPBS then treated with drugs in RPMI 1640 media containing 10\% fetal bovine serum (normal serum) or $1 \%$ fetal bovine serum (reduced serum). The cells were cultured for $48 \mathrm{~h}$ in either $21 \% \mathrm{O}_{2}$ or $1 \% \mathrm{O}_{2}$ as described above. After treatment, the media was replaced with RPMI 1640 containing 1mg/ml of MTT (2,3-bis-(2-methoxy-4-nitro-5sulfophenyl)-2H-tetrazolium-5-carboxanilide), which was allowed to incubate at $37^{\circ} \mathrm{C}$ in a $5 \%$ CO2 incubator for $4 \mathrm{~h} .100 \mu \mathrm{l}$ of MTT lysis buffer (20\% SDS, $50 \%$ Metforamide) was then added to each well and allowed to incubate at $37^{\circ} \mathrm{C}$ overnight. The following day, absorbance was read at $570 \mathrm{~nm}$ and the means of quadruplicates were calculated. Values were normalized to 
control and shown as mean \pm standard deviation. Estimated $\mathrm{IC}_{50}$ values, representing 50\% relative absorbance, are also shown in tables accompanying each figure.

Immunoblot analysis - Cells were washed 3 times in ice cold 1xPBS then collected and lysed in RIPA supplemented with protease inhibitors ( $1 \mathrm{mM}$ sodium vanadate, $0.5 \mathrm{mM}$ dithiothreitol (DTT), $1 \mathrm{mM}$ phenylmethylsulfonyl fluoride (PMSF), $2 \mathrm{mM}$ leupeptin, $2 \mathrm{mM}$ aprotinin, and 2 $\mathrm{mM}$ pepstatin) on ice for $20 \mathrm{~m}$. The cells were then spun at $13,000 \mathrm{rpm}$ for $10 \mathrm{~m}$. The supernatant was assayed for protein concentration and aliquots of $40 \mu \mathrm{g}$ were separated on an SDS-PAGE polyacrylamide gel. Protein was then transferred to a nitrocellulose membrane and blocked in $5 \%$ nonfat dry milk in 1xTBS-T. Proteins were detected using primary antibodies directed against HIF-1 $\alpha$ (BD biosciences, San Jose, CA), caspase-3 (Santa Cruz biotechnology, Santa Cruz, CA) PARP (Santa Crux biotechnology, Santa Cruz, CA) and $\beta$-actin (Sigma, St. Louis, MO) and HRP-conjugated secondary antibodies (Pierce, Rockford, IL) and visualized through enhanced chemiluminescence reagent (Pierce, Rockford, IL).

Mitochondrial function - To quantify apoptosis in cells treated with taxol, mitochondrial function was assayed using MitoTracker Red CMXRos (Invitrogen, Carlsbad, CA). The cells were treated for $24 \mathrm{~h}$ with drug in reduced serum. After treatment, MitoTracker Red CMXRos dye was added to the cells and allowed to incubate for $30 \mathrm{~m}$. The cells were then trypsinized, collected and washed twice in 1xPBS. Fluorescence was then measured using flow cytometry and normalized to untreated control. Values are presented as means \pm standard deviation. 


\section{Results}

Treatment with common chemotherapeutic drugs inhibits HIF-1 $\alpha$ expression in ovarian and prostate cancer cells. To determine if commonly used chemotherapeutic agents affected HIF-1 $\alpha$ expression in ovarian and prostate cancer cells, we treated OVCAR-3 ovarian cancer cells with cisplatin (CDDP) for $6 \mathrm{~h}$ and found that the treatment decreased HIF-1 $\alpha$ expression in both cells expressing control siRNA (siControl) and cells expressing siRNA specific for HIF-1 $\alpha$ (siHIF-1 $\alpha$ ) (Fig. 1 A). Similarly, HIF-1 $\alpha$ expression was inhibited by CDDP in SKOV-3 cells stably expressing siControl or siHIF-1 $\alpha$ (Fig. 1 B). We observed similar inhibition of HIF-1 $\alpha$ in DU145 and PC-3 prostate cancer cell lines after treatment with taxol (Figs. 1 C \& D). Furthermore, the inhibitory effect of both CDDP and taxol on HIF-1 $\alpha$ expression was partially reversed by expression of HIF-1 $\alpha$ CA (Figs. $1 \mathrm{E} \& \mathrm{~F}$ ).

Inhibition of HIF-1 $\alpha$ via siRNA increased sensitivity to common chemotherapeutic agents in ovarian and prostate cancer cells. Because chemotherapeutic agents decrease HIF-1 $\alpha$ expression, we wanted to determine if specific inhibition of HIF-1 $\alpha$ via siRNA affected the response to treatment with commonly used chemotherapy agents. To do this we performed an MTT assay using OVCAR-3 stably expressing siControl or siHIF-1 $\alpha$ and treated with CDDP and taxol. Expression of siHIF-1 $\alpha$ dramatically increased the sensitivity of these cells to treatment with both CDDP and taxol (Figs. 2 A-D). In prostate cancer cells we also observed that expression of siHIF-1 $\alpha$ increased the sensitivity to taxol as well as doxorubicin treatment (Fig 2 E-L). This effect was observed in both $10 \%$ and $1 \%$ serum conditions. 
Expression of siHIF-1 $\alpha$ increases apoptosis induced by chemotherapy treatment. Because siHIF-1 $\alpha$ expression increases chemotherapy sensitivity in the MTT assay even under low serum conditions, which decreases cellular proliferation dramatically, we believed that expression of siHIF-1 $\alpha$ was mainly affecting drug-induced apoptosis. To determine if the observed increased sensitivity to chemotherapy in cells expressing siHIF-1 $\alpha$ was due to induction of apoptosis, we treated OVCAR-3 cells stably expressing siControl or siHIF-1 $\alpha$ with CDDP for $24 \mathrm{~h}$ then measured caspase-3 activation. Expression of siHIF-1 $\alpha$ increased the levels of caspase-3 and PARP cleavage in the presence of cisplatin, indicating that increased levels of caspase-dependent apoptosis (Fig. 3A). Similar effects were seen in SKOV-3 ovarian cancer cells expressing either siHIF-1 $\alpha$ (Fig. 3B). We also treated DU-145 and PC-3 cells with taxol and assayed micochondrial function as a measure of apoptosis, as we have previously found that taxol induced apoptosis in these cells in the absence of caspase- 3 activation (unpublished observations). We found that expression of siHIF- $1 \alpha$ renders cells more sensitive to the proapoptotic effects of taxol in both cell lines (Figs. $3 \mathrm{C} \& \mathrm{D}$ ). Thus, the increased sensitivity to chemotherapy in the cells expressing siHIF-1 $\alpha$ was due to induction of apoptosis. Expression of siHIF-1 $\alpha$ does not increase sensitivity to cisplatin in A2780/CP70 cells, but does increase their sensitivity to taxol. To determine if HIF-1 $\alpha$ plays a role in cisplatin resistance acquired after therapy with this drug, we treated A2780/CP70 cells with cisplatin. These cells were generated from the surviving colonies of cells cultured in the presence of cisplatin over a long period of time, thus acquiring cisplatin resistance. Expression of siHIF-1 $\alpha$ had no effect on sensitivity to cisplatin or cisplatin-induced apoptosis in A2780/CP70 cells (Figs. 4A-C). However, stable expression of siHIF-1 $\alpha$, did increase sensitivity to taxol in these cells in both normal and reduced serum conditions (Figs. 4D \& E). Thus, it would seem that while inhibition 
of HIF-1 $\alpha$ does not affect the pathway involved specifically in cisplatin resistance in these cells, HIF-1 $\alpha$ still plays a role in the general resistance to chemotherapy.

Expression of siHIF-1 $\alpha$ increased chemosensitivity under hypoxic conditions. Previously, it has been shown that hypoxia increases resistance to chemotherapeutic agents. To test whether inhibition of HIF-1 $\alpha$ played a role in this process, we treated OVCAR-3 and PC-3 cells stably expressing siHIF-1 $\alpha$ with chemotherapeutic agents under hypoxic conditions in the same manner as the previous experiments conducted in normoxia. We found that hypoxia increased chemoresistance in these cells to both cisplatin and taxol compared to the same treatments in normoxia (Figs. 5 A \& B). Furthermore, stable expression of siHIF-1 $\alpha$ in OVCAR-3 cells dramatically increased chemosensitivity in the presence of both cisplatin and taxol under hypoxic conditions, partially abrogating hypoxia-induced chemoresistance (Figs. 5 A \& B). Furthermore, this effect was due to increased caspase -3 activation and apoptosis in cells expressing siHIF-1 $\alpha$ (Figs. 5 C). Hypoxia increased resistance to taxol treatment when compared to PC-3 cells treated in normoxia (Fig. 5 D). Similarly, expression of siHIF-1 $\alpha$ increased sensitivity to taxol treatment in PC-3 prostate cancer cells in hypoxia, partially abrogating the protective effect of hypoxia (Fig. 5 D). This increase in chemosensitivity was due to the induction of apoptosis in cells expressing siHIF-1 $\alpha$ (Fig. 5 E).

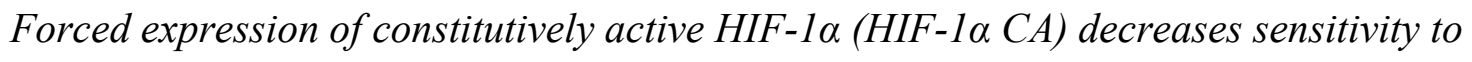
chemotherapy in both normoxic and hypoxic environments. Because we have observed significant increases in chemosensitivity due to inhibition of HIF-1 $\alpha$ in prostate and ovarian cancer cells, we wanted to determine whether over-expression of HIF-1 $\alpha$ under normoxic 
conditions (HIF-1 $\alpha \mathrm{CA}$ ) would affect chemoresistance. We performed experiments similar to those above, using cells expressing either empty pcDNA3 vector or HIF-1 $\alpha$ CA. In OVCAR-3 cells, a significant reduction in chemosensitivity to cisplatin and taxol was observed in both normal and reduced-serum conditions due to the expression of HIF-1 $\alpha$ CA (Figs. 6 A-D). Expression of HIF-1 $\alpha$ CA in PC-3 cells also decreased sensitivity to taxol and doxorubicin in both normal and reduced-serum conditions (Figs. 6 F-I). Furthermore, the increase in chemoresistance in cells expressing HIF-1 $\alpha \mathrm{CA}$ is due to an abrogation of drug-induced apoptosis, as measured by either activation of caspase-3 signaling in OVCAR-3 cells (Fig. 6 E) or increased mitochondrial permeability in PC-3 cells (Fig. 6 J). To determine if forced expression of HIF-1 $\alpha$ would also increase chemotherapy resistance under hypoxic conditions, we performed the same experimenst as described above under hypoxic conditions. Similarly, we observed that forced expression of HIF-1 $\alpha$ CA exerted a chemoprotective effect. Expression of HIF-1 $\alpha$ CA made OVCAR-3 cells more resistant to treatment with either cisplatin or taxol (Figs. $6 \mathrm{~K} \& \mathrm{~L}$ ). Furthermore, HIF-1 $\alpha$ CA expression also decreased chemosensitivity in PC-3 cells treated with either taxol or doxorubicin (Figs. $6 \mathrm{M} \& \mathrm{~N}$ ). This data indicates that forced expression of HIF-1 $\alpha$ increases chemoresistance to a variety of anti-tumor drugs in ovarian and prostate cancer cells.

\section{Discussion}

In this study we showed that HIF-1 $\alpha$ expression directly impacted ovarian and prostate cancer cell response to commonly used chemotherapeutic drugs. Both cisplatin and taxol decreased HIF-1 $\alpha$ expression. Specific inhibition of HIF-1 $\alpha$ increased chemosensitivity in both normoxia and hypoxia, while forced expression of stable HIF-1 $\alpha$ had the reverse effect. 
Furthermore, the effect of HIF- $1 \alpha$ in increasing chemotherapy resistance was due to decreased drug-induced apoptosis.

The cancer cell lines used in this study were either p53 null or express mutant p53. Therefore, although HIF-1 $\alpha$ has been shown previously to interact with p53 and affect its functioning $(1,10,17)$, it is unlikely that this is the mechanism by which HIF-1 $\alpha$ is exerting its effects on drug-induced apoptosis. Hypoxia regulates a number of targets that are thought to be involved in resistance to chemotherapy, such as MDR1 and Bid, via HIF-1 $\alpha$ expression (13-15). These factors could be working in combination to explain the dramatic increase in chemosensitivity seen with inhibition of HIF-1 $\alpha$ epression.

This study used several cell lines that exhibit variety of resistance to conventional chemotherapy. All of the ovarian cancer cell lines used exhibit some resistance to cisplatin, which was overcome by inhibition of HIF-1 $\alpha$ expressoion in all cell lines, except A2780/CP70. Interestingly, cisplatin resistant A2780/CP70 cells, which were generated from cisplatin resistant colonies in culture, was unaffected by inhibition of HIF-1 $\alpha$. Previous data has indicated that A2780/CP70 cells are resistant to cisplatin via alterations in the DNA damage repair pathway (28). In these cells HIF-1 $\alpha$ expression may not be affecting this pathway. Alternatively, because it has been shown that HIF-1 $\alpha$ can affect at least one DNA repair enzyme (24), targets of HIF-1 $\alpha$ in this pathway may be insensitive to regulation in A2780-CP70 cells contributing to cisplatin resistance.

Currently, inhibitors of HIF-1 $\alpha$ are being examined as possible anti-tumor and antiangiogenic agents. HIF-1 $\alpha$ inhibition as cancer therapy is promising, as HIF- $1 \alpha$ is barely expressed in normal tissues, but is over-expressed in many tumors and has been linked to tumor angiogenesis, metastasis and patient mortality $(2-5,38)$. However, the results of HIF-1 $\alpha$ 
inhibition in tumor xenograft models have thus far been inconclusive. In several studies, inhibition of HIF-1 $\alpha$ decreased tumor growth $(11,33)$, however other studies indicate that inhibition of HIF-1 $\alpha$ can lead to increased tumor growth (8) (Skinner et al 2005). The results of this study seem to indicate that inhibition of HIF-1 $\alpha$ might be more efficacious in combination with conventional chemotherapy, than as a stand alone therapy. This would be particularly true in tumors that are resistant to commonly used chemotherapy drugs, like cisplatin and taxol. Inhibition of HIF-1 $\alpha$ expression would sensitize the tumor to these drugs, allowing for lower doses which would decrease toxicity and side effects.

\section{Reference List}

1. An, W. G., M. Kanekal, M. C. Simon, E. Maltepe, M. V. Blagosklonny, and L. M. Neckers. 1998. Stabilization of wild-type p53 by hypoxia-inducible factor 1alpha. Nature 392:405-408.

2. Birner, P., B. Gatterbauer, G. Oberhuber, M. Schindl, K. Rossler, A. Prodinger, H. Budka, and J. A. Hainfellner. 2001. Expression of hypoxia-inducible factor-1 alpha in oligodendrogliomas: its impact on prognosis and on neoangiogenesis. Cancer 92:165-171.

3. Birner, P., M. Schindl, A. Obermair, G. Breitenecker, and G. Oberhuber. 2001. Expression of hypoxia-inducible factor 1alpha in epithelial ovarian tumors: its impact on prognosis and on response to chemotherapy. Clin.Cancer Res. 7:1661-1668.

4. Birner, P., M. Schindl, A. Obermair, C. Plank, G. Breitenecker, and G. Oberhuber. 2000. Overexpression of hypoxia-inducible factor 1alpha is a marker for an unfavorable prognosis in early-stage invasive cervical cancer. Cancer Res. 60:4693-4696.

5. Bos, R., H. Zhong, C. F. Hanrahan, E. C. Mommers, G. L. Semenza, H. M. Pinedo, M. D. Abeloff, J. W. Simons, P. J. van Diest, and W. E. van der. 2001. Levels of hypoxiainducible factor-1 alpha during breast carcinogenesis. J.Natl.Cancer Inst. 93:309-314.

6. Brizel, D. M., G. S. Sibley, L. R. Prosnitz, R. L. Scher, and M. W. Dewhirst. 1997. Tumor hypoxia adversely affects the prognosis of carcinoma of the head and neck. Int.J Radiat.Oncol.Biol.Phys. 38:285-289.

7. Brown, J. M. 2000. Exploiting the hypoxic cancer cell: mechanisms and therapeutic strategies. Mol.Med Today 6:157-162. 
8. Carmeliet, P., Y. Dor, J. M. Herbert, D. Fukumura, K. Brusselmans, M. Dewerchin, M. Neeman, F. Bono, R. Abramovitch, P. Maxwell, C. J. Koch, P. Ratcliffe, L. Moons, R. K. Jain, D. Collen, and E. Keshert. 1998. Role of HIF-1alpha in hypoxia-mediated apoptosis, cell proliferation and tumour angiogenesis

7. Nature 394:485-490.

9. Chen, C., N. Pore, A. Behrooz, F. Ismail-Beigi, and A. Maity. 2001. Regulation of glut1 mRNA by hypoxia-inducible factor-1. Interaction between H-ras and hypoxia 1. J.Biol.Chem. 276:9519-9525.

10. Chen, D., M. Li, J. Luo, and W. Gu. 2003. Direct interactions between HIF-1 alpha and Mdm2 modulate p53 function. J.Biol.Chem. 278:13595-13598.

11. Chen, J., S. Zhao, K. Nakada, Y. Kuge, N. Tamaki, F. Okada, J. Wang, M. Shindo, F. Higashino, K. Takeda, M. Asaka, H. Katoh, T. Sugiyama, M. Hosokawa, and M.

Kobayashi. 2003. Dominant-negative hypoxia-inducible factor-1 alpha reduces tumorigenicity of pancreatic cancer cells through the suppression of glucose metabolism

1. Am.J.Pathol. 162:1283-1291.

12. Cockman, M. E., N. Masson, D. R. Mole, P. Jaakkola, G. W. Chang, S. C. Clifford, E. R. Maher, C. W. Pugh, P. J. Ratcliffe, and P. H. Maxwell. 2000. Hypoxia inducible factoralpha binding and ubiquitylation by the von Hippel-Lindau tumor suppressor protein 7. J.Biol.Chem. 275:25733-25741.

13. Comerford, K. M., E. P. Cummins, and C. T. Taylor. 2004. c-Jun NH2-terminal kinase activation contributes to hypoxia-inducible factor 1alpha-dependent P-glycoprotein expression in hypoxia. Cancer Res 64:9057-9061.

14. Comerford, K. M., T. J. Wallace, J. Karhausen, N. A. Louis, M. C. Montalto, and S. P. Colgan. 2002. Hypoxia-inducible factor-1-dependent regulation of the multidrug resistance (MDR1) gene. Cancer Res 62:3387-3394.

15. Erler, J. T., C. J. Cawthorne, K. J. Williams, M. Koritzinsky, B. G. Wouters, C. Wilson, C. Miller, C. Demonacos, I. J. Stratford, and C. Dive. 2004. Hypoxia-mediated down-regulation of Bid and Bax in tumors occurs via hypoxia-inducible factor 1-dependent and independent mechanisms and contributes to drug resistance. Mol.Cell Biol. 24:2875-2889.

16. Greco, O., B. Marples, M. C. Joiner, and S. D. Scott. 2003. How to overcome (and exploit) tumor hypoxia for targeted gene therapy. J Cell Physiol 197:312-325.

17. Hansson, L. O., A. Friedler, S. Freund, S. Rudiger, and A. R. Fersht. 2002. Two sequence motifs from HIF-1alpha bind to the DNA-binding site of p53.

Proc.Natl.Acad.Sci.U.S.A 99:10305-10309.

18. Ivan, M., K. Kondo, H. Yang, W. Kim, J. Valiando, M. Ohh, A. Salic, J. M. Asara, W. S. Lane, and W. G. Kaelin, Jr. 2001. HIFalpha targeted for VHL-mediated destruction by proline hydroxylation: implications for $\mathrm{O} 2$ sensing

2. Science 292:464-468. 
19. Jaakkola, P., D. R. Mole, Y. M. Tian, M. I. Wilson, J. Gielbert, S. J. Gaskell, A. Kriegsheim, H. F. Hebestreit, M. Mukherji, C. J. Schofield, P. H. Maxwell, C. W. Pugh, and P. J. Ratcliffe. 2001. Targeting of HIF-alpha to the von Hippel-Lindau ubiquitylation complex by $\mathrm{O} 2$-regulated prolyl hydroxylation

3. Science 292:468-472.

20. Jiang, B. H., F. Agani, A. Passaniti, and G. L. Semenza. 1997. V-SRC induces expression of hypoxia-inducible factor 1 (HIF-1) and transcription of genes encoding vascular endothelial growth factor and enolase 1: involvement of HIF-1 in tumor progression 41. Cancer Res. 57:5328-5335.

21. Jiang, B. H., G. Jiang, J. Z. Zheng, Z. Lu, T. Hunter, and P. K. Vogt. 2001. Phosphatidylinositol 3-kinase signaling controls levels of hypoxia-inducible factor 1. Cell Growth Differ. 12:363-369.

22. Kalra, R., A. M. Jones, J. Kirk, G. E. Adams, and I. J. Stratford. 1993. The effect of hypoxia on acquired drug resistance and response to epidermal growth factor in Chinese hamster lung fibroblasts and human breast-cancer cells in vitro. Int.J Cancer 54:650-655.

23. Koch, S., F. Mayer, F. Honecker, M. Schittenhelm, and C. Bokemeyer. 2003. Efficacy of cytotoxic agents used in the treatment of testicular germ cell tumours under normoxic and hypoxic conditions in vitro. Br.J Cancer 89:2133-2139.

24. Koshiji, M., K. K. To, S. Hammer, K. Kumamoto, A. L. Harris, P. Modrich, and L. E. Huang. 2005. HIF-1alpha induces genetic instability by transcriptionally downregulating MutSalpha expression. Mol.Cell 17:793-803.

25. Liang, B. C. 1996. Effects of hypoxia on drug resistance phenotype and genotype in human glioma cell lines. J Neurooncol. 29:149-155.

26. Mazure, N. M., E. Y. Chen, K. R. Laderoute, and A. J. Giaccia. 1997. Induction of vascular endothelial growth factor by hypoxia is modulated by a phosphatidylinositol 3kinase/Akt signaling pathway in Ha-ras-transformed cells through a hypoxia inducible factor-1 transcriptional element 1. Blood 90:3322-3331.

27. Ohh, M., C. W. Park, M. Ivan, M. A. Hoffman, T. Y. Kim, L. E. Huang, N. Pavletich, V. Chau, and W. G. Kaelin. 2000. Ubiquitination of hypoxia-inducible factor requires direct binding to the beta-domain of the von Hippel-Lindau protein

8. Nat.Cell Biol. 2:423-427.

28. Parker, R. J., A. Eastman, F. Bostick-Bruton, and E. Reed. 1991. Acquired cisplatin resistance in human ovarian cancer cells is associated with enhanced repair of cisplatin-DNA lesions and reduced drug accumulation. J Clin Invest 87:772-777.

29. Sanna, K. and E. K. Rofstad. 1994. Hypoxia-induced resistance to doxorubicin and methotrexate in human melanoma cell lines in vitro. Int.J Cancer 58:258-262. 
30. Semenza, G. 2002. Signal transduction to hypoxia-inducible factor 1. Biochem.Pharmacol. 64:993-998.

31. Semenza, G. L. 2000. HIF-1: using two hands to flip the angiogenic switch

2. Cancer Metastasis Rev. 19:59-65.

32. Skinner, H. D., J. Z. Zheng, J. Fang, F. Agani, and B. H. Jiang. 2004. Vascular endothelial growth factor transcriptional activation is mediated by hypoxia-inducible factor 1alpha, HDM2, and p70S6K1 in response to phosphatidylinositol 3-kinase/AKT signaling 10. J.Biol.Chem. 279:45643-45651.

33. Stoeltzing, O., M. F. McCarty, J. S. Wey, F. Fan, W. Liu, A. Belcheva, C. D. Bucana, G. L. Semenza, and L. M. Ellis. 2004. Role of hypoxia-inducible factor 1alpha in gastric cancer cell growth, angiogenesis, and vessel maturation

2. J.Natl.Cancer Inst. 96:946-956.

34. Unruh, A., A. Ressel, H. G. Mohamed, R. S. Johnson, R. Nadrowitz, E. Richter, D. M. Katschinski, and R. H. Wenger. 2003. The hypoxia-inducible factor-1 alpha is a negative factor for tumor therapy. Oncogene 22:3213-3220.

35. Vaupel, P., D. K. Kelleher, and M. Hockel. 2001. Oxygen status of malignant tumors: pathogenesis of hypoxia and significance for tumor therapy. Semin.Oncol. 28:29-35.

36. Yokoi, K. and I. J. Fidler. 2004. Hypoxia increases resistance of human pancreatic cancer cells to apoptosis induced by gemcitabine. Clin Cancer Res 10:2299-2306.

37. Zagzag, D., H. Zhong, J. M. Scalzitti, E. Laughner, J. W. Simons, and G. L. Semenza. 2000. Expression of hypoxia-inducible factor 1alpha in brain tumors: association with angiogenesis, invasion, and progression

10. Cancer 88:2606-2618.

38. Zhong, H., A. M. De Marzo, E. Laughner, M. Lim, D. A. Hilton, D. Zagzag, P. Buechler, W. B. Isaacs, G. L. Semenza, and J. W. Simons. 1999. Overexpression of hypoxiainducible factor 1alpha in common human cancers and their metastases. Cancer Res. 59:58305835 . 
C
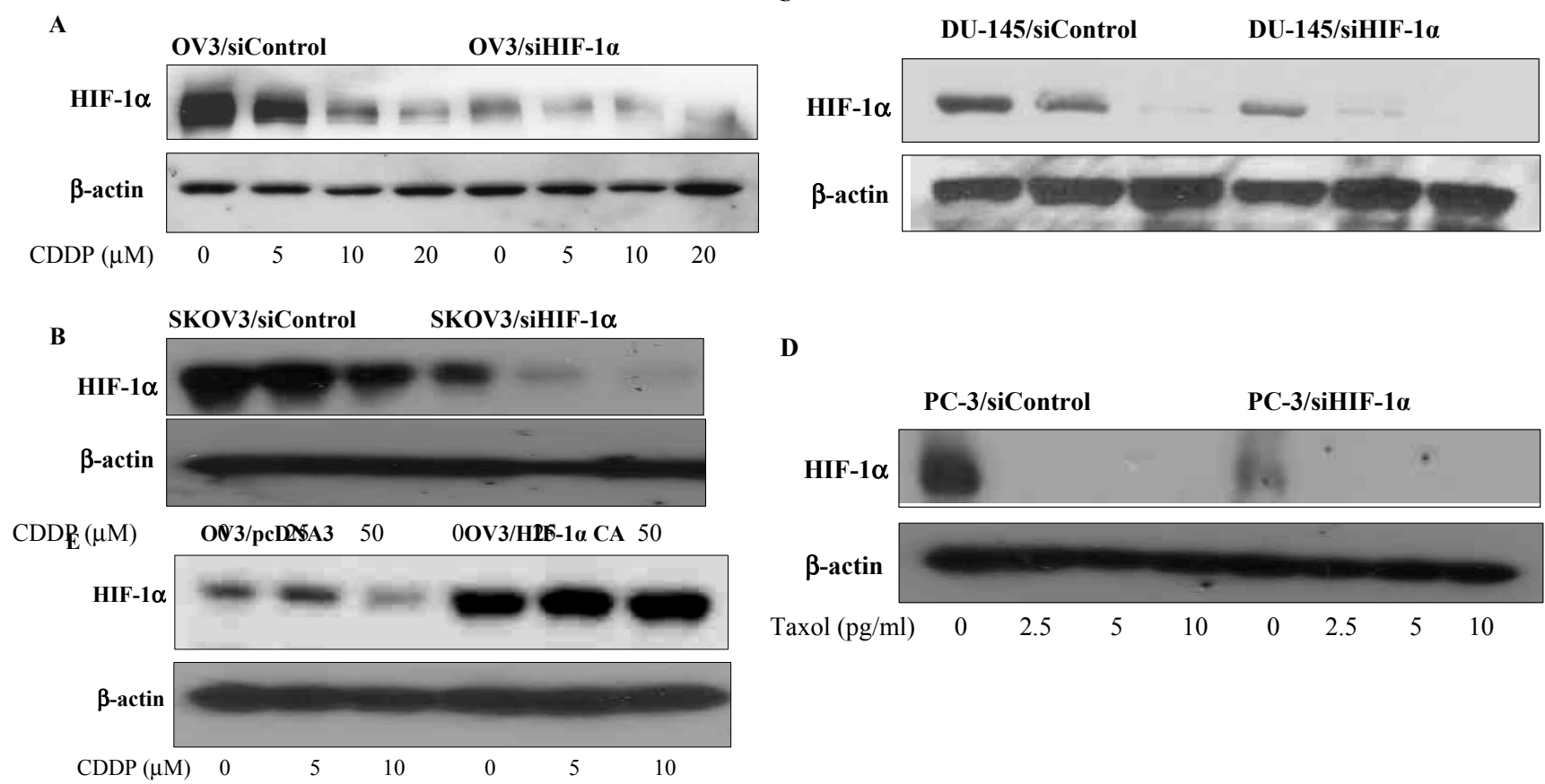

D

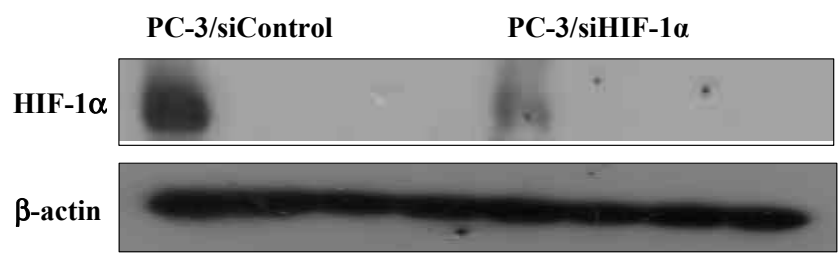

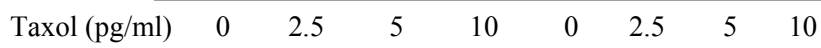

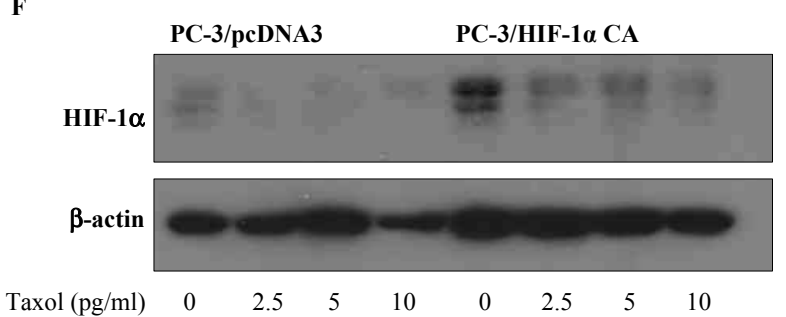

Figure 1. Treatment with common chemotherapeutic drugs decreases HIF-1 $\alpha$ expression.

A, OVCAR-3 cells stably expressing either control siRNA (siControl) or siRNA specific for HIF-1 $\alpha$ (siHIF-1 $\alpha)$ were treated with CDDP at the indicated doses for 6 h. Levels of HIF-1 $\alpha$ and $\beta$-actin expression were analyzed via immunoblotting. $\boldsymbol{B}, \mathrm{SKOV}-3$ cells stably expressing either control siControl or siHIF-1 $\alpha$ were treated with CDDP at the indicated doses for $6 \mathrm{~h}$. Levels of HIF-1 $\alpha$ and $\beta$-actin expression were analyzed via immunoblotting. $C$, DU-145 prostate cancer cells stably expressing either siControl or siHIF-1 $\alpha$ were treated with taxol at the indicated doses for $6 \mathrm{~h}$. Levels of HIF-1 $\alpha$ and $\beta$-actin expression were analyzed via immunoblotting. $D$, PC-3 prostate cancer cells expressing siControl or siHIF-1 $\alpha$.were were treated with taxol at the 
indicated doses for $6 \mathrm{~h}$. Levels of HIF-1 $\alpha$ and $\beta$-actin expression were analyzed via immunoblotting. $\boldsymbol{E}$, OVCAR-3 cells stably expressing either pcDNA3 or HIF-1 $\alpha$ CA were treated with CDDP at the indicated doses for 6 h. Levels of HIF-1 $\alpha$ and $\beta$-actin expression were analyzed via immunoblotting. F, PC-3 prostate cancer cells expressing either pcDNA3 or HIF$1 \alpha \mathrm{CA}$ were treated with taxol at the indicated doses for $6 \mathrm{~h}$. Levels of HIF- $1 \alpha$ and $\beta$-actin expression were analyzed via immunoblotting.

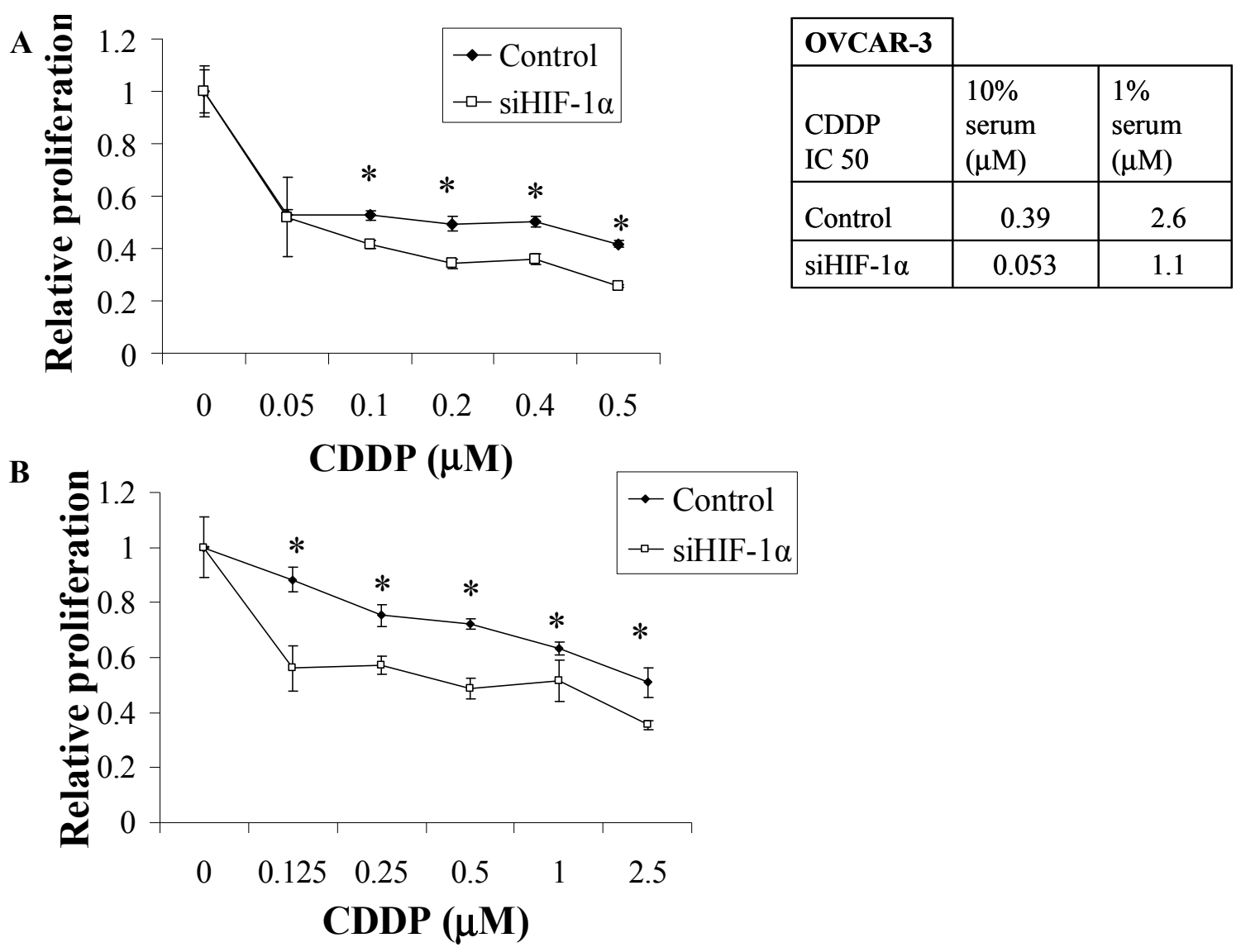




\section{C}

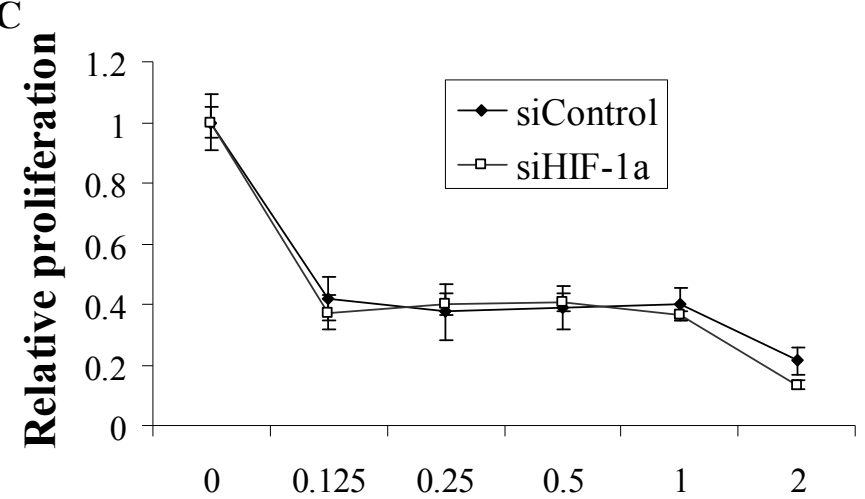

\begin{tabular}{|l|c|c|}
\cline { 1 - 1 } OVCAR-3 & \multicolumn{3}{|c|}{$\begin{array}{l}10 \% \\
\text { Taxol }\end{array}$} & $\begin{array}{l}1 \% \\
\text { IC } 50\end{array}$ & $\begin{array}{l}1 \% \\
\text { serum } \\
\text { serum } \\
(\mathrm{pg} / \mathrm{ml})\end{array}$ \\
\hline Control & 0.1 & 1.2 \\
\hline siHIF-1 $\alpha$ & 0.09 & 0.26 \\
\hline
\end{tabular}

D

Taxol (pg/ml)

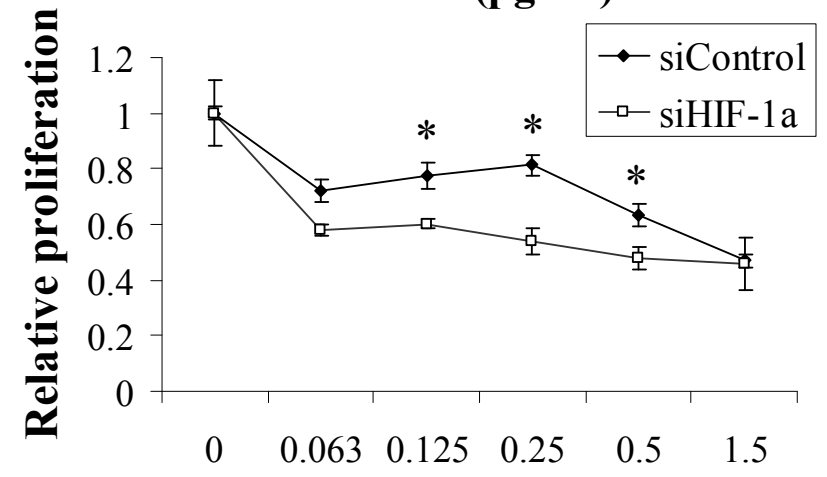

Taxol (pg/ml)

E

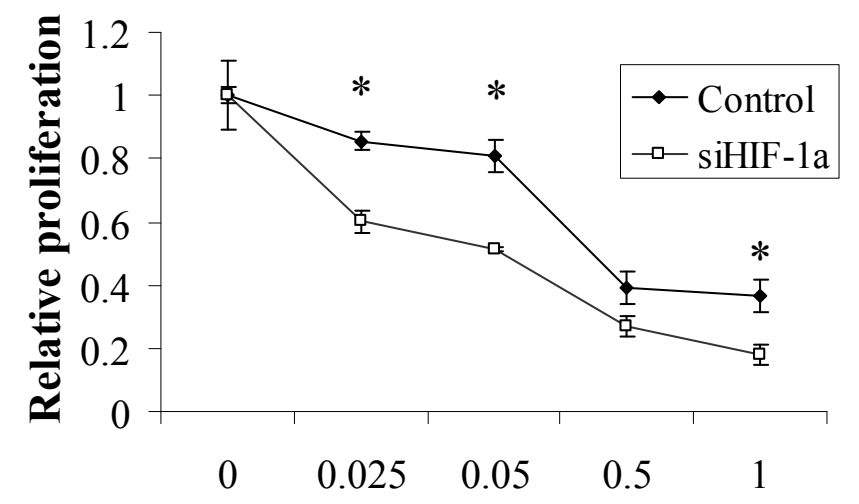

\begin{tabular}{|l|c|l|}
\cline { 1 - 1 } DU-145 & \multicolumn{3}{|l}{ Taxol } & $\begin{array}{l}10 \% \\
\text { serum } \\
\text { IC 50 }\end{array}$ & $\begin{array}{l}1 \% \\
\text { serum } \\
(\mu \mathrm{M})\end{array}$ \\
\hline Control & 0.42 & 2.05 \\
\hline siHIF-1 $\alpha$ & 0.08 & 0.9 \\
\hline
\end{tabular}

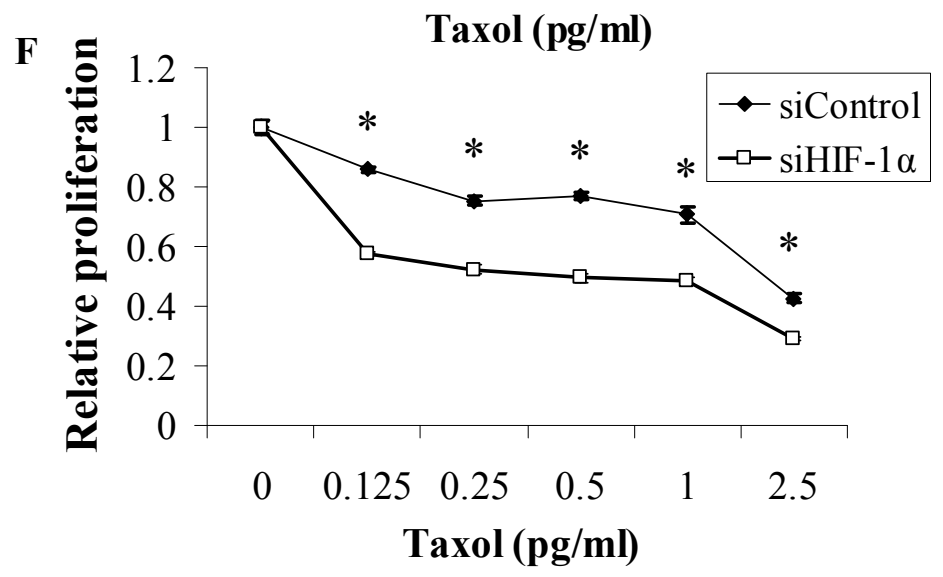



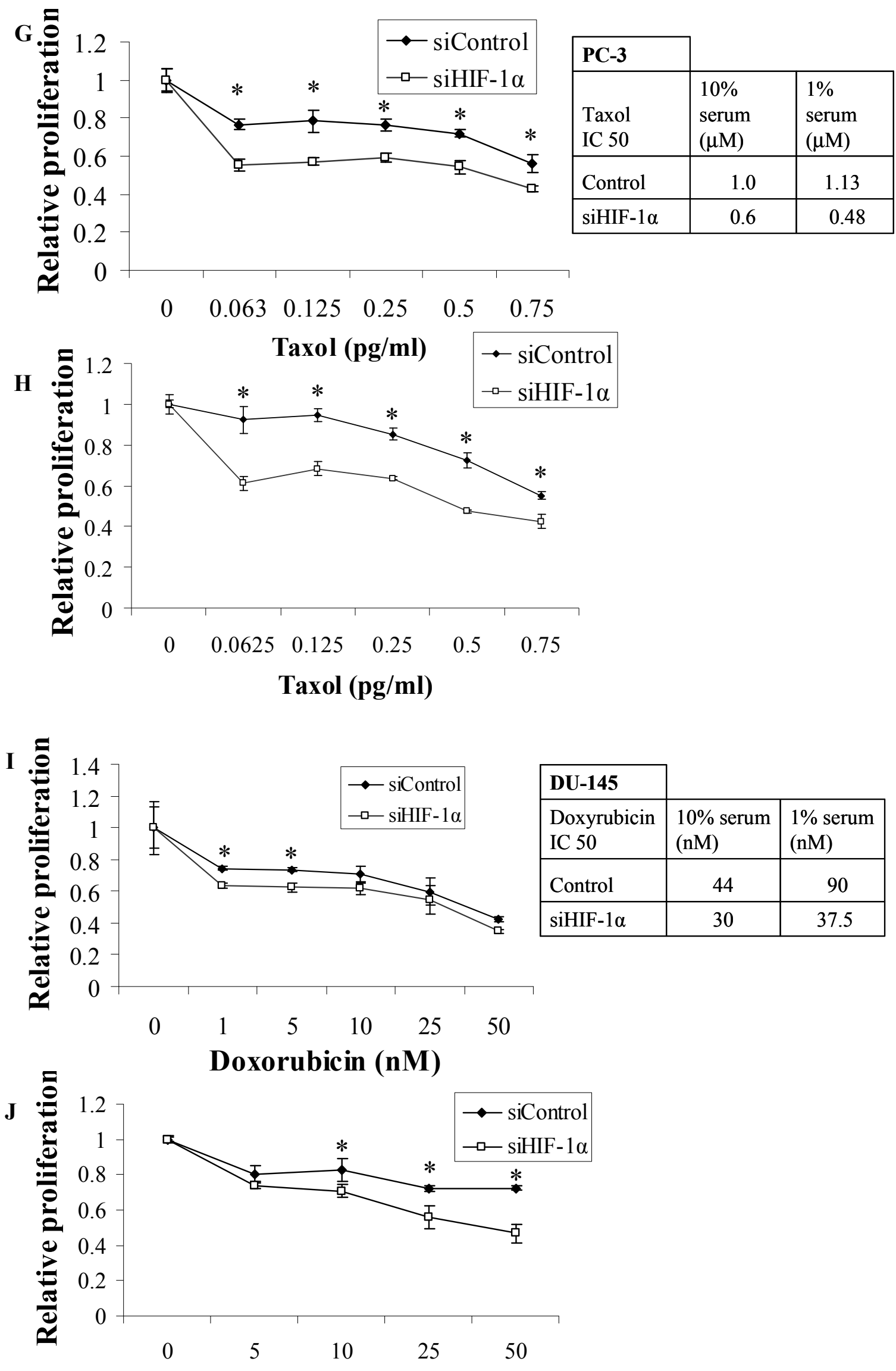

Doxorubicin (nM) 


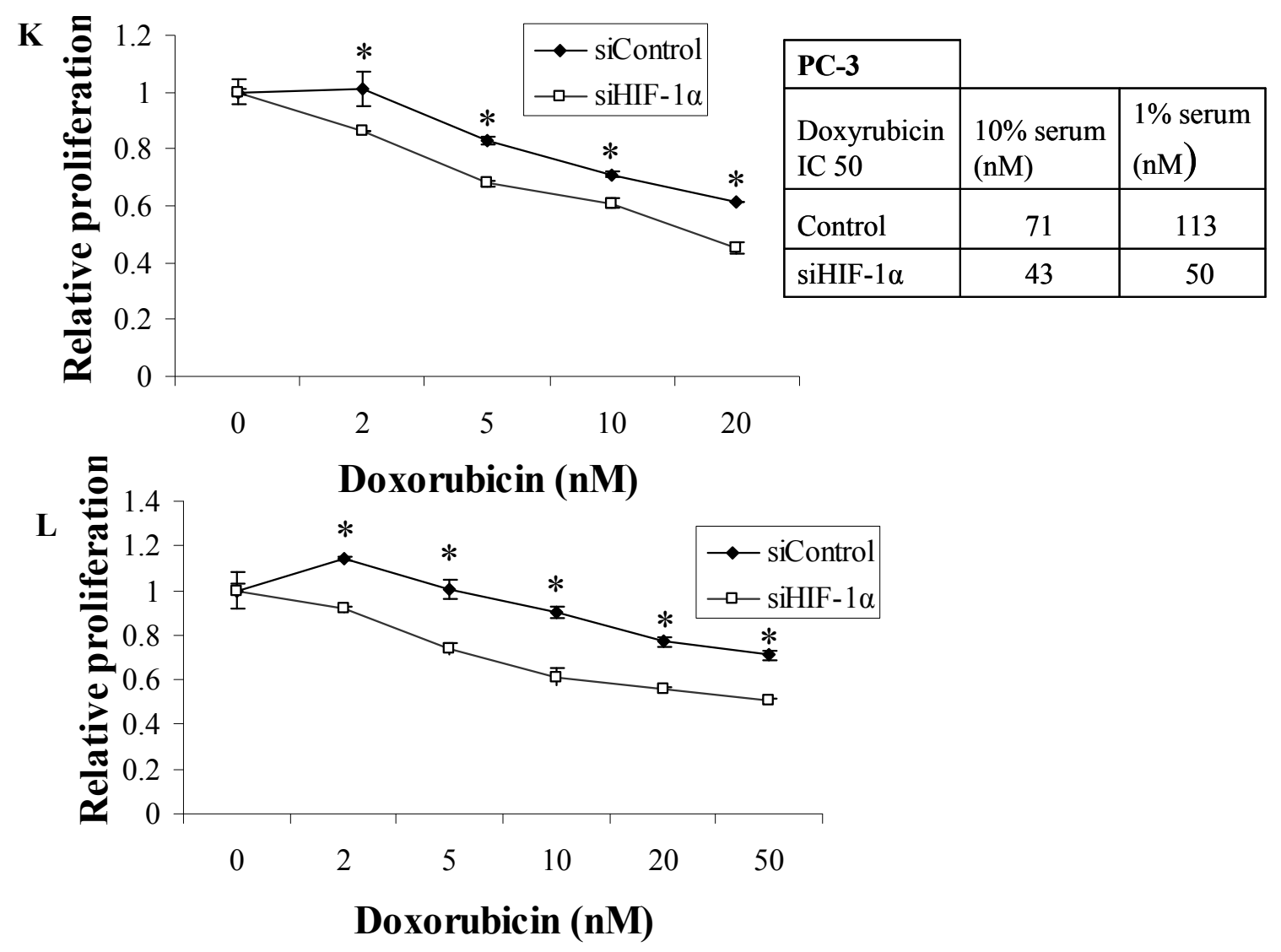

Figure 2. Stable expression of siHIF-1 $\alpha$ increased sensitivity to common chemotherapeutic agents. All cells were plated at 50,000 cells/well in a 96-well plate. The following day the cells were treated with the indicated chemotherapeutic drugs in medium containing either $10 \% 10 \%$ or 1\% serum. After 48 h, MTT (2,3-bis-(2-methoxy-4-nitro-5-sulfophenyl)-2H-tetrazolium-5carboxanilide) was added to the media, and allowed to incubate for $4 \mathrm{~h}$. The cells were then lysed and absorbance was read at 570nm. *-indicates significant difference between siControl and siHIF-1 $\alpha(\mathrm{p}<0.05)$ A and B, OVCAR-3 cells stably expressing siControl or siHIF- $1 \alpha$ were treated with the indicated doses of cisplatin (CDDP) containing either 10\% (A) or 1\% (B) serum. C and D, OVCAR-3 cells stably expressing siControl or siHIF-1 $\alpha$ were treated with the indicated doses of taxol containing either 10\% 10\% (C) or 1\% (D) serum. E and F, DU-145 cells stably expressing siControl or siHIF-1 $\alpha$ were treated with the indicated doses of taxol 
containing either $10 \%$ (E) or 1\% (F) serum. $\mathbf{G}$ and $\mathbf{H}$, PC-3 cells stably expressing siControl or siHIF-1 $\alpha$ were treated with the indicated doses of taxol containing either $10 \%(\mathrm{G})$ or $1 \%(\mathrm{H})$ serum. I and J, DU-145 cells stably expressing siControl or siHIF-1 $\alpha$ were treated with the indicated doses of doxorubicin containing either 10\% (I) or 1\% (J) serum. K and L, PC-3 cells stably expressing siControl or SiHIF-1 $\alpha$ were treated with the indicated doses of doxorubicin containing either $10 \%(\mathrm{~K})$ or $1 \%(\mathrm{~L})$ serum.
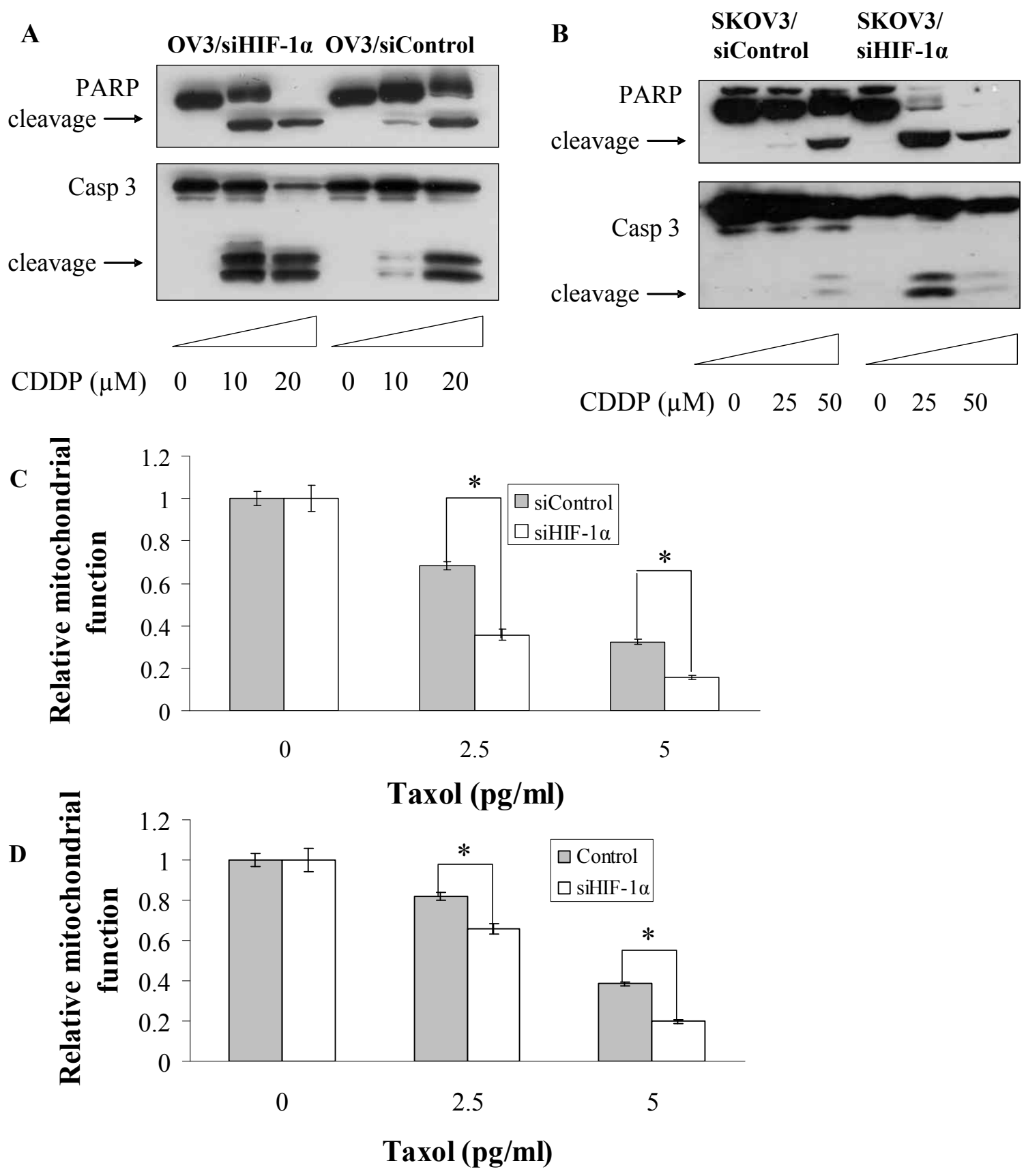
Figure 3. Stable expression of siHIF-1 $\alpha$ increases apoptosis in ovarian and prostate cancer cells treated with common chemotherapeutic drugs. A, OVCAR-3 cells stably expressing siControl or siHIF-1 $\alpha$ were treated with the indicated doses of cisplatin (CDDP) in serum free medium. After $24 \mathrm{~h}$, the cells were collected and levels of caspase 3 and PARP cleavage were assayed via immunoblotting. B, SKOV-3 cells stably expressing siControl or siHIF-1 $\alpha$ were treated with the indicated doses of cisplatin (CDDP) in serum free medium. After $24 \mathrm{~h}$, the cells were collected and levels of caspase 3 and PARP cleavage were assayed via immunoblotting. C, DU-145 cells stably expressing siControl or siHIF-1 $\alpha$ were treated with the indicated doses of taxol in serum free medium. After 24h Mito- Tracker Deep Red dye was added to the medium, and allowed to incubate for $30 \mathrm{~min}$. The cells were then fixed with ethanol and florescence was measured via flow cytometry. Fluorescence was proportional to cell viability as measured by mitochondrial functioning and was normalized to that of control. *-indicates significant difference between siControl and siHIF-1 $\alpha(\mathrm{p}<0.05)$. D, PC-3 cells stably expressing siControl or siHIF-1 $\alpha$ were treated with the indicated doses of taxol in serum free medium. After $24 \mathrm{~h}$ mitochondrial dye was added to the media and allowed to incubate for $30 \mathrm{~min}$. The cells were then processed and analyzed as above. Fluorescence was proportional to cell viability as measured by mitochondrial functioning and was normalized to that of control. *-indicates significant difference between siControl and siHIF-1 $\alpha(\mathrm{p}<0.05)$. 

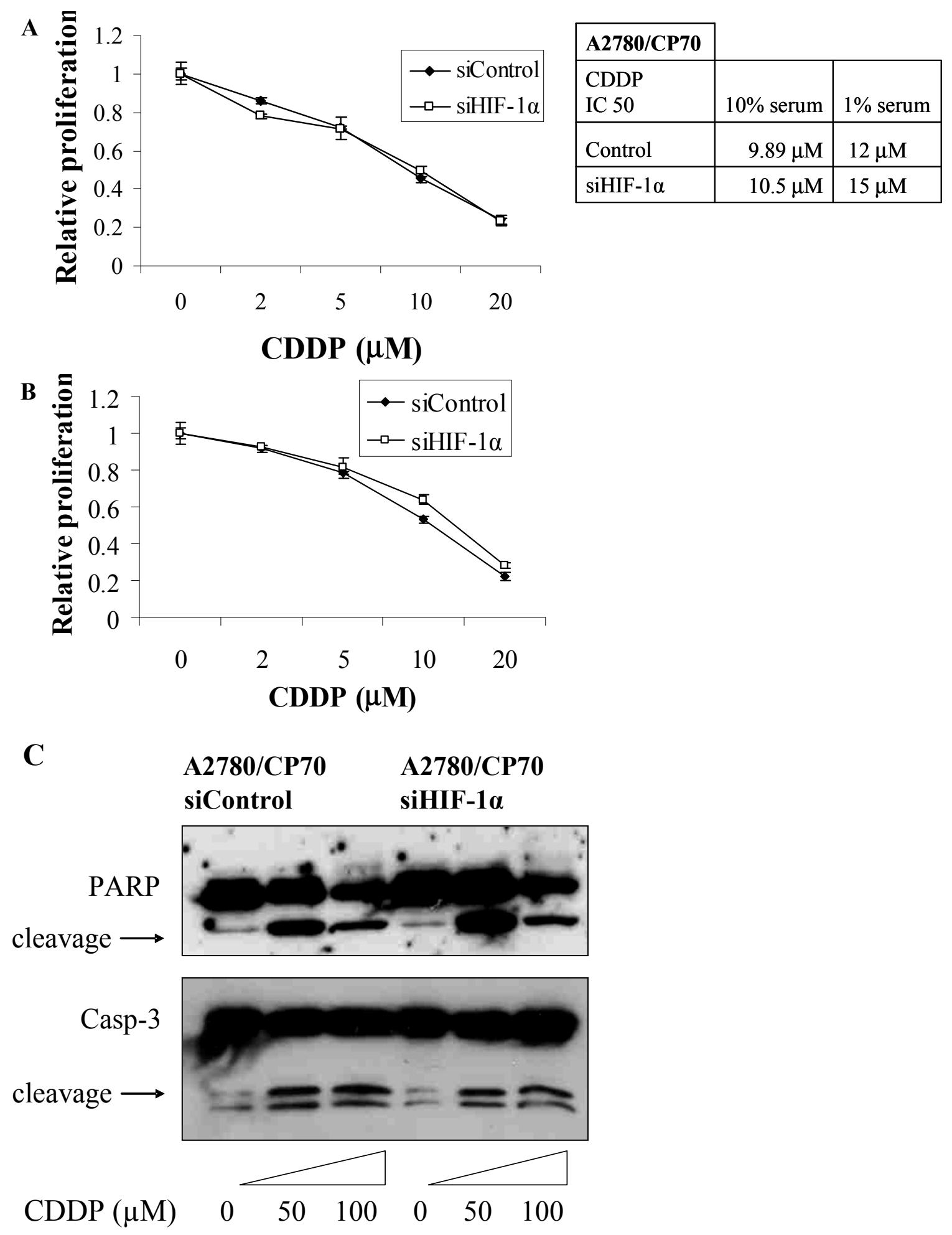


$$
\text { D }
$$

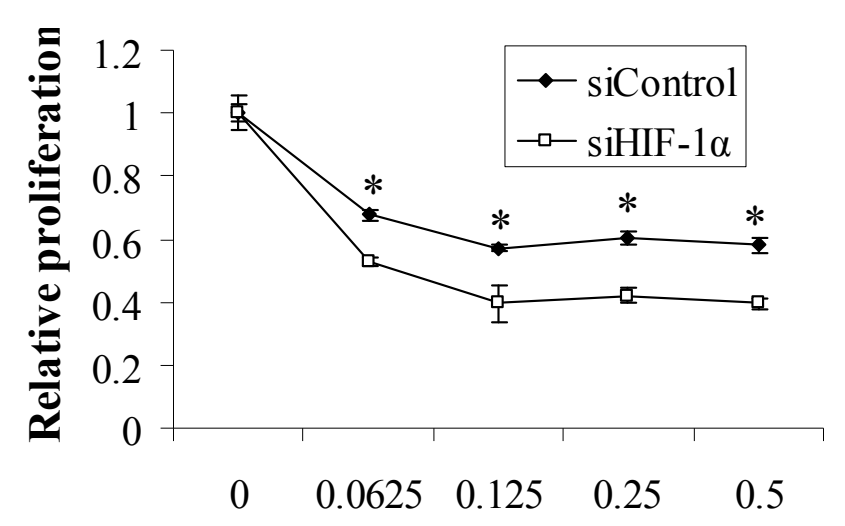

\begin{tabular}{|l|r|l|}
\hline A2780/CP70 & \multicolumn{2}{|l|}{} \\
\cline { 1 - 1 } $\begin{array}{l}\text { Taxol } \\
\text { IC } 50\end{array}$ & $10 \%$ serum & $1 \%$ serum \\
\hline Control & $1.1 \mu \mathrm{M}$ & $1.2 \mu \mathrm{M}$ \\
\hline siHIF-1 $\alpha$ & $0.1 \mu \mathrm{M}$ & $0.032 \mu \mathrm{M}$ \\
\hline
\end{tabular}

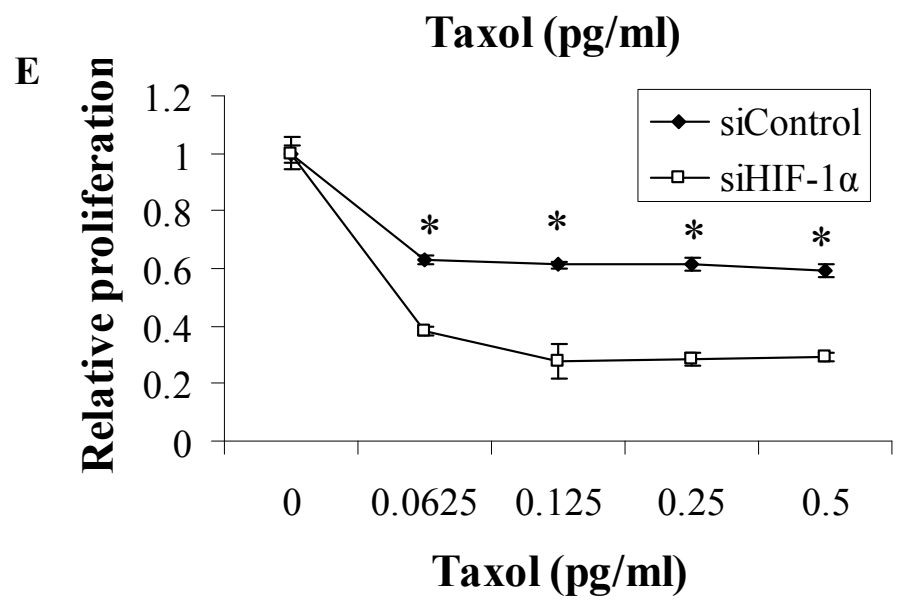

Figure 4. Stable expression of siHIF-1 $\alpha$ does not increase sensitivity to CDDP in cells selected for resistance to CDDP, but does increase their sensitivity to taxol. *-indicates significant difference between siControl and siHIF-1 $\alpha(\mathrm{p}<0.05)$. A and B, A2780/CP70 cells stably expressing siControl or siHIF-1 $\alpha$ were treated with the indicated doses of cisplatin (CDDP) containing either $10 \%$ (A) or 1\% (B) serum. C, A2780/CP70 cells stably expressing either siControl or siHIF-1 $\alpha$ were treated with the indicated doses of CDDP for 24h. The cells were collected and levels of caspase 3 and PARP cleavage were assayed via immunoblotting. D and E, A2780/CP70 cells stably expressing siControl or siHIF-1 $\alpha$ were treated with the indicated doses of taxol containing either $10 \%$ (B) or $1 \%$ (C) serum. Chemosensitivity was assayed by performing an MTT assay as decribed previously. 

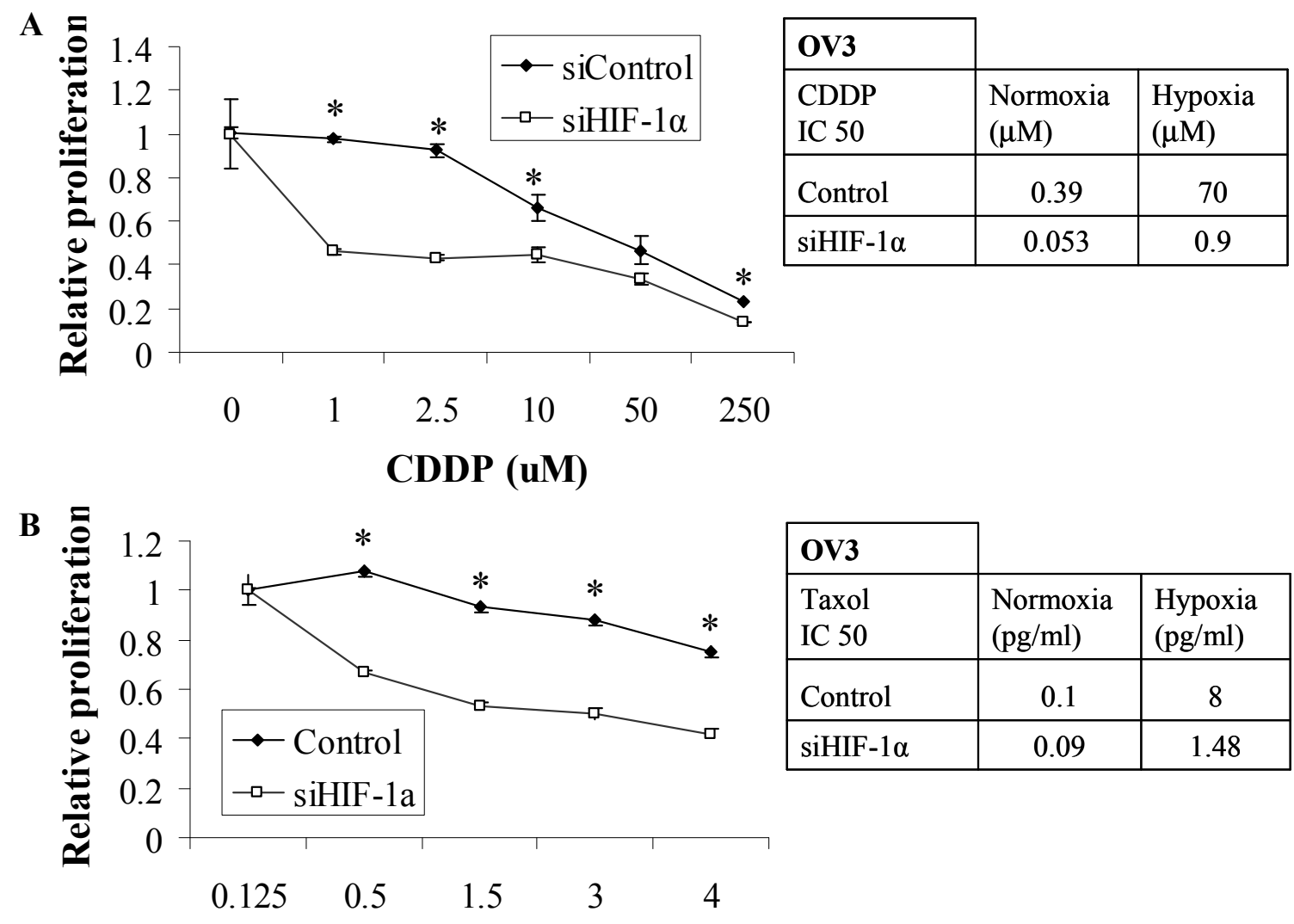

Taxol (pg/ml)

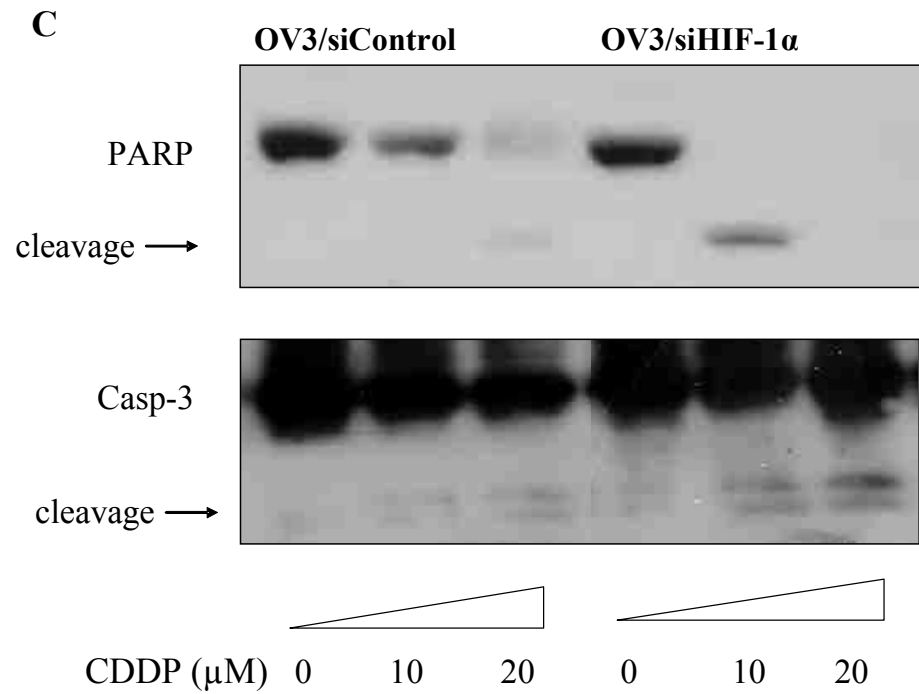




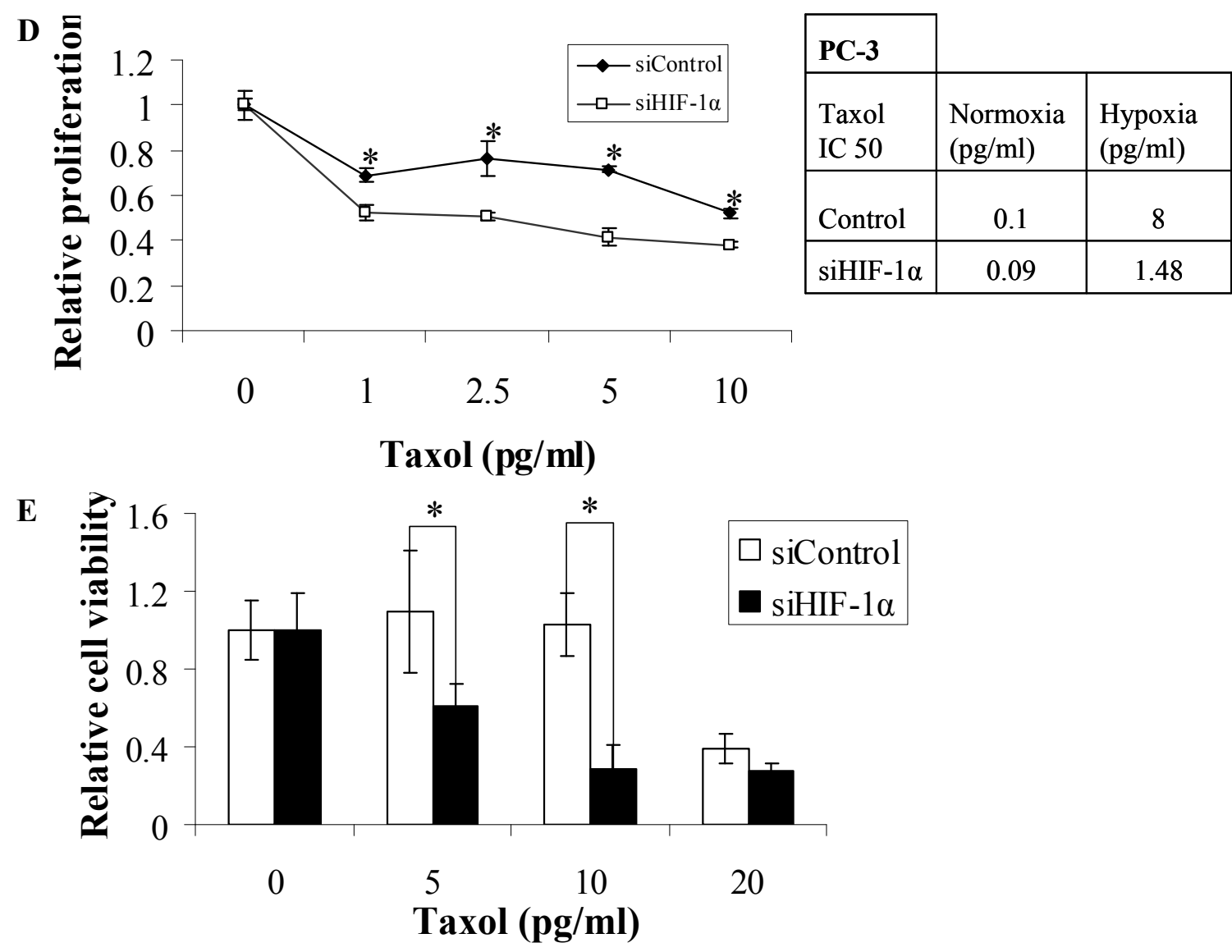

Figure 5. Stable expression of siHIF-1 $\alpha$ increased chemosensitivity in hypoxia due to the induction of apoptosis. For MTT assays, cells were plated at 50,000 cells/well in a 96-well plate. The following day the cells were treated with the indicated chemotherapeutic drugs. The cells were then cultured in a 1\% oxygen environment for $48 \mathrm{~h}$. Afterward MTT (2,3-bis-(2-methoxy4-nitro-5-sulfophenyl)-2H-tetrazolium-5-carboxanilide) was added to the medium and allowed to incubate for $4 \mathrm{~h}$. The cells were then lysed and absorbance was read at $570 \mathrm{~nm} . *$-indicates significant difference between siControl and siHIF-1 $\alpha(\mathrm{p}<0.05)$. A, OVCAR-3 cells stably expressing siControl or siHIF-1 $\alpha$ were treated with the indicated doses of CDDP (cisplatin) then cultured in hypoxia for $48 \mathrm{~h}$. B, OVCAR-3 cells stably expressing siControl or siHIF-1 $\alpha$ were 
treated with the indicated doses of taxol then cultured in hypoxia for $48 \mathrm{~h}$. C, OVCAR-3 cells were treated with the indicated doses of CDDP, then cultured in hypoxia for $24 \mathrm{~h}$. The cells were then collected and levels of caspase 3 and PARP cleavage were assayed via immunoblotting. D, PC-3 cells stably expressing siControl or siHIF-1 $\alpha$ were treated with the indicated doses of taxol, and then cultured in hypoxia for 48 h. E, PC-3 cells were treated with the indicated doses of taxol, and then cultured in hypoxia for $24 \mathrm{~h}$. Mito Tracker dye was then added to the media, and allowed to incubate for $30 \mathrm{~min}$. The cells were then fixed with ethanol and florescence was analyzed via flow cytometry. Florescence was proportional to cell viability and was normalized to that of control.

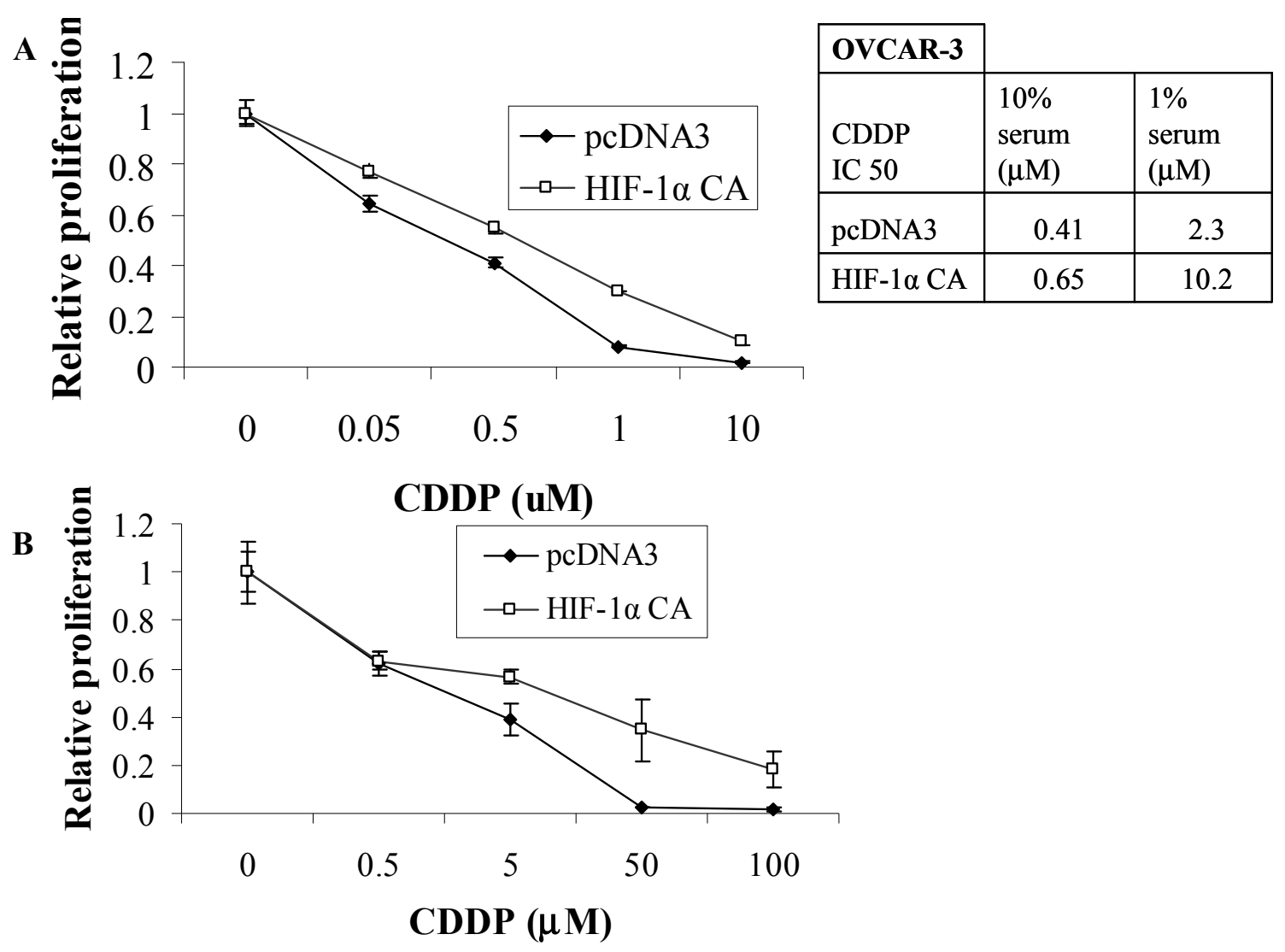



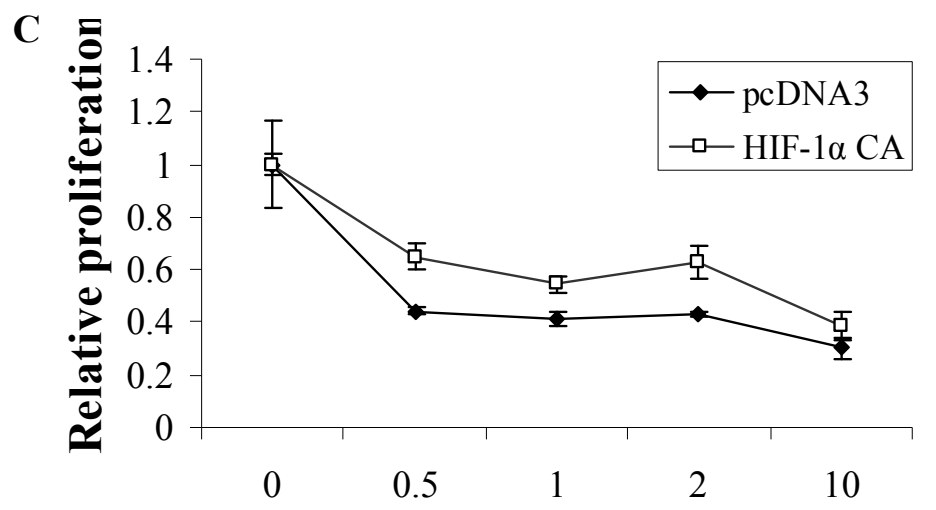

\begin{tabular}{|l|c|c|}
\cline { 1 - 2 } OVCAR-3 & \multicolumn{3}{|l}{} \\
\cline { 1 - 2 } Taxol & $\begin{array}{l}10 \% \\
\text { serum } \\
\text { IC 50 }\end{array}$ & $\begin{array}{l}1 \% \\
\text { serum } \\
(\mathrm{pg} / \mathrm{ml})\end{array}$ \\
\hline pcDNA3 & 0.21 & 1.2 \\
\hline HIF-1 $\alpha$ CA & 1.2 & 2.7 \\
\hline
\end{tabular}

D

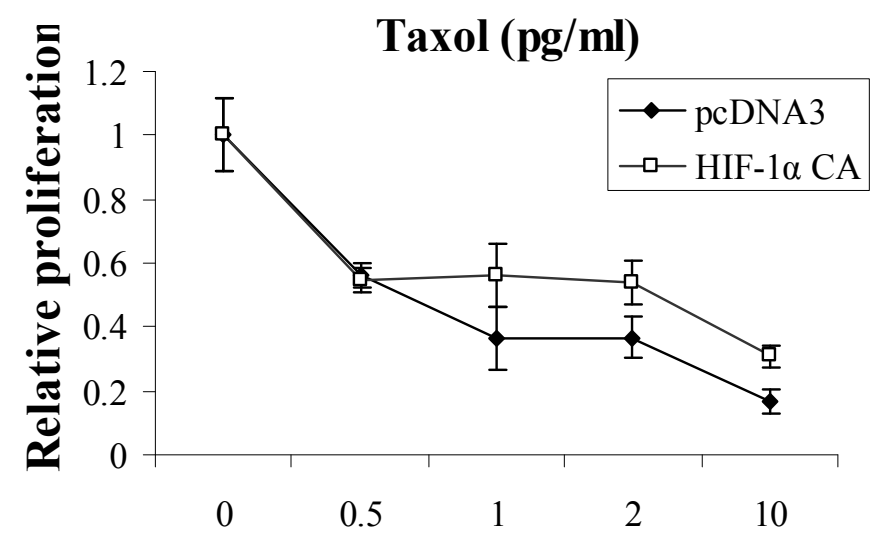

E

Taxol (pg/ml)
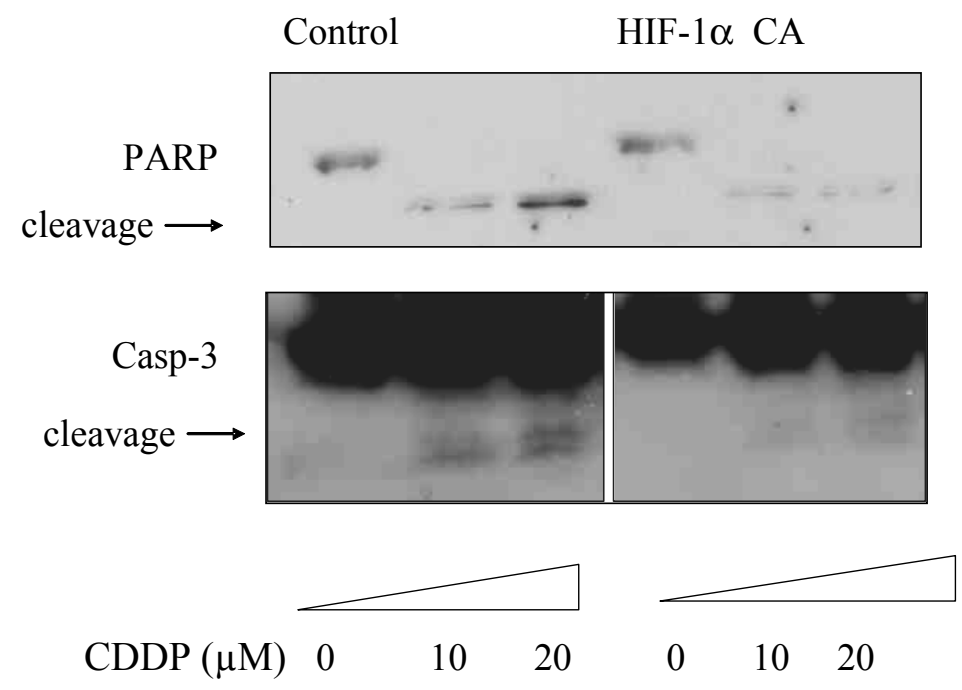


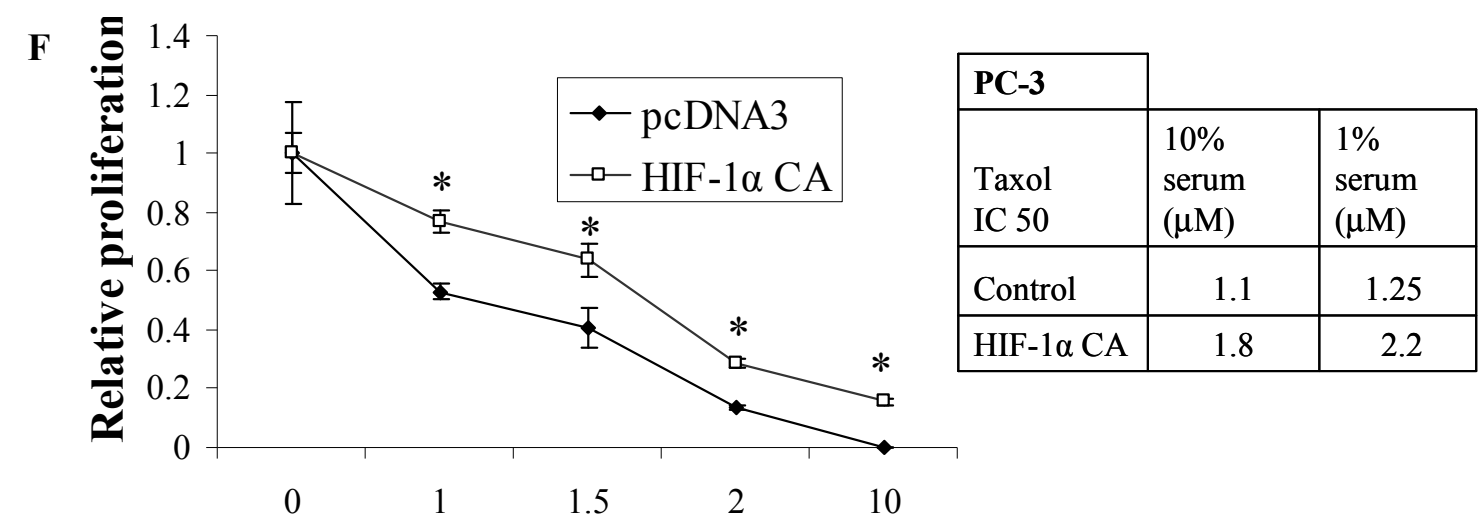

G

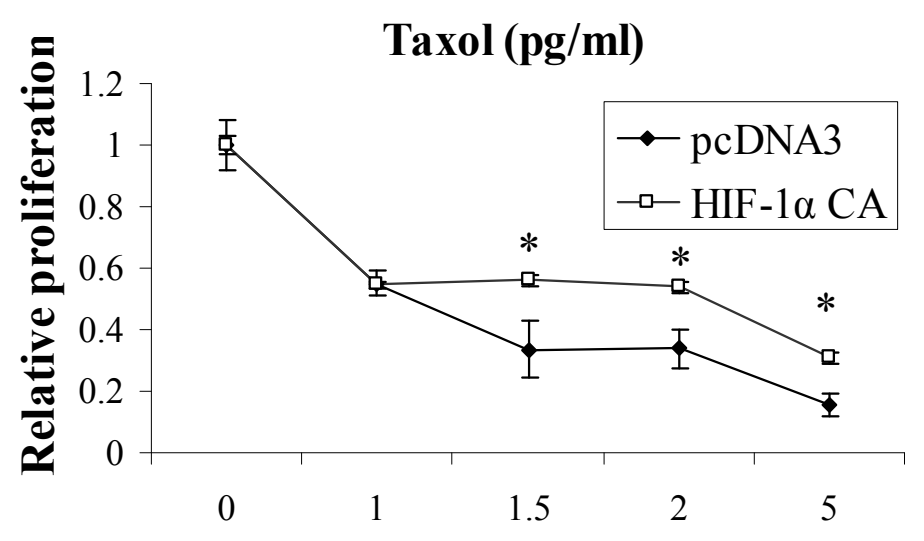

Taxol (pg/ml)
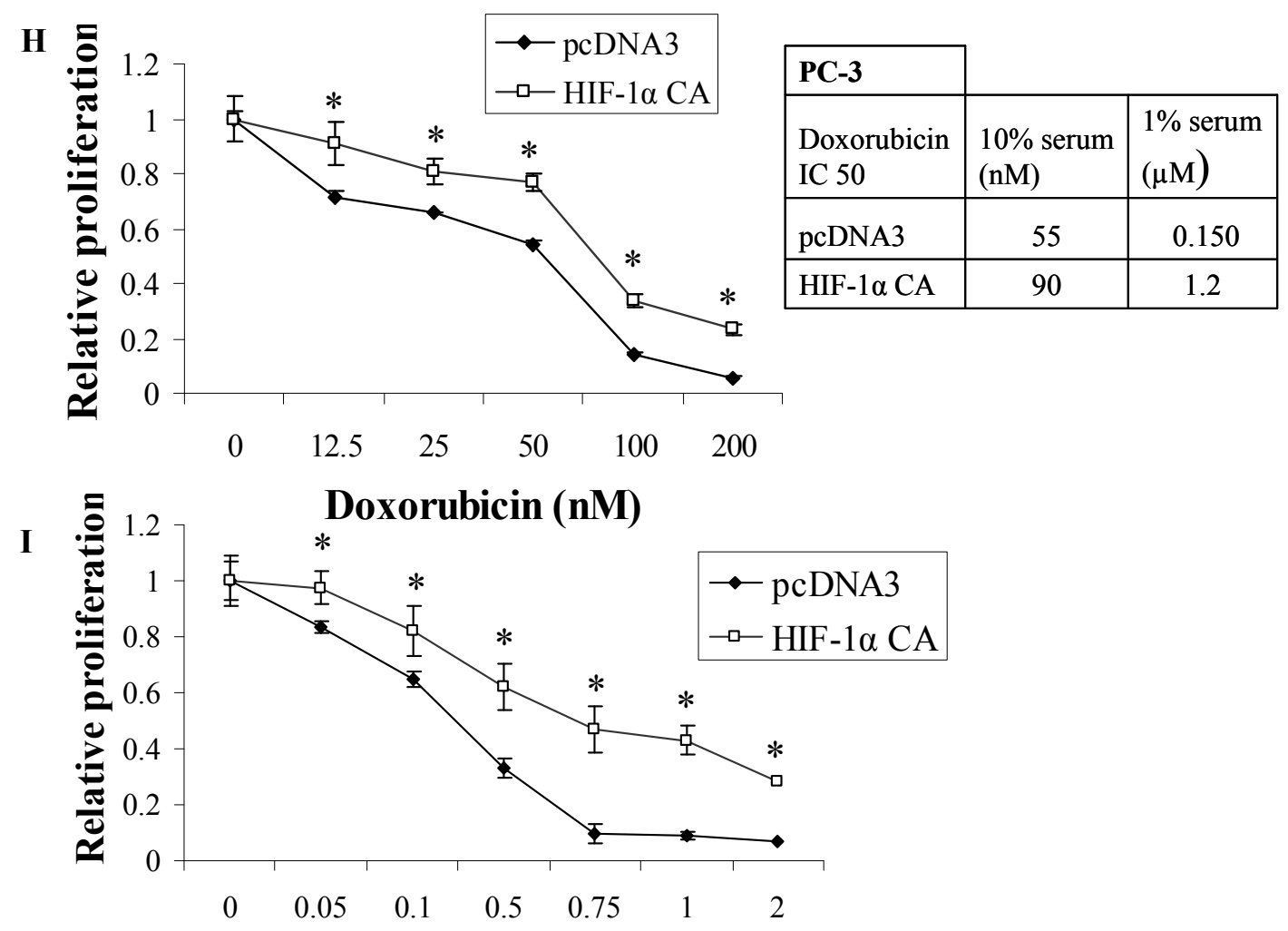

\section{Doxorubicin $(\mu \mathrm{M})$}




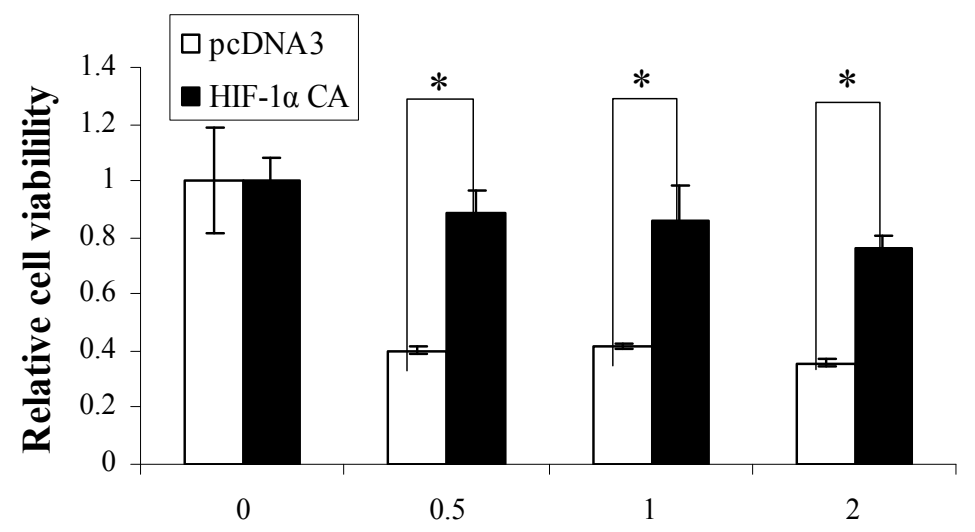

Taxol (pg/ml)

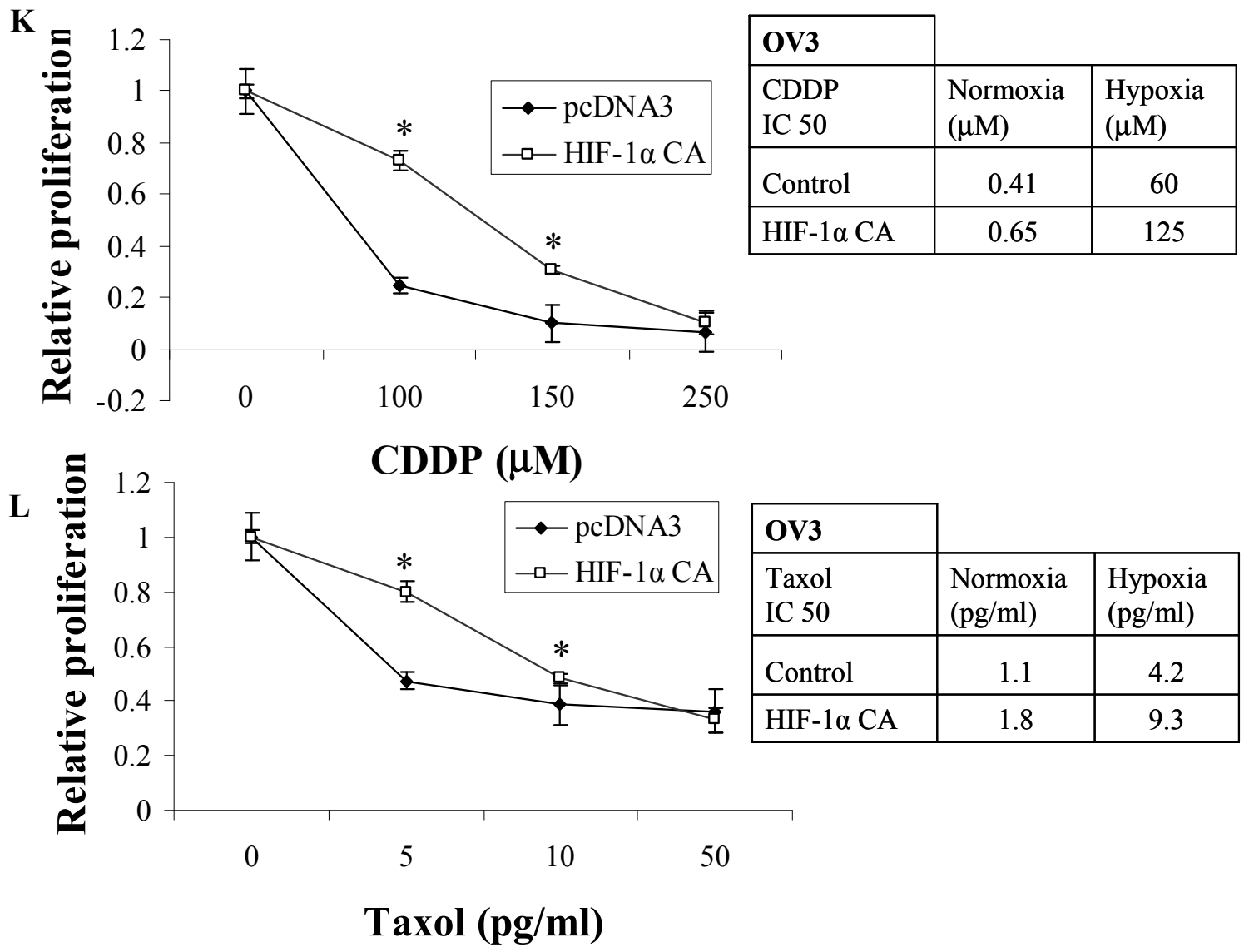




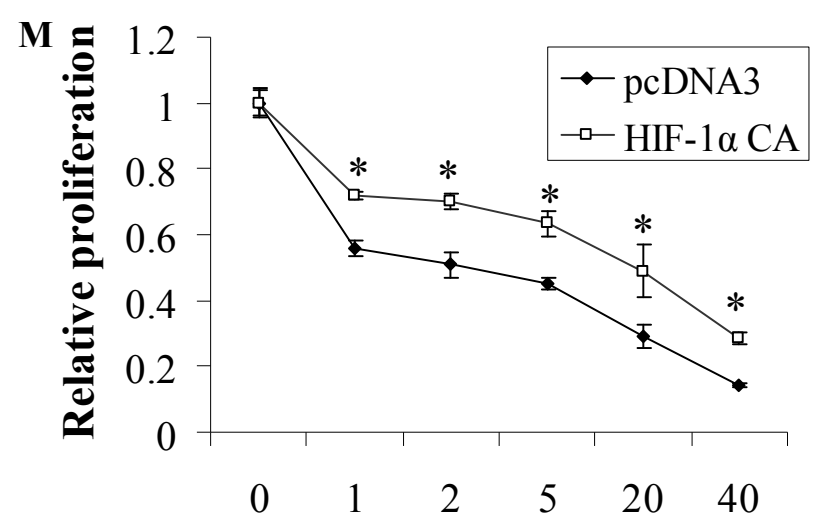

\begin{tabular}{|l|c|c|}
\hline PC-3 & \multicolumn{2}{|l}{} \\
\cline { 1 - 2 } $\begin{array}{l}\text { Taxol } \\
\text { IC 50 }\end{array}$ & $\begin{array}{l}\text { Normoxia } \\
(\mathrm{pg} / \mathrm{ml})\end{array}$ & $\begin{array}{l}\text { Hypoxia } \\
(\mathrm{pg} / \mathrm{ml})\end{array}$ \\
\hline Control & 1.1 & 3 \\
\hline HIF-1 $\alpha$ CA & 1.8 & 21 \\
\hline
\end{tabular}

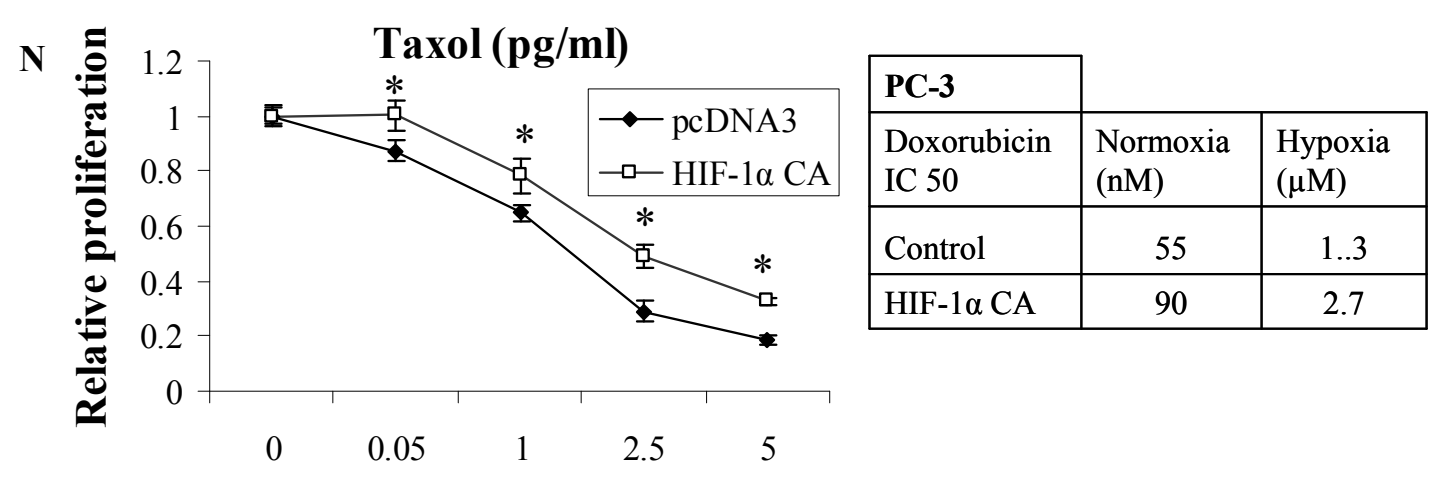

Doxorubicin $(\mu \mathrm{M})$

Figure 6. Over-expression of HIF-1 $\alpha$ partially reverses the effect of chemotherapy on cancer cells. MTT assays were performed as described previously. *-indicates significant difference between siControl and siHIF-1 $\alpha(\mathrm{p}<0.05)$. A and $\boldsymbol{B}$, OVCAR-3 cells stably expressing either pcDNA3 or HIF-1 $\alpha$ CA were treated with CDDP at the indicated doses for $48 \mathrm{~h}$ containing either $10 \%$ (A) and 1\% (B) serum containing media. $C$ and $D$, OVCAR-3 cells stably expressing either pcDNA3 of HIF-1 $\alpha$ CA were treated with taxol at the indicated doses for $48 \mathrm{~h}$ containing either $10 \%(\mathrm{C})$ and $1 \%$ (D) serum containing media. $\boldsymbol{E}$, OVCAR-3 cells stably expressing either pcDNA3 of HIF-1 $\alpha$ CA were treated with CDDP at the indicated doses. Levels of caspase-3 and PARP cleavage were visualized via immunoblotting. F and G, PC-3 cells stably expressing either pcDNA3 or HIF-1 $\alpha$ CA were treated with taxol at the indicated doses for $48 \mathrm{~h}$ containing 
either 10\% (F) and 1\% (G) serum containing media. $\mathbf{H}$ and I, PC-3 cells stably expressing either pcDNA3 or HIF-1 $\alpha$ CA were treated with doxorubicin at the indicated doses for $48 \mathrm{~h}$ containing either $10 \%(\mathrm{H})$ and $1 \%(\mathrm{I})$ serum containing media. $\mathbf{J}$, PC-3 cells stably expressing either pcDNA3 or HIF-1 $\alpha$ CA were treated with taxol for $24 \mathrm{~h}$. Mito Tracker dye was then added to the media and allowed to incubate for $30 \mathrm{~min}$. The cells were then ethanol fixed and florescence was analyzed via flow cytometry. Florescence was proportional to cell viability and normalized to control. $K$ and $L$, OVCAR-3 cells stably expressing either pcDNA3 of HIF-1 $\alpha$ CA were cultured in hypoxia and treated with either CDDP (K) or taxol (L) at the indicated doses for $48 \mathrm{~h}$. $M$ and N, PC-3 cells stably expressing either pcDNA3 of HIF-1 $\alpha$ CA were cultured in hypoxia and treated with either taxol (K) or doxorubicin (L) at the indicated doses for $48 \mathrm{~h}$. 


\title{
CHAPTER 5: HIF-1 $\alpha$ REGULATES BASAL AND HYPOXIA-INDUCED COX-2 EXPRESSION IN CANCER.
}

\author{
Heath D. Skinner ${ }^{1}$, Lesly Anne Lopez ${ }^{1}$, and Bing-Hua Jiang ${ }^{1 \#}$ \\ ${ }^{1}$ Mary Babb Randolph Cancer Center, Department of Microbiology, Immunology and Cell \\ Biology, West Virginia University, Morgantown, WV 26506-9300, USA.
}

Running title: HIF-1 $\alpha$ and COX-2 in cancer.

\# To whom correspondence should be addressed: Mary Babb Randolph Cancer Center, Department of Microbiology, Immunology and Cell Biology, West Virginia University, Morgantown, West Virginia 26506. Tel: 304-293-5949; Fax: 304-293-4667; E-mail: bhjiang@hsc.wvu.edu.

Key Words: cancer, hypoxia, hypoxia-inducible factor 1 (HIF-1), cyclooxygenase 2 (COX-2), Phosphatidylionsitol 3-kinase (PI3K)

\footnotetext{
* This work was supported by National Institutes of Health Grant RR16440 and by American Cancer Society Research Scholar Grant 04-076-01-TBE.
} 


\begin{abstract}
Hypoxia inducible factor-1 (HIF-1) is a heterodimeric basic-helix loop helix transcription factor composed of two subunits, HIF-1 $\alpha$ and HIF-1 $\beta$. HIF-1 $\alpha$, the regulatory subunit, is overexpressed in many human cancers and plays an important role in angiogenesis and tumorigenesis. Cyclooxygenase-2 (COX-2), an enzyme that converts arachadonic acid to prostanoids such as $\mathrm{PGE}_{2}$, is also activated in many types of cancer and is involved in angiogenesis. Previously it has been shown that HIF-1 $\alpha$ and COX-2 expression are correlated in tumors and that both are regulated by hypoxia. In this study we show that HIF-1 $\alpha$ expression regulates basal and hypoxia-induced $\mathrm{PGE}_{2}$ production and COX-2 expression in cancer cells. We also found that HIF- $1 \alpha$ regulates COX-2 expression at the transcriptional level via binding to an HRE located within the COX-2 promoter. Furthermore, we show that HIF-1-dependent COX-2 expression is regulated by phosphatidylinositol-3 kinase (PI3K) signaling, while PMA stimulates COX-2 expression in a HIF-1-independent manner through JNK and AP-1. These data indicate the existence of a possible pro-angiogenic positive feedback loop between HIF-1 $\alpha$, COX-2 and $\mathrm{PGE}_{2}$ activated by hypoxia in human cancer.
\end{abstract}




\section{INTRODUCTION}

Hypoxia is common in a variety of human tumors and has been shown to induce the production of several pro-angiogenic factors such as VEGF via the induction of hypoxia inducible factor-1 (HIF-1) (46). HIF-1 is a basic helix-loop-helix transcription factor composed of two subunits, HIF- $1 \alpha$ and HIF- $1 \beta$. While HIF- $1 \beta$ is constitutively expressed in cells, HIF- $1 \alpha$ expression can be upregulated by hypoxia, as well as other stimuli including growth factors and oncogenes (44). HIF-1 $\alpha$ protein expression is primarily regulated at the post-transcriptional level via several prolyl hydroxylase enzymes (PHD 1-4). Under normoxic conditions, PHDs hydroxylate highly conserved proline residues ( $\operatorname{Pro}^{402}$ and $\mathrm{Pro}^{564}$ ) within a region of HIF-1 $\alpha$ dubbed the oxygen dependent degradation domain (ODD) $(19,20,38)$. This hydroxylation allows binding to HIF-1 $\alpha$ by von Hippel Lindau protein (pVHL), leading to the ubquitinylation and subsequent degredation of HIF- $1 \alpha$ by the proteosome $(5,20,38)$. In the case of hypoxia, PHDs can not hydroxylate HIF-1 $\alpha$, which prevents its degradation. A variety of growth factors such as IGF-1 and EGF have also been shown to stimulate HIF-1 $\alpha$ expression via increased levels of its protein translation $(1,12,52)$, however the exact mechanism by which these and other growth factors regulate HIF- $1 \alpha$ remains unclear.

Previously, we and others have shown that one of the primary regulators of HIF-1 $\alpha$ expression in response to growth factors is the phosphatidylinositol-3 kinase (PI3K) signaling pathway $(13,18,21,36,47,48,52,58)$. Growth factor stimulation of HIF-1 $\alpha$ expression is abrogated by inhibition of PI3K $(21,47,48,52)$. Conversely, constitutive activation of PI3K, observed in several types of cancer including cancer of the ovary and prostate, leads to increased basal expression of HIF-1 $\alpha(21,47,57,58)$. Furthermore, several groups have found that PI3K 
signaling is linked to the stabilization of HIF-1 $\alpha$ in hypoxia $(18,36)$, however others have found contrary results $(14,33,34)$.

Another potent stimuli for angiogenesis in the tumor is the cyclooxygenase $2(\mathrm{COX}-2)$. COX-2 is an inducible, dual function enzyme that regulates the conversion of arachadonic acid precursors in the cell membrane to prostaglandins. Several products of COX-2, such as prostaglandin $\mathrm{E}_{2}\left(\mathrm{PGE}_{2}\right)$, thromboxane and prostacyclin, have been shown to promote angiogenesis (15). Conversely, NSAIDs as well as selective inhibitors of COX-2 inhibit endothelial cell tube formation (32-34) and angiogenesis in vivo (42). COX-2 expression is upregulated in a wide variety of cancers including colon, prostate and ovarian cancer. Furthermore, several specific COX-2 inhibitors are being investigated clinically as possible antitumor agents (15).

COX-2 and HIF- $1 \alpha$ expression are regulated by similar stimuli and control similar processes within the cell. Both are upregulated by hypoxia $(14,45)$ as well as by chemical mimics of hypoxia, such as $\mathrm{CoCl}_{2}$ and desferroxamine $(22,31,51,56)$. COX-2 and HIF-1 $\alpha$ are induce the production of VEGF and are potent stimulators of angiogenesis $(15,46)$. Expression of either COX-2 or HIF-1 $\alpha$ enhances cell migration $(6,28,53)$ and both are correlated with tumor invasion and metastasis $(26,29,37,59)$. Previously it has been thought that COX-2 can regulate HIF-1 $\alpha$ expression in a linear fashion. NSAIDs decrease HIF-1 $\alpha$ expression, although this effect has been found to be at least partially COX-2 independent $(2,23,39)$. Furthermore, overexpression of COX-2 or treatment with PGE2 leads to elevated VEGF levels via increased expression of HIF-1 $\alpha(17,30)$. However, the COX-2 promoter has been shown to contain several hypoxia response elements (2), one of which we predicted to be functional in vivo using computer software. Because of this, as well as the previously observed correlation between HIF- 
$1 \alpha$ and COX-2, we wanted to determine if HIF-1 $\alpha$ could regulate COX-2 expression in human cancer. Furthermore, because of our predicted functional HRE within the COX-2 promoter (HRE (-576/-584)), we wanted to determine if HIF-1 acted through this HRE to regulate COX-2 transcription.

\section{MATERIALS AND METHODS}

Reagents and Cell Culture-OVCAR-3 and A2780 ovarian cancer cells and PC-3 prostate cancer cells were cultured in RPMI 1640 media supplemented with 10\% FBS (Intergen, Purchase, NY), 0.2 units $/ \mathrm{ml}$ penicillin, and $50 \mu \mathrm{g} / \mathrm{ml}$ streptomycin (Invitrogen, Carlsbad, CA). Cells were cultured at $37^{\circ} \mathrm{C}$ in a $5 \% \mathrm{CO}^{2}$ incubator and trypsin $(0.25 \%)$ was used to detach adherent cells for subculture. LY294002 (Calbiochem, San Diego, CA), SP600125 (Calbiochem, San Diego, CA), and SB202190 (Calbiochem, San Diego, CA) were dissolved in DMSO. Pyrrolidinedithiocarbamate (PDTC) (Sigma, St. Louis, MI) was dissolved in 1xPBS. For culture in hypoxia, cells were incubated in a hypoxic chamber (Billups-Rothenberg, Del Mar, CA) with an atmosphere composed of 1\% oxygen, $5 \%$ CO2, and 94\% N2 (Airgas, Radnor, PA)

Generation of cancer cell lines stably expressing constitutively active HIF-1 $\alpha$ and siHIF-1 $\alpha-$ OVCAR-3, A2780 and PC-3 cells stably expressing siHIF-1 $\alpha$ were generated as described previously (Skinner et al 2005). Plasmid DNA encoding HIF-1 $\alpha$ with a mutation at Pro 564 (Pro $\rightarrow$ Ala) rendering HIF-1 $\alpha$ constitutively active (HIF-1 $\alpha \mathrm{CA}$ ) in pcDNA3 vector was a generous gift from Dr. Frank Lee, UPMC, Pittsburgh, PA.. OVCAR-3, A2780 and PC-3 cells were transfected with either pcDNA3 or pcDNA3/HIF-1 $\alpha$ CA using Lipofectamine (Invirtogen, 
Carlsbad, CA) according to the manufacturer's instructions. After $24 \mathrm{~h}$ of culture, $600 \mu \mathrm{g} / \mathrm{ml}$ G418 was added to the media and the cells were cultured normally. Surviving colonies after two weeks were pooled and cultured as described previously. No differences in cell morphology or basal levels of apoptosis were observed following selection of cells stably expressing pcDNA3 or pcDNA3/HIF-1 $\alpha$ CA.

RNA isolation and Real Time RT-PCR-Total mRNA was collected and isolated using Trizol reagent (Invitrogen, Carlsbad, CA) after treatment according to the manufacturer's instructions. $2 \mu \mathrm{g}$ of mRNA was used to generate the first strand cDNA using AMV reverse transcriptase (Promega, Madison, WI). The random oligo d(T) primers were annealed to the template at $42^{\circ} \mathrm{C}$ for $5 \mathrm{~min}$. The reaction mixture $(20 \mu \mathrm{l})$ was then incubated at $72^{\circ} \mathrm{C}$ for 1 hour to allow firststrand synthesis and spun for 1 min at max speed. $5 \mu l$ of the resultant mixture was then used to perform Real-time PCR using SYBR-Green master mix and primers for COX-2 and GAPDH (MJ Research, Waltham, MA). The comparative copy number of each gene in each sample was calculated using the method of Pfaffl (2001). Samples were also run out on agarose gels for comparison. COX-2 primers: 5'-TCAGCCATACAGCAAATCCTT-3' and 5'-

CTGCACTGTGTTAGTGG-3'. GAPDH primers: 5'-CACCCATGGCAAATTCCATGGCA3' and 5'-TCTAGACGGCAGGTCAGGTCCACC-3'

Site-directed mutagenesis -- The human full length COX-2 reporter used was a generous gift of Dr. Jian Li (Harvard Medical School). To generate the HRE mutant COX-2 reporter, we performed site-directed mutagenesis on the wild type COX-2 reporter according to the manufacturer's instructions (Invitrogen, Carlsbad, CA). Briefly, we generated primers specific 
for the HRE (-576/-584) present in the COX-2 promoter containing a three base mutation $(\mathrm{GAC} \rightarrow \mathrm{AAA})$ which has previously been shown to abrogate HIF-1 binding (11). This primer was then used to perform PCR on the wild type COX-2 reporter. After PCR replication, the methylated wild type COX-2 promoter was degraded using Dpn I. The resultant COX-2 mutant reporter was then electroporated into competent DH5 $\alpha$ cells and purified using a Qiagen Midi prep kit (Qiagen, Valencia, CA).

Luciferase assay-To perform the luciferase assay cells were seeded in a 12-well plate at a density of $0.3 \times 10^{6}$ cells per well. After $12 \mathrm{~h}$ of culture the cells were washed twice with warm 1xPBS and transfected with lipofectamine (Sigma, St. Louis, MO) per the manufacturer's instructions. Briefly, $0.5 \mu \mathrm{g}$ of the wild type or mutant COX-2 reporter were mixed with 2 $\mu 1 /$ well Lipofectamine in serum-free Opti-MEM media (Invitrogen, Carlsbad, CA) and allowed to incubate for $30 \mathrm{~min}$. The $\beta$-galactosidase/CMV promoter was used as a control plasmid for transfection efficiency. This solution was then added to the cells and allowed to incubate at $37^{\circ} \mathrm{C}$ for $4.5 \mathrm{~h}$. The Lipofectamine was then removed and cells were cultured as described previously for $24 \mathrm{~h}$, after which the cells treated as described in the Results. After treatment, the cells were collected in luciferase lysis buffer (Promega, Madison, WI) per the manufacturer's instructions. Briefly, $250 \mu \mathrm{l}$ of luciferase lysis buffer was added to each well and placed at $-70^{\circ} \mathrm{C}$ until frozen. Cells and lysis buffer were allowed to thaw and were spun at $13,000 \mathrm{rpm}$ for $1 \mathrm{~min}$ at $4^{\circ} \mathrm{C}$. The supernantant was incubated with luciferase substrate (Promega, Madison, WI), and the results were measured by a monolight luminometer. $\beta$-galactosidase ( $\beta$-gal) activity was determined as a control by the hydrolysis of onitrophenyl-b-D-galactopyranoside (ONPG) at $37^{\circ} \mathrm{C}$ for $1 \mathrm{~h}$. 
Immunoblot analysis - Cells were washed 3 times in cold PBS, harvested, and lysed in RIPA buffer containing $1 \mathrm{mM}$ sodium vanadate, $0.5 \mathrm{mM}$ dithiothreitol (DTT), $1 \mathrm{mM}$ phenylmethylsulfonyl fluoride (PMSF), $2 \mathrm{mM}$ leupeptin, $2 \mathrm{mM}$ aprotinin, and $2 \mathrm{mM}$ pepstatin on ice for $20 \mathrm{~min}$. Whole cell lysates were obtained by centrifugation at $13,000 \mathrm{rpm}$ for $15 \mathrm{~min}$ at $4^{\circ} \mathrm{C}$. Total cellular protein concentration was assayed using the Bio-Rad ${ }^{\circledR}$ protein assay reagent (Bio-Rad, Richmond, CA). Aliquots ( $40 \mu \mathrm{g})$ of protein were loaded onto an SDS/polyacrylamide gel and resolved via electrophoresis. Proteins were then transferred to a nitrocellulose membrane and blocked in 5\% nonfat dry milk in 1xTBS-T. Proteins were detected via horseradish-peroxidase conjugated antibodies (NEN, Boston, MA), and visualized through enhanced chemiluminescence reagent (NEN, Boston, MA).

$P G E_{2}$ ELISA-Cells were plated at $0.1 \times 10^{6}$ cells/well of a $24-w e l l$ plate and were allowed to recover overnight. The following day, the cells were fed with fresh media and then cultured in normoxia or hypoxia $\left(1 \% \mathrm{O}_{2}\right)$ for $24 \mathrm{~h}$. The conditioned media was then collected and cleared of cellular debris by centrifugation at 2,000 rpm for 2 min. PGE2 concentration was then determined using an ELISA kit per the manufacturer's instructions (R \& D Systems, Minneapolis, $\mathrm{MN})$.

Chromatin Immunoprecipitation Assay-A2780 ovarian cancer cells were cultured in normoxia or hypoxia for $8 \mathrm{~h}$. Formaldehyde (1\%) was then added to the cells and allowed to incubate at room temperature for $10 \mathrm{~m}$ to cross-link the DNA. Cells were then washed twice in ice cold PBS and collected in PBS supplemented with protease inhibitors (Leupeptin $2 \mathrm{mg} / \mathrm{ml}$, Aprotinin $2 \mathrm{mg} / \mathrm{ml}$, PMSF 0.2 M), spun and lysed in Sonication buffer (1\% Triton X-100, 0.1\% 
Deoxycholate, $50 \mathrm{mM}$ Tris-Cl pH 8.0, $150 \mathrm{mM}$ naCL, $5 \mathrm{mM}$ EDTA) at $4^{\circ} \mathrm{C}$ for $10 \mathrm{~m}$. Cell lysates were sonicated to yield DNA fragments ranging in size from 200-900bp and centrifuged for $15 \mathrm{~m}$ at $4^{\circ} \mathrm{C}$. Samples were diluted and pre-cleared with protein A/G Sepharose $(40 \mu \mathrm{l})$ for 1 h at $4^{\circ} \mathrm{C}$. Eluates were then incubated with HIF-1 $\alpha$ antibody at $4^{\circ} \mathrm{C}$ overnight. The next day, $40 \mu$ l of protein $\mathrm{A} / \mathrm{G}$ agarose was then added and the mixture was allowed to incubate for $2 \mathrm{~h}$. Sepharose beads were then pelleted and washed sequentially for $10 \mathrm{~m}$ at $4^{\circ} \mathrm{C}$ in TSE I $(0.1 \%$ SDS, $1 \%$ Triton X-100, 2 mM EDTA, $20 \mathrm{mM}$ Tris-Cl pH 8.1, $150 \mathrm{mM} \mathrm{NaCL})$, TSE II (0.1\% SDS, 1\% Triton X-100, 2 mM EDTA, 20mM Tris-Cl pH 8.1, $500 \mathrm{mM} \mathrm{NaCl)} \mathrm{and} \mathrm{Buffer} \mathrm{III}$ (0.25 M LiCl, 1\% Nonidet P-40, 1\% deoxycholate, 1 mM EDTA, 10mM Tris $\mathrm{pH} 8.1$ ). Beads were washed another three times in Tris-EDTA, $\mathrm{pH} 8.0$, then the DNA-protein complexes were eluted in $500 \mu 1$ of elution buffer. Chemical cross-linking was reversed by incubating the samples at $65^{\circ} \mathrm{C}$ for $4 \mathrm{~h}$. DNA fragments were extracted with phenol/chloroform/isoamyl alcohol and purified using ethanol precipitation. Real-time PCR was performed using the following primer pairs: VEGF primer pair flanking the HRE 5'-

GTAGGTTTGAATCATCACGCAGG-3' and 5'-GCACCAAGTTTGTGGAGCTGA-3'; COX-2 primer pair flanking the HRE 5'-TATACAGCCTATTAAGCGTCGTCA-3' and 5'CGTGTCTGGTCTGTACGTCTTTAG-3’.

Data analysis - Data are expressed as means \pm standard error. One-way analysis of variance (ANOVA) with post-hoc Tukey's protected t-test was used to determine statistical significance between and within multiple groups. $\mathrm{p}<0.05$ was considered statistically significant. 


\section{RESULTS}

HIF-1 $\alpha$ expression regulated basal and hypoxia-induced COX-2 expression. Both HIF- $1 \alpha$ and COX-2 expression are associated with tumor angiogenesis and are over-expressed in cancer. Several stimuli, such as desferroxamine, $\mathrm{CoCl} 2$ and hypoxia stimulate both HIF- $1 \alpha$ and COX-2 expression. In light of these data, we wanted to determine if HIF-1 $\alpha$ regulated COX-2 expression in cancer. We generated A2780 ovarian cancer and PC-3 prostate cancer cell lines that stably expressed either siRNA specific for HIF-1 $\alpha$ (siHIF-1 $\alpha$; described previously in Skinner et al 2005) or siRNA with no known mammalian homology (siControl). We also generated A2780 and PC-3 cells that stably expressed a construct encoding HIF-1 $\alpha$ that was stabilized in normoxic conditions by a mutation in the ODD domain $\left(\mathrm{Pro}^{564} \rightarrow \mathrm{Ala}^{564}\right)(\mathrm{HIF}-1 \alpha$ $\mathrm{CA}$ ) or the empty vector (pcDNA3). We then examined COX-2 protein expression and $\mathrm{PGE}_{2}$ production in these cells. Similar to previous results, A2780 and PC-3 cells exhibited detectable basal levels of COX-2 under normal culture conditions, and COX-2 protein was increased by hypoxia in both cell lines (Figs. 1A \& B). Hypoxia also increased $\mathrm{PGE}_{2}$ levels in the conditioned media (Figs. 1C \& D). Interestingly, in both cell lines, stable expression of HIF-1 $\alpha$ CA led to induction of COX-2 protein, as well as production of $\mathrm{PGE}_{2}$, at levels similar to those seen during hypoxia in the control cells (Figs. 1 A, C, E \& G). Furthermore, in cells expressing HIF-1 $\alpha$ CA, which is greatly stabilized in normoxia, hypoxia led to no increase in either COX-2 protein or $\mathrm{PGE}_{2}$ (Figs. $1 \mathrm{~A}, \mathrm{C}, \mathrm{E} \& \mathrm{G}$ ). Conversely, inhibition of HIF-1 $\alpha$ expression completely abrogated basal expression of COX-2 as well as basal production of $\mathrm{PGE}_{2}$ (Figs. $1 \mathrm{~B}, \mathrm{D}, \mathrm{F} \& \mathrm{H}$ ). Expression of siHIF-1 $\alpha$ also abrogated the stimulatory effect of hypoxia on COX-2 protein expression and $\mathrm{PGE}_{2}$ production in both cell lines (Figs. $1 \mathrm{~B}, \mathrm{D}, \mathrm{F} \& \mathrm{H}$ ). To determine if the 
observed effect of HIF- $1 \alpha$ expression on COX-2 was due to regulation of COX-2 mRNA expression, we performed similar experiments as those described above and measured COX-2 mRNA. Again, expression of HIF-1 $\alpha$ CA increased COX-2 mRNA expression to levels normally observed after hypoxic stimulation (Figs. 1 I-L). Furthermore, hypoxia could not further increase COX-2 mRNA expression in cells expressing HIF-1 $\alpha$ CA (Figs. 1 I-L). Conversely, expression of siHIF- $1 \alpha$ dramatically decreased COX-2 mRNA expression and completely abrogated the effects of hypoxia on COX-2 expression (Figs. 1 I-L). These data indicate that indeed HIF- $1 \alpha$ regulates basal and hypoxia- induced $\mathrm{PGE}_{2}$ production and COX-2 protein and mRNA expression.

PMA-induced COX-2 expression was not regulated through HIF-1 $\alpha$ expression. We performed experiments similar to those above, but used phorbol ester (PMA) to stimulate COX-2 expression. PMA stimulated COX-2 in a dose-dependent and time-dependent manner in both control and HIF-1 $\alpha$ CA expressing cells in both cell lines (Figs. 2 A-C). Expression of siHIF-1 $\alpha$ decreased COX-2 protein expression below the level of detection of immunoblotting (Figs. 2 DF); however inhibition of HIF-1 $\alpha$ did not abrogate the stimulatory effect of PMA on COX-2 mRNA expression (Fig. 2 G). The ration between unstimulated and PMA-stimulated groups in both the pcDNA3 and HIF-1 $\alpha$ expressing cells was similar. This indicates that the higher levels of COX-2 protein in cells stably expressing HIF- $1 \alpha$ CA treated with PMA, compared to control treated with PMA is largely due to the elevated basal levels of COX-2 protein in cells stable expressing HIF-1 $\alpha$ CA. Furthermore, PMA stimulated COX-2 mRNA expression even in cells that expressed HIF-1 $\alpha \mathrm{CA}$, which was not the case for hypoxia-induced COX-2 expression (Fig. 2G). When we examined the pathways signaling from PMA to COX-2, we found that 
inhibition of JNK, but not PI3K or NF- $\mathrm{KB}$, abrogated the effect of PMA on COX-2 protein expression in both control and HIF-1 $\alpha$ CA-expressing cells, indicating that the primary transcriptional mediator of PMA-induced COX-2 expression in these cells may be AP-1 and not HIF-1 $\alpha$ or NF-אB (Fig. $2 \mathrm{H})$.

HIF-1 regulates COX-2 expression at the transcriptional level by binding to a hypoxia responsive element (HRE) in the COX-2 promoter. Because COX-2 can be regulated at multiple levels $(7,40)$, we wanted to determine the mechanism by which HIF-1 $\alpha$ regulates COX-2 expression. To examine the effect of HIF- $1 \alpha$ on COX-2 transcriptional activation, we performed a series of experiments using the full-length COX-2 promoter coupled to firefly luciferase. Transfection with either wild type HIF-1 $\alpha$ (HIF-1 $\alpha$ wt) or HIF-1 $\alpha$ CA increased COX-2 transcription in a concentration-dependent manner (Figs. 3 A \& B) in OVCAR-3 ovarian cancer cells. Expression of HIF-1 $\alpha$ wt also increased COX-2 transcriptional activity in a concentrationdependent manner in A2780 (Fig. 3 C) and PC-3 cells (Fig. 3 D). Conversely, expression of either HIF-1 $\alpha$ dominant negative (HIF-1 $\alpha$ DN) or siHIF- $1 \alpha$ led to a concentration-dependent decrease in COX-2 transcription in OVCAR-3 (Figs. 3 E \& F), A2780 (Figs. 3 G \& H) and PC-3 (Figs. 3 I \& J) cells. Previously it has been shown that the COX-2 promoter has several hypoxia responsive elements. Although HREs are present in the promoters of many genes, not all are functional. We predicted that HRE (-576/-584) in the COX-2 promoter would be functional. To test this hypothesis, we generated a COX-2 reporter construct containing the COX-2 promoter with a mutation in the HRE (-576/-584) (GAC $\rightarrow$ AAA) coupled to luciferase (COX-2 MUT/LUC). This mutation has been shown previously to completely abrogate HIF-1 DNA binding and transcriptional activity (11). We then co-transfected this COX-2 mutant reporter 
with either HIF-1 $\alpha$ DN or HIF- $1 \alpha$ wt to determine if HIF-1 was indeed binding the HRE (-576/584) to regulate COX-2 expression. Inhibition of HIF-1 $\alpha$ had no effect on COX-2 MUT transcriptional activity in OVCAR-3 (Fig. 4A), A2780 (Fig. 4B) and PC-3 (Fig. 4C) cells. Similarly, HIF-1 $\alpha$ overexpression had no effect on COX-2 mutant reporter activity in any of the cell lines tested (Figs. 4D-F). From these data we conclude that HIF-1 $\alpha$ regulates COX-2 transcription via the HRE (-576/-584) located in the COX-2 promoter.

Hypoxia regulates COX-2 transcription via HIF-1 $\alpha$ expression. To determine if hypoxia stimulates COX-2 expression at the level of transcription via stabilization of HIF-1 $1 \alpha$, we cotransfected several cell types with COX-2 reporter and HIF-1 $\alpha$ DN. Hypoxia stimulated COX-2 transcriptional activation in all cell types (Figs. 5). Furthermore, inhibition of HIF-1 $\alpha$ completely eliminated this effect in OVCAR-3 (Fig. 5 A), A2780 (Fig. 5 B) and PC-3 (Fig. 5 C) cells. We also tested A2780 and PC-3 cells stably transfected with either siHIF-1 $\alpha$ or HIF-1 $\alpha$ CA for COX-2 transcriptional activity. Expression of siHIF-1 $\alpha$ decreased basal and completely abrogated hypoxia-induced COX-2 transcriptional activity (Figs. 5 D \& E). Conversely, cells stably expressing HIF-1 $\alpha$ CA exhibited basal levels of COX-2 transcriptional activity similar to those of control cells stimulated by hypoxia (Figs. $5 \mathrm{~F} \& \mathrm{G}$ ). To determine if the HRE (-576/584) is necessary for hypoxia-induced COX-2 transcriptional activation, we transfected A2780 and PC-3 cells with either the wild type COX-2 reporter or the COX- 2 HRE (-576/-584) mutant reporter. We then subjected the cells to hypoxia for $24 \mathrm{~h}$ and measured luciferase activity. Hypoxia stimulated COX-2 transcriptional activity in both cell lines transfected with the wild type COX-2 reporter; furthermore, basal and hypoxia stimulated COX-2 transcriptional activity was dramatically decreased by the mutation in the HRE (Figs. $5 \mathrm{H} \& \mathrm{I}$ ). We performed similar 
experiments in A2780 and PC-3 cells stably transfected with HIF-1 $\alpha$ CA, and found even more dramatic decreases in COX-2 transcriptional activity due to the HRE mutation (Figs. $5 \mathrm{~J} \& \mathrm{~K}$ ). Conversely, A2780 and PC-3 cells stably expressing siHIF-1 $\alpha$ exhibited much less difference in COX-2 transcriptional activity between the wild type promoter and the HRE mutant promoter (Figs. $5 \mathrm{~L} \& \mathrm{M}$ ). Overall, these data indicate that hypoxic induction of COX-2 expression is dependent upon HIF-1 and a functional HIF-1 DNA binding activity in HRE (-576/-584).

HIF-1 binds the COX-2 promoter in vivo in a hypoxia dependent manner. To ensure that HIF-1 was indeed regulating COX-2 expression directly via interaction with the COX-2 promoter, we performed chromatin immunoprecipitation (CHiP). A2780 cells were cross-linked with formalin and subjected to immunoprecipitation with HIF-1 $\alpha$ antibody after which DNA fragments could be collected, purified and used in PCR reactions together with primers flanking either the VEGF HRE, as a positive control, or the HRE in the COX-2 promoter. In Fig. 6 A, we show that HIF-1 bound the HRE on the VEGF promoter, and that this binding was increased by hypoxia, as expected. We also show that HIF-1 binds to the COX-2 promoter, and that this binding is further increased by hypoxia, although not to the levels of VEGF (Fig. 6 B). Thus, HIF-1 directly binds the COX-2 promoter in vivo at the HRE.

PI3K can regulate COX-2 transcription through HIF-1 $\alpha$. Previously our group and others have shown that PI3K regulates HIF-1 $\alpha$ under a variety of conditions in the cell $(44,47)$. Furthermore, it has been shown previously that PI3K can regulate COX-2 expression in some cell types $(3,50,55)$. To determine if PI3K regulates COX-2 expression via HIF-1 $\alpha$, we stimulated A2780 and PC-3 cells stably expressing either HIF-1 $\alpha$ CA or siHIF-1 $\alpha$ with hypoxia for $8 \mathrm{~h}$ in the 
presence or absence of LY294002, a PI3K inhibitor, or PDTC, an NFKB inhibitor. Treatment with LY294002 greatly decreased COX-2 mRNA expression due to hypoxia in the control group for both cell lines (Figs. 7 A \& B). However, expression of HIF-1 $\alpha$ CA partially reversed the effect of PI3K inhibition on COX-2 mRNA expression (Figs. 7 A \& B). Furthermore, expression of siHIF- $1 \alpha$ decreased COX-2 mRNA expression to levels that were not further decreased by treatment with LY294002 in both cell lines (Figs. 7 A \& B). Because NF-kB is also thought to act downstream of PI3K to regulate COX-2 expression we treated both cell lines with PDTC, an NF- $\mathrm{KB}$ inhibitor. Treatment with PDTC strongly inhibited hypoxic induction of COX-2 mRNA in the control groups of both cell lines. However, expression of HIF-1 $\alpha$ CA partially reversed this inhibition (Figs. 7 A \& B). Furthermore, PDTC had almost no effect on COX-2 mRNA expression in the cells stably expressing siHIF-1 $\alpha$ (Figs. 7 A \& B). To determine if COX-2 protein expression is similarly regulated, we treated A2780 cells stably expressing HIF-1 $\alpha$ CA with a variety of inhibitors under normoxic and hypoxic conditions and performed immunoblots for HIF- $1 \alpha$ and COX-2. We then examined the effects of PI3K and NF- $\mathrm{KB}$ inhibition on hypoxia-induced COX-2 protein expression and found that expression of HIF-1 $\alpha$ CA completely reversed the effects of both inhibitors on hypoxia-induced COX-2 expression (Fig. 7C). We also found that inhibition of JNK did not decrease and actually slightly increased hypoxic induction of COX-2 protein in both control and HIF-1 $\alpha$ CA expressing cells (Fig. 7D). From these data we conclude that basal and hypoxia-induced COX-2 expression is mediated by PI3K via interaction with NF-אB and HIF-1 $\alpha$.

PI3K regulates basal and hypoxia- stimulated COX-2 expression at the transcriptional level through HIF-1 binding to a functional HRE (-576/-584). We next examined the effects of PI3K 
inhibition on COX-2 transcriptional activity. A2780 cells transfected with siRNA specific for Akt (siAkt) exhibited a dramatic decrease in COX-2 reporter activity (Fig. 8A), as did cells treated with LY294002 or PDTC for $24 \mathrm{~h}$ (Fig. 8B). Stable expression of siHIF-1 $\alpha$ eliminated the inhibitory effect of LY294002 on COX-2 transcriptional activity and partially abrogated the effect of PDTC (Figs. 8B). Inhibition of PI3K also reversed hypoxic stimulation of COX-2 reporter activity in both A2780 and PC-3 cells (Figs. 8C \& D). Conversely, mutation of the HRE (-576/-584) partially abrogated the effect of PI3K inhibition on basal and hypoxia-induced COX2 reporter activity (Fig. 8D). From these data we concluded that PI3K regulates basal and hypoxia-induced COX-2 expression via modulation of HIF-1 transcriptional activity.

\section{DISCUSSION}

This study examines the role of HIF-1 $\alpha$ in the regulation of COX-2 expression.

Previously it has been shown that HIF- $1 \alpha$ and COX-2 expression are both upregulated in cancer $(4,8)$, and are regulated by many of the same stimuli $(14,45)(22,31,51,56)$. Furthermore, the COX-2 promoter contains several HREs, one of which we predicted to be functional. Here we show that HIF-1 $\alpha$ regulates COX-2 expression and function both under basal conditions as well as in response to hypoxia in cancer cells. Furthermore, a functional HRE (-576/-584) in the COX-2 promoter is required for HIF-1 $\alpha$ to stimulate COX-2 expression. Because $\mathrm{PGE}_{2}$, a product of COX-2 enzymatic activity, has been shown to stimulate HIF-1 $\alpha$ expression, this points to a positive feedback loop, in which COX-2 induction by HIF-1 $\alpha$ in hypoxia leads to the production of $\mathrm{PGE}_{2}$. This event would lead to further stimulation of HIF-1 $\alpha$ expression by $\mathrm{PGE}_{2}$ in an autocrine or paracrine manner (Fig . 9). This autocrine signaling loop is not without precedent. One study has shown that VEGF signals in an autocrine manner, upregulating HIF- 
$1 \alpha$ expression and, in turn the expression of VEGFR2 (49). Furthermore, IGF-2 has been shown to stimulate HIF-1 $\alpha$ expression, and is in turn upregulated at the level of transcription by HIF-1 (9). The proposed HIF-1 $\alpha-\mathrm{COX}-2-\mathrm{PGE}_{2}$ angiogenic cascade would be minimally active in cancer cells until subjected to hypoxia, which would be the initial signaling event leading to the stabilization of HIF-1 $\alpha$. Thus, in hypoxic conditions, such as those that prevail in oxygen deprived tumors, pro-angiogenic factors such as VEGF and $\mathrm{PGE}_{2}$ could stimulate their own production. This would lead to a positive feedback loop stimulating angiogenesis in tumors as long as the environment remained hypoxic. This process would be advantageous to developing tumors which need to produce new blood vessels to grow beyond a small size.

In this study we also investigated the role of PI3K in HIF-1 $\alpha$ mediated COX-2 expression. Previously, we and others have shown that PI3K is constitutively active in a variety of different types of cancer $(47,54)$. Others have indicated that PI3K can regulate COX-2 expression $(3,50,55)$. Here we show a direct link between PI3K signaling and activation of COX-2 transcription in several different cancer cell lines via HIF-1 $\alpha$ expression. Others have shown that PI3K can mediate COX-2 transcription via NF- $\kappa \mathrm{B}(3,55)$, and that hypoxia also stimulates COX-2 transcription by upregulating NF- $\kappa$ B DNA binding (43). Here we do show that an inhibitor of $\mathrm{NF}-\kappa \mathrm{B}, \mathrm{PDTC}$, has an inhibitory effect on $\mathrm{COX}-2$ transcription. However, this effect was completely reversed by expression of constitutively active HIF-1 $\alpha$ and, furthermore, was lessened in cells with depleted HIF-1 $\alpha$ expression. Several studies indicate that NF- $\kappa \mathrm{B}$ can regulate HIF-1 $\alpha$ expression downstream of PI3K $(10,24,25,60)$, partially explaining the results we obtained using an inhibitor of NF- $\mathrm{kB}$. Furthermore, as the HRE in the COX-2 promoter was required for regulation of COX-2 by HIF-1 $\alpha$, we can rule out the possibility that HIF-1 $\alpha$ is regulating COX-2 via a non-specific, non-transcriptional mechanism. Our data and 
previous studies seem to indicate some form of cooperative regulation of COX-2 transcription between NF- $\mathrm{kB}$ and HIF-1 $\alpha$ in the cells. Further study is warranted to examine the interaction between HIF- $1 \alpha$ and NF- $\mathrm{KB}$ in the regulation of COX-2, and perhaps other common transcriptional targets of HIF- $1 \alpha$ and NF-KB.

In summary, in this study we showed that COX-2 expression in cancer cells under basal conditions as well as in hypoxia, was dependent upon transcriptional regulation of COX-2 by HIF-1 $\alpha$. HIF-1-dependent regulation of COX-2 required a functional HRE (-576/-584), and was regulated by PI3K signaling.

\section{Reference List}

1. Bardos, J. I., N. M. Chau, and M. Ashcroft. 2004. Growth factor-mediated induction of HDM2 positively regulates hypoxia-inducible factor 1alpha expression 1. Mol.Cell Biol. 24:2905-2914.

2. Bazan, N. G. and W. J. Lukiw. 2002. Cyclooxygenase-2 and presenilin-1 gene expression induced by interleukin-1beta and amyloid beta 42 peptide is potentiated by hypoxia in primary human neural cells

16. J.Biol.Chem. 277:30359-30367.

3. Chang, M. S., W. S. Lee, B. C. Chen, J. R. Sheu, and C. H. Lin. 2004. YC-1-induced cyclooxygenase- 2 expression is mediated by cGMP-dependent activations of Ras, phosphoinositide-3-OH-kinase, Akt, and nuclear factor-kappaB in human pulmonary epithelial cells. Mol.Pharmacol. 66:561-571.

4. Chun, K. S. and Y. J. Surh. 2004. Signal transduction pathways regulating cyclooxygenase-2 expression: potential molecular targets for chemoprevention.

Biochem.Pharmacol. 68:1089-1100.

5. Cockman, M. E., N. Masson, D. R. Mole, P. Jaakkola, G. W. Chang, S. C. Clifford, E. R. Maher, C. W. Pugh, P. J. Ratcliffe, and P. H. Maxwell. 2000. Hypoxia inducible factoralpha binding and ubiquitylation by the von Hippel-Lindau tumor suppressor protein 7. J.Biol.Chem. 275:25733-25741. 
6. Cowden Dahl, K. D., S. E. Robertson, V. M. Weaver, and M. C. Simon. 2005. Hypoxiainducible factor regulates alphavbeta3 integrin cell surface expression

42. Mol.Biol.Cell 16:1901-1912.

7. Dixon, D. A., C. D. Kaplan, T. M. McIntyre, G. A. Zimmerman, and S. M. Prescott. 2000. Post-transcriptional control of cyclooxygenase-2 gene expression. The role of the 3'untranslated region. J Biol.Chem. 275:11750-11757.

8. Escuin, D., J. W. Simons, and P. Giannakakou. 2004. Exploitation of the HIF axis for cancer therapy. Cancer Biol.Ther. 3:608-611.

9. Feldser, D., F. Agani, N. V. Iyer, B. Pak, G. Ferreira, and G. L. Semenza. 1999. Reciprocal positive regulation of hypoxia-inducible factor 1alpha and insulin-like growth factor 2. Cancer Res 59:3915-3918.

10. Figueroa, Y. G., A. K. Chan, R. Ibrahim, Y. Tang, M. E. Burow, J. Alam, A. B. Scandurro, and B. S. Beckman. 2002. NF-kappaB plays a key role in hypoxia-inducible factor1-regulated erythropoietin gene expression. Exp.Hematol. 30:1419-1427.

11. Forsythe, J. A., B. H. Jiang, N. V. Iyer, F. Agani, S. W. Leung, R. D. Koos, and G. L. Semenza. 1996. Activation of vascular endothelial growth factor gene transcription by hypoxiainducible factor 1. Mol.Cell Biol. 16:4604-4613.

12. Fukuda, R., K. Hirota, F. Fan, Y. D. Jung, L. M. Ellis, and G. L. Semenza. 2002. Insulin-like growth factor 1 induces hypoxia-inducible factor 1-mediated vascular endothelial growth factor expression, which is dependent on MAP kinase and phosphatidylinositol 3-kinase signaling in colon cancer cells. J.Biol.Chem. 277:38205-38211.

13. Gao, N., M. Ding, J. Z. Zheng, Z. Zhang, S. S. Leonard, K. J. Liu, X. Shi, and B. H. Jiang. 2002. Vanadate-induced expression of hypoxia-inducible factor 1 alpha and vascular endothelial growth factor through phosphatidylinositol 3-kinase/Akt pathway and reactive oxygen species

29. J.Biol.Chem. 277:31963-31971.

14. Gately, S. 2000. The contributions of cyclooxygenase-2 to tumor angiogenesis 1. Cancer Metastasis Rev. 19:19-27.

15. Gately, S. and W. W. Li. 2004. Multiple roles of COX-2 in tumor angiogenesis: a target for antiangiogenic therapy

1. Semin.Oncol. 31:2-11.

16. Gupta, S., M. Srivastava, N. Ahmad, D. G. Bostwick, and H. Mukhtar. 2000. Overexpression of cyclooxygenase-2 in human prostate adenocarcinoma 3. Prostate 42:73-78.

17. Huang, S. P., M. S. Wu, C. T. Shun, H. P. Wang, C. Y. Hsieh, M. L. Kuo, and J. T. Lin. 2005. Cyclooxygenase-2 increases hypoxia-inducible factor-1 and vascular endothelial growth factor to promote angiogenesis in gastric carcinoma 


\section{J.Biomed.Sci. 12:229-241.}

18. Hudson, C. C., M. Liu, G. G. Chiang, D. M. Otterness, D. C. Loomis, F. Kaper, A. J. Giaccia, and R. T. Abraham. 2002. Regulation of hypoxia-inducible factor 1alpha expression and function by the mammalian target of rapamycin. Mol.Cell Biol. 22:7004-7014.

19. Ivan, M., K. Kondo, H. Yang, W. Kim, J. Valiando, M. Ohh, A. Salic, J. M. Asara, W. S. Lane, and W. G. Kaelin, Jr. 2001. HIFalpha targeted for VHL-mediated destruction by proline hydroxylation: implications for $\mathrm{O} 2$ sensing

2. Science 292:464-468.

20. Jaakkola, P., D. R. Mole, Y. M. Tian, M. I. Wilson, J. Gielbert, S. J. Gaskell, A. Kriegsheim, H. F. Hebestreit, M. Mukherji, C. J. Schofield, P. H. Maxwell, C. W. Pugh, and P. J. Ratcliffe. 2001. Targeting of HIF-alpha to the von Hippel-Lindau ubiquitylation complex by O2-regulated prolyl hydroxylation

3. Science 292:468-472.

21. Jiang, B. H., G. Jiang, J. Z. Zheng, Z. Lu, T. Hunter, and P. K. Vogt. 2001.

Phosphatidylinositol 3-kinase signaling controls levels of hypoxia-inducible factor 1. Cell Growth Differ. 12:363-369.

22. Jiang, B. H., J. Z. Zheng, S. W. Leung, R. Roe, and G. L. Semenza. 1997.

Transactivation and inhibitory domains of hypoxia-inducible factor 1alpha. Modulation of transcriptional activity by oxygen tension

42. J.Biol.Chem. 272:19253-19260.

23. Jones, M. K., I. L. Szabo, H. Kawanaka, S. S. Husain, and A. S. Tarnawski. 2002. von Hippel Lindau tumor suppressor and HIF-1alpha: new targets of NSAIDs inhibition of hypoxiainduced angiogenesis

3. FASEB J. 16:264-266.

24. Jung, Y. J., J. S. Isaacs, S. Lee, J. Trepel, and L. Neckers. 2003. Microtubule disruption utilizes an NFkappa B-dependent pathway to stabilize HIF-1alpha protein. J Biol.Chem.

278:7445-7452.

25. Kimba, Y., T. Abe, J. L. Wu, R. Inoue, M. Fukiki, K. Kohno, and H. Kobayashi. 2005. Mutant IkappaBalpha suppresses hypoxia-induced VEGF expression through downregulation of HIF-1alpha and COX-2 in human glioma cells. Oncol.Res 15:139-149.

26. Kitada, T., S. Seki, H. Sakaguchi, T. Sawada, K. Hirakawa, and K. Wakasa. 2003. Clinicopathological significance of hypoxia-inducible factor-1 alpha expression in human pancreatic carcinoma

2. Histopathology 43:550-555.

27. Klimp, A. H., H. Hollema, C. Kempinga, A. G. van der Zee, E. G. de Vries, and T. Daemen. 2001. Expression of cyclooxygenase-2 and inducible nitric oxide synthase in human ovarian tumors and tumor-associated macrophages

1. Cancer Res. 61:7305-7309. 
28. Krishnamachary, B., S. Berg-Dixon, B. Kelly, F. Agani, D. Feldser, G. Ferreira, N. Iyer, J. LaRusch, B. Pak, P. Taghavi, and G. L. Semenza. 2003. Regulation of colon carcinoma cell invasion by hypoxia-inducible factor 1. Cancer Res. 63:1138-1143.

29. Kurokawa, T., M. Miyamoto, K. Kato, Y. Cho, Y. Kawarada, Y. Hida, T. Shinohara, T. Itoh, S. Okushiba, S. Kondo, and H. Katoh. 2003. Overexpression of hypoxia-induciblefactor 1alpha(HIF-1alpha) in oesophageal squamous cell carcinoma correlates with lymph node metastasis and pathologic stage

23. Br.J.Cancer 89:1042-1047.

30. Liu, X. H., A. Kirschenbaum, M. Lu, S. Yao, A. Dosoretz, J. F. Holland, and A. C. Levine. 2002. Prostaglandin E2 induces hypoxia-inducible factor-1alpha stabilization and nuclear localization in a human prostate cancer cell line 1. J.Biol.Chem. 277:50081-50086.

31. Liu, X. H., A. Kirschenbaum, S. Yao, M. E. Stearns, J. F. Holland, K. Claffey, and A. C. Levine. 1999. Upregulation of vascular endothelial growth factor by cobalt chloridesimulated hypoxia is mediated by persistent induction of cyclooxygenase- 2 in a metastatic human prostate cancer cell line

3. Clin.Exp.Metastasis 17:687-694.

32. Majima, M., I. Hayashi, M. Muramatsu, J. Katada, S. Yamashina, and M. Katori. 2000. Cyclo-oxygenase-2 enhances basic fibroblast growth factor-induced angiogenesis through induction of vascular endothelial growth factor in rat sponge implants

18. Br.J.Pharmacol. 130:641-649.

33. Majima, M., M. Isono, Y. Ikeda, I. Hayashi, K. Hatanaka, Y. Harada, O. Katsumata, S. Yamashina, M. Katori, and S. Yamamoto. 1997. Significant roles of inducible cyclooxygenase $(\mathrm{COX})-2$ in angiogenesis in rat sponge implants 25. Jpn.J.Pharmacol. 75:105-114.

34. Masferrer, J. L., K. M. Leahy, A. T. Koki, B. S. Zweifel, S. L. Settle, B. M. Woerner, D. A. Edwards, A. G. Flickinger, R. J. Moore, and K. Seibert. 2000. Antiangiogenic and antitumor activities of cyclooxygenase-2 inhibitors

19. Cancer Res. 60:1306-1311.

35. Matsumoto, Y., O. Ishiko, M. Deguchi, E. Nakagawa, and S. Ogita. 2001.

Cyclooxygenase-2 expression in normal ovaries and epithelial ovarian neoplasms 4. Int.J.Mol.Med. 8:31-36.

36. Mazure, N. M., E. Y. Chen, K. R. Laderoute, and A. J. Giaccia. 1997. Induction of vascular endothelial growth factor by hypoxia is modulated by a phosphatidylinositol 3kinase/Akt signaling pathway in Ha-ras-transformed cells through a hypoxia inducible factor-1 transcriptional element 1. Blood 90:3322-3331. 
37. Murata, H., S. Kawano, S. Tsuji, M. Tsuji, H. Sawaoka, Y. Kimura, H. Shiozaki, and M. Hori. 1999. Cyclooxygenase-2 overexpression enhances lymphatic invasion and metastasis in human gastric carcinoma

4. Am.J.Gastroenterol. 94:451-455.

38. Ohh, M., C. W. Park, M. Ivan, M. A. Hoffman, T. Y. Kim, L. E. Huang, N. Pavletich, V. Chau, and W. G. Kaelin. 2000. Ubiquitination of hypoxia-inducible factor requires direct binding to the beta-domain of the von Hippel-Lindau protein

8. Nat.Cell Biol. 2:423-427.

39. Palayoor, S. T., P. J. Tofilon, and C. N. Coleman. 2003. Ibuprofen-mediated reduction of hypoxia-inducible factors HIF-1alpha and HIF-2alpha in prostate cancer cells

1. Clin.Cancer Res. 9:3150-3157.

40. Ramsay, R. G., D. Ciznadija, M. Vanevski, and T. Mantamadiotis. 2003.

Transcriptional regulation of cyclo-oxygenase expression: three pillars of control. Int.J Immunopathol.Pharmacol. 16:59-67.

41. Sano, H., Y. Kawahito, R. L. Wilder, A. Hashiramoto, S. Mukai, K. Asai, S. Kimura, H. Kato, M. Kondo, and T. Hla. 1995. Expression of cyclooxygenase-1 and -2 in human colorectal cancer

1. Cancer Res. 55:3785-3789.

42. Sawaoka, H., S. Tsuji, M. Tsujii, E. S. Gunawan, Y. Sasaki, S. Kawano, and M. Hori. 1999. Cyclooxygenase inhibitors suppress angiogenesis and reduce tumor growth in vivo 3. Lab Invest 79:1469-1477.

43. Schmedtje, J. F., Jr., Y. S. Ji, W. L. Liu, R. N. DuBois, and M. S. Runge. 1997. Hypoxia induces cyclooxygenase-2 via the NF-kappaB p65 transcription factor in human vascular endothelial cells. J Biol.Chem. 272:601-608.

44. Semenza, G. 2002. Signal transduction to hypoxia-inducible factor 1. Biochem.Pharmacol. 64:993-998.

45. Semenza, G. L. 2000. HIF-1: mediator of physiological and pathophysiological responses to hypoxia

15. J.Appl.Physiol 88:1474-1480.

46. Semenza, G. L. 2000. HIF-1: using two hands to flip the angiogenic switch

2. Cancer Metastasis Rev. 19:59-65.

47. Skinner, H. D., J. Z. Zheng, J. Fang, F. Agani, and B. H. Jiang. 2004. Vascular endothelial growth factor transcriptional activation is mediated by hypoxia-inducible factor 1alpha, HDM2, and p70S6K1 in response to phosphatidylinositol 3-kinase/AKT signaling 10. J.Biol.Chem. 279:45643-45651. 
48. Stiehl, D. P., W. Jelkmann, R. H. Wenger, and T. Hellwig-Burgel. 2002. Normoxic induction of the hypoxia-inducible factor 1alpha by insulin and interleukin-1beta involves the phosphatidylinositol 3-kinase pathway

1. FEBS Lett. 512:157-162.

49. Tang, N., L. Wang, J. Esko, F. J. Giordano, Y. Huang, H. P. Gerber, N. Ferrara, and R. S. Johnson. 2004. Loss of HIF-1 alpha in endothelial cells disrupts a hypoxia-driven VEGF autocrine loop necessary for tumorigenesis. Cancer Cell 6:485-495.

50. Tang, Q., M. Gonzales, H. Inoue, and G. T. Bowden. 2001. Roles of Akt and glycogen synthase kinase 3 beta in the ultraviolet B induction of cyclooxygenase- 2 transcription in human keratinocytes. Cancer Res 61:4329-4332.

51. Tanji, K., T. Imaizumi, T. Matsumiya, H. Itaya, K. Fujimoto, X. Cui, T. Toki, E. Ito, H. Yoshida, K. Wakabayashi, and K. Satoh. 2001. Desferrioxamine, an iron chelator, upregulates cyclooxygenase- 2 expression and prostaglandin production in a human macrophage cell line

1. Biochim.Biophys.Acta 1530:227-235.

52. Treins, C., S. Giorgetti-Peraldi, J. Murdaca, G. L. Semenza, and E. Van Obberghen. 2002. Insulin stimulates hypoxia-inducible factor 1 through a phosphatidylinositol 3kinase/target of rapamycin-dependent signaling pathway. J.Biol.Chem. 277:27975-27981.

53. Tsujii, M., S. Kawano, and R. N. DuBois. 1997. Cyclooxygenase-2 expression in human colon cancer cells increases metastatic potential

8. Proc.Natl.Acad.Sci.U.S.A 94:3336-3340.

54. Vivanco, I. and C. L. Sawyers. 2002. The phosphatidylinositol 3-Kinase AKT pathway in human cancer. Nat.Rev.Cancer 2:489-501.

55. Volanti, C., N. Hendrickx, J. Van Lint, J. Y. Matroule, P. Agostinis, and J. Piette. 2005. Distinct transduction mechanisms of cyclooxygenase 2 gene activation in tumour cells after photodynamic therapy. Oncogene 24:2981-2991.

56. Wang, G. L. and G. L. Semenza. 1993. Desferrioxamine induces erythropoietin gene expression and hypoxia-inducible factor 1 DNA-binding activity: implications for models of hypoxia signal transduction

1. Blood 82:3610-3615.

57. Zhang, L., N. Yang, D. Katsaros, W. Huang, J. W. Park, S. Fracchioli, C. Vezzani, Rigault de la Longrais IA, W. Yao, S. C. Rubin, and G. Coukos. 2003. The oncogene phosphatidylinositol 3'-kinase catalytic subunit alpha promotes angiogenesis via vascular endothelial growth factor in ovarian carcinoma. Cancer Res. 63:4225-4231.

58. Zhong, H., K. Chiles, D. Feldser, E. Laughner, C. Hanrahan, M. M. Georgescu, J. W. Simons, and G. L. Semenza. 2000. Modulation of hypoxia-inducible factor 1alpha expression by the epidermal growth factor/phosphatidylinositol 3-kinase/PTEN/AKT/FRAP pathway in 
human prostate cancer cells: implications for tumor angiogenesis and therapeutics. Cancer Res. 60:1541-1545.

59. Zhong, H., A. M. De Marzo, E. Laughner, M. Lim, D. A. Hilton, D. Zagzag, P. Buechler, W. B. Isaacs, G. L. Semenza, and J. W. Simons. 1999. Overexpression of hypoxiainducible factor 1alpha in common human cancers and their metastases. Cancer Res. 59:58305835 .

60. Zhou, J., M. Callapina, G. J. Goodall, and B. Brune. 2004. Functional integrity of nuclear factor kappaB, phosphatidylinositol 3'-kinase, and mitogen-activated protein kinase signaling allows tumor necrosis factor alpha-evoked Bcl-2 expression to provoke internal ribosome entry site-dependent translation of hypoxia-inducible factor 1alpha. Cancer Res 64:9041-9048.
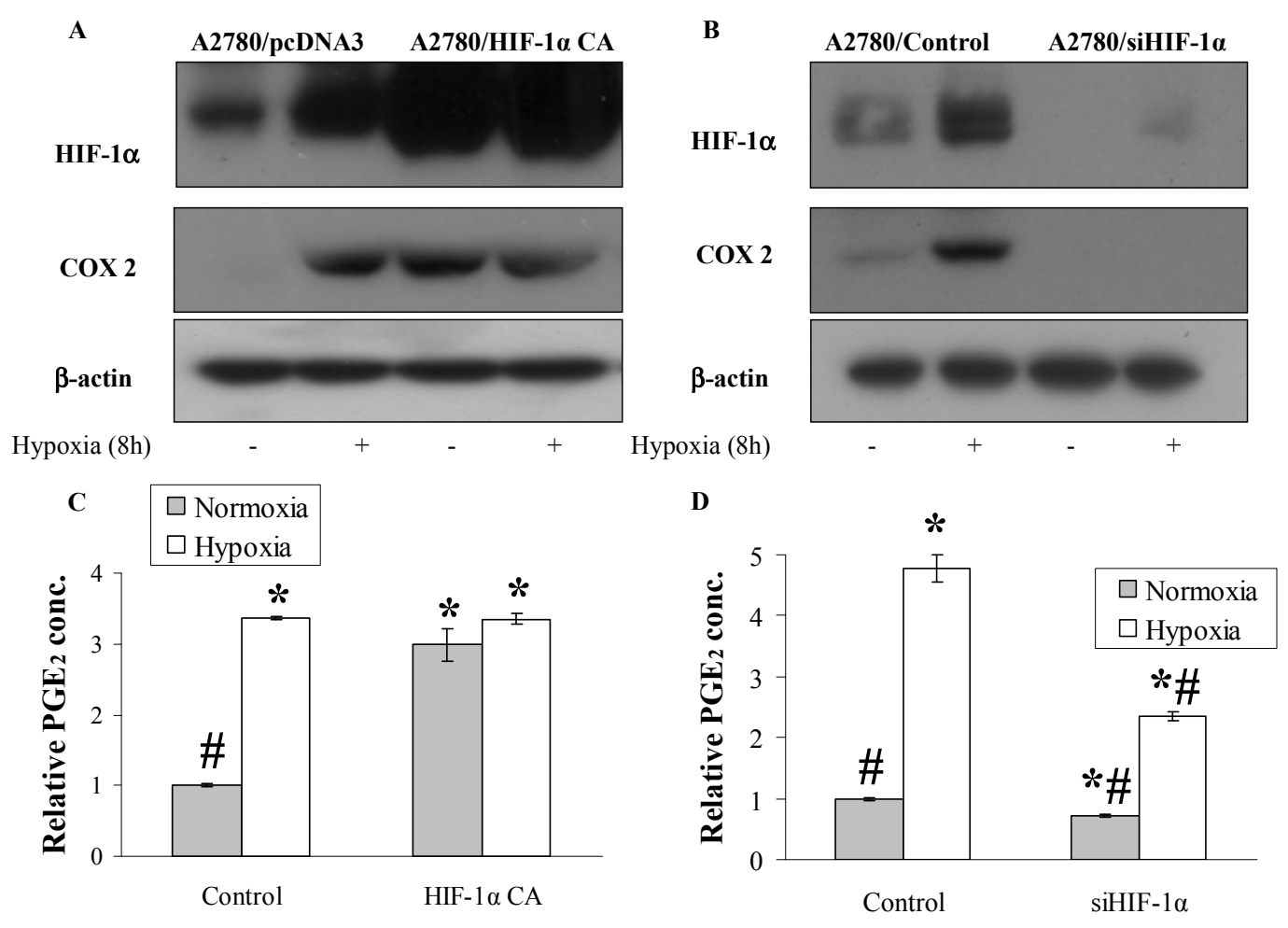

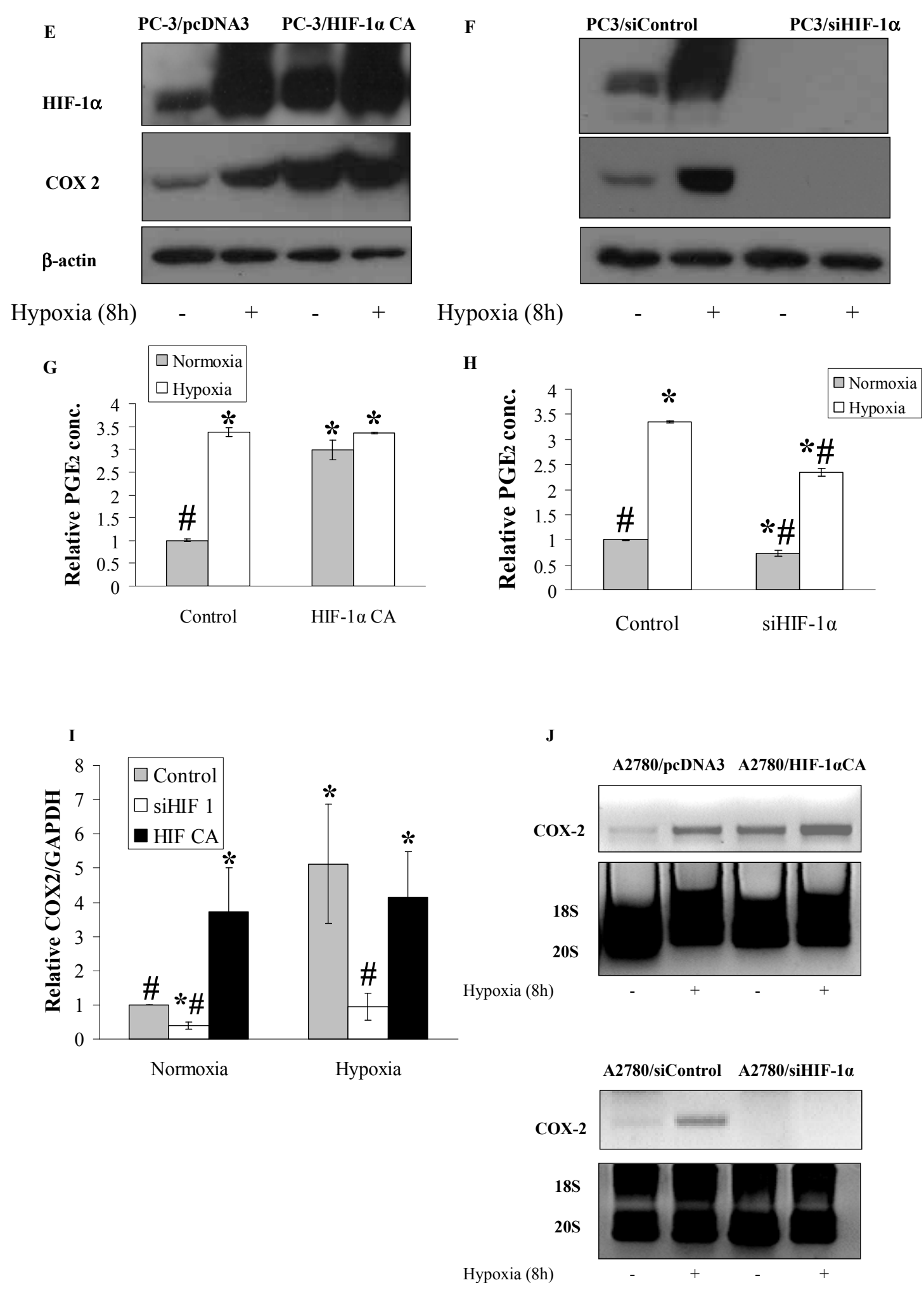


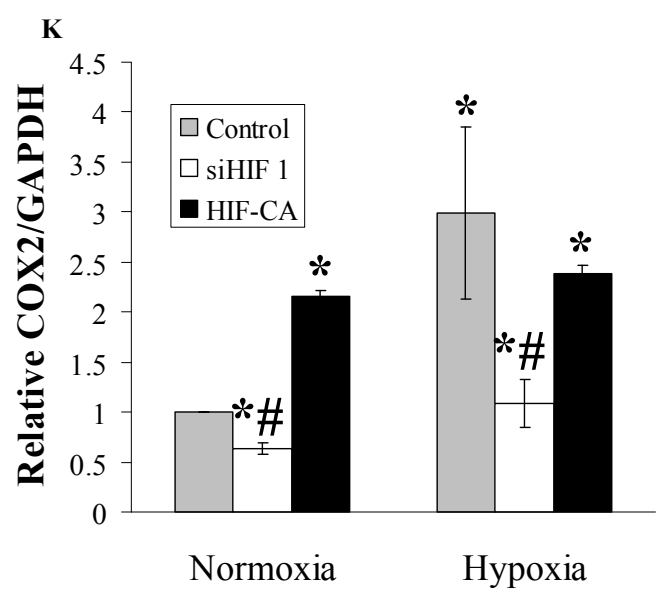

$\mathbf{L}$

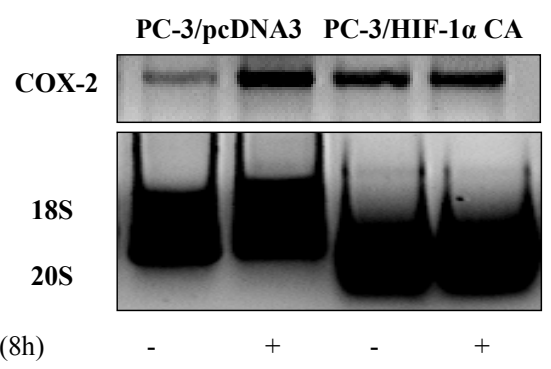

Hypoxia (8h)

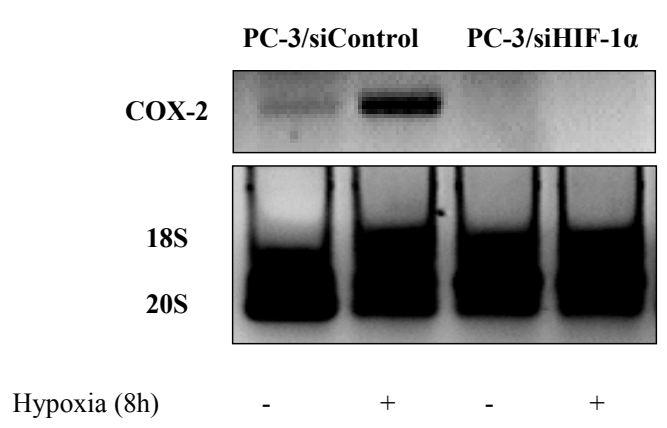

Figure 1. HIF-1 $\alpha$ regulates basal and hypoxia-stimulated $\mathrm{PGE}_{2}$ production, $\mathrm{COX}-2$ protein and mRNA expression. A, A2780 cells stably expressing either pcDNA3 vector or HIF-1 $\alpha$ CA were cultured in normoxia or hypoxia for $8 \mathrm{~h}$. The cells were collected, and HIF-1 $\alpha$, COX-2 and $\beta-$ actin protein expression were analyzed by immunoblot. B, A2780 cells stably expressing either Control siRNA (siControl) or HIF-1 $\alpha$ siRNA (siHIF-1 $\alpha$ ) were cultured in normoxia or hypoxia for $8 \mathrm{~h}$. The cells were collected and levels of HIF- $1 \alpha, \mathrm{COX}-2$ and $\beta$-actin protein expression were analyzed by immunoblotting. C, A2780 cells stably expressing either pcDNA3 vector or HIF-1 $\alpha$ CA were cultured in normoxia or hypoxia for $24 \mathrm{~h}$. The conditioned media were analyzed for PGE2 levels via ELISA. Results were normalized to the cell number and standardized to that of normoxic control. *-indicates significant difference from normoxic control ( $\mathrm{p}<0.01)$. \#-indicates significant difference from normoxic cells expressing HIF-1 $\alpha$ CA $(\mathrm{p}<0.05) . \quad D, A 2780$ cells stably expressing either siControl or siHIF-1 $\alpha$ were cultured in normoxia or hypoxia for 24h. The conditioned media was analyzed for PGE2 levels via ELISA. Results were normalized to the cell number and standardized to that of normoxic control. *- 
indicates significant difference from normoxic control $(\mathrm{p}<0.05)$. \#-indicates significant difference from hypoxic control $(\mathrm{p}<0.05)$. $\boldsymbol{E}$, PC-3 cells stably expressing either pcDNA3 vector or HIF-1 $\alpha$ CA were cultured in normoxia or hypoxia for $8 \mathrm{~h}$. The cells were collected and levels of HIF-1 $\alpha, \mathrm{COX}-2$ and $\beta$-actin protein expression were analyzed by immunobloting. $F$, PC-3 cells stably expressing either siControl or siHIF-1 $\alpha$ were cultured in normoxia or hypoxia for $8 \mathrm{~h}$. The cells were collected and levels of HIF-1 $\alpha, \mathrm{COX}-2$ and $\beta$-actin protein expression were analyzed by immunoblotting. G, PC-3 cells stably expressing either pcDNA3 vector or HIF-1 $\alpha$ CA were cultured in normoxia or hypoxia for $24 \mathrm{~h}$. Supernatant was collected and analyzed for $\mathrm{PGE}_{2}$ expression. Values were normalized to the cell number and standardized to that of normoxic control. *-indicates significant difference from normoxic control $(\mathrm{p}<0.05)$. \#indicates significant difference from hypoxic cells $(\mathrm{p}<0.05) . \quad H$, PC-3 cells stably expressing either siControl or siHIF-1 $\alpha$ were cultured in normoxia or hypoxia for $24 \mathrm{~h}$. Supernatant was collected and analyzed for $\mathrm{PGE}_{2}$ expression. Values were normalized to the cell number and standardized to that of normoxic control. *-indicates significant difference from normoxic control $(\mathrm{p}<0.05)$. \# -indicates significant difference from normoxic cells expressing siHIF-1 $\alpha$ $(\mathrm{p}<0.05)$. I, A2780 cells stably expressing siHIF-1 $\alpha$ or HIF-1 $\alpha$ CA were cultured in normoxia or hypoxia for $8 \mathrm{~h}$. COX-2 mRNA was measured using Real-time RT-PCR as described in Materials and Methods and values were normalized to GAPDH. J, Representative results of the above experiment measured via qualitative RT-PCR. 18S mRNA served as an internal control. $\boldsymbol{K}$, PC-3 cells stably expressing siHIF-1 $\alpha$ or HIF-1 $\alpha$ CA were cultured in normoxia or hypoxia for 8h. COX- 2 mRNA was measured using Real-time RT-PCR as described in Materials and Methods. GAPDH served as an internal control. $\mathbf{L}$, Representative results of the above experiment analyzed via Qualitative RT-PCR. 18S mRNA served as an internal control. 
A A2780/pcDNA3 A2780/HIF-1 $\alpha$ CA

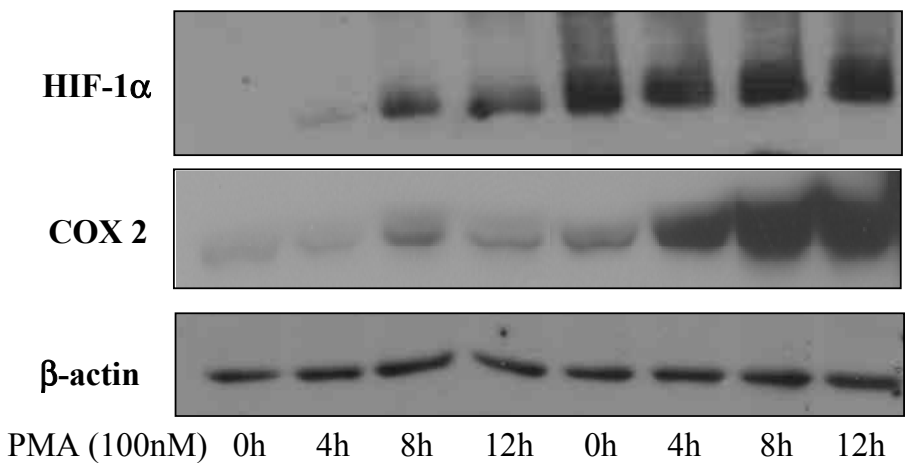

B A2780/pcDNA3 A2780/HIF-1 $\alpha$ CA

HIF-1 $\alpha$

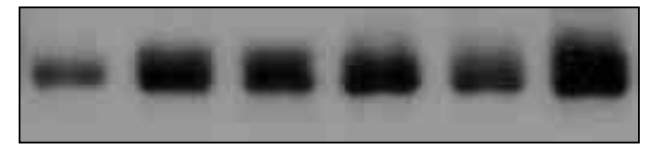

$\operatorname{COX} 2$
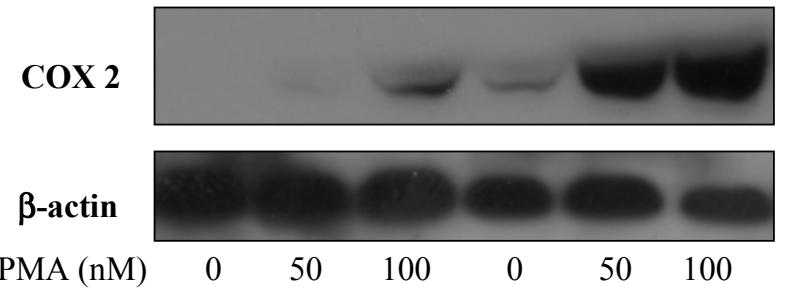

C PC3/pcDNA3 PC3/HIF-1 $\alpha$ CA

HIF-1 $\alpha$

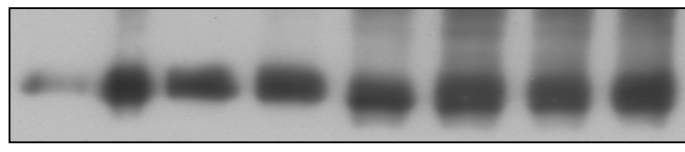

$\operatorname{COX} 2$

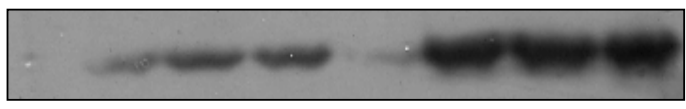

$\beta$-actin

$\begin{array}{lllllllll}\text { PMA (nM) } & 0 & 25 & 50 & 100 & 0 & 25 & 50 & 100\end{array}$ 
D

A2780/siControl

A2780/siHIF-1 $\alpha$

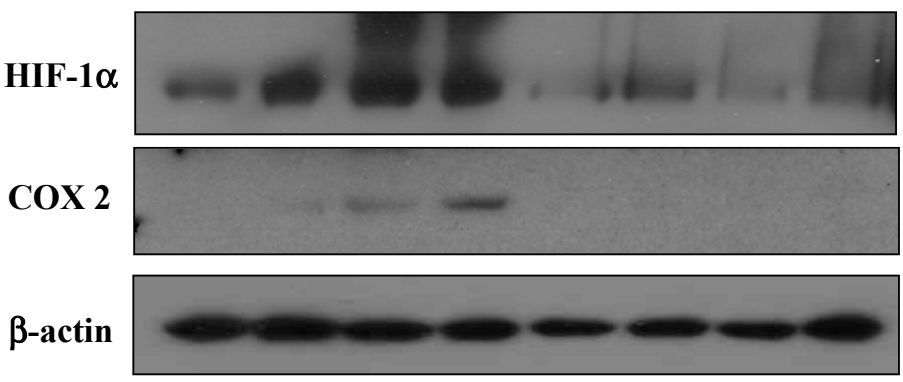

PMA (100nM) $\quad 0 h \quad 2 h \quad 4 h \quad 8 h \quad 0 h \quad 4 h \quad 8 h \quad 12 h$

$\mathbf{E}$

A2780/siControl

A2780/siHIF-1 $\alpha$

HIF-1 $\alpha$

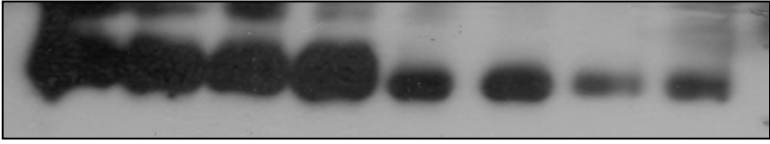

COX 2

$\beta$-actin

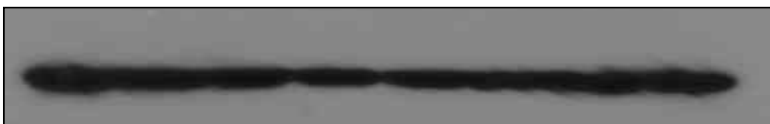

$\begin{array}{lllllllll}\text { PMA (nM) } & 0 & 25 & 50 & 100 & 0 & 25 & 50 & 100\end{array}$

F

PC3/siControl PC3/siHIF-1 $\alpha$

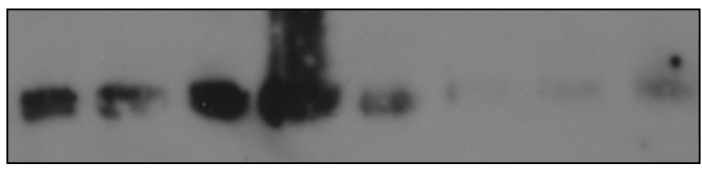

COX 2

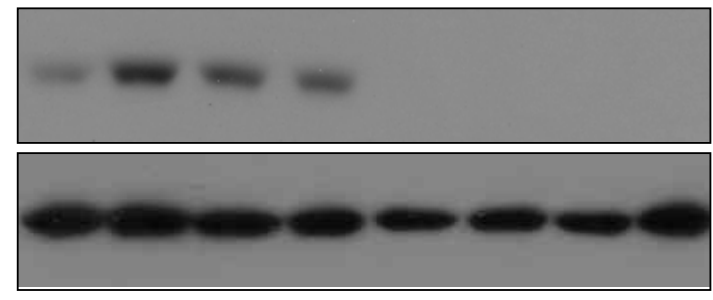

$\begin{array}{lllllllll}\text { PMA (nM) } & 0 & 25 & 50 & 100 & 0 & 25 & 50 & 100\end{array}$ 


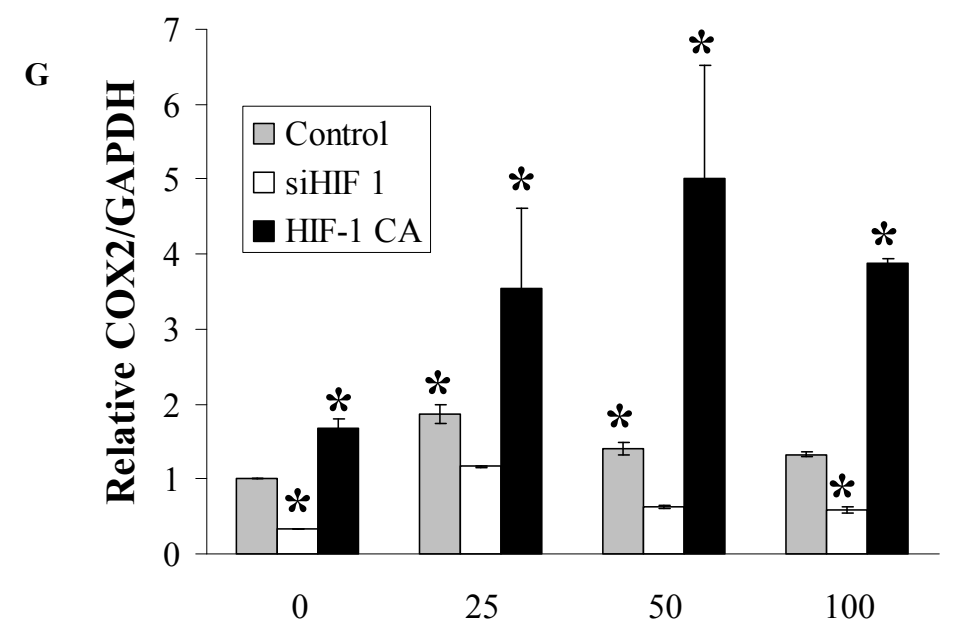

H

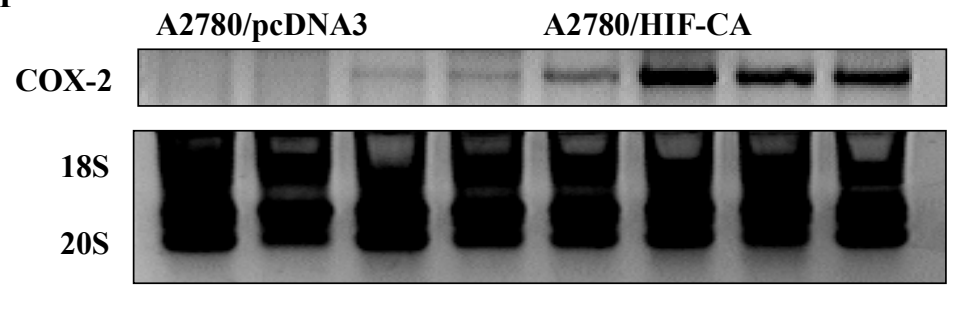

$\begin{array}{lllllllll}\text { PMA (nM) } & 0 & 25 & 50 & 100 & 0 & 25 & 50 & 100\end{array}$

I

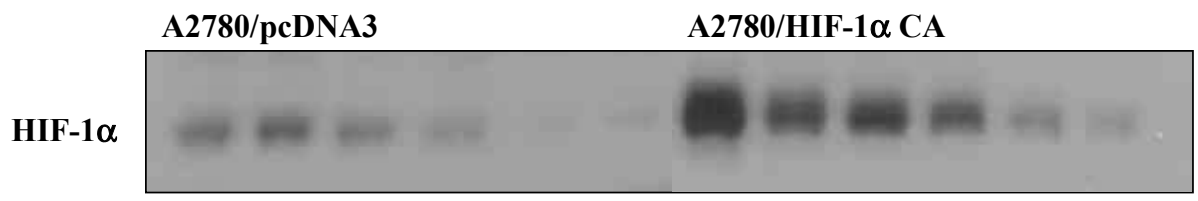

COX

$\beta$-actin

PMA (100nM)

$\operatorname{PDTC}(\mu \mathrm{M})$

LY294002 $(\mu \mathrm{M})$

$\mathrm{SP} 600125(\mu \mathrm{M})$
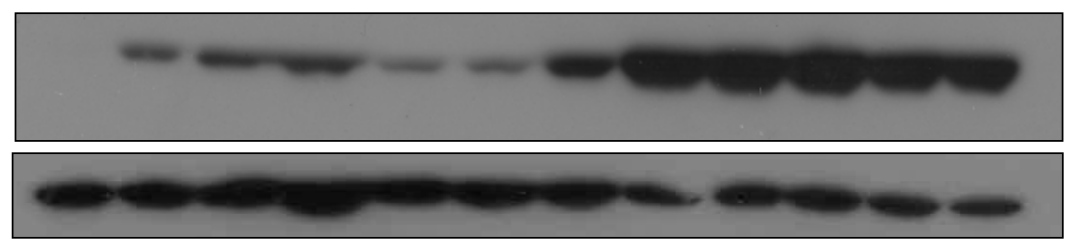

$\begin{array}{cccccccccccc}- & + & + & + & + & + & - & + & + & + & + & + \\ 0 & 0 & 20 & 0 & 0 & 0 & 0 & 0 & 20 & 0 & 0 & 0 \\ 0 & 0 & 0 & 20 & 0 & 0 & 0 & 0 & 0 & 20 & 0 & 0 \\ 0 & 0 & 0 & 0 & 10 & 20 & 0 & 0 & 0 & 0 & 10 & 20\end{array}$


Figure 2. HIF-1 $\alpha$ does not regulate PMA-induced COX-2 activity A, A2780 cells stably expressing either pcDNA3 vector or HIF-1 $\alpha$ CA were stimulated with 100nM PMA for the indicated time periods. The cells were collected and levels of HIF-1 $\alpha$, COX-2 and $\beta$-actin protein expression were analyzed by immunoblotting. B, A2780 cells stably expressing either pcDNA3 vector or HIF-1 $\alpha$ CA were stimulated with the indicated doses of PMA for $8 \mathrm{~h}$. The cells were collected and levels of HIF- $1 \alpha, \mathrm{COX}-2$ and $\beta$-actin protein expression were analyzed by immunoblotting. $\boldsymbol{C}$, PC-3 cells stably expressing pcDNA3 or HIF-1 $\alpha$ CA were treated with the indicated doses of PMA for $8 \mathrm{~h}$. Levels of HIF-1 $\alpha$, COX-2 and $\beta$-actin protein expression were analyzed by immunoblotting. $\boldsymbol{D}$, A2780 cells stably expressing siControl or siHIF-1 $\alpha$ were treated with $100 \mathrm{nM}$ PMA for the indicated times. Levels of HIF- $1 \alpha$, COX-2 and $\beta$-actin protein expression were analyzed by immunoblotting. $\boldsymbol{E}$, A2780 cells stably expressing siControl or siHIF- $1 \alpha$ were treated the indicated doses of PMA for $8 \mathrm{~h}$. Levels of HIF-1 $\alpha$, COX-2 and $\beta$-actin protein expression were analyzed by immunoblotting. F, PC-3 cells stably expressing siControl or siHIF-1 $\alpha$ were treated with the indicated doses of PMA for $8 \mathrm{~h}$. Levels of HIF-1 $\alpha$, COX-2 and $\beta$-actin protein expression were analyzed by immunoblotting. G, A2780 cells stably expressing siHIF-1 $\alpha$ or HIF-1 $\alpha$ CA were treated with PMA for $4 \mathrm{~h}$. COX-2 mRNA was measured using Real-time RT-PCR as described in Materials and Methods. GAPDH served as an internal control. *-indicates significant difference from normoxic vector expressing control $(\mathrm{p}<0.05)$. $\boldsymbol{H}$, Representative results of the above experiment analyzed via qualitative RT-PCR. 18S mRNA served as an internal control. I, A2780 cells stably expressing pcDNA3 or HIF-1 $\alpha$ CA were pretreated with PDTC, an NF-אB inhibitor and SP600125, a JNK inhibitor, for 30 min prior to stimulation with PMA (100nM) for $8 \mathrm{~h}$. HIF-1 $\alpha$, COX-2 and $\beta$-actin protein expression were analyzed by immunoblotting. 
A.

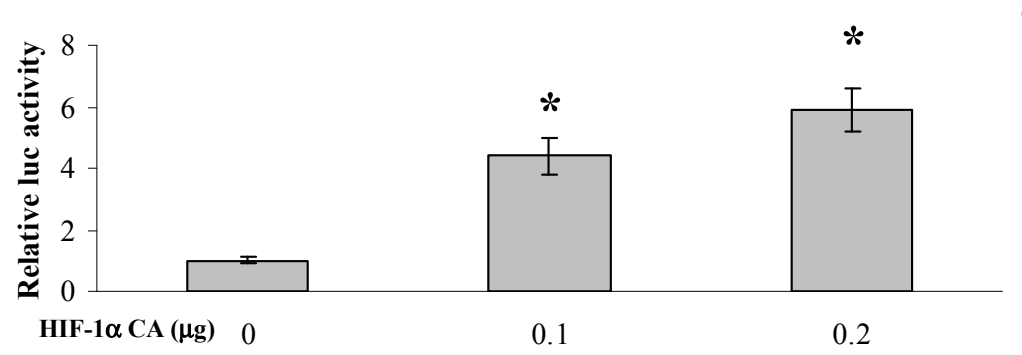

B.

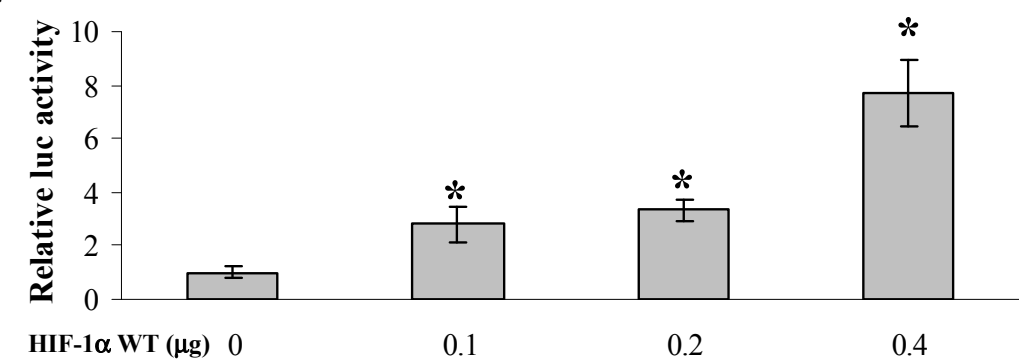

E

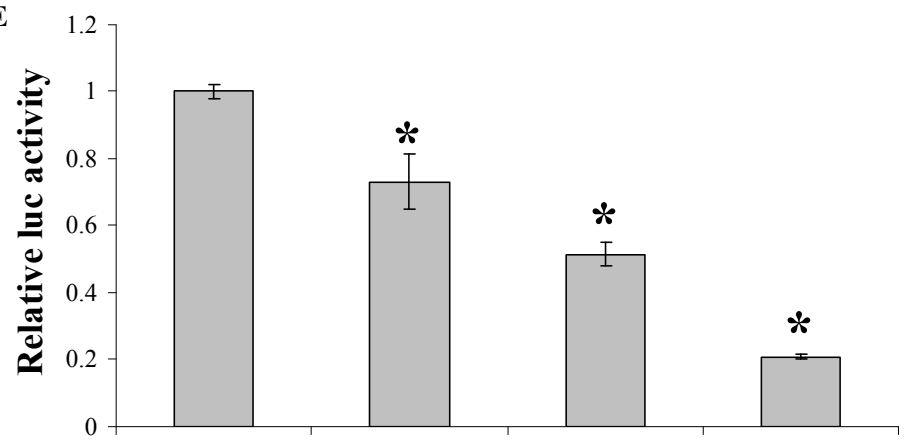

HIF-1 $\alpha$ DN $(\mu \mathrm{g}) \quad 0$

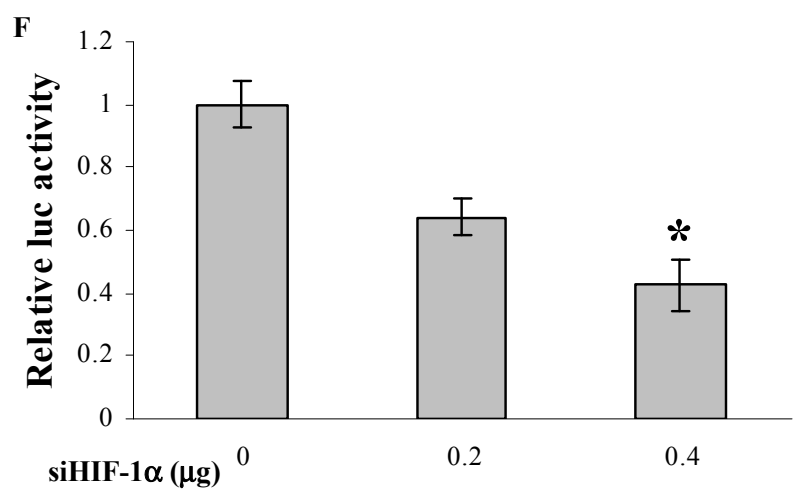

C

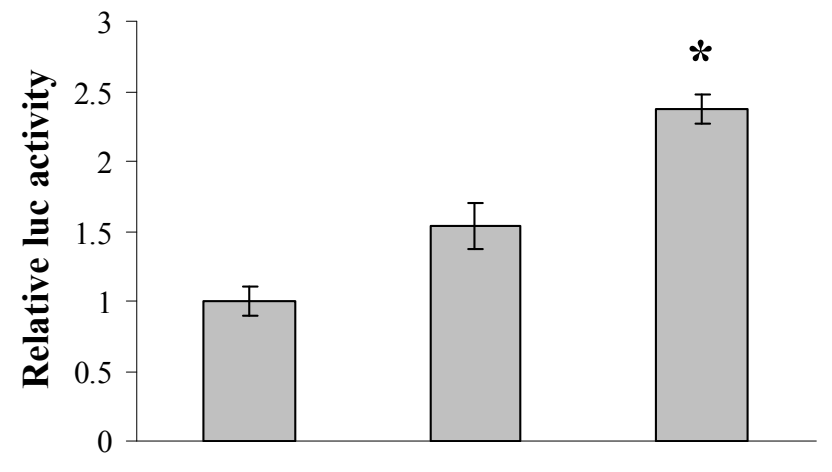

D

HIF-1 $\alpha$ WT $(\mu \mathrm{g}) \quad 0$

0.2

0.4

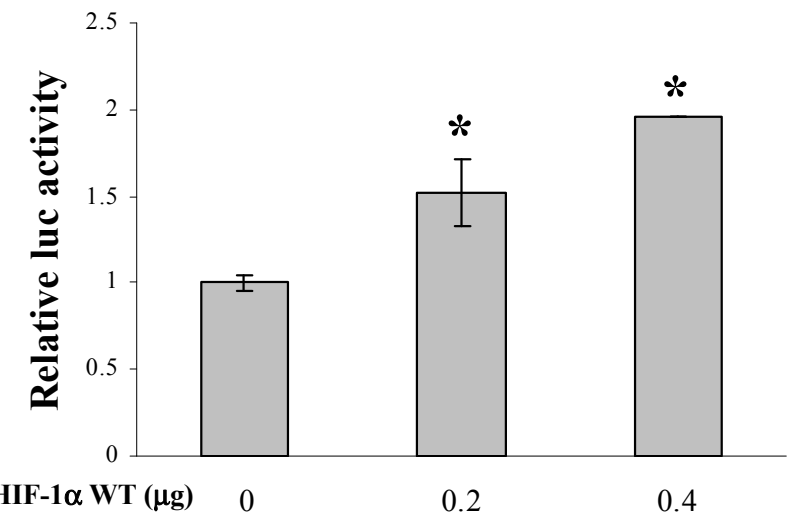

G
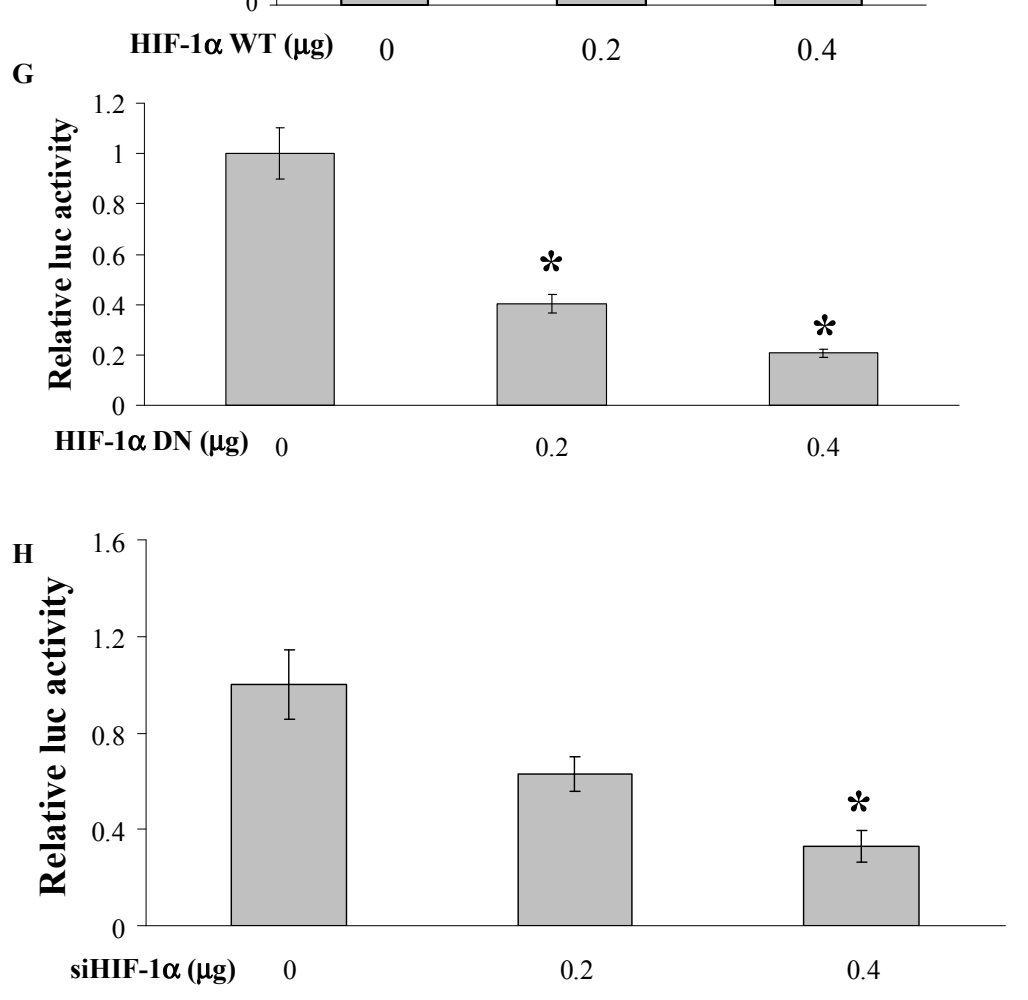
Figure 3. HIF-1 $\alpha$ expression controls COX-2 transcriptional activity. To assay the COX-2 transcriptional activiation, OVCAR3 and A2780 ovarian cancer cells and PC-3 prostate cancer cells were co-transfected with a COX-2 reporter containing the functional COX-2 promoter coupled to firefly luciferase (COX-2/LUC) and a pCMV- $\beta$ gal plasmid. Relative luciferase activity was determined by the ratio of luciferase: $\beta$-gal activity and normalized to the control. *_-indicates significant difference from normoxic control $(\mathrm{p}<0.05)$. A and $\boldsymbol{B}$, OVCAR-3 cells transfected with COX-2 reporter and either HIF-1 $\alpha$ CA (A) and HIF-1 $\alpha$ WT (B). C, A2780 cells transfected with COX-2 reporter and HIF-1 $\alpha$ WT. D, PC-3 cells transfected with COX-2 reporter and HIF-1 $\alpha$ WT. E and F, OVCAR-3 cells transfected with COX-2 reporter and either HIF-1 $\alpha$ DN (E) or siHIF-1 $\alpha$ (F). G and $\boldsymbol{H}$, A2780 cells transfected with COX-2 reporter and either HIF-1 $\alpha$ DN (G) or siHIF-1 $\alpha(\mathrm{H})$. I and J, PC-3 cells transfected with COX-2 reporter and either HIF-1 $\alpha$ DN (I) or siHIF-1 $\alpha(\mathrm{J})$.

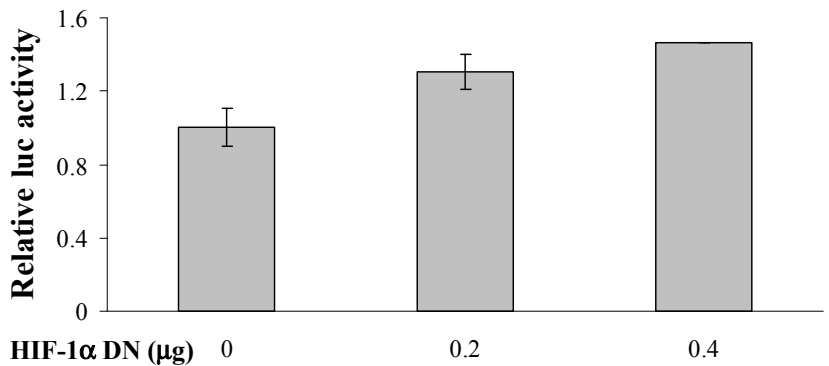

B

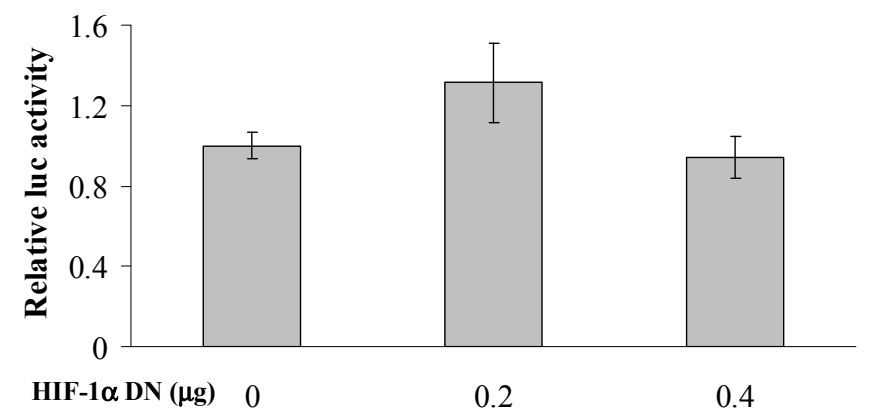

C

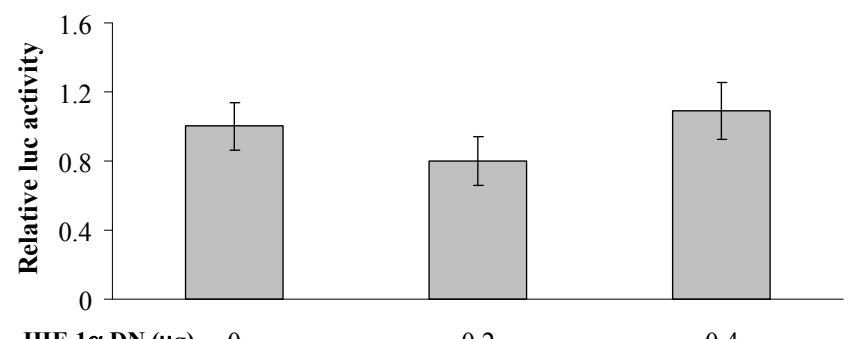

HIF-1 $\alpha$ DN $(\mu \mathrm{g}) \quad 0$

0.2

D

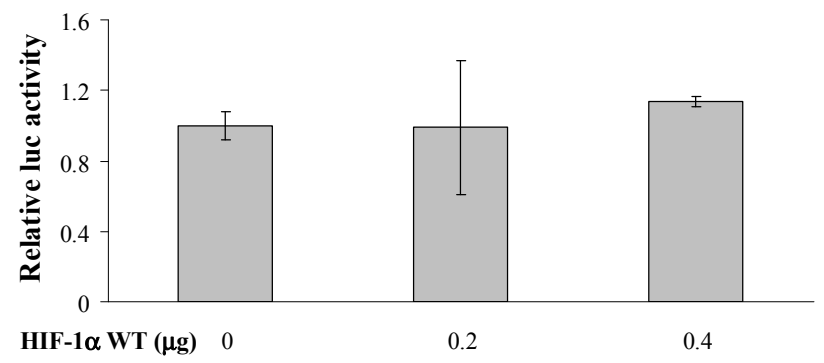


E

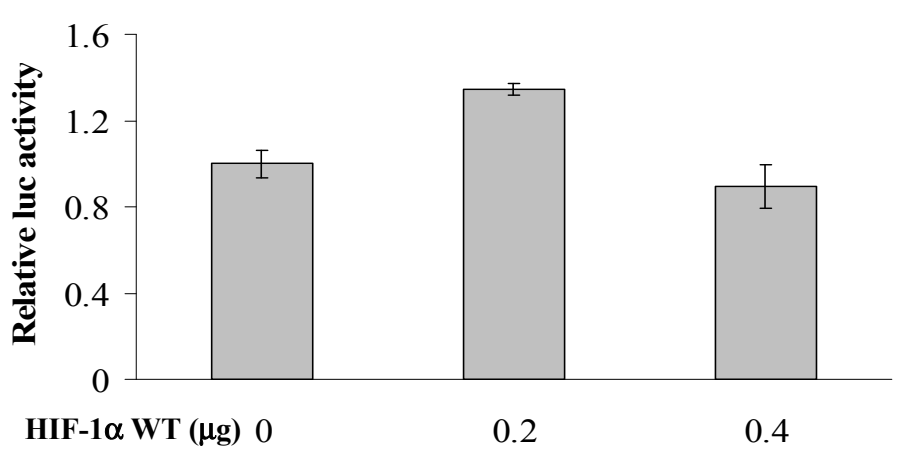

$\mathbf{F}$

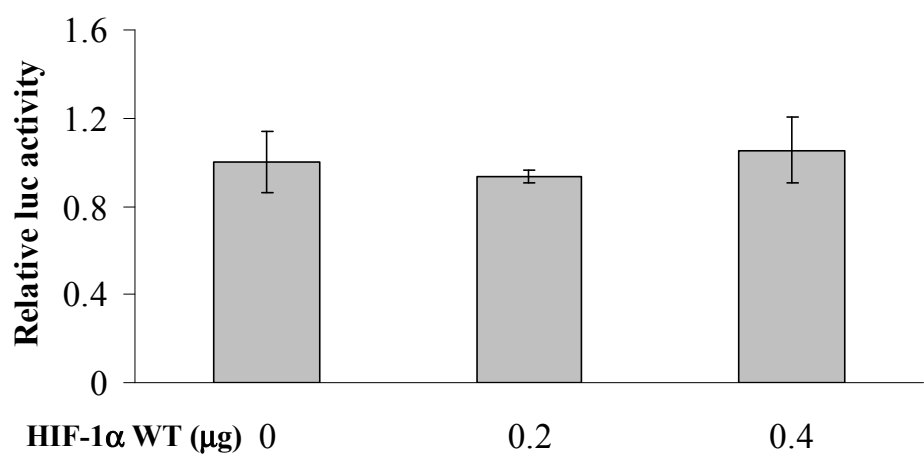

Figure 4. HIF-1 DNA binding is necessary for HIF-1 $\alpha$ to regulate COX-2 transcriptional activity. OVCAR-3 and A2780 ovarian cancer cells and PC-3 prostate cancer cells were cotransfected a COX-2 reporter containing the functional COX-2 promoter with a 3 bp substituition in the HRE rendering HIF-1 unable to bind, coupled to firefly luciferase (COX2 MUT/LUC), and a pCMV-Bgal plasmid. Relative luciferase activity was determined by the ratio of luciferase to $\beta$-gal activity and normalized to the control. * - indicates significant difference from normoxic control $(\mathrm{p}<0.05)$. A, OVCAR-3 cells were transfected with COX-2 mutant reporter and the indicated concentrations of HIF-1 $\alpha$ DN. B, A2780 cells were transfected with COX-2 mutant reporter and the indicated concentrations of HIF-1 $\alpha$ DN. C, PC-3 cells were transfected with COX-2 mutant reporter and the indicated concentrations of HIF-1 $\alpha$ DN. D, OVCAR-3 cells were transfected with COX-2 mutant reporter and the indicated concentrations of HIF-1 $\alpha$ WT. E, A2780 cells were transfected with COX-2 mutant reporter and the indicated concentrations of 
HIF-1 $\alpha$ WT. F, PC-3 cells were transfected with COX-2 mutant reporter and the indicated concentrations of HIF-1 $\alpha$ WT.

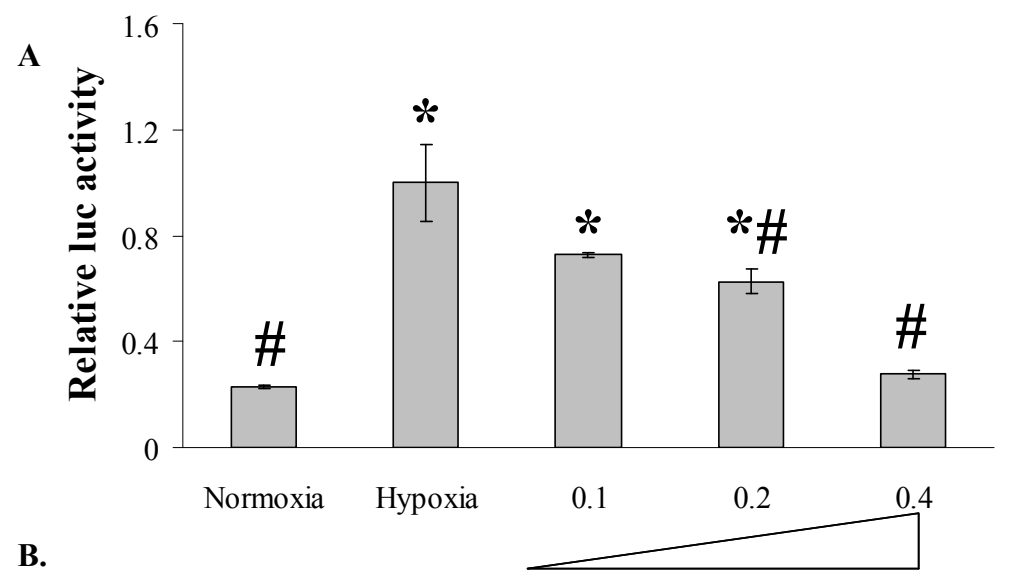

B.
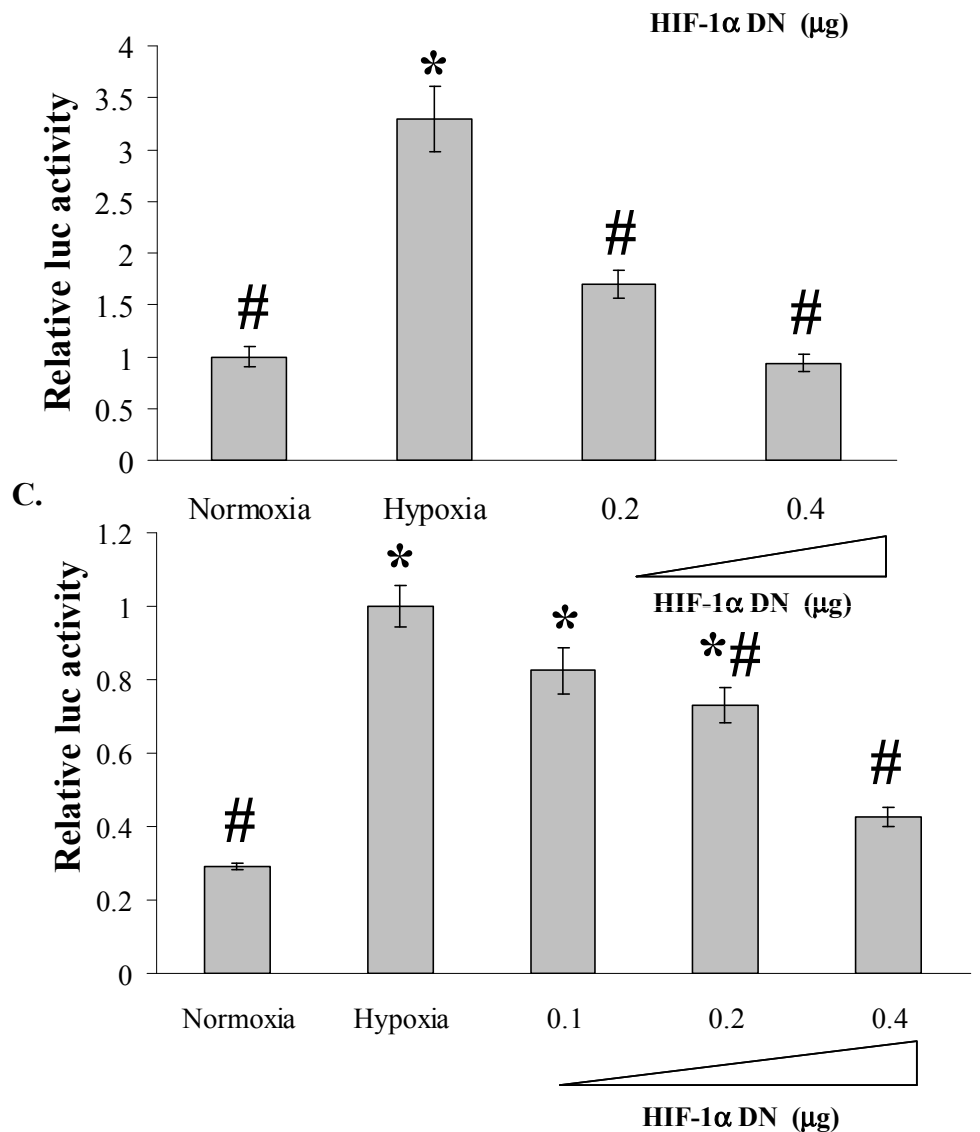

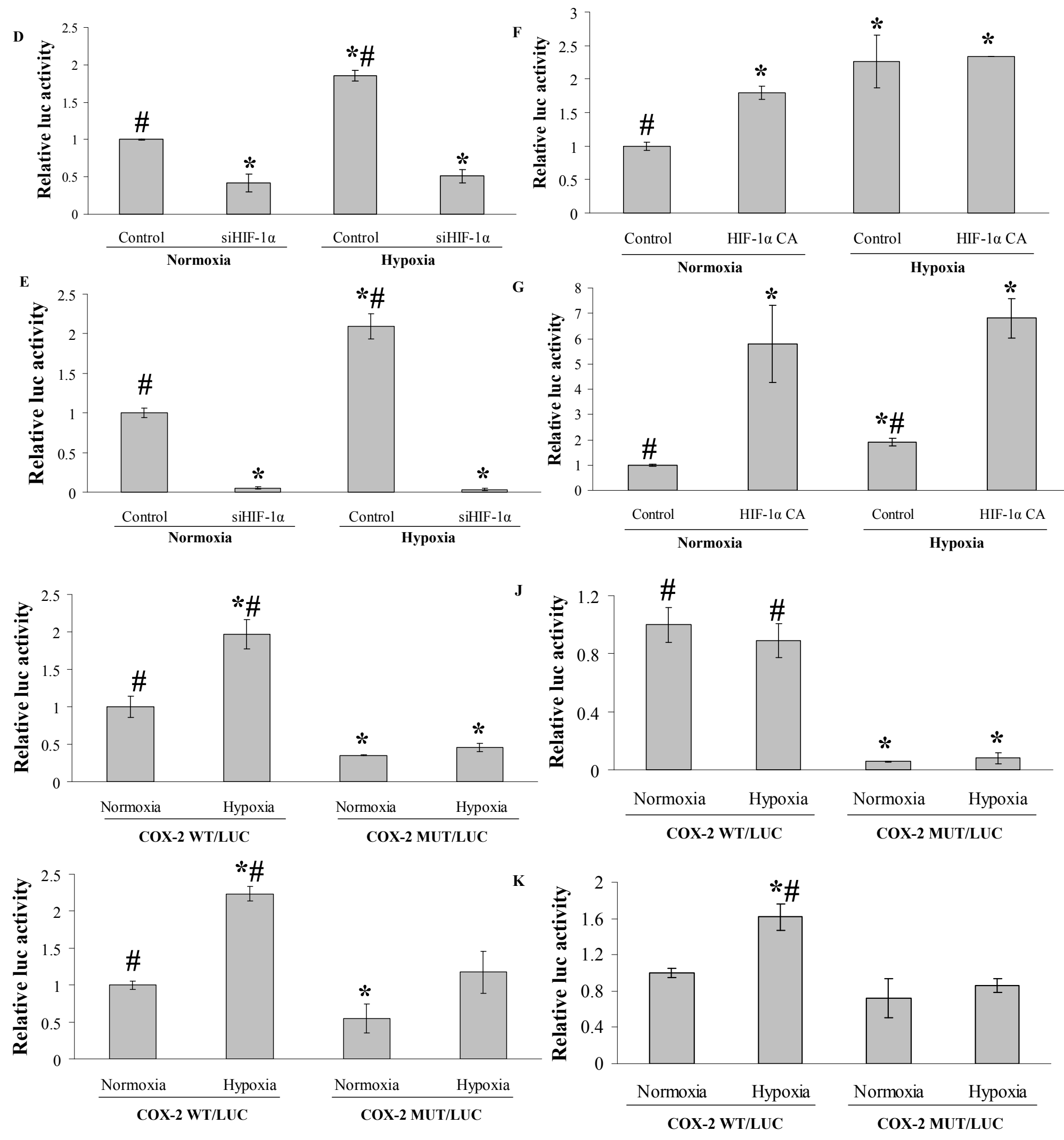


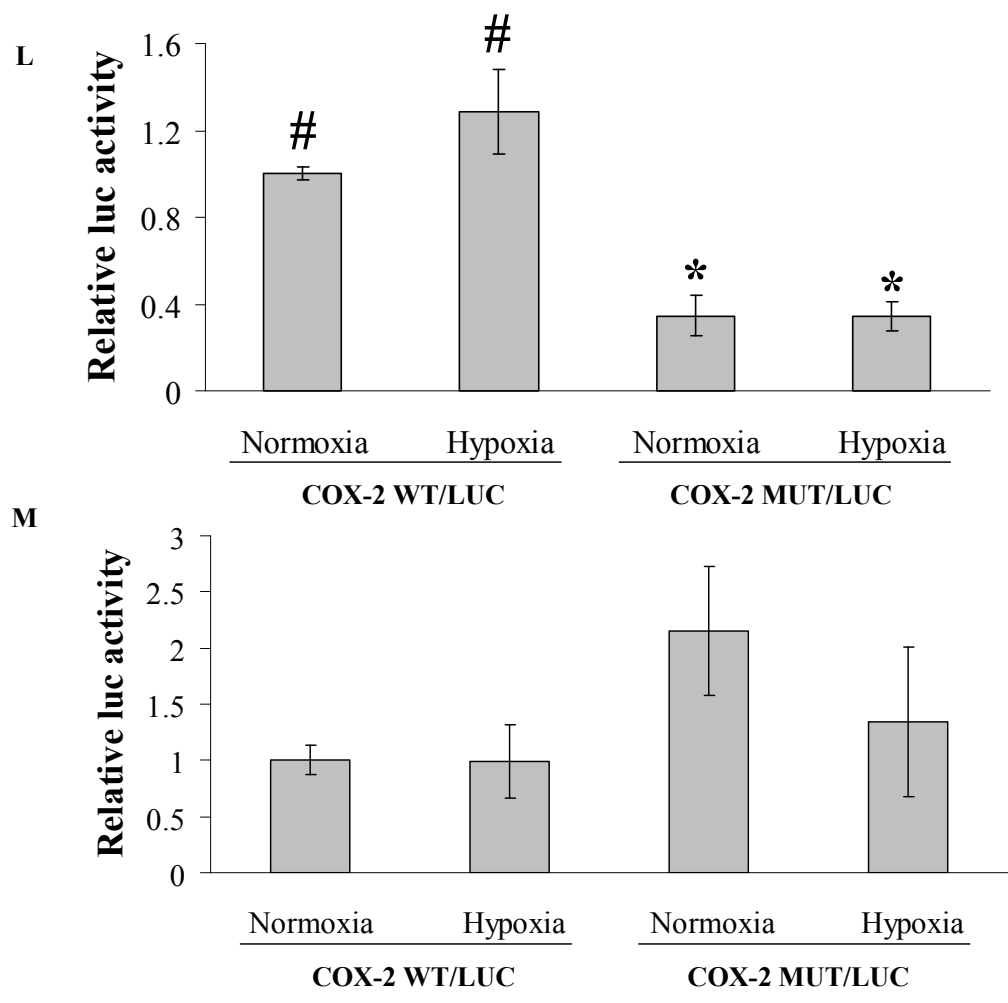

Figure 5. Hypoxic upregulation of COX-2 reporter activity requires HIF-1 binding to a functional HRE (-576/-584) in the COX-2 promoter. OVCAR-3 (A), A2780 (B) and PC-3 (C) cells were transfected with either HIF-1 $\alpha$ dominant negative or empty vector and COX-2 reporter then exposed to hypoxia for $24 \mathrm{~h}$ prior to collection. * - indicates significant difference from normoxic control $(\mathrm{p}<0.05)$. \#-indicates significant difference from cells cultured in hypoxia $(\mathrm{p}<0.05) . \quad$ D, A2780 cells stably expressing siControl or siHIF-1 $\alpha$ were transfected with COX-2 reporter then cultured in normoxia or hypoxia for $24 \mathrm{~h}$ prior to collection. *_-indicates significant difference from normoxic control $(\mathrm{p}<0.05)$. \#-indicates significant difference from normoxic cells expressing siHIF-1 $\alpha(\mathrm{p}<0.05)$. $\boldsymbol{E}$, PC-3 cells stably expressing either siControl or siHIF-1 $\alpha$ were transfected with COX-2 reporter and cultured in normoxia or hypoxia for $24 \mathrm{~h}$ prior to collection. *_-indicates significant difference from normoxic control $(\mathrm{p}<0.05)$. \#indicates significant difference from normoxic cells expressing siHIF-1 $\alpha(p<0.05)$. F, A2780 
cells stably expressing either pcDNA3 or HIF-1 $\alpha$ CA were transfected with COX-2 reporter and cultured in normoxia or hypoxia for $24 \mathrm{~h}$ prior to collection. *-indicates significant difference from normoxic control $(\mathrm{p}<0.05)$. \#-indicates significant difference from normoxic cells expressing HIF-1 $\alpha$ CA $(\mathrm{p}<0.05)$. G, PC-3 cells stably expressing either pcDNA3 or HIF-1 $\alpha$ CA were transfected with COX-2 reporter and cultured in normoxia or hypoxia for $24 \mathrm{~h}$ prior to collection. *-indicates significant difference from normoxic control $(\mathrm{p}<0.05)$. \#—indicates significant difference from normoxic cells expressing HIF-1 $\alpha$ CA $(\mathrm{p}<0.05) . \quad H, A 2780$ cells were transfected with either COX-2/LUC or COX-2 MUT/LUC, then cultured in normoxia or hypoxia for $24 \mathrm{~h} . *$ - indicates significant difference from normoxic control COX-2/LUC $(\mathrm{p}<0.05)$. \#-indicates significant difference from normoxic cells expressing COX2MUT/LUC $(\mathrm{p}<0.05)$. I, PC-3 cells were transfected with either COX-2/LUC or COX-2 MUT/LUC then cultured in normoxia or hypoxia for $24 \mathrm{~h} . *$-indicates significant difference from normoxic control COX-2/LUC) $(\mathrm{p}<0.05)$. \#-indicates significant difference from normoxic cells expressing COX2MUT/LUC. $\boldsymbol{J}$, A2780 cells stably expressing pcDNA3 or HIF-1 $\alpha$ CA transfected with either COX-2/LUC or COX-2 MUT/LUC, then cultured in normoxia or hypoxia for 24h. *-indicates significant difference from normoxic control COX-2/LUC $(\mathrm{p}<0.05)$. \#indicates significant difference from normoxic cells expressing COX2MUT/LUC. $\boldsymbol{K}$, A2780 cells stably expressing siControl or siHIF- $1 \alpha$ were transfected with either COX-2/LUC or COX2 MUT/LUC, then cultured in normoxia or hypoxia for $24 \mathrm{~h} . *$ - indicates significant difference from normoxic control COX-2/LUC $(\mathrm{p}<0.05)$. \# -indicates significant difference from normoxic cells expressing COX2MUT/LUC. L, PC-3 cells stably expressing pcDNA3 or HIF$1 \alpha$ CA were transfected with either COX-2/LUC or COX-2 MUT/LUC, then cultured in normoxia or hypoxia for $24 \mathrm{~h} . *$ - indicates significant difference from normoxic control COX- 
2/LUC $(\mathrm{p}<0.05)$. \#-indicates significant difference from normoxic cells expressing COX2MUT/LUC. $K$, PC-3 cells stably expressing siControl or siHIF-1 $\alpha$ were transfected with either COX-2/LUC or COX-2 MUT/LUC, then cultured in normoxia or hypoxia for $24 \mathrm{~h}$.

A

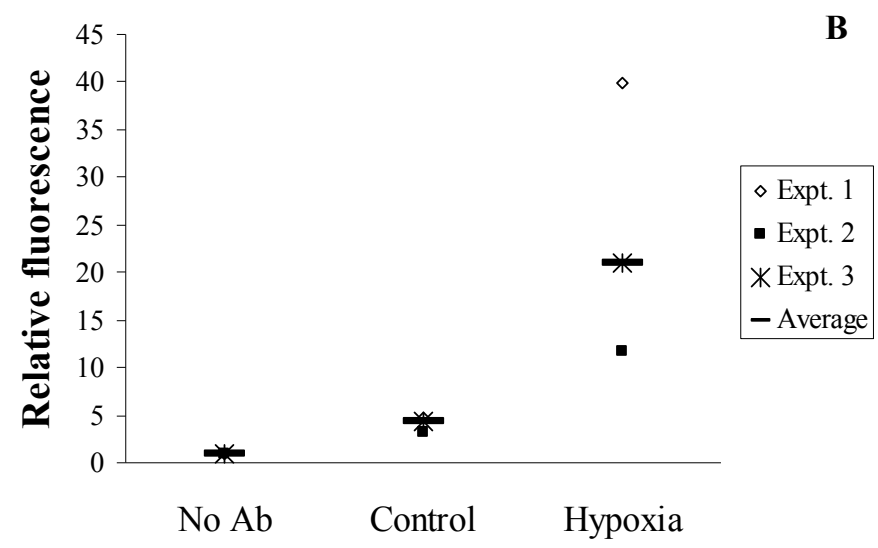

B

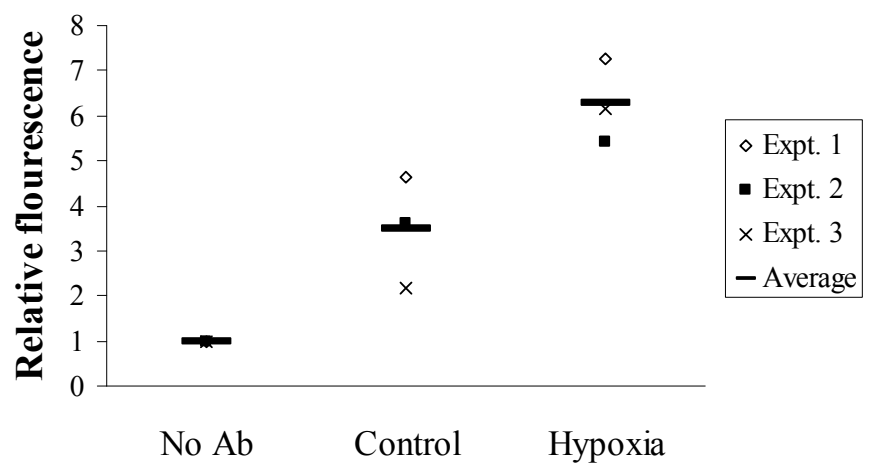

Figure 6. HIF-1 $\alpha$ binds the COX-2 promoter in A2780 cells in a hypoxia-dependent manner. A, A2780 cells were cultured for $8 \mathrm{~h}$ in normoxia or hypoxia, then crosslinked with formalin, sonicated and immunoprecipitated with HIF- $1 \alpha$ antibody as described in Materials and Methods. Real-time PCR results are normalized to $10 \%$ input control. The VEGF promoter sequence was amplified in these experiments using primers that flank the putative HRE in the VEGF promoter to determine the efficacy of our technique. The data shown are the results of three separate experiments. B, A2780 cells were cultured for $8 \mathrm{~h}$ in hypoxia, then crosslinked with formalin, sonicated and immunoprecipitated with HIF- $1 \alpha$ antibody as described in Materials and Methods. Real-time PCR results are normalized to $10 \%$ input control. The COX-2 promoter sequence was amplified using primers that flank the HRE (-576/-584). The data shown are the results of three separate experiments. 

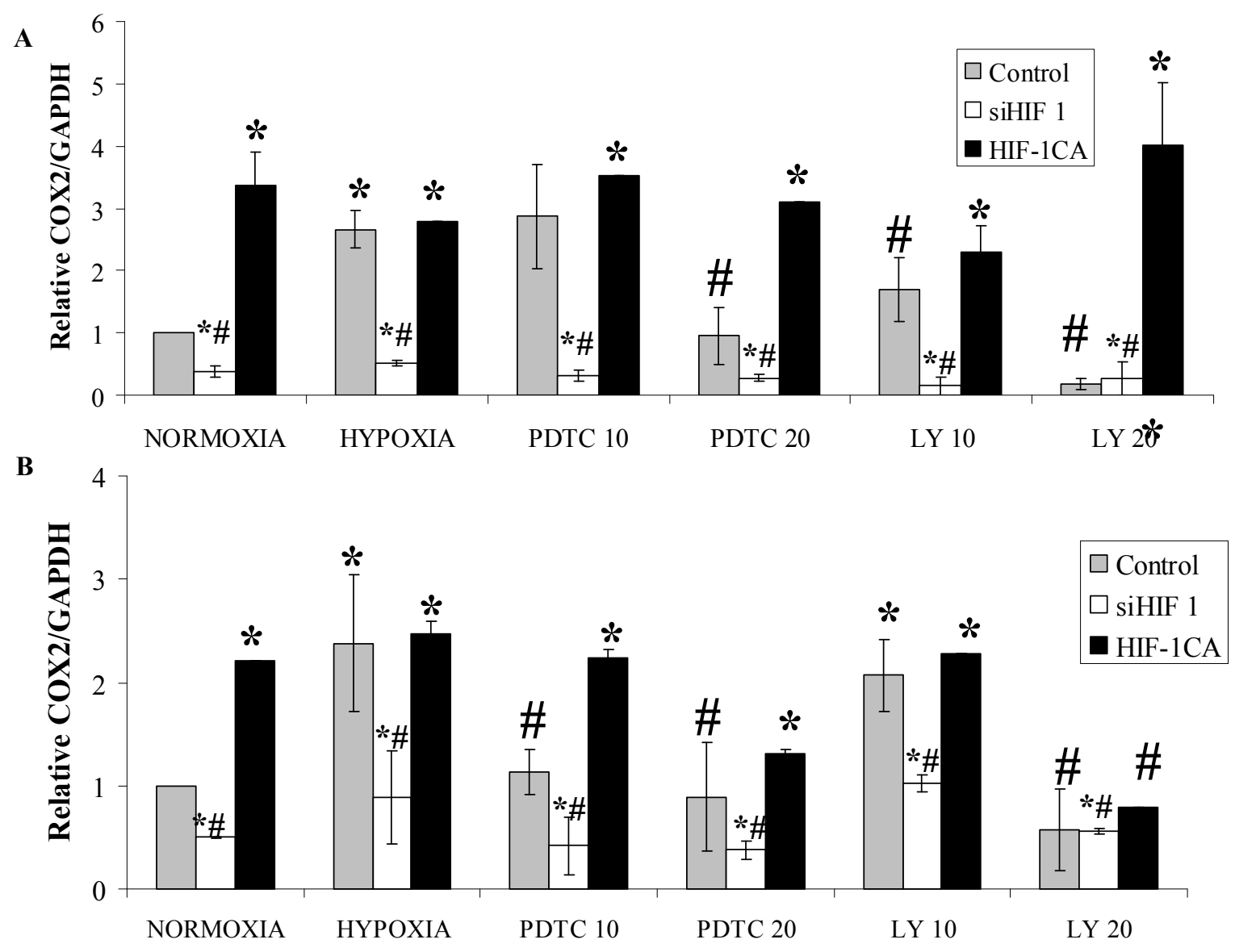

C

A2780/pcDNA3 A2780/HIF-CA

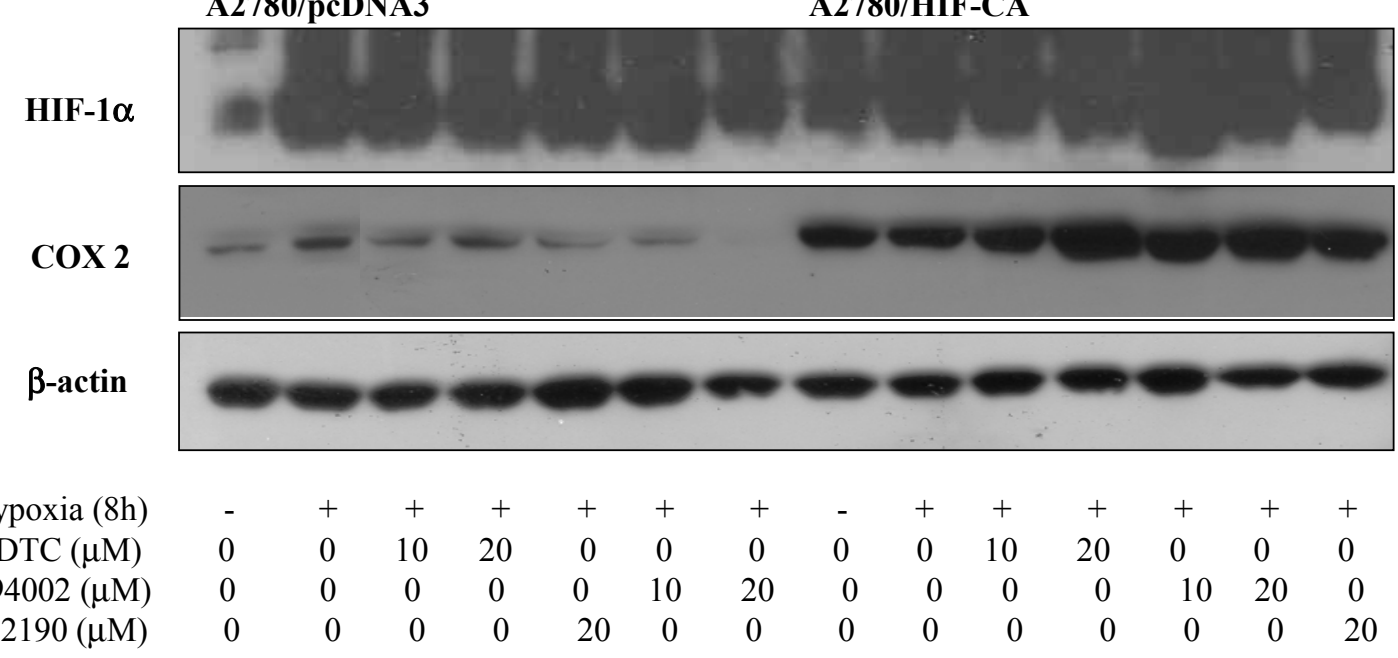


D

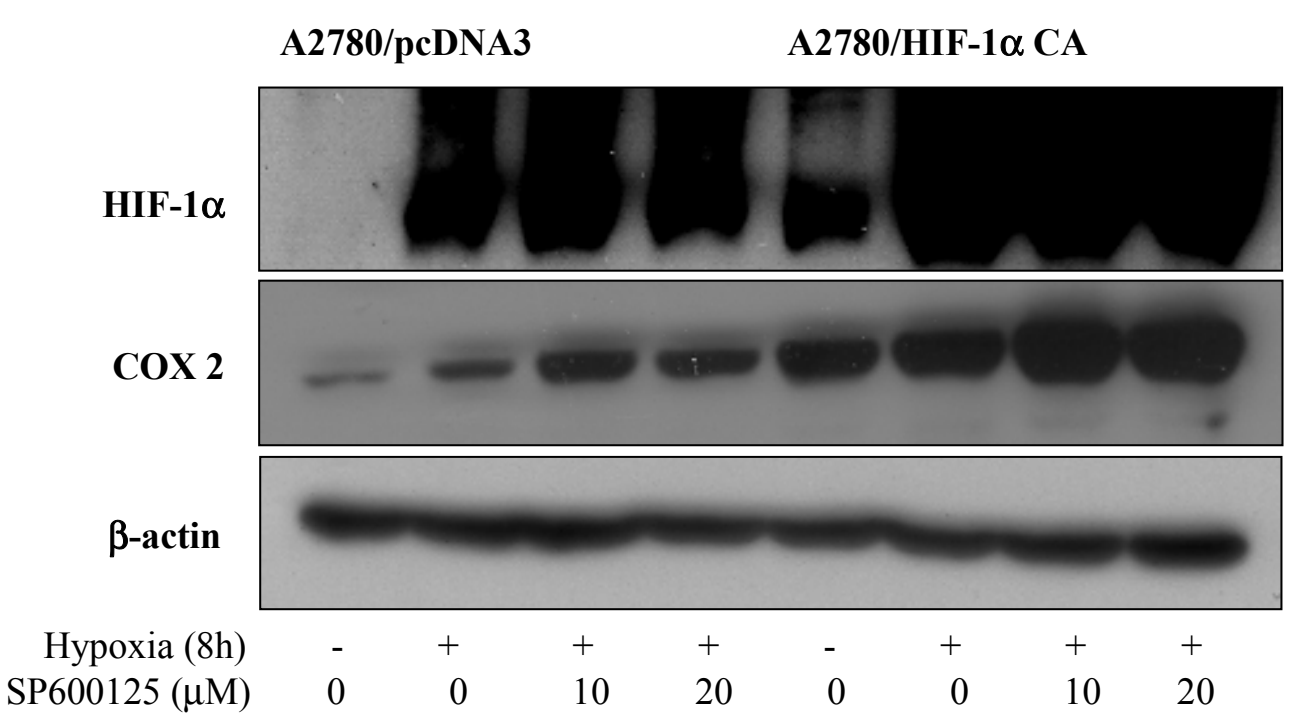

Figure 7. Inhibition of PI3K and NF- $\mathrm{KB}$ inhibits COX-2 mRNA and protein expression in a HIF$1 \alpha$ dependent manner. A and B, A2780 (A) and PC-3 (B) cells stably expressing siHIF-1 $\alpha$ or HIF-1 $\alpha$ CA were pretreated for 30min with the indicated inhibitors, then cultured in normoxia or hypoxia for 8h. mRNA was measured using Real-time RT-PCR as described in Materials and Methods. *_indicates significant difference from normoxic vector control $(\mathrm{p}<0.05)$. \#indicates significant difference from vector-expressing cells subjected to hypoxia $(\mathrm{p}<0.05) . C$, A2780 cells stably expressing PCDNA 3 or HIF-1 $\alpha$ CA were treated as above. Levels of HIF$1 \alpha$, COX-2 and $\beta$-actin protein expression were analyzed by immunoblotting. $\quad \boldsymbol{D}$ and $\boldsymbol{E}$. A2780 cells stably expressing HIF-1 $\alpha$ CA were pretreated with the indicated drugs for $30 \mathrm{~min}$, and then cultured in normoxia or hypoxia for $8 \mathrm{~h}$. Levels of HIF-1 $\alpha, \mathrm{COX}-2$ and $\beta$-actin protein expression were analyzed by immunoblotting. 
A.

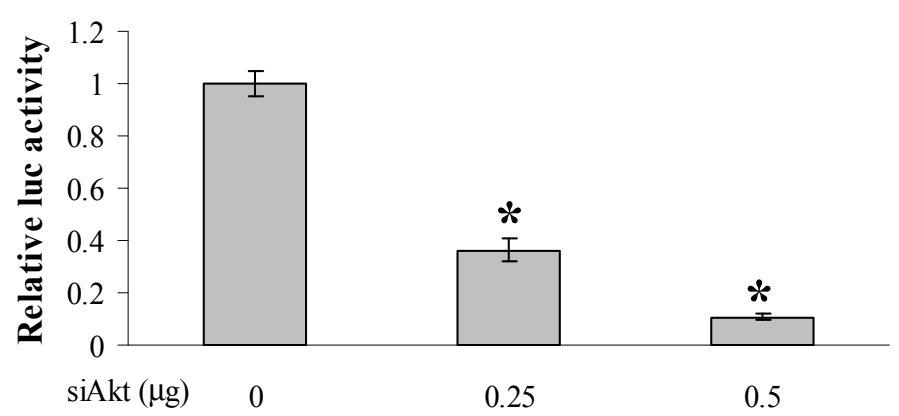

B.

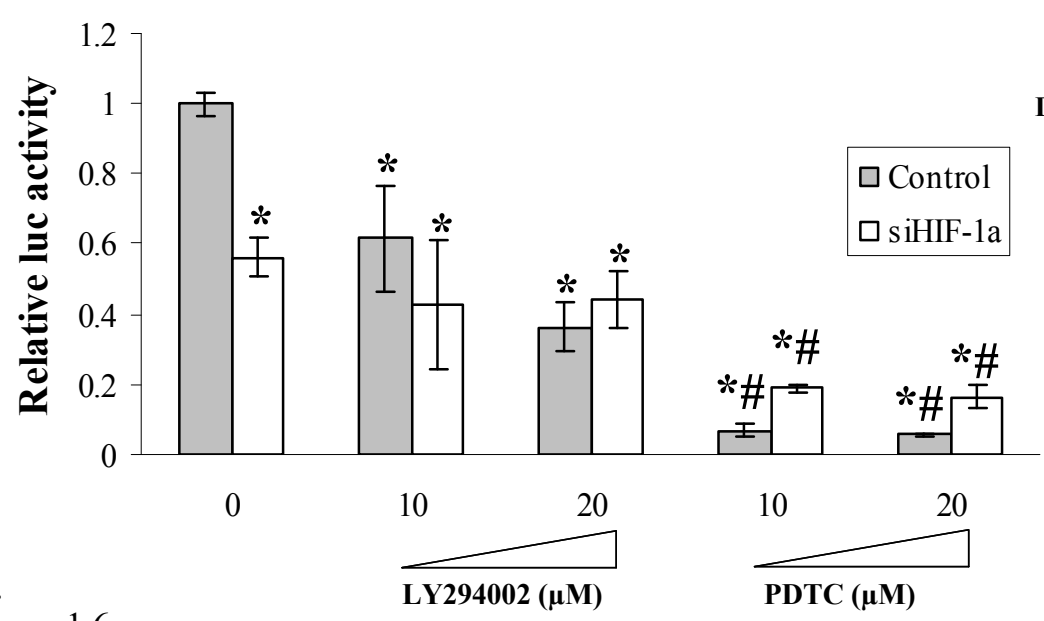

E.

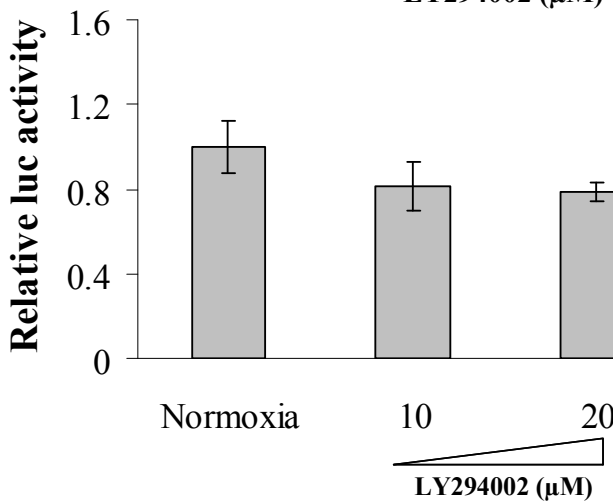

C.

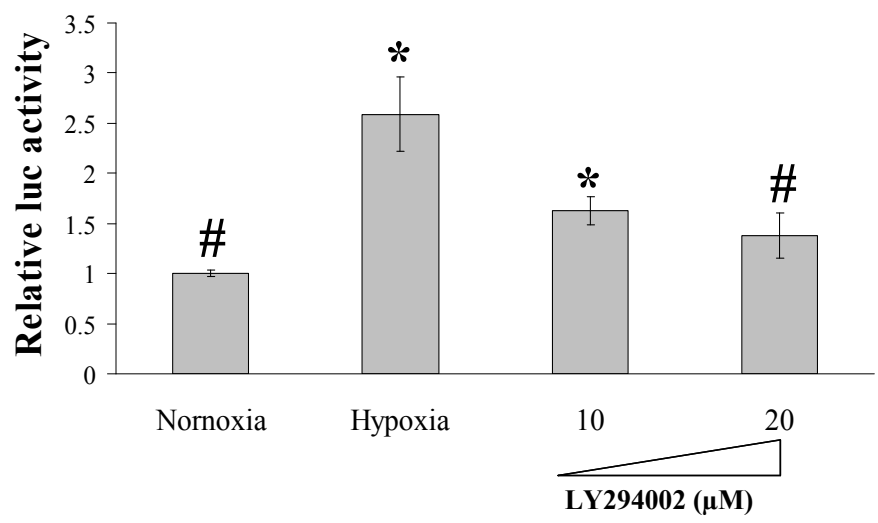

D.

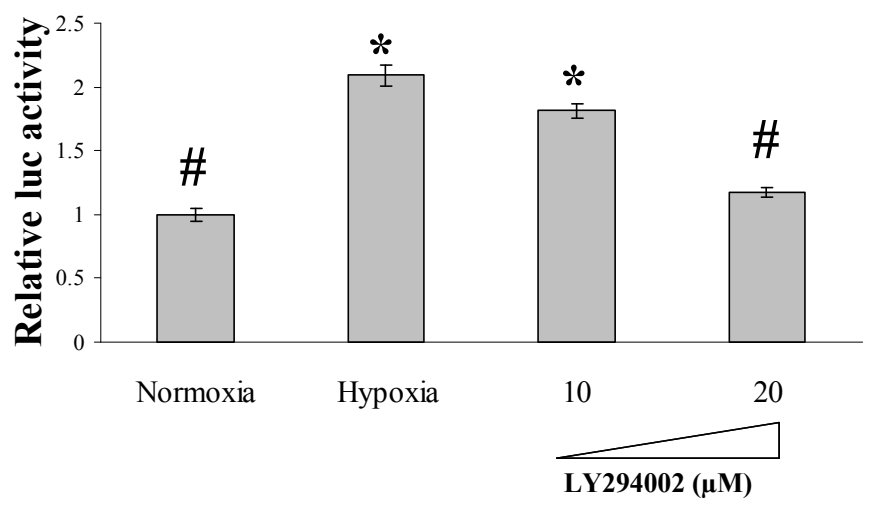

Figure 8. PI3K regulates COX-2 transcription through HIF-1 $\alpha$ and the predicted HRE (-576/584) in the COX-2 promoter. COX-2 transcriptional activity was measured as described above using COX-2/LUC. A, A2780 cells were co-transfected with COX2/LUC and siRNA specific for Akt (siAkt). *-indicates significant difference from control $(\mathrm{p}<0.05) . \quad \boldsymbol{B}$, A2780 cells stably expressing either siControl or siHIF-1 $\alpha$ were transfected with COX2/LUC, and then treated with the indicated doses of the PI3 kinase inhibitor, LY294002 or the NF- $\kappa$ B inhibitor, PDTC. *- 
indicates significant difference from control $(\mathrm{p}<0.05)$. \#-indicates significant difference from cells expressing HIF-1 $\alpha(\mathrm{p}<0.05)$. C, A2780 cells were transfected with COX2/LUC, pre-treated with LY294002 for $30 \mathrm{~min}$, then cultured in normoxia or hypoxia for $24 \mathrm{~h} . *$ _-indicates significant difference from normoxic control $(\mathrm{p}<0.05)$. \#-indicates significant difference from cells cultured in hypoxia $(\mathrm{p}<0.05)$. $\boldsymbol{D}$, PC-3 cells were transfected with COX2/MUT, pretreated with LY294002 for $30 \mathrm{~min}$, then cultured in normoxia or hypoxia for $24 \mathrm{~h} .{ }^{*}$ _-indicates significant difference from normoxic control $(\mathrm{p}<0.05)$. \#-indicates significant difference from cells cultured in normoxia or hypoxia $(\mathrm{p}<0.05)$. $\boldsymbol{E}, \mathrm{A} 2780$ cells were transfected with COX-2 MUT/LUC, pre-treated with LY294002, then cultured in normoxia or hypoxia for 24h. \#indicates significant difference from cells exposed to hypoxia $(\mathrm{p}<0.05)$.

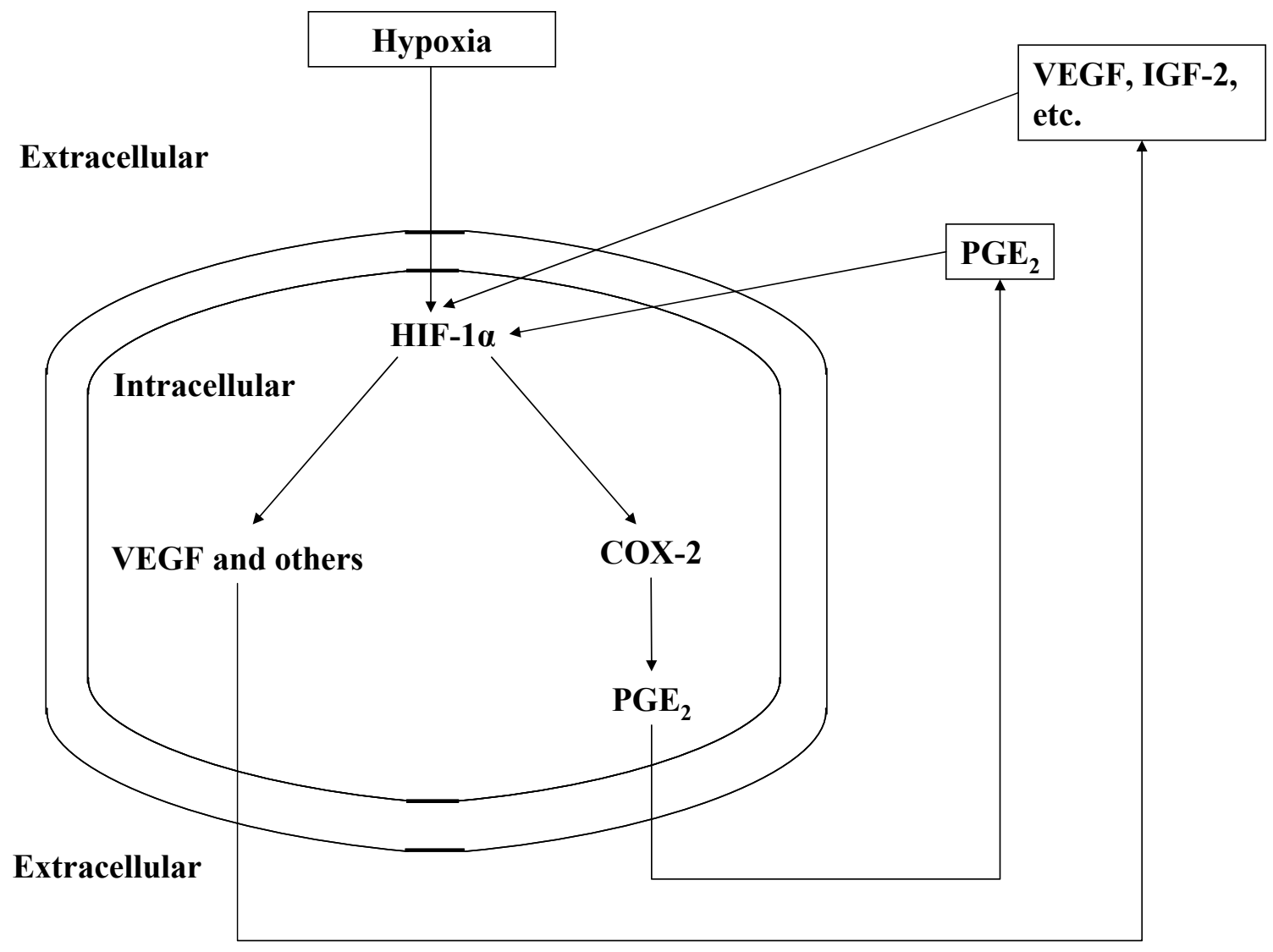


Figure 9. Proposed HIF-1-COX2- $\mathrm{PGE}_{2}$ positive feed-back loop. Hypoxia triggers HIF-1 $\alpha$ stabilization in a tumor, which induces the expression of pro-angiogenic factors, such as VEGF and $\mathrm{PGE}_{2}$ are released. These secreted factpors could, in turn, act in an autocrine or paracrine fashion to stimulate HIF-1 $\alpha$ expression, leading to even greater levels of angiogenesis within a tumor in areas of hypoxia. 
CHAPTER 6: GENERAL SUMMARY AND CONCLUSIONS 
The studies performed for this dissertation seek to understand the role of HIF-1 $\alpha$ in human cancer using ovarian and prostate cancer cells as model systems. Initially we wanted to study the mechanism by which HIF-1 $\alpha$ is over-expressed in the absence of stimuli in cancer cells with activated PI3K/Akt signaling. We found that PI3K/Akt was regulating HIF-1 $\alpha$ expression via two distinct targets, p70S6K1 and hdm2. Similarly, Bardos et al. showed that PI3K regulates growth factor stimulation of HIF-1 $\alpha$ expression at the level of translation rate via HDM2 (6). Furthermore, one of our collaborators has shown that HIF-1 $\alpha$ and Mdm2 interact physically in a p53-independent manner (74). This interaction was shown to activate HIF-1 $\alpha$ and HIF-1 transcriptional activity, which is consistent with our results (74). These data suggest that PI3K controls HIF-1 $\alpha$ expression and HIF-1 dependent transcription at several levels.

After examining the mechanism by which basal expression of HIF-1 $\alpha$ is upregulated in cancer cells by activation of PI3K signaling, we wanted to determine if this effect had physiological significance. To do this, we generated cancer cells that stably expressed siRNA specific to HIF-1 $\alpha$ (siHIF-1 $\alpha$ ) and examined the characteristics of these cells. In chapter 3 , we observed that cells expressing siHIF-1 $\alpha$ exhibited decreased motility and invasion. Furthermore, tumors generated from cells expressing siHIF-1 $\alpha$ exhibited dramatically different behavior based upon their microenvironment. In an avascular microenvironment, inhibition of HIF-1 $\alpha$ expression by siRNA dramatically decreased tumor size and angiogenesis. Conversely, in a subcutaneous microenvironment which has a pre-existing microvasculature, inhibition of HIF-1 slightly increased tumor size with no visible effect on angiogenesis. During the preparation of this work, another study found that vascularity of the microenvironment also dramatically affected the role of HIF-1 $\alpha$ in glioblastoma (12). These results have significant implications for tumor therapy. Currently, several HIF-1 $\alpha$ inhibitors are in clinical trials for a variety of different 
types of cancer. Our data and the study mentioned previously indicate that the efficacy of these treatments will depend on the microenvironment of the tumor being treated.

In chapter 4 , we further investigate the role of HIF-1 $\alpha$ in cancer. In this study we showed that chemotherapy inhibited HIF-1 $\alpha$, and that inhibition of HIF-1 $\alpha$ expression led to increased sensitivity to chemotherapy in ovarian and prostate cancer cells. Furthermore, forced expression of an active form of HIF- $1 \alpha$ led to increased chemoresistance. It is well established that hypoxia can contribute chemotherapy resistance in cancer (41). Bid, a pro-apoptotic member of the Bcl2 family, is also down-regulated by HIF-1 $1 \alpha$ expression and has been linked to resistance to chemotherapy (32). It has been shown that p-glycoprotein, the product of the multi-drug resistance gene, is upregulated by hypoxia through HIF-1 $\alpha$ expression (22). Here we show functional evidence linking chemoresistance and HIF-1 $\alpha$ expression levels in ovarian and prostate cancer. Our data indicate that inhibition of HIF-1 $\alpha$ expression will be advantageous as an adjunct to conventional chemotherapy in the treatment of human cancer.

In the final chapter, we found that COX-2 is a novel transcriptional target of HIF-1 $\alpha$ in human cancer. COX-2 is a potent inducer of angiogenesis via its secreted products PGE2 and TXA. It is also upregulated by many of the stimuli that also affect HIF-1 $\alpha$ expression such as growth factors, oncogenes and hypoxia (27). However, previous data indicated that the observed upregulation of COX-2 expression in hypoxia is mediated by NF- $\mathrm{\kappa B}$ (92). Our data do not rule out a role for NF- $\mathrm{\kappa B}$ in regulating $\mathrm{COX}-2$ transcription, but we show that the primary mediator of COX-2 transcriptional activity in cancer is mediated by HIF-1 $\alpha$. Because $\mathrm{PGE}_{2}$, a product of COX-2 enzymatic activity, can increase the expression of HIF-1 $\alpha$ we proposed a possible autocrine or paracrine positive feedback loop connecting HIF-1 $\alpha$ and COX-2 (Ch. 5, Figs. 9) in which hypoxia triggers HIF-1 $\alpha$ expression and HIF-1 mediated transcriptional activation of 
$\mathrm{COX}-2$. This leads to increased $\mathrm{PGE}_{2}$ production which further stimulates HIF-1 $\alpha$ expression.

This positive feedback loop would be essential in the early development of a tumor, when the tumor requires angiogenesis for growth. Even a low level of hypoxia would be sufficient to drive angiogenesis, rendering the tumor even more sensitive to decreased blood flow.

Overall we have shown that PI3K-mediated HIF-1 $\alpha$ expression plays a crucial role in ovarian cancer, not only because of its effects on angiogenesis, but also due to an effect on other negative measures of clinical outcome, such as invasiveness and chemotherapy resistance.

Furthermore, our data also indicates, with several caveats, that HIF-1 $\alpha$ will be a good target for clinical therapy, particularly in combination with conventional chemotherapy.

\section{Reference List}

1. Alessi, D. R., S. R. James, C. P. Downes, A. B. Holmes, P. R. Gaffney, C. B. Reese, and P. Cohen. 1997. Characterization of a 3-phosphoinositide-dependent protein kinase which phosphorylates and activates protein kinase Balpha. Curr.Biol. 7:261-269.

2. Anderson, K. E., J. Coadwell, L. R. Stephens, and P. T. Hawkins. 1998. Translocation of PDK-1 to the plasma membrane is important in allowing PDK-1 to activate protein kinase B. Curr.Biol. 8:684-691.

3. Anderson, K. E. and S. P. Jackson. 2003. Class I phosphoinositide 3-kinases. Int.J.Biochem.Cell Biol. 35:1028-1033.

4. Aoki, M., O. Batista, A. Bellacosa, P. Tsichlis, and P. K. Vogt. 1998. The akt kinase: molecular determinants of oncogenicity. Proc.Natl.Acad.Sci.U.S.A 95:14950-14955.

5. Attiga, F. A., P. M. Fernandez, A. T. Weeraratna, M. J. Manyak, and S. R. Patierno. 2000. Inhibitors of prostaglandin synthesis inhibit human prostate tumor cell invasiveness and reduce the release of matrix metalloproteinases. Cancer Res 60:4629-4637.

6. Bardos, J. I., N. M. Chau, and M. Ashcroft. 2004. Growth factor-mediated induction of HDM2 positively regulates hypoxia-inducible factor 1alpha expression 1. Mol.Cell Biol. 24:2905-2914.

7. Besson, A., S. M. Robbins, and V. W. Yong. 1999. PTEN/MMAC1/TEP1 in signal transduction and tumorigenesis. Eur.J.Biochem. 263:605-611. 
8. Bi, L., I. Okabe, D. J. Bernard, A. Wynshaw-Boris, and R. L. Nussbaum. 1999. Proliferative defect and embryonic lethality in mice homozygous for a deletion in the p110alpha subunit of phosphoinositide 3-kinase. J.Biol.Chem. 274:10963-10968.

9. Birner, P., B. Gatterbauer, G. Oberhuber, M. Schindl, K. Rossler, A. Prodinger, H. Budka, and J. A. Hainfellner. 2001. Expression of hypoxia-inducible factor-1 alpha in oligodendrogliomas: its impact on prognosis and on neoangiogenesis. Cancer 92:165-171.

10. Birner, P., M. Schindl, A. Obermair, G. Breitenecker, and G. Oberhuber. 2001. Expression of hypoxia-inducible factor 1alpha in epithelial ovarian tumors: its impact on prognosis and on response to chemotherapy. Clin.Cancer Res. 7:1661-1668.

11. Birner, P., M. Schindl, A. Obermair, C. Plank, G. Breitenecker, and G. Oberhuber. 2000. Overexpression of hypoxia-inducible factor 1alpha is a marker for an unfavorable prognosis in early-stage invasive cervical cancer. Cancer Res. 60:4693-4696.

12. Blouw, B., H. Song, T. Tihan, J. Bosze, N. Ferrara, H. P. Gerber, R. S. Johnson, and G. Bergers. 2003. The hypoxic response of tumors is dependent on their microenvironment. Cancer Cell 4:133-146.

13. Bos, R., H. Zhong, C. F. Hanrahan, E. C. Mommers, G. L. Semenza, H. M. Pinedo, M. D. Abeloff, J. W. Simons, P. J. van Diest, and W. E. van der. 2001. Levels of hypoxiainducible factor-1 alpha during breast carcinogenesis. J.Natl.Cancer Inst. 93:309-314.

14. Brunn, G. J., J. Williams, C. Sabers, G. Wiederrecht, J. C. Lawrence, Jr., and R. T. Abraham. 1996. Direct inhibition of the signaling functions of the mammalian target of rapamycin by the phosphoinositide 3-kinase inhibitors, wortmannin and LY294002. EMBO J. 15:5256-5267.

15. Buchanan, F. G., D. Wang, F. Bargiacchi, and R. N. DuBois. 2003. Prostaglandin E2 regulates cell migration via the intracellular activation of the epidermal growth factor receptor. $\mathrm{J}$ Biol.Chem. 278:35451-35457.

16. Carmeliet, P., Y. Dor, J. M. Herbert, D. Fukumura, K. Brusselmans, M. Dewerchin, M. Neeman, F. Bono, R. Abramovitch, P. Maxwell, C. J. Koch, P. Ratcliffe, L. Moons, R. K. Jain, D. Collen, and E. Keshert. 1998. Role of HIF-1alpha in hypoxia-mediated apoptosis, cell proliferation and tumour angiogenesis

7. Nature 394:485-490.

17. Chan, D. A., P. D. Sutphin, N. C. Denko, and A. J. Giaccia. 2002. Role of prolyl hydroxylation in oncogenically stabilized hypoxia-inducible factor-1alpha. J.Biol.Chem. 277:40112-40117.

18. Chang, H. W., M. Aoki, D. Fruman, K. R. Auger, A. Bellacosa, P. N. Tsichlis, L. C. Cantley, T. M. Roberts, and P. K. Vogt. 1997. Transformation of chicken cells by the gene encoding the catalytic subunit of PI 3-kinase. Science 276:1848-1850. 
19. Chapple, K. S., N. Scott, P. J. Guillou, P. L. Coletta, and M. A. Hull. 2002. Interstitial cell cyclooxygenase- 2 expression is associated with increased angiogenesis in human sporadic colorectal adenomas. J Pathol 198:435-441.

20. Chen, J., S. Zhao, K. Nakada, Y. Kuge, N. Tamaki, F. Okada, J. Wang, M. Shindo, F. Higashino, K. Takeda, M. Asaka, H. Katoh, T. Sugiyama, M. Hosokawa, and M. Kobayashi. 2003. Dominant-negative hypoxia-inducible factor-1 alpha reduces tumorigenicity of pancreatic cancer cells through the suppression of glucose metabolism

1. Am.J.Pathol. 162:1283-1291.

21. Cianchi, F., C. Cortesini, P. Bechi, O. Fantappie, L. Messerini, A. Vannacci, I. Sardi, G. Baroni, V. Boddi, R. Mazzanti, and E. Masini. 2001. Up-regulation of cyclooxygenase 2 gene expression correlates with tumor angiogenesis in human colorectal cancer. Gastroenterology 121:1339-1347.

22. Comerford, K. M., T. J. Wallace, J. Karhausen, N. A. Louis, M. C. Montalto, and S. P. Colgan. 2002. Hypoxia-inducible factor-1-dependent regulation of the multidrug resistance (MDR1) gene. Cancer Res 62:3387-3394.

23. Cowden Dahl, K. D., S. E. Robertson, V. M. Weaver, and M. C. Simon. 2005. Hypoxia-inducible factor regulates alphavbeta3 integrin cell surface expression 42. Mol.Biol.Cell 16:1901-1912.

24. Cross, D. A., D. R. Alessi, P. Cohen, M. Andjelkovich, and B. A. Hemmings. 1995. Inhibition of glycogen synthase kinase-3 by insulin mediated by protein kinase B. Nature 378:785-789.

25. Dang, C. V. and G. L. Semenza. 1999. Oncogenic alterations of metabolism. Trends Biochem.Sci. 24:68-72.

26. del Peso, L., M. Gonzalez-Garcia, C. Page, R. Herrera, and G. Nunez. 1997. Interleukin-3-induced phosphorylation of BAD through the protein kinase Akt. Science 278:687689.

27. Dempke, W., C. Rie, A. Grothey, and H. J. Schmoll. 2001. Cyclooxygenase-2: a novel target for cancer chemotherapy? J Cancer Res Clin Oncol. 127:411-417.

28. Dhand, R., K. Hara, I. Hiles, B. Bax, I. Gout, G. Panayotou, M. J. Fry, K. Yonezawa, M. Kasuga, and M. D. Waterfield. 1994. PI 3-kinase: structural and functional analysis of intersubunit interactions. EMBO J. 13:511-521.

29. Di Cristofano, A. and P. P. Pandolfi. 2000. The multiple roles of PTEN in tumor suppression. Cell 100:387-390.

30. Dohadwala, M., J. Luo, L. Zhu, Y. Lin, G. J. Dougherty, S. Sharma, M. Huang, M. Pold, R. K. Batra, and S. M. Dubinett. 2001. Non-small cell lung cancer cyclooxygenase-2dependent invasion is mediated by CD44. J Biol.Chem. 276:20809-20812. 
31. Egawa, K., H. Maegawa, K. Shi, T. Nakamura, T. Obata, T. Yoshizaki, K. Morino, S. Shimizu, Y. Nishio, E. Suzuki, and A. Kashiwagi. 2002. Membrane localization of 3phosphoinositide-dependent protein kinase-1 stimulates activities of Akt and atypical protein kinase $\mathrm{C}$ but does not stimulate glucose transport and glycogen synthesis in 3T3-L1 adipocytes. J.Biol.Chem. 277:38863-38869.

32. Erler, J. T., C. J. Cawthorne, K. J. Williams, M. Koritzinsky, B. G. Wouters, C. Wilson, C. Miller, C. Demonacos, I. J. Stratford, and C. Dive. 2004. Hypoxia-mediated down-regulation of Bid and Bax in tumors occurs via hypoxia-inducible factor 1-dependent and independent mechanisms and contributes to drug resistance. Mol.Cell Biol. 24:2875-2889.

33. Esteller, M., J. Xercavins, and J. Reventos. 1999. Advances in the molecular genetics of endometrial cancer (Review). Oncol.Rep. 6:1377-1382.

34. Firth, J. D., B. L. Ebert, C. W. Pugh, and P. J. Ratcliffe. 1994. Oxygen-regulated control elements in the phosphoglycerate kinase 1 and lactate dehydrogenase A genes: similarities with the erythropoietin 3' enhancer. Proc.Natl.Acad.Sci.U.S.A 91:6496-6500.

35. Forsythe, J. A., B. H. Jiang, N. V. Iyer, F. Agani, S. W. Leung, R. D. Koos, and G. L. Semenza. 1996. Activation of vascular endothelial growth factor gene transcription by hypoxiainducible factor 1. Mol.Cell Biol. 16:4604-4613.

36. Fujiwaki, R., K. Iida, H. Kanasaki, T. Ozaki, K. Hata, and K. Miyazaki. 2002. Cyclooxygenase-2 expression in endometrial cancer: correlation with microvessel count and expression of vascular endothelial growth factor and thymidine phosphorylase. Hum.Pathol 33:213-219.

37. Gallo, O., E. Masini, B. Bianchi, L. Bruschini, M. Paglierani, and A. Franchi. 2002. Prognostic significance of cyclooxygenase-2 pathway and angiogenesis in head and neck squamous cell carcinoma. Hum.Pathol 33:708-714.

38. Gately, S. 2000. The contributions of cyclooxygenase-2 to tumor angiogenesis 1. Cancer Metastasis Rev. 19:19-27.

39. Gately, S. and W. W. Li. 2004. Multiple roles of COX-2 in tumor angiogenesis: a target for antiangiogenic therapy

1. Semin.Oncol. 31:2-11.

40. Gout, I., R. Dhand, G. Panayotou, M. J. Fry, I. Hiles, M. Otsu, and M. D.

Waterfield. 1992. Expression and characterization of the p85 subunit of the phosphatidylinositol 3-kinase complex and a related p85 beta protein by using the baculovirus expression system. Biochem.J. 288 ( Pt 2):395-405.

41. Greco, O., B. Marples, M. C. Joiner, and S. D. Scott. 2003. How to overcome (and exploit) tumor hypoxia for targeted gene therapy. J Cell Physiol 197:312-325. 
42. Hansson, L. O., A. Friedler, S. Freund, S. Rudiger, and A. R. Fersht. 2002. Two sequence motifs from HIF-1alpha bind to the DNA-binding site of p53.

Proc.Natl.Acad.Sci.U.S.A 99:10305-10309.

43. Haupt, Y., R. Maya, A. Kazaz, and M. Oren. 1997. Mdm2 promotes the rapid degradation of p53. Nature 387:296-299.

44. Honda, R., H. Tanaka, and H. Yasuda. 1997. Oncoprotein MDM2 is a ubiquitin ligase E3 for tumor suppressor p53. FEBS Lett. 420:25-27.

45. Hu, P. and J. Schlessinger. 1994. Direct association of p1 10 beta phosphatidylinositol 3-kinase with p85 is mediated by an N-terminal fragment of p110 beta. Mol.Cell Biol. 14:25772583.

46. Ivan, M., K. Kondo, H. Yang, W. Kim, J. Valiando, M. Ohh, A. Salic, J. M. Asara, W. S. Lane, and W. G. Kaelin, Jr. 2001. HIFalpha targeted for VHL-mediated destruction by proline hydroxylation: implications for $\mathrm{O} 2$ sensing

2. Science 292:464-468.

47. Jaakkola, P., D. R. Mole, Y. M. Tian, M. I. Wilson, J. Gielbert, S. J. Gaskell, A. Kriegsheim, H. F. Hebestreit, M. Mukherji, C. J. Schofield, P. H. Maxwell, C. W. Pugh, and P. J. Ratcliffe. 2001. Targeting of HIF-alpha to the von Hippel-Lindau ubiquitylation complex by O2-regulated prolyl hydroxylation

3. Science 292:468-472.

48. Jiang, B. H., G. Jiang, J. Z. Zheng, Z. Lu, T. Hunter, and P. K. Vogt. 2001. Phosphatidylinositol 3-kinase signaling controls levels of hypoxia-inducible factor 1. Cell Growth Differ. 12:363-369.

49. Jiang, B. H., E. Rue, G. L. Wang, R. Roe, and G. L. Semenza. 1996. Dimerization, DNA binding, and transactivation properties of hypoxia-inducible factor 1. J.Biol.Chem. 271:17771-17778.

50. Jiang, B. H., J. Z. Zheng, M. Aoki, and P. K. Vogt. 2000. Phosphatidylinositol 3kinase signaling mediates angiogenesis and expression of vascular endothelial growth factor in endothelial cells 34. Proc.Natl.Acad.Sci.U.S.A 97:1749-1753.

51. Jimenez, C., D. R. Jones, P. Rodriguez-Viciana, A. Gonzalez-Garcia, E. Leonardo, S. Wennstrom, C. von Kobbe, J. L. Toran, L. Borlado, V. Calvo, S. G. Copin, J. P. Albar, M. L. Gaspar, E. Diez, M. A. Marcos, J. Downward, A. Martinez, I. Merida, and A. C. Carrera. 1998. Identification and characterization of a new oncogene derived from the regulatory subunit of phosphoinositide 3-kinase. EMBO J. 17:743-753.

52. Kane, L. P., V. S. Shapiro, D. Stokoe, and A. Weiss. 1999. Induction of NF-kappaB by the Akt/PKB kinase. Curr.Biol. 9:601-604. 
53. Kase, S., M. Osaki, S. Honjo, H. Adachi, S. Tsujitani, N. Kaibara, and H. Ito. 2003. Expression of cyclo-oxygenase-2 is correlated with high intratumoral microvessel density and low apoptotic index in human esophageal squamous cell carcinomas. Virchows Arch. 442:129135.

54. Kinugasa, Y., M. Hatori, H. Ito, Y. Kurihara, D. Ito, and M. Nagumo. 2004. Inhibition of cyclooxygenase-2 suppresses invasiveness of oral squamous cell carcinoma cell lines via down-regulation of matrix metalloproteinase-2 and CD44. Clin Exp.Metastasis 21:737745.

55. Klippel, A., J. A. Escobedo, Q. Hu, and L. T. Williams. 1993. A region of the 85kilodalton (kDa) subunit of phosphatidylinositol 3-kinase binds the 110-kDa catalytic subunit in vivo. Mol.Cell Biol. 13:5560-5566.

56. Klippel, A., M. A. Escobedo, M. S. Wachowicz, G. Apell, T. W. Brown, M. A. Giedlin, W. M. Kavanaugh, and L. T. Williams. 1998. Activation of phosphatidylinositol 3kinase is sufficient for cell cycle entry and promotes cellular changes characteristic of oncogenic transformation. Mol.Cell Biol. 18:5699-5711.

57. Koul, D., R. Shen, A. Garyali, L. D. Ke, T. J. Liu, and W. K. Yung. 2002. MMAC/PTEN tumor suppressor gene regulates vascular endothelial growth factor-mediated angiogenesis in prostate cancer. Int.J.Oncol. 21:469-475.

58. Krishnamachary, B., S. Berg-Dixon, B. Kelly, F. Agani, D. Feldser, G. Ferreira, N. Iyer, J. LaRusch, B. Pak, P. Taghavi, and G. L. Semenza. 2003. Regulation of colon carcinoma cell invasion by hypoxia-inducible factor 1. Cancer Res. 63:1138-1143.

59. Kubbutat, M. H., S. N. Jones, and K. H. Vousden. 1997. Regulation of p53 stability by Mdm2. Nature 387:299-303.

60. Kulp, S. K., Y. T. Yang, C. C. Hung, K. F. Chen, J. P. Lai, P. H. Tseng, J. W. Fowble, P. J. Ward, and C. S. Chen. 2004. 3-phosphoinositide-dependent protein kinase-1/Akt signaling represents a major cyclooxygenase-2-independent target for celecoxib in prostate cancer cells. Cancer Res 64:1444-1451.

61. Kurose, K., X. P. Zhou, T. Araki, S. A. Cannistra, E. R. Maher, and C. Eng. 2001. Frequent loss of PTEN expression is linked to elevated phosphorylated Akt levels, but not associated with p27 and cyclin D1 expression, in primary epithelial ovarian carcinomas. Am.J.Pathol. 158:2097-2106.

62. Lee, P. J., B. H. Jiang, B. Y. Chin, N. V. Iyer, J. Alam, G. L. Semenza, and A. M. Choi. 1997. Hypoxia-inducible factor-1 mediates transcriptional activation of the heme oxygenase-1 gene in response to hypoxia 43. J.Biol.Chem. 272:5375-5381.

63. Li, H., H. P. Ko, and J. P. Whitlock. 1996. Induction of phosphoglycerate kinase 1 gene expression by hypoxia. Roles of Arnt and HIF1alpha. J.Biol.Chem. 271:21262-21267. 
64. Li, J., C. Yen, D. Liaw, K. Podsypanina, S. Bose, S. I. Wang, J. Puc, C. Miliaresis, L. Rodgers, R. McCombie, S. H. Bigner, B. C. Giovanella, M. Ittmann, B. Tycko, H. Hibshoosh, M. H. Wigler, and R. Parsons. 1997. PTEN, a putative protein tyrosine phosphatase gene mutated in human brain, breast, and prostate cancer. Science 275:1943-1947.

65. Liu, X. H., A. Kirschenbaum, M. Lu, S. Yao, A. Dosoretz, J. F. Holland, and A. C. Levine. 2002. Prostaglandin E2 induces hypoxia-inducible factor-1alpha stabilization and nuclear localization in a human prostate cancer cell line 1. J.Biol.Chem. 277:50081-50086.

66. Liu, X. H., A. Kirschenbaum, S. Yao, M. E. Stearns, J. F. Holland, K. Claffey, and A. C. Levine. 1999. Upregulation of vascular endothelial growth factor by cobalt chloridesimulated hypoxia is mediated by persistent induction of cyclooxygenase- 2 in a metastatic human prostate cancer cell line 3. Clin.Exp.Metastasis 17:687-694.

67. Liu, X. H., A. Kirschenbaum, K. Yu, S. Yao, and A. C. Levine. 2005. Cyclooxygenase-2 suppresses hypoxia-induced apoptosis via a combination of direct and indirect inhibition of p53 activity in a human prostate cancer cell line. J Biol.Chem. 280:3817-3823.

68. Maehama, T. and J. E. Dixon. 1998. The tumor suppressor, PTEN/MMAC1, dephosphorylates the lipid second messenger, phosphatidylinositol 3,4,5-trisphosphate. J.Biol.Chem. 273:13375-13378.

69. Mayo, L. D. and D. B. Donner. 2001. A phosphatidylinositol 3-kinase/Akt pathway promotes translocation of $\mathrm{Mdm} 2$ from the cytoplasm to the nucleus. Proc.Natl.Acad.Sci.U.S.A 98:11598-11603.

70. McGinty, A., Y. W. Chang, A. Sorokin, D. Bokemeyer, and M. J. Dunn. 2000. Cyclooxygenase-2 expression inhibits trophic withdrawal apoptosis in nerve growth factordifferentiated PC12 cells. J Biol.Chem. 275:12095-12101.

71. Mills, G. B., Y. Lu, X. Fang, H. Wang, A. Eder, M. Mao, R. Swaby, K. W. Cheng, D. Stokoe, K. Siminovitch, R. Jaffe, and J. Gray. 2001. The role of genetic abnormalities of PTEN and the phosphatidylinositol 3-kinase pathway in breast and ovarian tumorigenesis, prognosis, and therapy. Semin.Oncol. 28:125-141.

72. Minet, E., G. Michel, D. Mottet, M. Raes, and C. Michiels. 2001. Transduction pathways involved in Hypoxia-Inducible Factor-1 phosphorylation and activation. Free Radic.Biol.Med. 31:847-855.

73. Nakae, J., B. C. Park, and D. Accili. 1999. Insulin stimulates phosphorylation of the forkhead transcription factor FKHR on serine 253 through a Wortmannin-sensitive pathway. J.Biol.Chem. 274:15982-15985.

74. Nieminen, A. L., S. Qanungo, E. A. Schneider, B. H. Jiang, and F. H. Agani. 2005. Mdm2 and HIF-1alpha interaction in tumor cells during hypoxia. J Cell Physiol 204:364-369. 
75. Ogawara, Y., S. Kishishita, T. Obata, Y. Isazawa, T. Suzuki, K. Tanaka, N. Masuyama, and Y. Gotoh. 2002. Akt enhances Mdm2-mediated ubiquitination and degradation of p53. J.Biol.Chem. 277:21843-21850.

76. Ohno, R., K. Yoshinaga, T. Fujita, K. Hasegawa, H. Iseki, H. Tsunozaki, W. Ichikawa, Z. Nihei, and K. Sugihara. 2001. Depth of invasion parallels increased cyclooxygenase-2 levels in patients with gastric carcinoma. Cancer 91:1876-1881.

77. Oikawa, T. and M. Shimamura. 1996. Potent inhibition of angiogenesis by wortmannin, a fungal metabolite. Eur.J.Pharmacol. 318:93-96.

78. Okami, J., S. Nakamori, N. Hiraoka, M. Tsujie, N. Hayashi, H. Yamamoto, Y. Fujiwara, H. Nagano, K. Dono, K. Umeshita, M. Sakon, and M. Monden. 2003. Suppression of pancreatic cancer cell invasion by a cyclooxygenase-2-specific inhibitor. Clin Exp.Metastasis 20:577-584.

79. Ozes, O. N., L. D. Mayo, J. A. Gustin, S. R. Pfeffer, L. M. Pfeffer, and D. B. Donner. 1999. NF-kappaB activation by tumour necrosis factor requires the Akt serine-threonine kinase. Nature 401:82-85.

80. Page, E. L., G. A. Robitaille, J. Pouyssegur, and D. E. Richard. 2002. Induction of hypoxia-inducible factor-1alpha by transcriptional and translational mechanisms. J.Biol.Chem. 277:48403-48409.

81. Pai, R., T. Nakamura, W. S. Moon, and A. S. Tarnawski. 2003. Prostaglandins promote colon cancer cell invasion; signaling by cross-talk between two distinct growth factor receptors. FASEB J 17:1640-1647.

82. Palayoor, S. T., P. J. Tofilon, and C. N. Coleman. 2003. Ibuprofen-mediated reduction of hypoxia-inducible factors HIF-1alpha and HIF-2alpha in prostate cancer cells

1. Clin.Cancer Res. 9:3150-3157.

83. Philp, A. J., I. G. Campbell, C. Leet, E. Vincan, S. P. Rockman, R. H. Whitehead, R. J. Thomas, and W. A. Phillips. 2001. The phosphatidylinositol 3'-kinase p85alpha gene is an oncogene in human ovarian and colon tumors

1. Cancer Res. 61:7426-7429.

84. Rasheed, B. K., R. N. Wiltshire, S. H. Bigner, and D. D. Bigner. 1999. Molecular pathogenesis of malignant gliomas. Curr.Opin.Oncol. 11:162-167.

85. Ravi, R., B. Mookerjee, Z. M. Bhujwalla, C. H. Sutter, D. Artemov, Q. Zeng, L. E. Dillehay, A. Madan, G. L. Semenza, and A. Bedi. 2000. Regulation of tumor angiogenesis by p53-induced degradation of hypoxia-inducible factor 1alpha. Genes Dev. 14:34-44.

86. Rena, G., S. Guo, S. C. Cichy, T. G. Unterman, and P. Cohen. 1999. Phosphorylation of the transcription factor forkhead family member FKHR by protein kinase B. J.Biol.Chem. 274:17179-17183. 
87. Rodriguez-Viciana, P., P. H. Warne, B. Vanhaesebroeck, M. D. Waterfield, and J. Downward. 1996. Activation of phosphoinositide 3-kinase by interaction with Ras and by point mutation. EMBO J. 15:2442-2451.

88. Romashkova, J. A. and S. S. Makarov. 1999. NF-kappaB is a target of AKT in antiapoptotic PDGF signalling. Nature 401:86-90.

89. Ryan, H. E., M. Poloni, W. McNulty, D. Elson, M. Gassmann, J. M. Arbeit, and R. S. Johnson. 2000. Hypoxia-inducible factor-lalpha is a positive factor in solid tumor growth 2. Cancer Res. 60:4010-4015.

90. Sandau, K. B., H. G. Faus, and B. Brune. 2000. Induction of hypoxia-inducible-factor 1 by nitric oxide is mediated via the PI 3K pathway. Biochem.Biophys.Res.Commun. 278:263267.

91. Sawaoka, H., S. Tsuji, M. Tsujii, E. S. Gunawan, Y. Sasaki, S. Kawano, and M. Hori. 1999. Cyclooxygenase inhibitors suppress angiogenesis and reduce tumor growth in vivo 3. Lab Invest 79:1469-1477.

92. Schmedtje, J. F., Jr., Y. S. Ji, W. L. Liu, R. N. DuBois, and M. S. Runge. 1997. Hypoxia induces cyclooxygenase-2 via the NF-kappaB p65 transcription factor in human vascular endothelial cells. J Biol.Chem. 272:601-608.

93. Scott, P. H., G. J. Brunn, A. D. Kohn, R. A. Roth, and J. C. Lawrence, Jr. 1998. Evidence of insulin-stimulated phosphorylation and activation of the mammalian target of rapamycin mediated by a protein kinase B signaling pathway. Proc.Natl.Acad.Sci.U.S.A 95:7772-7777.

94. Semenza, G. L. 2000. HIF-1: using two hands to flip the angiogenic switch 2. Cancer Metastasis Rev. 19:59-65.

95. Semenza, G. L. 2002. HIF-1 and tumor progression: pathophysiology and therapeutics 10. Trends Mol.Med. 8:S62-S67.

96. Semenza, G. L., F. Agani, G. Booth, J. Forsythe, N. Iyer, B. H. Jiang, S. Leung, R. Roe, C. Wiener, and A. Yu. 1997. Structural and functional analysis of hypoxia-inducible factor 1

44. Kidney Int. 51:553-555.

97. Semenza, G. L., B. H. Jiang, S. W. Leung, R. Passantino, J. P. Concordet, P. Maire, and A. Giallongo. 1996. Hypoxia response elements in the aldolase A, enolase 1, and lactate dehydrogenase A gene promoters contain essential binding sites for hypoxia-inducible factor 1. J.Biol.Chem. 271:32529-32537.

98. Shayesteh, L., Y. Lu, W. L. Kuo, R. Baldocchi, T. Godfrey, C. Collins, D. Pinkel, B. Powell, G. B. Mills, and J. W. Gray. 1999. PIK3CA is implicated as an oncogene in ovarian cancer

3. Nat.Genet. 21:99-102. 
99. Shirahama, T., J. Arima, S. Akiba, and C. Sakakura. 2001. Relation between cyclooxygenase-2 expression and tumor invasiveness and patient survival in transitional cell carcinoma of the urinary bladder. Cancer 92:188-193.

100. Singh, B., J. A. Berry, A. Shoher, V. Ramakrishnan, and A. Lucci. 2005. COX-2 overexpression increases motility and invasion of breast cancer cells. Int.J Oncol. 26:1393-1399.

101. Steck, P. A., M. A. Pershouse, S. A. Jasser, W. K. Yung, H. Lin, A. H. Ligon, L. A. Langford, M. L. Baumgard, T. Hattier, T. Davis, C. Frye, R. Hu, B. Swedlund, D. H. Teng, and S. V. Tavtigian. 1997. Identification of a candidate tumour suppressor gene, MMAC1, at chromosome 10q23.3 that is mutated in multiple advanced cancers. Nat.Genet. 15:356-362.

102. Stiehl, D. P., W. Jelkmann, R. H. Wenger, and T. Hellwig-Burgel. 2002. Normoxic induction of the hypoxia-inducible factor 1alpha by insulin and interleukin-1beta involves the phosphatidylinositol 3-kinase pathway

1. FEBS Lett. 512:157-162.

103. Stoeltzing, O., M. F. McCarty, J. S. Wey, F. Fan, W. Liu, A. Belcheva, C. D. Bucana, G. L. Semenza, and L. M. Ellis. 2004. Role of hypoxia-inducible factor 1alpha in gastric cancer cell growth, angiogenesis, and vessel maturation

2. J.Natl.Cancer Inst. 96:946-956.

104. Stokoe, D., L. R. Stephens, T. Copeland, P. R. Gaffney, C. B. Reese, G. F. Painter, A. B. Holmes, F. McCormick, and P. T. Hawkins. 1997. Dual role of phosphatidylinositol-3,4,5trisphosphate in the activation of protein kinase B. Science 277:567-570.

105. Subbaramaiah, K., N. Altorki, W. J. Chung, J. R. Mestre, A. Sampat, and A. J. Dannenberg. 1999. Inhibition of cyclooxygenase-2 gene expression by p53. J Biol.Chem. 274:10911-10915.

106. Sun, M., G. Wang, J. E. Paciga, R. I. Feldman, Z. Q. Yuan, X. L. Ma, S. A. Shelley, R. Jove, P. N. Tsichlis, S. V. Nicosia, and J. Q. Cheng. 2001. AKT1/PKBalpha kinase is frequently elevated in human cancers and its constitutive activation is required for oncogenic transformation in NIH3T3 cells. Am.J.Pathol. 159:431-437.

107. Symowicz, J., B. P. Adley, M. M. Woo, N. Auersperg, L. G. Hudson, and M. S. Stack. 2005. Cyclooxygenase-2 functions as a downstream mediator of lysophosphatidic acid to promote aggressive behavior in ovarian carcinoma cells. Cancer Res 65:2234-2242.

108. Tang, T. C., R. T. Poon, C. P. Lau, D. Xie, and S. T. Fan. 2005. Tumor cyclooxygenase-2 levels correlate with tumor invasiveness in human hepatocellular carcinoma. World J Gastroenterol. 11:1896-1902.

109. Tanji, K., T. Imaizumi, T. Matsumiya, H. Itaya, K. Fujimoto, X. Cui, T. Toki, E. Ito, H. Yoshida, K. Wakabayashi, and K. Satoh. 2001. Desferrioxamine, an iron chelator, upregulates cyclooxygenase-2 expression and prostaglandin production in a human macrophage cell line

1. Biochim.Biophys.Acta 1530:227-235. 
110. Timoshenko, A. V., G. Xu, S. Chakrabarti, P. K. Lala, and C. Chakraborty. 2003. Role of prostaglandin E2 receptors in migration of murine and human breast cancer cells. Exp.Cell Res 289:265-274.

111. Treins, C., S. Giorgetti-Peraldi, J. Murdaca, G. L. Semenza, and E. Van Obberghen. 2002. Insulin stimulates hypoxia-inducible factor 1 through a phosphatidylinositol 3kinase/target of rapamycin-dependent signaling pathway. J.Biol.Chem. 277:27975-27981.

112. Tsujii, M., S. Kawano, S. Tsuji, H. Sawaoka, M. Hori, and R. N. DuBois. 1998. Cyclooxygenase regulates angiogenesis induced by colon cancer cells. Cell 93:705-716.

113. Vousden, K. H. and X. Lu. 2002. Live or let die: the cell's response to p53. Nat.Rev.Cancer 2:594-604.

114. Wang, G. L., B. H. Jiang, E. A. Rue, and G. L. Semenza. 1995. Hypoxia-inducible factor 1 is a basic-helix-loop-helix-PAS heterodimer regulated by cellular $\mathrm{O} 2$ tension 6. Proc.Natl.Acad.Sci.U.S.A 92:5510-5514.

115. Wang, G. L. and G. L. Semenza. 1993. Desferrioxamine induces erythropoietin gene expression and hypoxia-inducible factor 1 DNA-binding activity: implications for models of hypoxia signal transduction

1. Blood 82:3610-3615.

116. Wang, G. L. and G. L. Semenza. 1993. General involvement of hypoxia-inducible factor 1 in transcriptional response to hypoxia

3. Proc.Natl.Acad.Sci.U.S.A 90:4304-4308.

117. Wen, S., J. Stolarov, M. P. Myers, J. D. Su, M. H. Wigler, N. K. Tonks, and D. L. Durden. 2001. PTEN controls tumor-induced angiogenesis. Proc.Natl.Acad.Sci.U.S.A 98:46224627.

118. Whitman, M., C. P. Downes, M. Keeler, T. Keller, and L. Cantley. 1988. Type I phosphatidylinositol kinase makes a novel inositol phospholipid, phosphatidylinositol-3phosphate. Nature 332:644-646.

119. Wu, X., J. H. Bayle, D. Olson, and A. J. Levine. 1993. The p53-mdm-2 autoregulatory feedback loop. Genes Dev. 7:1126-1132.

120. Wu, X., K. Senechal, M. S. Neshat, Y. E. Whang, and C. L. Sawyers. 1998. The PTEN/MMAC1 tumor suppressor phosphatase functions as a negative regulator of the phosphoinositide 3-kinase/Akt pathway. Proc.Natl.Acad.Sci.U.S.A 95:15587-15591.

121. Yazawa, K., N. H. Tsuno, J. Kitayama, K. Kawai, Y. Okaji, M. Asakage, E. Sunami, S. Kaisaki, N. Hori, T. Watanabe, K. Takahashi, and H. Nagawa. 2005. Selective inhibition of cyclooxygenase- 2 inhibits colon cancer cell adhesion to extracellular matrix by decreased expression of beta1 integrin. Cancer Sci. 96:93-99. 
122. Yuan, Z. Q., M. Sun, R. I. Feldman, G. Wang, X. Ma, C. Jiang, D. Coppola, S. V. Nicosia, and J. Q. Cheng. 2000. Frequent activation of AKT2 and induction of apoptosis by inhibition of phosphoinositide-3-OH kinase/Akt pathway in human ovarian cancer. Oncogene 19:2324-2330.

123. Zagzag, D., H. Zhong, J. M. Scalzitti, E. Laughner, J. W. Simons, and G. L. Semenza. 2000. Expression of hypoxia-inducible factor 1alpha in brain tumors: association with angiogenesis, invasion, and progression

10. Cancer 88:2606-2618.

124. Zha, S., V. Yegnasubramanian, W. G. Nelson, W. B. Isaacs, and A. M. De Marzo. 2004. Cyclooxygenases in cancer: progress and perspective. Cancer Lett. 215:1-20.

125. Zhang, Z. and R. N. DuBois. 2000. Par-4, a proapoptotic gene, is regulated by NSAIDs in human colon carcinoma cells. Gastroenterology 118:1012-1017.

126. Zhong, H., A. M. De Marzo, E. Laughner, M. Lim, D. A. Hilton, D. Zagzag, P. Buechler, W. B. Isaacs, G. L. Semenza, and J. W. Simons. 1999. Overexpression of hypoxiainducible factor 1alpha in common human cancers and their metastases. Cancer Res. 59:58305835.

127. Zhong, H., M. Willard, and J. Simons. 2004. NS398 reduces hypoxia-inducible factor (HIF)-1alpha and HIF-1 activity: multiple-level effects involving cyclooxygenase-2 dependent and independent mechanisms

1. Int.J.Cancer 112:585-595.

128. Zundel, W., C. Schindler, D. Haas-Kogan, A. Koong, F. Kaper, E. Chen, A. R. Gottschalk, H. E. Ryan, R. S. Johnson, A. B. Jefferson, D. Stokoe, and A. J. Giaccia. 2000. Loss of PTEN facilitates HIF-1-mediated gene expression

1. Genes Dev. 14:391-396. 